\title{
Mediterranean-Atlantic water exchange over the Miocene-Pliocene boundary.
}

A multi-proxy study on IODP Hole U1387C in the Gulf of Cadiz.

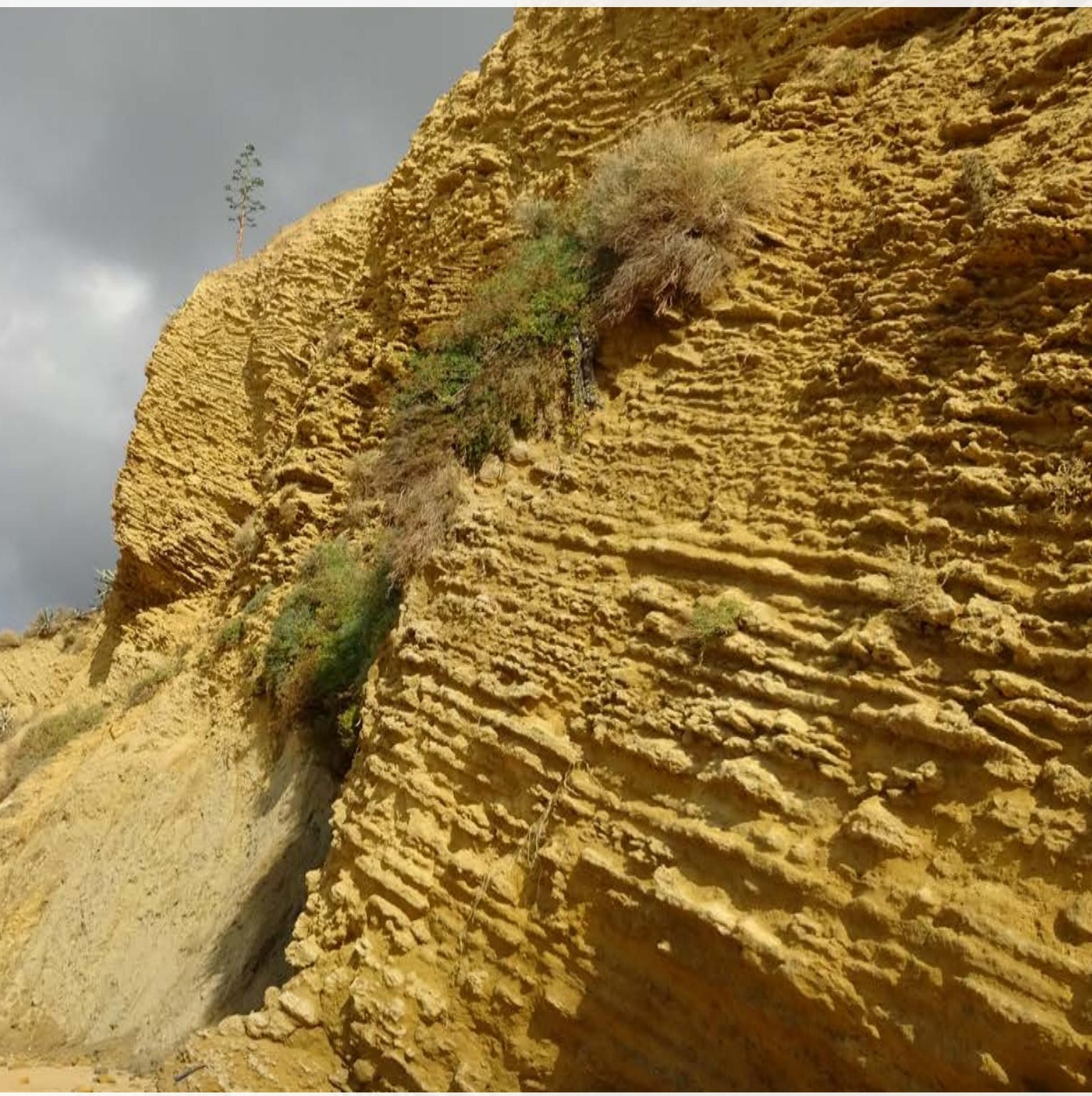

Marlies van der Schee 
Book Cover:

Early Pliocene sediments of the Flamenco section, Conil de la Frontera, Spain. November 2014. 




\section{Mediterranean-Atlantic water exchange over the Miocene-Pliocene boundary.}

A multi-proxy study on IODP Hole U1387C in the Gulf of Cadiz.

Marlies van der Schee

September 2016

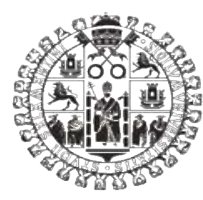

VNiVERSiDAD

DSALAMANCA 


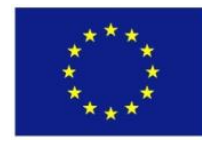

The research leading to these results has received funding from the People Programme (Marie Curie Actions) of the European Union's Seventh Framework Programme FP7/20072013/ under REA Grant Agreement No. 290201 MEDGATE and was partially supported through Castilla y Leon project SA263U14. 
Dr. D. Francisco Javier Sierro Sánchez y Dr. D. José Abel Flores Villarejo, profesores del Área de Paleontología en el Departamento de Geología en la Facultad de Ciencias (Universidad de Salamanca)

\section{CERTIFICAN QUE:}

ELISABETH VAN DER SCHEE ha realizado en el Departamento de Geología en la Universidad de Salamanca y baja nuestra supervisión, el trabajo

\section{"Mediterranean-Atlantic water exchange over the Miocene-Pliocene boundary."}

Y para que conste, firmamos el presente certificado en Salamanca, Julio de 2016

Los Directores:

Francisco Javier Sierro Sánchez

José Abel Flores Villarejo

El doctorando:

Elisabeth van den Schee 

"Imagination is the highest form of research."

- Albert Einstein 

"For his tenth labor, Hercules was prescribed by Eurysteus to steal the cattle of Geryon from the island of Erythia. Reaching the western end of the habitable world, he decided to set up the Pillars of Heracles to commemorate his campaign. Hercules narrowed the passage between the Libyan and European continental promontories, whereas before that time a larger space had stood between them. Making it shallow, he might prevent great sea-monsters from passing out of the ocean into the inner sea. However, some authorities say just the opposite; the two continents were originally joined and Hercules cut a passage between them. On this question, it is upon every man to think as he pleases."

Based on Diodorus Siculus 4.18.5

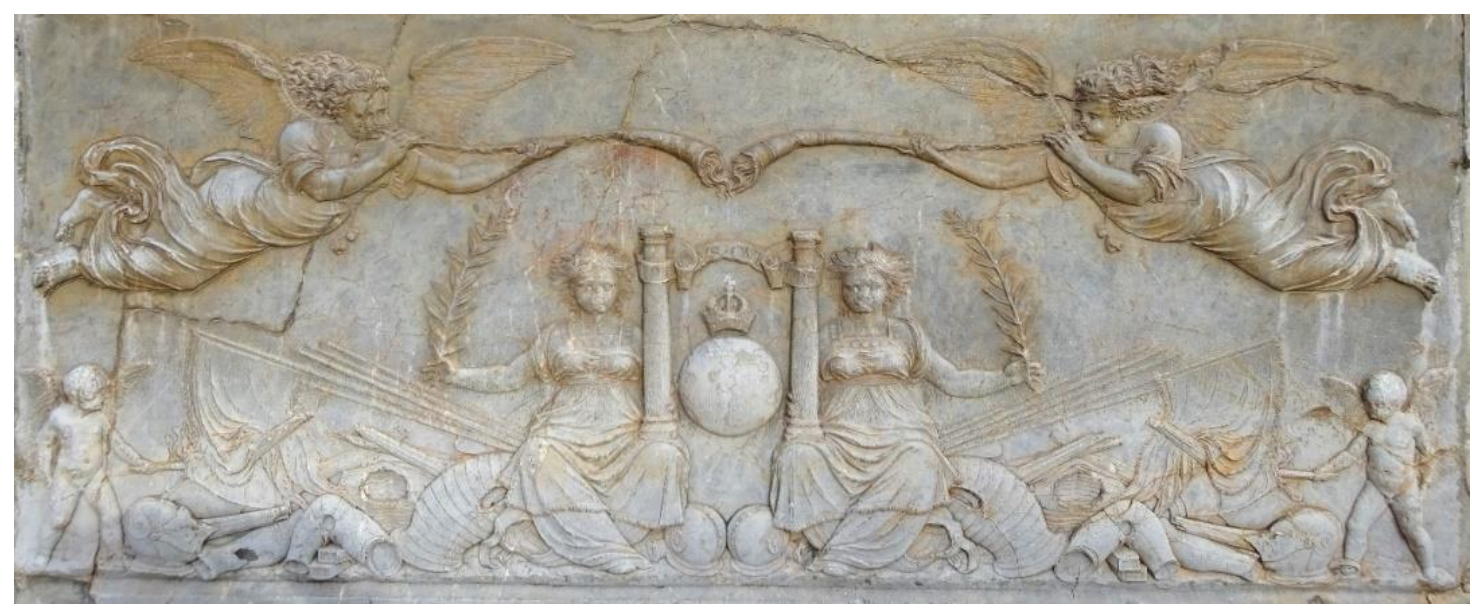

Relief sculpture. Two goddesses of Victory hold the Pillars of Hercules and the globe, while two angels set fire to weapons with torches. Detail of façade Palacio Carlos V, Granada, Pedro Machuca, 1527- - 



\section{Table of Contents}

$\begin{array}{ll}\text { Abstract } & 1\end{array}$

Thesis objectives $\quad 3$

Introduction $\quad 5$

Chapter 1

Evidence of early bottom water current flow after the Messinian Salinity Crisis in the Gulf of Cadiz.

Chapter 2

Sedimentary cycles and oceanographic circulation under the influence of MOW over the Miocene-Pliocene boundary in the Gulf of Cadiz.

\section{Chapter 3}

Controls on authigenic $\mathrm{Nd}$ and $\mathrm{Pb}$ isotope in Gulf of Cadiz sediments over the MiocenePliocene boundary.

\section{Chapter 4}

Improved biostratigraphic dating of upper Miocene sediments in the western Betics suggests late Tortonian closure of the Guadalhorce Corridor.

\section{Conclusions}

Resumen

Appendices

I. Objectives of MEDGATE.

II. Evolution of the Gulf of Cadiz margin and southwest Portugal contourite depositional system: Tectonic, sedimentary and paleoceanographic implications from IODP expedition 339.

Acknowledgements

Scientific publications 


\begin{abstract}
The Mediterranean-Atlantic gateway connection plays a major role in hydrographic ocean circulation flow patterns. During the Messinian Salinity Crisis (MSC; 5.33-5.97 Ma), water exchange between the Mediterranean Sea and the Atlantic Ocean was restricted or even absent, resulting in extensive evaporitic deposits. The Miocene-Pliocene boundary marks the re-establishment of Mediterranean-Atlantic exchange. A modern like Mediterranean Outflow water (MOW) developed after the MSC. This thesis is focused on the initiation and development of MOW recorded outside the Mediterranean in the Gulf of Cadiz.
\end{abstract}

An age model combining bio-, magneto, and cyclostratigraphy was constrained for Hole Integrated Ocean Drilling Program (IODP) U1387C located on the upper slope in the Gulf of Cadiz (559 $\mathrm{m}$ water depth). The Miocene-Pliocene boundary is associated with a distinct an abrupt change in depositional environment. During the latest Messinian, hemipelagic sediments exhibit precession induced cyclic carbonate cycles, in which the largest detrital input are found during Northern Hemisphere insolation minima, rich in silicates. These cyclical patterns are related to nearby Montemayor-1 drill core and thus most likely induced by overland terrigenous input towards the basin. Larger vegetation cover during insolation maxima can explain the reduced suspended load. Above the Miocene-Pliocene boundary, two contouritic bigradational sandy-beds and an immediate increase with more variable XRF core scanning Zr/Al ratios than the underlying sediment indicate processes related to particle sorting. This provides evidence for the onset of bottom water current flow immediately at or just above the Miocene-Pliocene boundary.

Stricking coupling between the sedimentary variations and benthic $\delta^{18} \mathrm{O}$ and $\delta^{13} \mathrm{C}$ indicate that orbitally forced enhancements of bottom water currents are plausibly originated in the Mediterranean Sea. During these intervals, similar stable isotopic expressions are found in Hole $\mathrm{U} 1387 \mathrm{C}$ as in a Mediterranean benthic foraminiferal record, characterized by well-ventilated and presumably warmer waters. In contrast, when bottom water currents are sluggish or even absent, expressed by more aluminosilicate rich beds with lower weight percentages in grain size fractions (> $63 \mu \mathrm{m}$ ), stable isotopes do not match the Mediterranean record. Bottom waters were presumably cold and poorly ventilated, what is linked to more influence of Atlantic bottom water. Sea surface records of $\delta^{18} \mathrm{O}$ and relative abundances of Globigerinoides show coeval transitions, but in opposite direction; when bottom waters become cold, a warming occurs at surface. This opposite behaviour is attributed to an estuarine circulation in the Mediterranean Sea, when its water budget was positive or to a vertical shift of the MOW-plume towards shallower depths. However, the latter does not explain the quick synchronous shifts.

The origin of bottom water masses in the Gulf of Cadiz was also investigated through the use of authigenic Neodymium ( $\mathrm{Nd}$ ) and Lead (Pb) isotopes. Isotopic ratios of Ferro-Manganese (Fe-Mn) oxyhydroxide sediment leachates of Hole $\mathrm{U} 1387 \mathrm{C}$ are compared to ratios in three Fe-Mn crusts of different water depths in the NE Atlantic (Abouchami et al., 1999; Muiños et al., 2008) and sediments leachates of the Alboran Sea, to investigate endmember compositions of MOW and NE 
Atlantic water during the studied time period. The imprint of the isotopes for $\mathrm{Nd}$ do not match any of isotopic signatures and thus the $\mathrm{Nd}$ record is thought to be mainly controlled by local processes. $\mathrm{Pb}$ isotopic ratios are incompatible with endmember interpretations of the Fe- $\mathrm{Mn}$ crusts relying on the interpretations of the more traditional stable isotope. If however, the sediment leachate samples from the Alboran Sea reliably records $\mathrm{Pb}$ isotopic compositions for MOW, then the leachate compositions match the stable isotope interpretations. Although a $\mathrm{Pb}$ isotopic record with major influences of preferential incongruent weathering cannot be excluded, these results imply that the $\mathrm{Pb}$ isotopic oxyhydroxides could be used as a bottom water mass tracer in the marginal settings of the Gulf of Cadiz.

Before the MSC, the Betic Corridor in southern Spain and the Rifian Corridor in North West Morocco connected the Mediterranean Atlantic Ocean. These two gateways ceased during the late Miocene, but the actual timing of the closure of these Corridors has been under debate. In the western Betic Cordilleras, upper Miocene basins nearby Ronda, Antequera and Arcos de la Frontera are adjacent to the late Miocene Guadalhorce Corridor, what is thought to have been the last remaining branch of the Betic Corridor. Sedimentary sequences in these Basins are characterized by a transition from deeper marine sandy marls to shallow marine calcarenites or limestones. Biostratigraphic analyses of the marls indicate an age of deposition before 7.58 Ma. The overlying calcarenites and limestones were not reliably dated due to the lack of adequate material, however, based on the typical high sedimentation rates of these deposits, it seems unlikely that the calcarenites and limestones are much younger than the marls. This implies that the Guadalhorce Corridor most likely terminated during the late Tortonian or early Messinian. Therefore, considering similarities in timing and lithological successions, the shallowing upward sequences are linked to the same tectonic pulse that closed the remaining branches in the eastern Betics. 


\section{Thesis objectives}

This thesis is centered on the establishment of Mediterranean Outflow water (MOW) in the Gulf of Cadiz after the re-establishment of Mediterranean-Atlantic exchange ending the Messinian Salinity Crisis (MSC). For this, sediments from Integrated Ocean Drilling Program (IODP) Hole U1387C from 731.20 to 865.85 meter below seafloor (mbsf) are studied in detail with a multi-proxy approach. The most important open scientific questions answered in this thesis are elaborated with its scientific context.

1. Timing of events related to the onset of Mediterranean-Atlantic exchange are important to relate this study to other previous published studies. Therefore, an age-model had to be established for the studied sediments. Rough age estimations provided by Shipboard Expedition 339 scientists indicated a Miocene to Pliocene age for the studied interval of IODP Hole U1387C (Expedition 339 Scientists, 2013a). After this, the Miocene-Pliocene boundary was traced from Site U1387 to well-hole log of the Algarve-2 in HernándezMolina et al., (2016) at about 826 mbsf. Chapter 1 comprises the updated stratigraphic framework with detailed bio-, cyclo and magnetostratigraphic analyses, so that the lower Pliocene sediments are detected.

2. While it is generally thought that MOW was either sluggish or restricted in the early Pliocene, there is no general consensus on how hydrographic patterns persisted in detail (Flecker et al., 2015) or if MOW was even distinct enough from Atlantic waters to be detected (Rogerson et al., 2012a). However, the presence, direction and strength of MOW has important implications for the gateway configurations (Simon and Meijer, 2015) and environmental conditions (Marzocchi et al., 2016). The earliest evidence of MOW along its pathway in the Gulf of Cadiz are contourite deposits recognized in seismic profiles at 4.2-4.5 Ma (Expedition 339 Scientists, 2013a, 2012; Hernández-Molina et al., 2014b). Therefore, high resolution grain size fraction data $(>63 \mu \mathrm{m})$ and XRF scanning $\mathrm{Zr} / \mathrm{Al}$ ratios are used to reveal the youngest sediments influenced by bottom water current flow during the late Miocene and earliest Pliocene. These give an age estimation for the actual onset of the current.

3. After providing evidence for the earliest current flow in the Pliocene, the origin of the water mass that causes the sedimentary and geochemical imprint remains unknown. Chapter 2 disentangles in detail the depositional environment and hydrographical patterns before and after the abrupt event that ended the MSC. Changes over the Miocene-Pliocene boundary in sedimentary depositional environment are studied with XRF scanning data. These analyses separate sedimentary cyclicities either invoked by detrital input or bottom water currents. Benthic stable isotopes are used to trace the origin of the bottom water masses.

4. Recently, Neodymium (Nd) isotopic compositions are increasingly used to trace origins of bottom water masses. This proxy has been used to trace MOW during the late Pliocene in the NE Atlantic (Khélifi et al., 2014), but a Nd record has never been constructed this 
close to the Gibraltar Strait or over the Miocene-Pliocene boundary. Lead (Pb) isotopic compositions are also used as a bottom water proxy (e.g. Gutjahr et al., 2007), but this proxy is less extensively studied and processes dominating isotopic signature are less well known. With the established influence of water masses over the studied time period, the radiogenic proxies are evaluated concerning dominating controls on isotopic composition in the Gulf of Cadiz.

5. Ongoing debate regarding Mediterranean-Atlantic exchange has been going on not only during and after the MSC, but also leading towards final stages of gateway restrictions. It is unknown which gateway was the last remaining branch. Related ongoing studies suggest late Tortonian closure of the Rifian Corridor in North West Morocco, what makes the Guadalhorce Corridor in South West Spain a good candidate as the last standing gateway. Age constrains have been problematic in the region of the Guadalhorce River valley and the adjacent late Miocene nearby basins of Ronda, Arcos de la Frontera and Antequera due to the lack of appropriate key sections and sedimentary deposits with clear bio-markers and magnetostratigrahic data. Therefore, a comprehensive biostratigraphic sample campaign of the Guadalhorce River valley, Ronda, Arcos de la Frontera and Antequera areas is carried out to revise the age constrains of the deposited sediments and linked to the tectonic evolution of the Betic Cordilleras. 


\section{Introduction.}

\section{Evolution of the late Miocene Mediterranean- Atlantic water exchange.}

This introduction is based on;

Flecker, R., Krijgsman, W., Capella, W., de Castro Martíns, C., Dmitrieva, E., Mayser, J.P., Marzocchi, A., Modestou, S., Ochoa D.P., Simon, D., Tulbure, M., Van den Berg, B., Van der Schee, M., de Lange, G., Ellam, R., Govers, R., Gutjahr, M., Hilgen, F., Kouwenhoven, T., Lofi, J., Meijer, P., Sierro, F.J., Bachiri, N., Barhoun, N., Alami, A.C., Chacon, B., Flores, J.A., Gregory, J., Howard, J., Lunt, D., Ochoa, D., Pancost, R., Vincent, S., Yousfi, M.Z., 2015. Evolution of the Late Miocene Mediterranean-Atlantic gateways and their impact on regional and global environmental change. Earth-Science Reviews 150, 365-392.

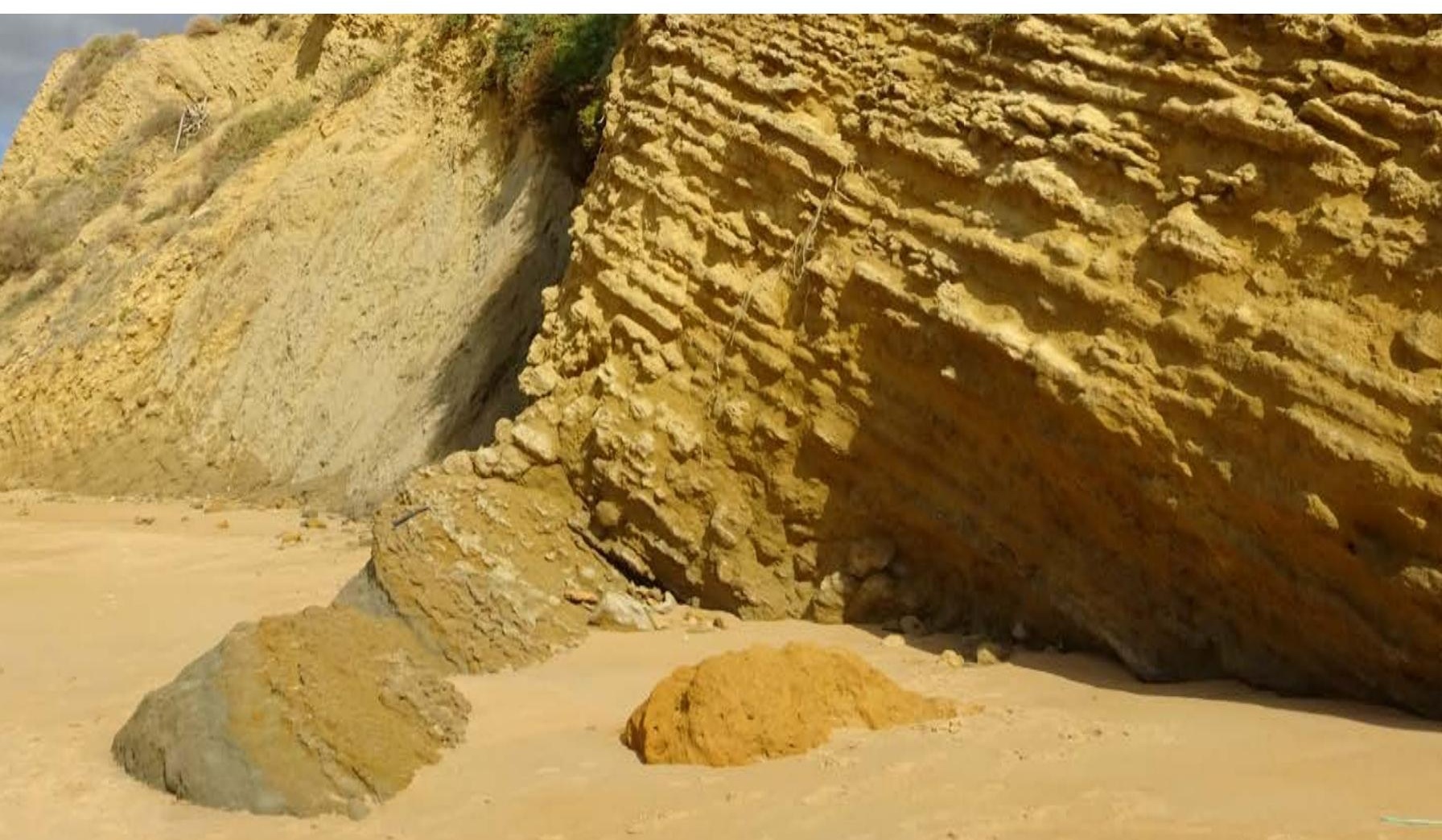




\section{Evolution of the late Miocene Mediterranean-Atlantic water exchange}

Marine gateways play a critical role in the exchange of water, heat, salt and nutrients between oceans and seas. As a result, changes in gateway geometry can significantly alter both the pattern of global ocean circulation and associated heat transport and climate, as well as having a profound impact on local environmental conditions. Mediterranean-Atlantic marine corridors that pre-date the modern Gibraltar Strait, closed during the late Miocene and are now exposed on land in northern Morocco and southern Spain. The restriction and closure of these Miocene connections resulted in extreme salinity fluctuations in the Mediterranean, leading to the precipitation of thick evaporites. This event is known as the Messinian Salinity Crisis (MSC; 5.97-5.33 Ma). The evolution and closure of the Mediterranean-Atlantic gateways are a critical control on the MSC, but at present the location, geometry and age of these gateways are still highly controversial. After the MSC, a physical gateway connection must have been present, but the presence and of Mediterranean outflow water (MOW) on the Atlantic side of the Strait immediately after the establishment of the connection has never been proven.

\section{The Messinian Salinity Crisis}

The Mediterranean's near-landlocked configuration makes it sensitive to subtle changes in climate (e.g. Thunnel et al., 1988). Consequently, the first environmental responses to gradual restriction of exchange with the Atlantic recorded in the Mediterranean (e.g. faunal and isotopic changes; Fig. 1), predate any evaporite precipitation there by a million years or more. The most extreme palaeoenvironmental changes took place during the MSC (Fig. 1) when extensive gypsum deposits precipitated in the Mediterranean's marginal basins and kilometre thick halite units formed in the deep basins (e.g. Hsü et al., 1973; Ryan, 1973). This was followed by a period during which the sediments recorded highly fluctuating conditions varying from brackish to hypersaline, before returning, in the early Pliocene, to open marine conditions (Fig. 1; Hsü et al., 1973). These late Miocene low salinity intervals, known as the Lago Mare, may be the product of an additional freshwater source supplied to the Mediterranean from Paratethys, the lacustrine precursor to the Black and Caspian seas. Like other major freshwater sources, this is a key component of the Mediterranean's freshwater budget, which combined with the gateway dimensions determine its salinity.

The large volume of salt preserved in the Mediterranean necessitates that one or more marine connections with the open ocean remained, at least until the end of the halite stage (5.55 Ma; Krijgsman and Meijer, 2008). However, the location of the last gateway(s) remains highly ambiguous. Field studies of the sedimentary basins in southern Spain (the Betic Corridor) and northern Morocco (the Rifian Corridor) thought to be part of the corridor network (Fig. 2), typically indicate that these areas were closed to marine exchange well before the MSC (e.g. (Betzler et al., 2006; Ivanovic et al., 2013; Krijgsman, 1999; Soria et al., 1999; van Assen et al., 2006), while the Gibraltar Strait is thought to have first opened at the beginning of the Pliocene (5.33 Ma) 
bringing the MSC to an end (e.g. Blanc, 2002; García-Castellanos et al., 2009; Hsü et al., 1977, 1973). The key problem is that it is extremely difficult to pinpoint the exact location or timing of closure from field data alone, because the sedimentary successions within the corridors have been uplifted and eroded (e.g. Hüsing et al., 2010). Using other datasets to identify the location of each marine corridor, reconstructing its geometry and reducing uncertainty in the age of closure is therefore critical for constraining the process-response chain linking gateway evolution with the development of the Mediterranean's MSC succession. The Atlantic response to a change in gateway configuration is reliant on changes to the density and volume of Mediterranean Outflow and consequently also depends on an ability to reconstruct gateway dimensions and the patterns of exchange.

\section{Mediterranean-Atlantic connectivity from outside the}

\section{Mediterranean}

As a mid-latitude semi-enclosed marginal basin, the Mediterranean Sea plays a fundamental role in supplying dense waters to the global ocean (Price and O'Neil Baringer, 1994; Price et al., 1993) impacting the thermohaline structure of the North Atlantic (Artale et al., 2002; Hecht et al., 1997; Mauritzen et al., 2001) and ultimately global climate ( $\mathrm{Li}, 2006)$. Today, two-layer flow exists in the Gibraltar Strait, and colder, more saline MOW flows along the continental slope. En route it entrains significant quantities of Atlantic water (Baringer and Price, 1999) which decreases the density and velocity of the resulting water mass and causes it settle out into the Atlantic at intermediate depths ( $\sim 500-1400$ m; Fig. 3; Ambar and Howe, 1979). This distinctive water mass which is the combination of MOW and ambient Atlantic water. Although MOW undergoes rapid dilution due to mixing and entrainment processes (Dietrich et al., 2008), the resulting MOW remains a well-defined water mass in the Gulf of Cadiz (Fig. 3). Subsequently MOW divides into two distinct pathways and can be traced both westward to the Bermuda Rise and northward, over most of the central North Atlantic basin (Armi and Bray, 1982; Curry et al., 2003; lorga and Lozier, 1999; Lozier and Stewart, 2008). MOW influences the heat and salt balance of the North Atlantic (Dietrich et al., 2008) and contributes to deep-water formation by keeping relatively high salinities at the surface (Price and O’Neil Baringer, 1994; Reid, 1979) and thus influencing global climate.

The interaction of MOW with the Iberian Margin's slope system results in an extensive contourite depositional system in the Gulf of Cadiz (Fig. 3), visible in both seismic profiles and bathymetry (García et al., 2009). Thick sedimentary deposits generated by these currents and by bottom currents on the eastern (Alboran Sea) side of the Gibraltar Straits, provide extensive records of past Mediterranean-Atlantic dynamics (Rogerson et al., 2010; Stow et al., 2013). These records, along with observational data suggest that Mediterranean-Atlantic exchange exhibits significant variability over seasonal (García Lafuente et al., 2007), interannual (Lozier and Sindlinger, 2009), and glacial-interglacial time scales (Rogerson et al., 2005; Voelker et al., 2006). MediterraneanAtlantic exchange through the Gibraltar Strait, is assumed to have been established immediately after the Zanclean flood (5.33 Ma; e.g. laccarino et al., 1999). However, to date, no direct evidence 


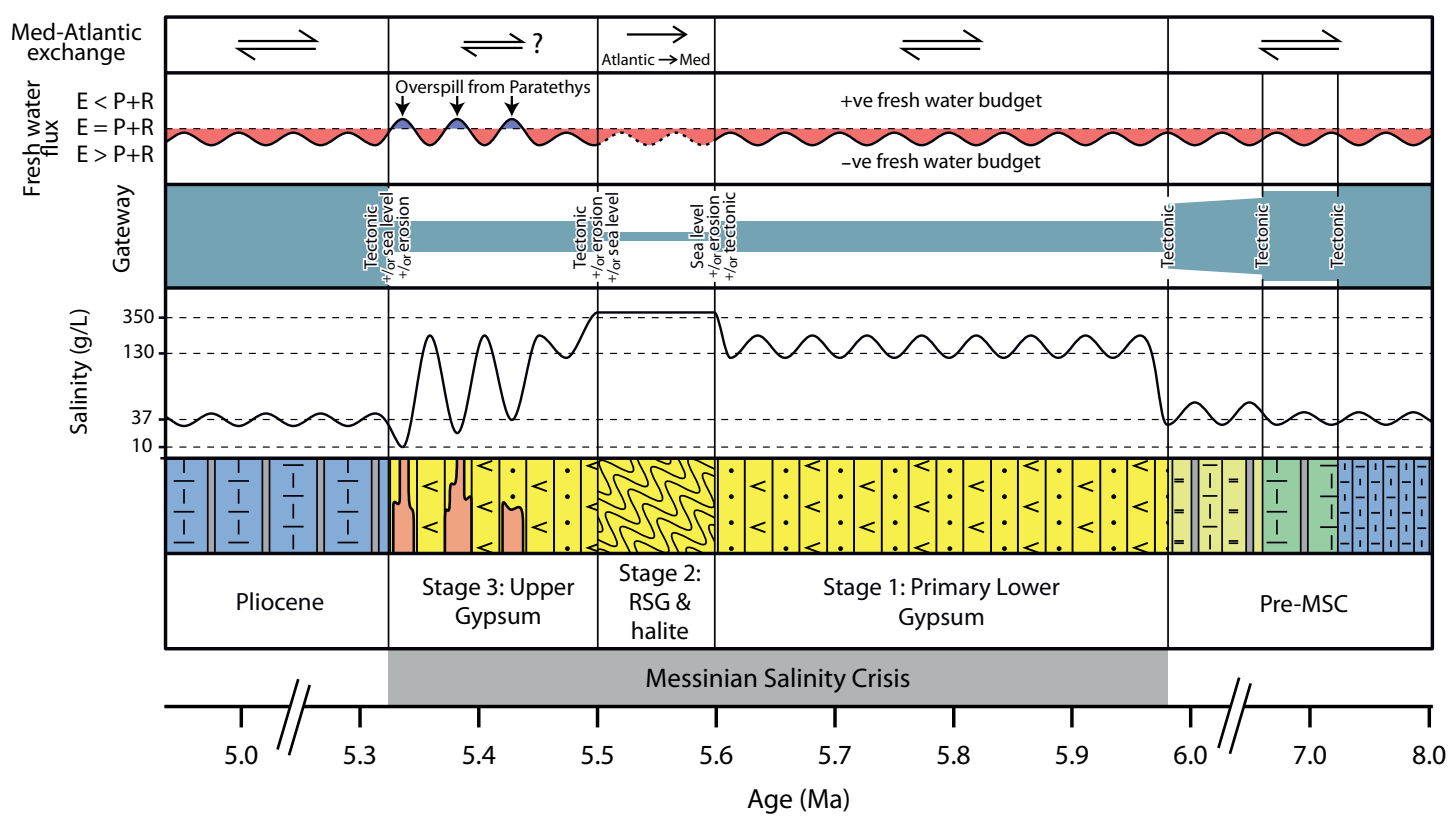

Figure 1. Summary figure illustrating the main features of the Mediterranean's exchange history in the Late Miocene-Pliocene including lithology, Mediterranean salinity, a qualitative representation of gateway size and the probable drivers (tectonics, erosion, sea level) of changing dimensions, the Mediterranean's fresh water flux where $\mathrm{E}$ and $\mathrm{P}$ = evaporation and precipitation over the Mediterranean respectively and $\mathrm{R}$ is the river discharge into the Mediterranean Sea, and arrows representing one-way or two-way exchange between the Mediterranean and Atlantic (Flecker et al., 2015).

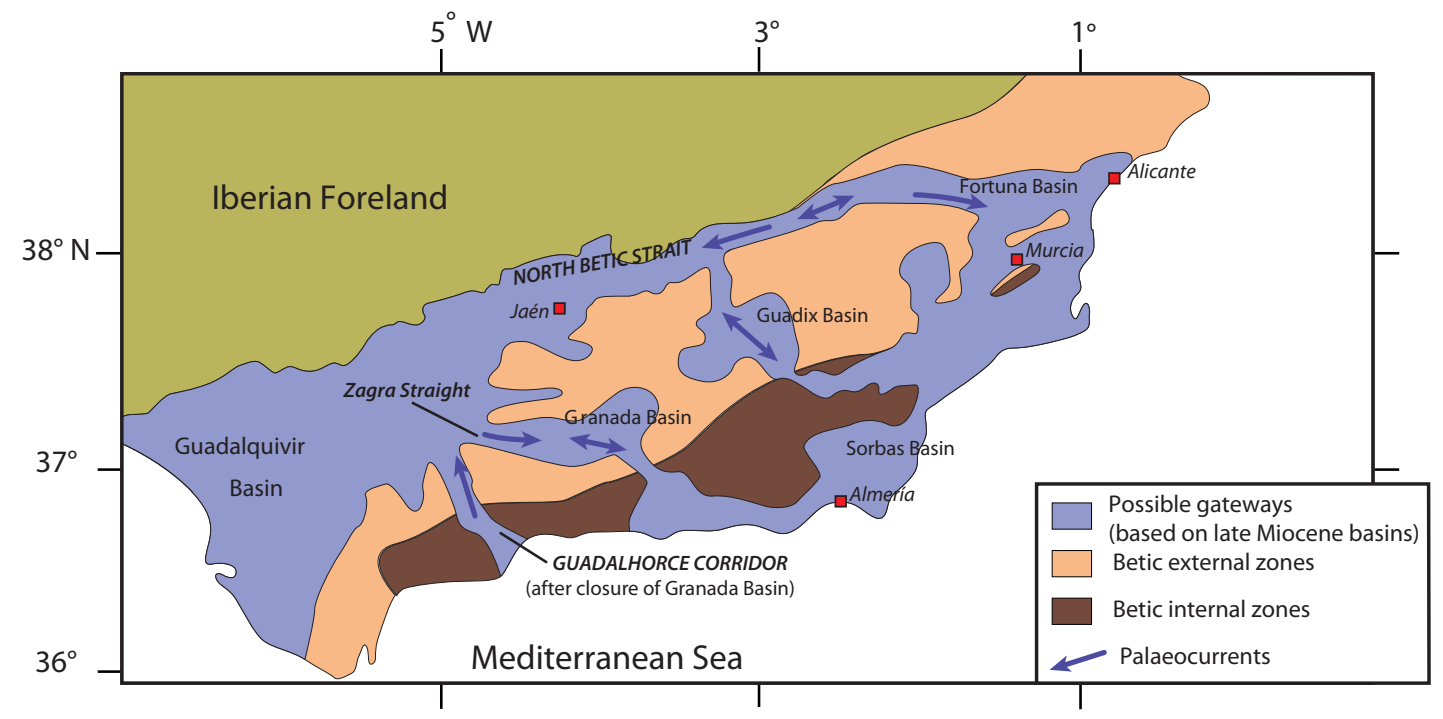

Figure 2. Detail map of the Betic Corridor showing the main geological units, corridors and paleocurrent indicators (modified after Santisteban and Taberner, (1983)). Paleocurrents from (Benson et al., 1991; Martín et al., 2014, 2001; Santisteban and Taberner, 1983). 
exists to enable the characterization of MO just after the opening of Gibraltar. IODP drilling in the Gulf of Cadiz recovered turbidites and debrites deposited between $\sim 4.5-4.2 \mathrm{Ma}$ (Fig. 4). These indicate the presence of relatively high flow strength in the Early Pliocene (Hernández-Molina et al., 2014b, 2013). From 3.8 Ma onwards these deposits developed into the extensive contourite depositional system. MOW circulation strengthened from 3.2-2.1 Ma, where two major sedimentary hiatuses from 3.2-3.0 Ma and 2.4-2.1 Ma indicate strong bottom water currents (Hernández-Molina et al., 2014b). The first hiatus has been linked with geochemical evidence of a rise in MOW density and it has been suggested that this intensified Upper North Atlantic Deep water (NADW) formation (Khélifi et al., 2014, 2009). (Rogerson et al., 2012b) concluded that the MOW pathway comparable to that of today (Fig. 3) could have been established around $1.8 \mathrm{Ma}$ (e.g. Brackenridge et al., 2011; Llave et al., 2007, 2001).

Consequently, exchange through the late Miocene Mediterranean-Atlantic gateways may have been quite different to that seen today in the Gibraltar Strait, and the evolution of the Atlantic's sedimentary and geochemical response to MOW may well reflect the evolution of the gateway itself. Three hypotheses can be formulated to explain the absence of evidence for MOW before the earliest turbidites and debrites. Firstly, the outflow was insufficiently powerful to generate such current flow related deposits at 4.2-4.5 Ma (Hernández-Molina et al., 2013). This is consistent with the interpretation of the onset of Gulf of Cadiz contourites and the geochemical signal of outflow as a strengthening or intensification of MOW rather than its initiation (Hernández-Molina et al., 2013; Khélifi et al., 2009). Secondly, Mediterranean and Atlantic waters may have had physical properties too similar to leave traceable geochemical evidence of $\mathrm{MO}$ in the Atlantic (Rogerson et al., 2010). During the Early Pliocene global climate was warmer and the gateway may have been deeper (Esteras et al., 2000; Raymo et al., 2006). It is suggested that such conditions would not be met at the time of the gateway opening, but there is no proof of this (Rogerson et al., 2012b). A third possibility for the absence of early Pliocene contourites from Leg 339 Sites is that early Pliocene MOW did exist, but MOW did not follow the present day route along the Iberian Margin and therefore it was not recovered during IODP Expedition 339. However, Rogerson et al., (2012a) demonstrated that the relationship between the salinity of MOW and its flow pathway while not intuitive, is predictable. Increased salinity of MOW could result in increased flow velocity and not in a variation of the plume's depth.

\section{Radiogenic $\mathrm{Nd}$ and $\mathrm{Pb}$ isotopes tracers of Mediterranean Outflow}

Attempts have been made to deduce the presence of MOW in the Atlantic during the Miocene using geochemical tracers such as neodymium $(\mathrm{Nd})$ and lead $(\mathrm{Pb})$ isotopes. While $\mathrm{Nd}$ has a residence time in seawater on the order of 200-1000 years (Tachikawa et al., 1999), on a global average $\mathrm{Pb}$ is removed from the water column within 10-100 years (Henderson and Maier-Reimer, 2002). These relatively short residence times enable the $\mathrm{Pb}$ and $\mathrm{Nd}$ isotope systems to vary regionally in seawater. $\mathrm{Nd}$ isotopic compositions (expressed as $\varepsilon_{\mathrm{Nd}}$, the ratio of ${ }^{143} \mathrm{Nd} /{ }^{144} \mathrm{Nd}$ in a sample normalized to the bulk earth value in parts per 10-4; Jacobsen and Wasserburg, 1980) are used as water mass tracers for open ocean paleocirculation reconstructions (e.g. (Frank et al., 

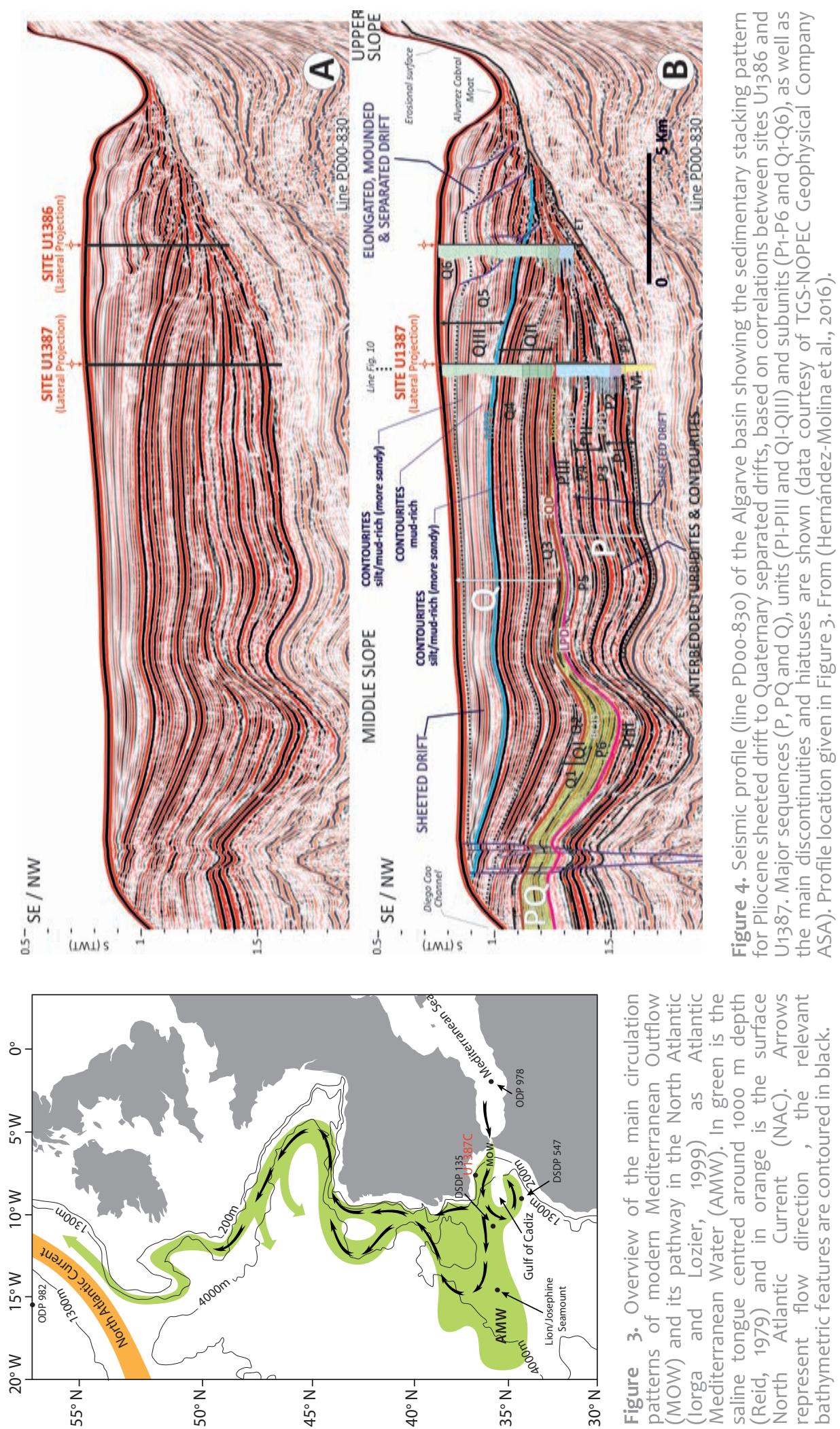

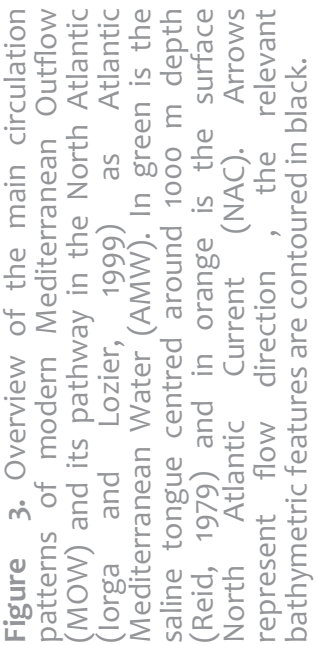


2002; Robinson et al., 2010; Thomas et al., 2003). Within the Mediterranean- Atlantic gateway region, clarifying $\varepsilon_{N d}$ signal provenance is complicated by riverine and eolian input (e.g. Henry et al., 1994; Sholkovitz and Szymczak, 2000) and boundary exchange at the sediment-bottom water interface (see Lacan and Jeandel, 2005). Nevertheless, since MOW and Atlantic Inflow Water (AIW) have measurably different $\varepsilon_{N d}(-9.4$ and -11.8 respectively; Piepgras and Wasserburg, 1983; Spivack, A.J., Wasserburg, 1988; Tachikawa et al., 2004), this isotope system theoretically has the potential to monitor past exchange.

Fe-Mn crusts record both the $\mathrm{Nd}$ and $\mathrm{Pb}$ isotopic composition of overlying bottom seawater (Frank, 2002). $\mathrm{Pb}$ is commonly analysed alongside $\mathrm{Nd}$ as it contributes complimentary information such as insight into local changes related to continental weathering and other climate-induced signals (Christensen et al., 1997; Gutjahr et al., 2009; Harlavan and Erel, 2002). Pb and Nd isotope records from the Lion Seamount west of Gibraltar, which is bathed in MOW today, provide no evidence for the cessation of MOW during the Messinian (Abouchami et al., 1999; Muiños et al., 2008). Unfortunately, the temporal resolution of both studies is too coarse to clearly rule out changes in Atlantic-Mediterranean exchange during the different stages of the MSC.

\section{Mediterranean-Atlantic connection through the Betic Corridor}

The Betic Corridor can be subdivided into four distinct connections that link the Atlantic with the Mediterranean during the late Miocene: the North-Betic Strait; the Granada Basin; the Guadix Basin and the Guadalhorce Basin (Fig. 3). All these basins contain large-scale paleocurrent structures typically in coarse-grained sand or conglomeratic sediments indicating high energy currents (Martín et al., 2014). These coarse clastics which commonly form the last part of the preserved succession are difficult to date. However, some of the Betic successions also contain evaporite and continental sediments that predate the MSC suggesting that these connections were conduits for Mediterranean-Atlantic exchange before the formation of the Mediterranean's saline giant.

This most northerly corridor, known as the North Betic Strait, connects the Guadalquivir Basin and the Mediterranean through the Fortuna and Lorca basins (Fig. 2; Martín et al., 2009). Integrated stratigraphic studies were carried out on the Fortuna Basin at the eastern end (Garcés et al., 1998; Krijgsman et al., 2000). These indicate that sedimentation changed from marls to diatomites and evaporites at 7.8 Ma, before deposition of continental deposits at 7.6 Ma. The Granada Basin connects the Guadalquivir Basin to the Mediterranean via the Zagra strait (Martín et al., 2014). The restriction of the Granada Basin has recently been more precisely dated using biostratigraphy by Corbí et al., (2012) demonstrating that a short phase of evaporite precipitation occurred between 7.37 to 7.24 Ma, followed by a less well constrained phase of continental sedimentation. The Gaudix Basin was a relatively open marine passage (around 12-15 km wide), probably permitting two-way flow, with coarse grained sediments deposited on the edges while marls accumulated in its central part. Later it evolved into a narrow strait with strong bottom currents flowing from the Mediterranean to the Atlantic (Betzler et al., 2006). Although there is broad 
consensus that the Guadix Basin corridor (or Dehesas de Guadix strait; Martín et al., 2014) was open during the late Tortonian (Betzler et al., 2006; Hüsing et al., 2010; Soria et al., 1999), the detailed timing of the closure is disputed. According to Betzler et al. (2006) the strait narrowed to about $2 \mathrm{~km}$ and was finally blocked at $\sim 7.8 \mathrm{Ma}$ by a tectonic swell fringed by reefs (7.8-7.4 Ma). This is contradicted by more recent magnetobiostratigraphic results for the same section (La Lancha; Hüsing et al., 2010) which show that there is a major hiatus of at least 2 Myr between open marine sediments of $\sim 7.85 \mathrm{Ma}$ and continental deposits, dated at 5.5 Ma (Fig. 2). The history of the Guadalhorce Corridor (Fig. 3; Martín et al., 2001) is less well known than the other Betic Basins. Its sedimentary record consists predominantly of siliciclastics containing unidirectional crossbeds with sets over $100 \mathrm{~m}$ in length and ranging from 10 to $20 \mathrm{~m}$ in thickness. These structures have been interpreted as indicating that the corridor was at least 60-120 $\mathrm{m}$ deep and subject to an extremely fast (1.0-1.5 m/s $\mathrm{s}^{-1}$ ) unidirectional current flowing northwest (Martín et al., 2001). Foraminifera-bearing marls intercalated with carbonates in one of the outcrops towards the bottom of this unit have an early Messinian age (6.3-7.2 Ma; Martín et al., 2001). Consequently, the Guadalhorce Corridor was considered to be a conduit for MOW prior to the MSC.

In summary, of the four possible Betic Corridors that may have supplied Atlantic water to the Mediterranean during the late Miocene, two are known to have been closed during the MSC (the North Betic Corridor and the Granada Corridor) while the successions of the remaining two (Guadix and the Guadalhorce Corridors) contain large unconformities and uncertainties that span the critical late Miocene period. It is therefore not currently possible to rule out definitively an open or intermittent connection within the Betic Corridor area during the MSC. 


\section{Chapter 1.}

\section{Evidence of early bottom water current flow after the Messinian Salinity Crisis in the Gulf of Cadiz.}

Van der Schee, M., Sierro, F.J., Jimenez-Espejo, F.J., Flecker, R., HernándezMolina, F.J., Flores, J.A., Acton, G., Gutjahr, M., Grunert, P., García-Gallardo, A., Andersen, N..Evidence of bottom water current flow after the Messinian Salinity Crisis in the Gulf of Cadiz. Marine Geology, in press.

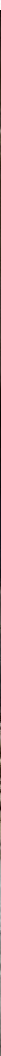


Chapter Cover:

Angular unconformity between Miocene and Pliocene sandy marls, Conil de la Frontera, Spain. 


\title{
Evidence of early bottom water current flow after the Messinian Salinity Crisis in the Gulf of Cadiz
}

\author{
Marlies van der Schee*(1), F.J. Sierro(1), F.J. Jiménez-Espejo(2), F.J. Hernández-Molina(3), R. Flecker ${ }^{(4)}$, \\ J.A. Flores ${ }^{(1)}$, G. Acton ${ }^{(5)}$, M. Gutjahr ${ }^{(6)}$, P. Grunert ${ }^{(7)}$, Á. García-Gallardo(7), N. Andersen ${ }^{(8)}$. \\ (1) Dept. de Geología, University of Salamanca, Plaza de los Caídos s/n, 37008 Salamanca, Spain \\ (2) Dept. of Biogeosciences, JAMSTEC, Yokosuka 237-0061, Japan \\ (3) Dept. Earth Sciences, Royal Holloway Univ. London, Egham, Surrey TW20 oEX, UK \\ (4) BRIDGE, School of Geographical Sciences, Cabot Institute, University of Bristol, University Road, \\ Bristol, BS8 1SS, UK \\ (5) Dept. Geography and Geology, Sam Houston State University, Huntsville, TX, 77341-2148, USA \\ (6) GEOMAR Helmholtz Centre for Ocean Research Kiel, Wischhofstr. 1-3, D-24148 Kiel, Germany \\ (7) Inst. für Erdwissenschaften, Karl-Franzens-Universität Graz, NAWI-Graz, Heinrichstrasse 26, 8010 \\ Graz, Austria \\ (8) Leibniz-Laboratory for Radiometric Dating and Isotope Research, Christian-Albrechts-Universität \\ Kiel, Max-Eyth-Str. 11-13, 24118 Kiel, Germany
}

\begin{abstract}
Integrated Ocean Drilling Program (IODP) Expedition 339 cored multiple sites in the Gulf of Cadiz in order to study contourite deposition resulting from Mediterranean Outflow water (MOW). One Hole, $\mathrm{U} 1387 \mathrm{C}$, was cored to a depth of $865.85 \mathrm{~m}$ below seafloor (mbsf) with the goal of recovering the latest Miocene to Pliocene transition in order to evaluate the history of MOW immediately after the end of the Messinian Salinity Crisis. To understand this history, an accurate age model for the succession is needed, but is challenging to construct, because the Miocene-Pliocene boundary is not marked by a clear biostratigraphic event in the Atlantic and coring gaps occur within the recovered stratigraphic record. These limitations are overcome by combining a variety of chronostratigraphic datasets to construct an age model that fits the currently available age indicators and demonstrates that coring in Hole $\mathrm{U} 1387 \mathrm{C}$ did indeed recover the Miocene-Pliocene boundary at about 826 mbsf. This boundary is associated with a distinct and abrupt change in depositional environment. During the latest Messinian, hemipelagic sediments exhibiting precession-induced climate variability were deposited. These are overlain by Pliocene sediments deposited at a much higher sedimentation rate, with much higher and more variable XRF core scanning Zr/Al ratios than the underlying sediment, and that show evidence of winnowing, particle sorting and increasing grain size, which we interpret to be related to the increasing flow of MOW. Pliocene sedimentary cyclicity is clearly visible in both the benthic $\delta^{18} \mathrm{O}$ record and the $\mathrm{Zr} / \mathrm{Al}$ data and is probably also precessionally controlled. Two contouritic bigradational sandy-beds are revealed above the third sedimentary cycle of the Pliocene. On the basis of these results, we conclude that sedimentation associated with weak Mediterranean-Atlantic exchange, began in the Gulf of Cadiz virtually at or shortly after the Miocene-Pliocene boundary.
\end{abstract}




\section{Introduction}

Today, Mediterranean Outflow water (MOW) is the dominant intermediate water mass in the Gulf of Cadiz (Hernández-Molina et al., 2014a). The mixture of relatively warm and saline Mediterranean water and colder, less saline Eastern North Atlantic Central Water (ENACW) proceeds north and north-westwards along the middle slope of the Algarve Margin (Fig. 1; Hernández-Molina et al., 2003) and preconditions Atlantic Meridional Overturning Circulation, hence also influencing global climate (Ivanovic et al., 2014; Rogerson et al., 2012a).

The present day gateway configuration through the Gibraltar Strait dates back to the astronomically dated Miocene-Pliocene boundary (5.332 Ma; e.g. Lourens et al., 1996; Van Couvering et al., 2000; Blanc, 2002; Duggen et al., 2003; Roveri et al., 2014). Before this, AtlanticMediterranean seawater exchange took place through two marine connections, the Betic Corridor in southern Spain and the Rifian Corridor in north west Morocco (e.g. Benson et al., 1991; Santisteban and Taberner, 1983). Exchange became progressively restricted during the late Miocene as a result of a complex combination of tectonic and relative sea-level processes until the two water bodies became almost completely disconnected (Krijgsman et al., 1999; Kuroda et al., 2016; Lofi et al., 2005; Meijer and Krijgsman, 2005; Ohneiser et al., 2015; Simon and Meijer, 2015). Between 5.97 and $5.33 \mathrm{Ma}$, the chemical composition and salinity of Mediterranean water must have changed dramatically and thick evaporites precipitated in the Mediterranean Basin during an extraordinary event known as the Messinian Salinity Crisis (MSC; e.g. Hsu et al., 1973). Immediately after the Messinian, it is thought that physically the Mediterranean and the Atlantic were reconnected through the single gateway. However, the nature of the initial early Pliocene Atlantic-Mediterranean water mass exchange is still unclear (Hernández-Molina et al., 2014a).

Analyses of benthic foraminiferal assemblages indicate that water from the Atlantic Ocean penetrated the eastern Mediterranean within a few precession cycles above the MiocenePliocene boundary (laccarino et al., 1999a). This, combined with the transition back to normal marine salinities in the Mediterranean, suggests that exchange between the two water bodies took place through the Gibraltar Strait immediately after the Miocene-Pliocene boundary. Seismic reflection profiles, however, are interpreted to indicate that contourites associated with the earliest active bottom water current along the pathway of the MOW were deposited significantly later at 4.2-4.5 Ma (Expedition 339 Scientists, 2013a, 2012; Hernández-Molina et al., 2014b). The question remains whether any record of early Pliocene MOW prior to 4.2-4.5 Ma can be identified. Possible reasons for the absence of a clear early Pliocene record of MOW include the lack of appropriately located, well-dated sedimentary archives or that the MOW and ENACW are too similar to distinguish from each other (Rogerson et al., 2012b).

Integrated Ocean Drilling Program (IODP) Expedition 339 cored Hole U1387C (Fig. 1) in order to recover the first upper Miocene to lower Pliocene sediment record in the Gulf of Cadiz and to 


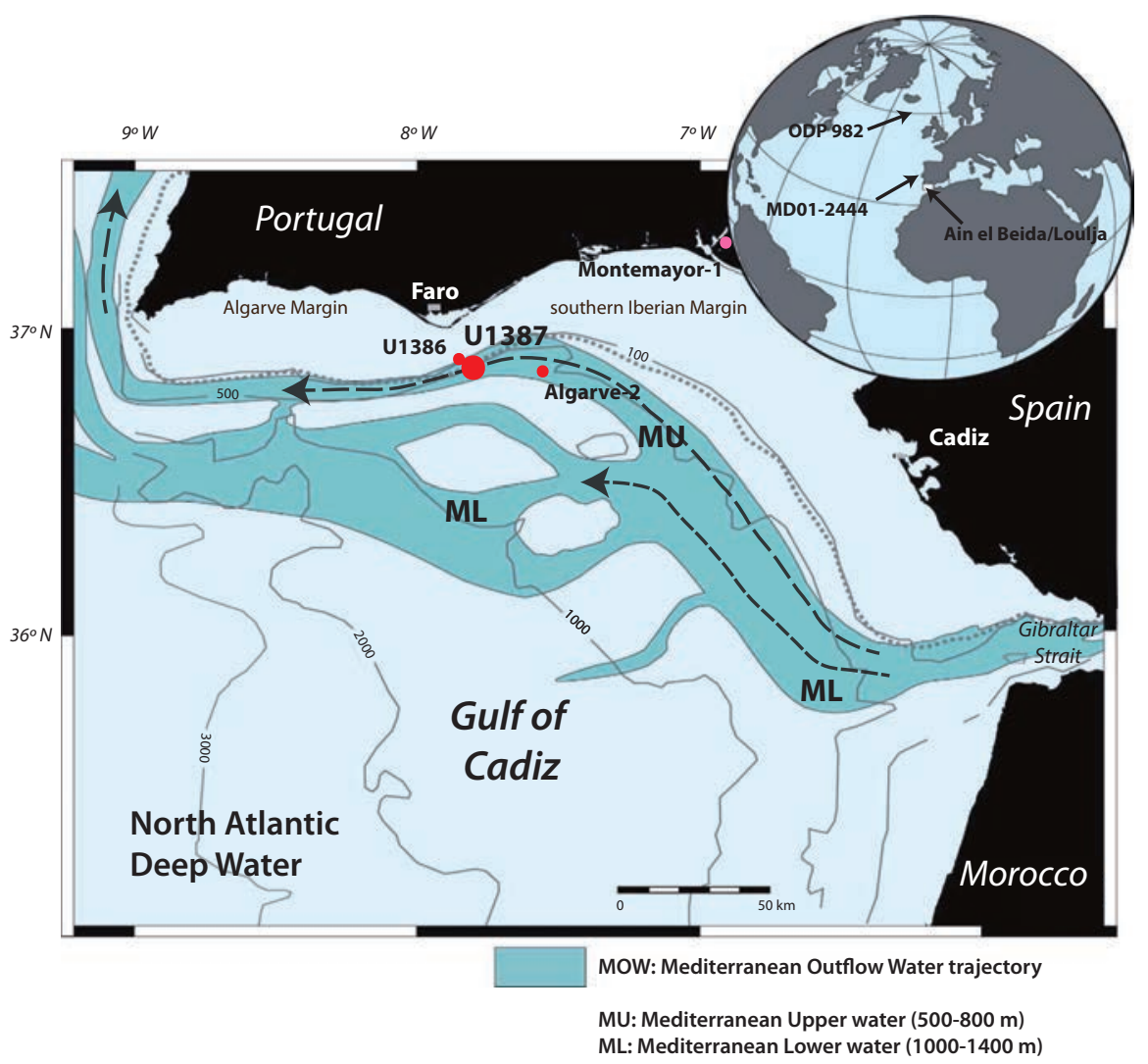

Figure 1. Hydrography of the Gulf of Cadiz showing the main modern flow paths of MOW, specified as the Upper and Lower branch. Locations of IODP Sites U1386 and U1387, Algarve-2, Site ODP 982, MD01-2444, the onshore Montemayor-1 core in SW Spain and exposed section of Ain el Beida/Loulja in NW Morocco are indicated. Modified after Hernández-Molina et al., (2003).

Table 1. Planktic biostratigraphic events used in the present study and their position (mbsf) in IODP Hole $\mathrm{U} 1387 \mathrm{C}$ and if it is stated in the preliminary IODP report (Expedition 339 Scientist, 2012). FO = First Occurrence, LO = Last Occurrence.

\begin{tabular}{|c|c|c|c|c|c|c|}
\hline \multirow{2}{*}{$\begin{array}{l}\text { Planktic foraminifera } \\
\text { biohorizon }\end{array}$} & \multicolumn{3}{|c|}{ Hole U1387C depth [mbsf] } & \multirow{2}{*}{$\begin{array}{l}\text { Preliminary } \\
\text { IODP report }\end{array}$} & \multirow{2}{*}{$\begin{array}{l}\text { Age Bio-event } \\
{[\mathrm{Ma}]}\end{array}$} & \multirow[t]{2}{*}{ Reference } \\
\hline & Top & Bottom & Mean & & & \\
\hline LO G. margaritae & 558.9 & 561.89 & 560.4 & Yes & 3.85 & Lourens et al., 2004 \\
\hline FO G. puncticulata & 629.12 & 632.52 & 630.82 & Yes & 4.52 & Lourens et al., 2004 \\
\hline Influx G. menardii & 752.40 & 751.30 & 751.85 & No & $5.55,5.51,5.31$ & $\begin{array}{l}\text { Krijgsman et al., 2004; Van der } \\
\text { laan et al., } 2006\end{array}$ \\
\hline \multirow{2}{*}{$\begin{array}{l}\text { Dextral to sinistral coiling } \\
\text { change } N \text {. acostaensis }\end{array}$} & & \multirow[t]{2}{*}{809.52} & \multirow[t]{2}{*}{808.87} & \multirow{2}{*}{ No } & \multirow{2}{*}{$5 \cdot 30,5 \cdot 32$} & \multirow{2}{*}{$\begin{array}{l}\text { Lourens et al., 1996; laccarino } \\
\text { et al., 1999b }\end{array}$} \\
\hline & 841.80 & & & & & \\
\hline \multirow{2}{*}{ "Acme" G. margaritae > 10\% } & \multirow{2}{*}{\multicolumn{3}{|c|}{$\begin{array}{l}\text { Not present } \\
\text { (below base of the Hole) }\end{array}$}} & \multirow{2}{*}{ No } & $5.75-5.84$ & Van den Berg et al., 2015 \\
\hline & & & & & $5.70-5.84$ & Krijgsman et al., 2004 \\
\hline $\begin{array}{l}\text { Sinistral to dextral coiling } \\
\text { change N. acostaensis }\end{array}$ & (belov & $\begin{array}{l}\text { Not pres } \\
v \text { base of }\end{array}$ & Hole) & Yes & 6.37 & $\begin{array}{l}\text { Hilgen and Krijgsman, 1999; } \\
\text { Krijgsman et al., 2004; Sierro } \\
\text { et al., 2001, Hilgen et al., } 2012\end{array}$ \\
\hline
\end{tabular}


evaluate the (re-)establishment of Mediterranean-Atlantic exchange after the MSC (Stow et al., 2011). Unfortunately, the Miocene-Pliocene boundary is not easy to identify in the Gulf of Cadiz, since its global stratotype has been established in the Mediterranean where it is associated with the facies shift from Messinian evaporites to Zanclean marls (Van Couvering et al., 2000). Consequently, the Miocene-Pliocene boundary outside the Mediterranean Basin can only be identified using alternative chronostratigraphic methods.

Analyses to detect bottom water currents, for example of Mediterranean-Atlantic exchange, are increasingly done by analysing X-ray fluorescence (XRF) scanning Zr/Al levels in combination with grain size analysis (Bahr et al., 2015; Kaboth et al., 2015; Lamy et al., 2015; Voelker et al., 2015b). In cases where $\mathrm{Zr}$ is associated with coarser grain sizes in marine environments, such as in the Gulf of Cadiz, it becomes a typical indicator for sediments affected by changes in bottom water current strength (Bahr et al., 2014; Bertrand et al., 2012; Ganeshram et al., 1999). The element Zr is most often associated with the dense refractory mineral zircon (e.g. McLennan et al., 1993). Zr/Al peaks are associated with higher proportions of non-aluminosilicate minerals, such as quartz, feldspars, and heavy minerals (zircon). Lower Zr/Al ratios are linked to finer grained Al-rich minerals, such as clays. Bottom water current sorting promotes the separation between coarser siliciclastic sediment components, enrich in $\mathrm{Zr}$, and Al-rich finer grained minerals. For example, Bahr et al. (2014) showed that latest Pleistocene (0-140 ka) contourites at Site U1387 exhibited high Zr/Al ratios in sandy intervals, which were deposited under high bottom water current flow conditions. By contrast, Zr/Al levels in the hemipelagic core MD01-2444 (Fig. 1) are dominated by long-term variability and shows only small-scale oscillations.

In this study, we establish a refined chronostratigraphic framework for upper Miocene to lower Pliocene sediments recovered at IODP Site U1387 based on seismic correlation, biostratigraphic constrains (planktic foraminifers, calcareous nannofossils), magnetostratigraphy and cyclostratigraphy. We then evaluate the imprint of bottom water currents on the Gulf of Cadiz sediments spanning the Miocene to Pliocene transition using lithology, grain size fractions (>63 $\mu \mathrm{m}$ ) and elemental XRF scanning Zr/Al ratios. Our key aim is to identify deposits characteristic for elevated bottom water currents, to evaluate current strength, and if possible to date the onset of post MSC MOW.

\section{Background}

IODP Site U1387 is located on the continental margin of the Iberian Peninsula at the eastern end of the Faro Drift ( $36^{\circ} 48^{\prime} \mathrm{N}, 7^{\circ} 43^{\prime} \mathrm{W}$ ) at $559 \mathrm{~m}$ water depth (Fig. 1; Expedition 339 Scientists, 2013a, 2012). This study focuses on the lowermost section of Hole U1387C from 731.20 mbsf to the base of the sediment sequence at 865.85 mbsf. These are the oldest sediments recovered during the IODP Expedition 339. Core recovery over this interval was $64 \%$ and downhole logging data was not collected because of borehole wall collapse, which means that the record contains significant gaps.

Using the last occurrence of Globorotalia margaritae (older than $3.85 \mathrm{Ma}$; Hilgen et al., 2012) at $560.4 \mathrm{mbsf}$, the first occurrence of Globorotalia puncticulata (older than 4.52 Ma; Lourens et al., 

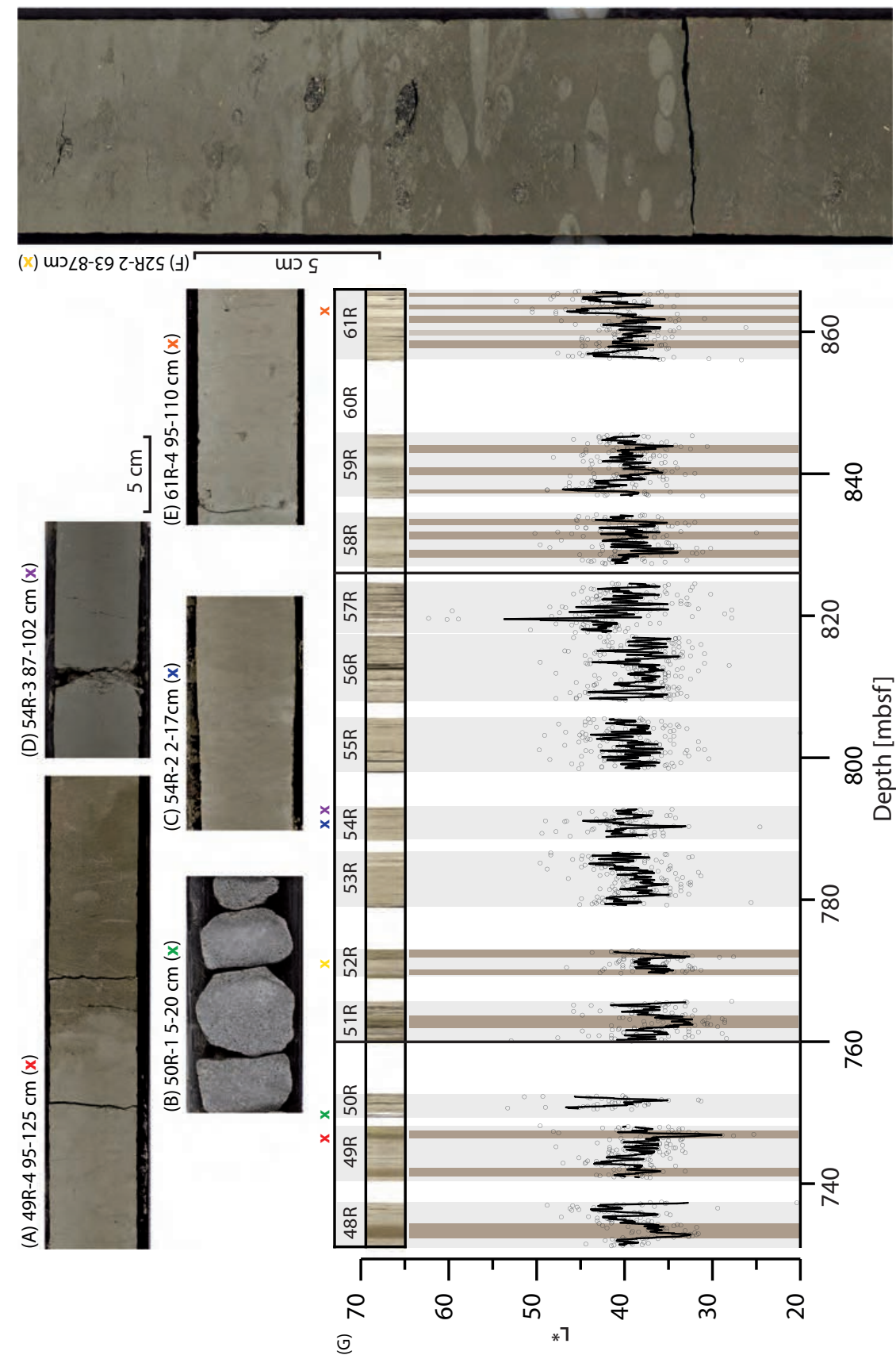

D

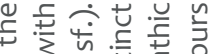
ज है ज्ञ $3 \vec{m}$ 인 。

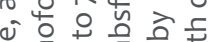

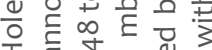

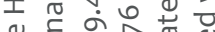
ᄃ खे

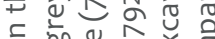
4 +0 व ป็

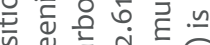

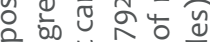

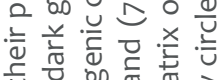

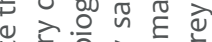

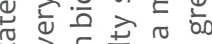

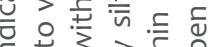
$\leqq+3$ बे

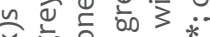
×

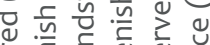

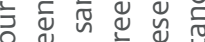

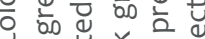

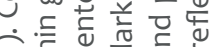
它突需 这芆过出范。

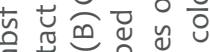

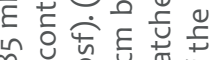
杄论

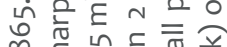

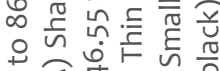
○疋古会 กิ m

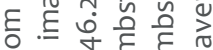

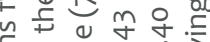

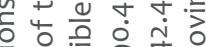
पू

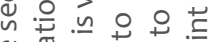

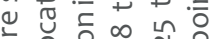

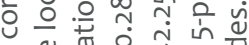

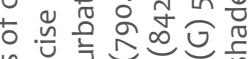
ที ญै

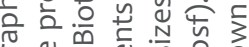
के $\frac{0}{\pi}$ है जै 일

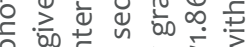

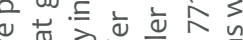

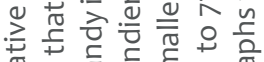
एँ ¿ 凹

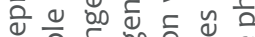
ฯ 당 는

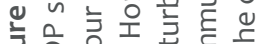

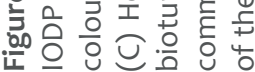


2004) at 630.8 mbsf in combination with the presence of $G$. margaritae at the base of the Hole (younger than 6.08 Ma; Hilgen et al., 2012) and the predominantly dextral coiling direction of Neogloboquadrina acostaensis (younger than 6.37 Ma; Hilgen et al., 2012; Table 1; see Section 5.1.1), shipboard scientists suggested that sediments from 731.20 to 865.85 mbsf were Miocene/Pliocene in age (Expedition 339 Scientists, 2012; Hernández-Molina et al., 2014b; Stow et al., 2013). However, there is no robust justification of the depth for the Miocene-Pliocene boundary due to limited tie point identifications during the Expedition (Expedition 339 Scientists, 2013a, 2012). Although the exact depth of the boundary is never clearly stated in any of these publications, it is apparent from the various stratigraphic summary figures that so far the boundary was poorly constrained. The preferred depth of 730 mbsf used in the summary in Hernández-Molina et al. (2014b), centred on IODP Expedition 339 results, was based on a lithologic transition from hemipelagites of presumed Miocene age to turbidites and debrites of presumed Pliocene age.

Recently, 3D and 2D seismic reflection profiles have been used to correlate the Algarve-2 well to IODP Hole U1387C (Figure 1, Hernández-Molina et al., 2015). The Miocene-Pliocene boundary in Algarve-2 has been identified at 1455-1460 mbsf using a combination of biostratigraphic data and cyclostratigraphic tuning of resistivity logs (Hernández-Molina et al., 2015). The Miocene-Pliocene boundary is manifested as an increase in reflection amplitudes on seismic lines (M-reflector) truncating towards the basin margins. This reflector was correlated in Hernández-Molina et al., (2015) to an abrupt sedimentary change in Site U1387 at 826 mbsf with an uncertainty of 15-20 m.

Shipboard colour reflectance data $\left(L^{*}\right)$ mirrors to some extent darker and lighter colours of core photographs (Fig. 2G). Core descriptions prepared during IODP Expedition 339 describe the lithology between 731.20 to 748.09 mbsf as greenish grey to very dark greenish grey nannofossil (silty) mud or sand with biogenic carbonate (Fig. 2A; Expedition 339 Scientists, 2013a). Cemented grey medium sandstone with biogenic carbonate is found between 748.10 and 750.92 mbsf (Fig. 2B). From 760 mbsf to the base of the core, dark greenish grey nannofossil mud and muddy/clayey nannofossil ooze is found commonly interbedded with $2 \mathrm{~cm}$ thick beds of dark greenish grey silty sand (Fig. 2D). The deepest occurrence of a thick $(\sim 80 \mathrm{~cm})$ silty bed is observed at about $801 \mathrm{mbsf}$ (Fig. 2C). Distinct bioturbation is present from 827.20 to $865.85 \mathrm{mbsf}$ (Fig. 2E) and is less extensive higher up the sequence. Hence, compositional lithological changes exist at several depths in the studied section. While the Miocene-Pliocene boundary was previously presumed to be associated with the significant change in lithology at 730 mbsf (Hernández-Molina et al., 2014b), it was just as likely represented by one of the other notable changes in lithology.

Finally, shallow water benthic foraminifers, such as Ammonia, Elphidium and Asterigerinata were recorded from 792.80 mbsf upwards and have particular high abundances above 765.72 mbsf (Expedition 339 Scientists, 2013a). 


\section{Methods}

\subsection{Sample preparation}

Bulk sediment samples from IODP Hole U1387 of $\sim 25 \mathrm{~cm}^{3}$ were collected the IODP Bremen Core Repository for micropaleontological, stable isotope, and grain size analyses. Samples were taken at least every $40 \mathrm{~cm}$ from 731.20 to 748.10 mbsf and every $20 \mathrm{~cm}$ from 751.12 to $865.85 \mathrm{mbsf}$. All samples were freeze-dried overnight, weighed, disaggregated in tap water overnight, sieved through $>63$ and $>150 \mu \mathrm{m}$ sieves, dried, and weighed again. The $>63 \mu \mathrm{m}$ fraction as a percentage of the total dry weight (wt.\%) was used as the sand fraction, that is in certain cases indicative for bottom water current flow strength (Rogerson et al., 2005).

Paleomagnetic samples consisted of the archive halves of all core sections and oriented discrete sediment samples, which were collected by inserting a hollow extruder into the middle of the working half of the split-core sections and then extruding the sediments into plastic cubes $(2 \mathrm{~cm}$ $\times 2 \mathrm{~cm} \times 2 \mathrm{~cm}$, with an internal volume of $\sim 7 \mathrm{~cm}^{3}$ ) as described in Expedition 339 Scientists, (2013b).

\subsection{Micropaleontological studies}

Planktic foraminiferal biostratigraphic analyses was performed on the $>150 \mu \mathrm{m}$ fraction of the prepared samples. A microsplitter was used to split residues until about 150 planktic specimens remained. All planktic foraminiferal species were counted and classified including the biostratigraphic marker species G. margaritae, Globorotalia menardii and sinistral or dextral coiling N. acostaensis. Presence/absence data of benthic foraminiferal species on the $>150 \mu \mathrm{m}$ fraction were used to provide a rough paleobathymetry estimation [A detailed quantitative analysis will be available in a separate publication by García-Gallardo et al., in preparation]. Five samples were chosen for detailed calcareous nannofossils biostratigraphic analysis, implementing the settling technique described in Flores and Sierro (1997).

\subsection{Stable isotope analyses}

Between two and fifteen specimens of benthic foraminifers Cibicidoides pachyderma $>250 \mu \mathrm{m}$ were hand-picked from each sample for carbon and oxygen stable isotope analysis $\left(\delta^{13} \mathrm{C}, \delta^{18} \mathrm{O}\right)$. Specimens were washed with ethanol, ultrasonicated for several seconds and dried for $24 \mathrm{~h}$ to remove all liquids.

Samples from 731.20 to 747.7 . mbsf and 828.22 to 865.15 mbsf were analysed in the Godwin Laboratory for Palaeoclimate Research at the University of Cambridge. Isotope analyses were performed using a Thermo Finnigan MAT253 mass spectrometer fitted with a Kiel device. Analytical precision on an in-house standard, calibrated against international carbonate standard NBS-19, is $\pm 0.06 \%$ for $\delta^{13} \mathrm{C}$ and $\pm 0.08 \%$ for $\delta^{18} \mathrm{O}$. Samples from $751 \mathrm{mbsf}$ to $824 \mathrm{mbsf}$ were analysed in the Leibniz-Laboratory for Radiometric Dating and Isotope Research at the Christian-AlbrechtsUniversity in Kiel with a MAT 253 mass spectrometer connected to a Kiel IV carbonate preparation device. The analytical precision of the NBS-19 international standard and three laboratory-internal standards was better than $\pm 0.05 \%$ for $\delta^{13} \mathrm{C}$ and $\pm 0.08 \%$ for $\delta^{18} \mathrm{O}$. At the Christian-Albrechts- 
University, large foraminiferal samples with more than six individuals were crushed to homogenize the samples before analysis of a representative subsample was undertaken. Results are reported relative to the Vienna Pee Dee Belemnite standard (VPDB).

\subsection{X-ray fluorescence analyses}

We used the XRF core scanner II, (AVAATECH Serial No. 2) at the MARUM-University of Bremen to retrieve elemental $\mathrm{Zr} / \mathrm{Al}$ ratios. XRF core scanner data were collected every $3 \mathrm{~cm}$ down-core over a $1.2 \mathrm{~cm}^{2}$ area with a down-core slit size of $10 \mathrm{~mm}$ in three separate runs using generator settings of 10, 30, and $50 \mathrm{kV}$, and currents of $0.2,1.0$, and $1.0 \mathrm{~mA}$, respectively. Sampling time was set to $20 \mathrm{~s}$ and scanning took place directly at the split core surface of the archive half. The split core surface was covered with a 4 ? $\mathrm{m}$ thin SPEXCerti Prep Ultralene1 foil to avoid contamination of the XRF measurement unit and desiccation of the sediment. The reported data have been acquired by a Canberra X-PIPS Silicon Drift Detector (SDD; Model SXD 15C-150-500) with 150 eV Xray resolution and the Canberra Digital Spectrum Analyzer DAS 1000. The XRF II scanner is equipped with an Oxford Instruments 50W XTF5011. Core disturbance from drilling (biscuiting) may have significantly degraded the quality of XRF measurements from 760.18 to 764.94 (Core $51 \mathrm{R}$ ) and inhibited measurements from 816.58 to 827.23 mbsf (Core 57R).

\subsection{Magnetostratigraphy}

As described in Expedition 339 Scientists (2013a, b), continuous paleomagnetic measurements were made every $5 \mathrm{~cm}$ along the split-core sections during Expedition 339 using the shipboard cryogenic magnetometer ( $2 \mathrm{G}$ Enterprises Model-760R). The natural remanent magnetization (NRM) was measured after progressive alternating field (AF) demagnetization at 0, 10, and $20 \mathrm{mT}$. The split-core data were further cleaned by removing results from disturbed intervals and from near the ends of the core sections, as these data contain biases. The cleaned data are available in Table T16 of Expedition 339 Scientists (2013a) and the raw data are available online from the IODP LIMS Database.

To permit more detail demagnetization experiments and to better assess the characteristic remanent magnetization (ChRM) directions, we also collected approximately one discrete paleomagnetic cube sample $\left(7 \mathrm{~cm}^{3}\right)$ from each core section (roughly one sample every $1.5 \mathrm{~m}$ ) during Expedition 339 for the interval from 700 mbsf to the base of the hole, for a total of 56 samples. Only four of these samples were measured during Expedition 339. The remaining 52 were measured post-cruise in the Paleomagnetism Laboratory at University of California-Davis. All 56 samples were subjected to progressive AF demagnetization generally using $5 \mathrm{mT}$ steps from o to $40 \mathrm{mT}$ and $10 \mathrm{mT}$ steps up to $100 \mathrm{mT}$. Paleomagnetic directions were determined from principal component analysis (PCA; Kirschvink, 1980) using ZPLOTIT software (Acton, 2011, http://paleomag.ucdavis.edu/software-zplotit.html). The remanence measurements from at least five demagnetization steps for each interval were fit to lines using only steps between 20 and 60 mT. PCA lines were fit using both the FREE option, in which the line is not required to pass through the origin of the plot, and the ANCHORED option, in which line is anchored to the origin (Supplementary Tables S17-S19). A Fisherian mean direction was also computed from the highest 
several demagnetization steps to estimate a stable end point (SEP). The paleomagnetic data and PCA results are provided in the Supplementary Material.

For each sample, we determined a preferred inclination from the PCA FREE, PCA ANCHORED, or SEP estimate of the ChRM. The selection of which method best resolved the ChRM was based on visual inspection of the sample directions plotted on orthogonal vector diagrams (modified Zijderveld plots) and stereonets. The results for each sample were ranked with a quality factor, where Quality 1 was reserved for samples that displayed very linear decay of magnetization during demagnetization as noted by PCA maximum angular deviation (MAD) angles < 5. Quality 2 are similar to Quality 1 but the MAD angles are between $5^{\circ}$ and $10^{\circ}$. These highest quality ( 1 and 2$)$ samples have very well resolved ChRM directions and the polarity can be determined with great confidence. Such high quality samples occur mainly in the upper part of section, and none are deeper than 550 mbsf. Quality 3 samples displayed moderate directional scatter during AF demagnetization but a relatively noisy ChRM can be determined from which the polarity can be established. Quality 4 samples have large directional scatter during AF demagnetization and generally a significant drilling overprint that overlaps much of the coercivity spectra of the ChRM. The ChRM cannot be accurately determined although it is often possible to determine the polarity of these samples because they trend towards positive (normal polarity) or negative (reverse polarity) inclinations as they are demagnetized above about 40-80 mT. Quality 5 samples have such highly variable directions during AF demagnetization or are so strongly overprinted that their polarity is indeterminate. Of the 56 samples below $700 \mathrm{mbsf}$, only 3 are Quality 3, 33 are Quality 4 , and the remaining 20 are Quality 5.

\section{Results}

The sedimentary sequence was divided into three intervals based on its lithological and geochemical properties (Fig. 3): Interval I ( $~ 826$ to 865.85 mbsf) is characterized by low $\mathrm{Zr} / \mathrm{Al}$ levels and consistently low wt.\% sand ( $>63 \mu \mathrm{m})$; Interval II ( $\sim 60$ to $\sim 826 \mathrm{mbsf}$ ) has higher, more variable $\mathrm{Zr} / \mathrm{Al}$ ratios and progressively higher and more variable wt.\% sand; Interval III (731.20 to $\sim 760 \mathrm{mbsf}$ ) is characterized by highly variable $\mathrm{Zr} / \mathrm{Al}$ oscillations and much higher sand grades commonly reaching $10-40 \mathrm{wt} . \%$.

\subsection{Sand fraction and composition}

The sand fraction (>63 $\mu \mathrm{m}$ ) of Interval I is consistently less than 3 wt.\% (Fig. 3). Microscopic inspection of washed samples revealed that this coarser fraction mainly consists of planktic foraminifers with minor lithic particles including pyrite and rare quartz. A similar sand-grade and

Figure 3 (next page). Paleoclimate records of IODP Site U1387C. Intervals I, II and III, magnetostratigraphic polarities, core numbers and their recovery, and colour patterns from core photographs are shown above the panel (Expedition 339 Scientists, 2013a). Light blue shaded areas indicate darker colours in core photographs. Age indications are displayed above the panel. $\mathrm{FO}=$ First Occurrence. $(\mathrm{A}) \delta^{18} \mathrm{O}$ (blue) and $\delta^{13} \mathrm{C}$ (green) of benthic C. pachyderma. Grey horizontal bars show average $\delta^{18} \mathrm{O}$ values per Interval. (B) Elemental $\mathrm{Zr} / \mathrm{Al}$ ratios with 5-point moving average (black). (C) Weight \% sand $>63 \mu \mathrm{m}$ as a percentage of total dry weight (orange). 


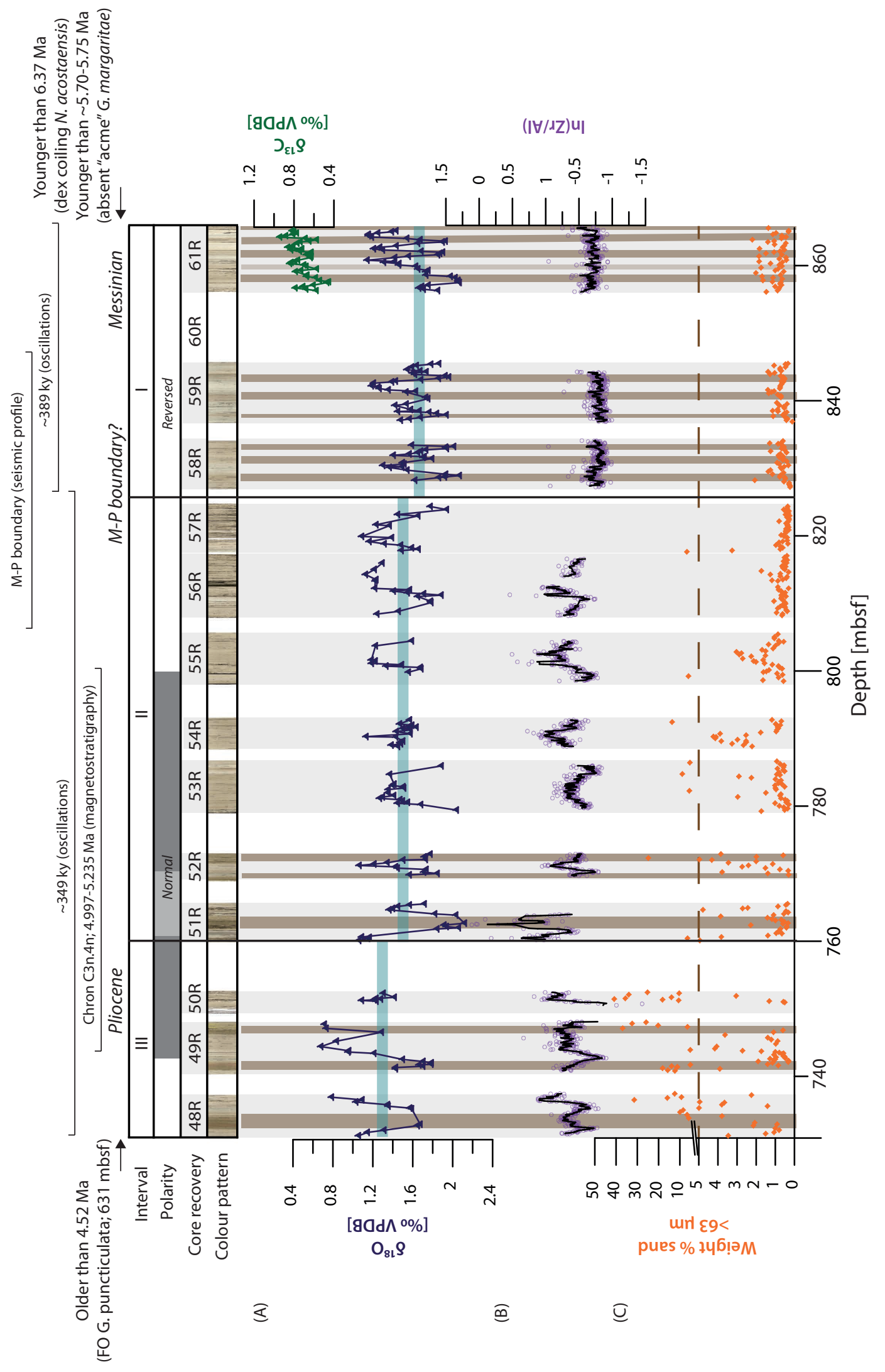


composition is observed in the lower part of Interval II (Cores 56R and 57R), but samples with distinctly higher wt.\% of the $>63$ ? $\mathrm{m}$ fraction occur increasingly commonly above $\sim 803 \mathrm{mbsf}$. The coarser grain size fraction is mainly associated with an increase in the quartz content. Sediments from 788.80 to $805.68 \mathrm{mbsf}$ in Cores $54 \mathrm{R}$ and $55 \mathrm{R}$ show distinct bigradational patterns with traces of bioturbation (Fig. 2D, 4). The sand fraction of these silt horizons is dominated by fine sand-grade material (e.g. between 63 and $150 \mu \mathrm{m}$; Fig. 4). The composition of the $>150 \mu \mathrm{m}$ fraction is mainly restricted to foraminifers and peaks in the abundance of this coarser size fraction show no relationship with the bigradational pattern seen in the fine sand material (Fig. 4). The higher sand content seen in Interval III is associated with more lithic particles, mainly quartz grains (Fig. 3).

\subsection{Stable isotope records}

The benthic $\delta^{18} \mathrm{O}$ isotope record shows regular fluctuations throughout the studied section. However, the different intervals are characterized by variations with different wavelengths and amplitudes (Fig. 3). The $\delta^{18} \mathrm{O}$ oscillations in Interval I have an average wavelength of $\sim 2.2 \mathrm{~m}$, considering an additional fourth alternation in Core $61 \mathrm{R}$ that is only visible in the $\delta^{13} \mathrm{C}$ during the larger $\delta^{18} \mathrm{O}$ oscillation from 856.68 to 860.48 mbsf (Table 2; Fig. 3, 9; see section 5.2.2) [a detailed interpretation of the $\delta^{13} \mathrm{C}$ record is beyond the scope of this paper and is the subject of a forthcoming paper (Van der Schee et al. in preparation)]. The regular $\delta^{18} \mathrm{O}$ alternations of Interval II typically have significantly longer wavelengths of $\sim 5.9 \mathrm{~m}$ on average. Limited recovery of Interval III makes the wavelength of its $\delta^{18} \mathrm{O}$ alternations more difficult to calculate, but it appears to be comparable to those of Interval II. The average $\delta^{18} \mathrm{O}$ of Interval II is lower than that of Interval I and the average of Interval III is lower than Intervals I and II (Fig. 3). In all three Intervals, distinctly darker layers tend to be associated with higher $\delta^{18} \mathrm{O}$.

\subsection{XRF scanning Zr/Al ratios}

$\mathrm{Zr} / \mathrm{Al}$ ratios of Interval I have consistently low ratios with the lack of obvious regular alternations that resemble the periodicity of those well developed in the $\delta^{18} \mathrm{O}$ (Fig. 3A, B). By contrast, Intervals II and III are characterized by distinct, high amplitude variability in $\mathrm{Zr} / \mathrm{Al}$ levels displaying oscillations with wavelengths similar to those of the benthic isotope record $(\sim 5.9 \mathrm{~m})$. In general in Interval II and III, these two records show negative co-variation.

Table 2. Wavelengths of cyclical alternations of $\delta^{18} \mathrm{O}$ for selected intervals. *Three cyclical alternations are visible in the $\delta^{18} \mathrm{O}$ record plus an additional cycle visible in $\delta^{13} \mathrm{C}$ is taken into consideration.

\begin{tabular}{|c|c|c|c|c|c|}
\hline \multirow[t]{2}{*}{ Core } & \multicolumn{2}{|c|}{ Hole U1387C depth [mbsf] } & \multirow{2}{*}{$\begin{array}{l}\text { Length } \\
\text { [m] }\end{array}$} & \multirow{2}{*}{$\begin{array}{c}\text { Cycles } \\
{[-]}\end{array}$} & \multirow{2}{*}{$\begin{array}{l}\text { Length/cycle } \\
\text { [m/cycle] }\end{array}$} \\
\hline & Top & Bottom & & & \\
\hline $48 \mathrm{R}$ & 731.2 & 736.91 & 5.71 & $<1$ & - \\
\hline $54 R-57 R$ & 790.44 & 819.91 & 29.47 & 5.0 & 5.89 \\
\hline $58 \mathrm{R}$ & 828.92 & 832.92 & 4.00 & 2.0 & 2.00 \\
\hline $59 R$ & 837.90 & 844.50 & 6.60 & 2.5 & 2.64 \\
\hline \multirow[t]{2}{*}{$61 R$} & 856.68 & 864.42 & 7.74 & $3.0+1^{*}$ & 1.94 \\
\hline & & \multicolumn{3}{|c|}{ Weighted average Interval I (58R-61R): } & 2.16 \\
\hline
\end{tabular}




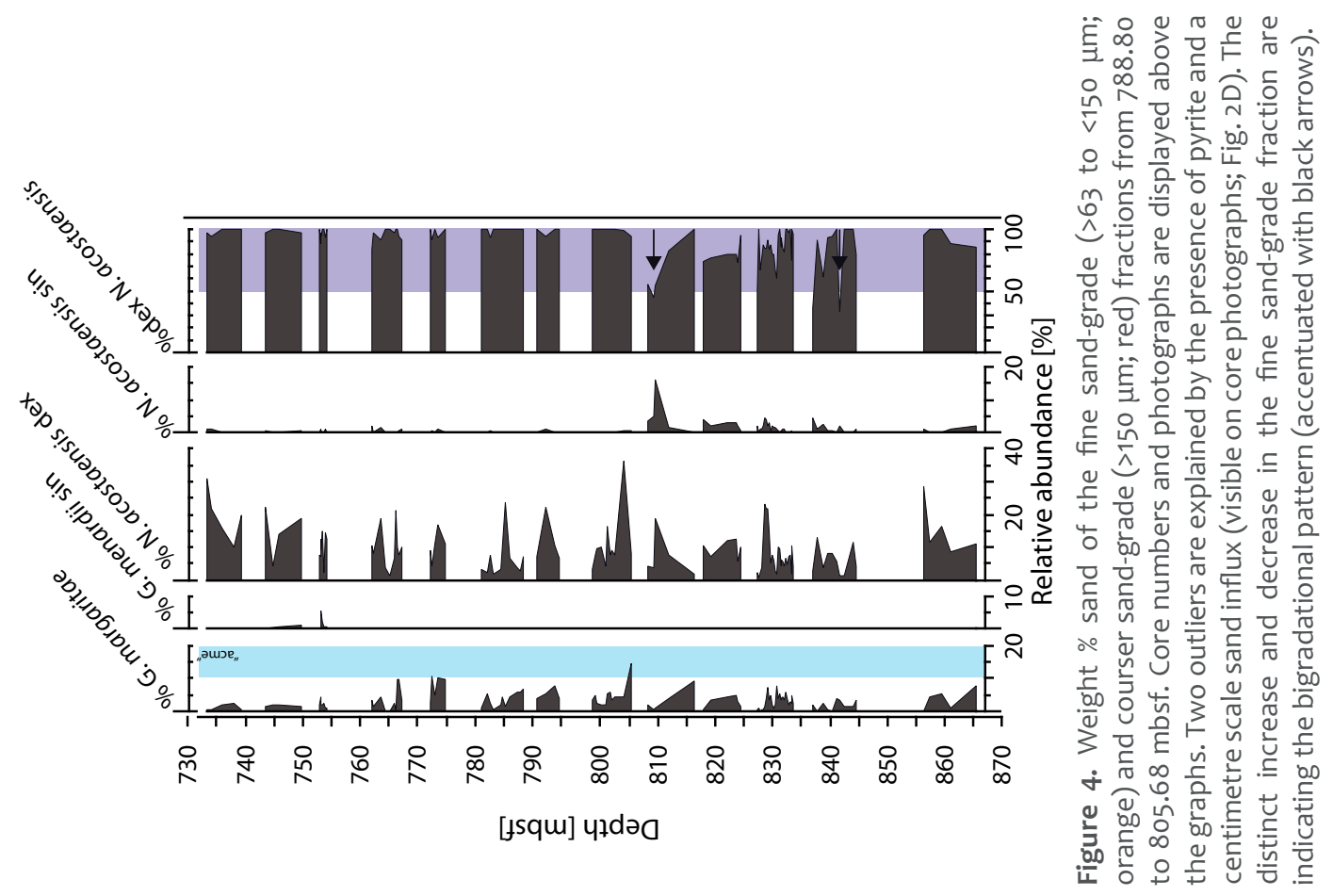

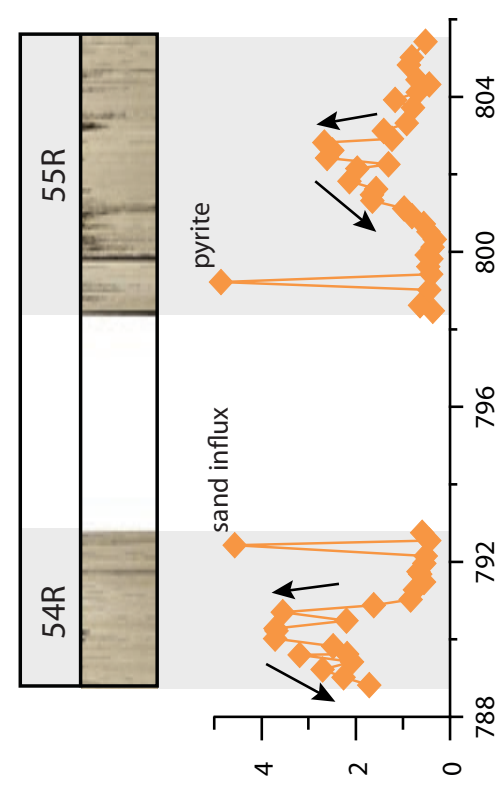

unt OSL $>$ of $\varepsilon 9<$

pues \% +4 6 เі!

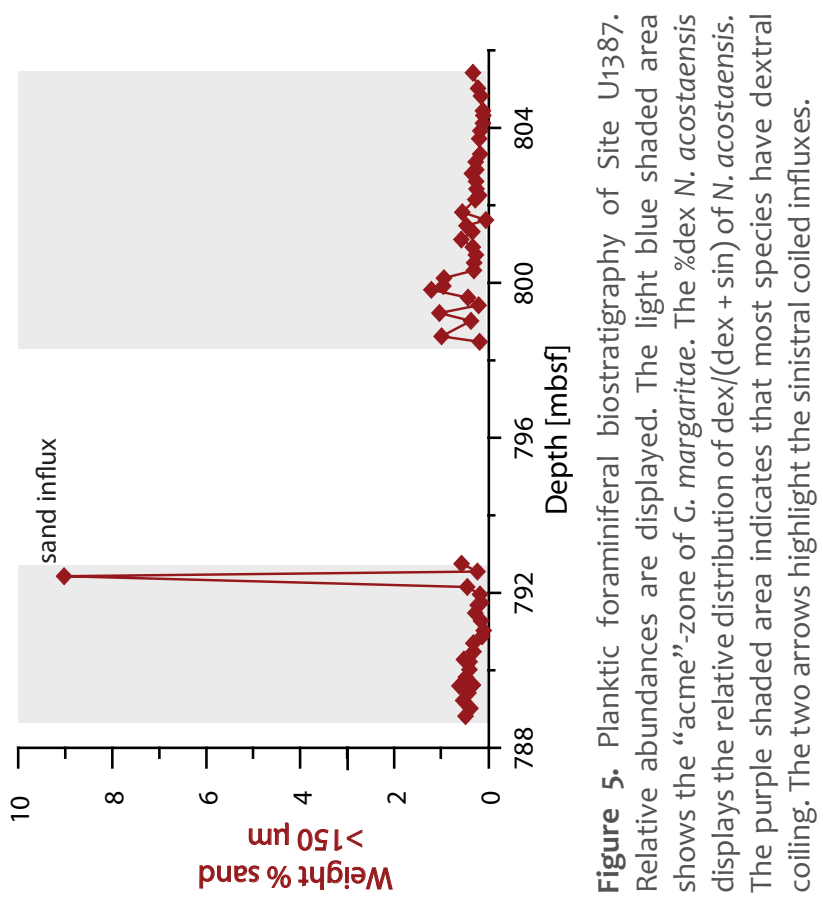



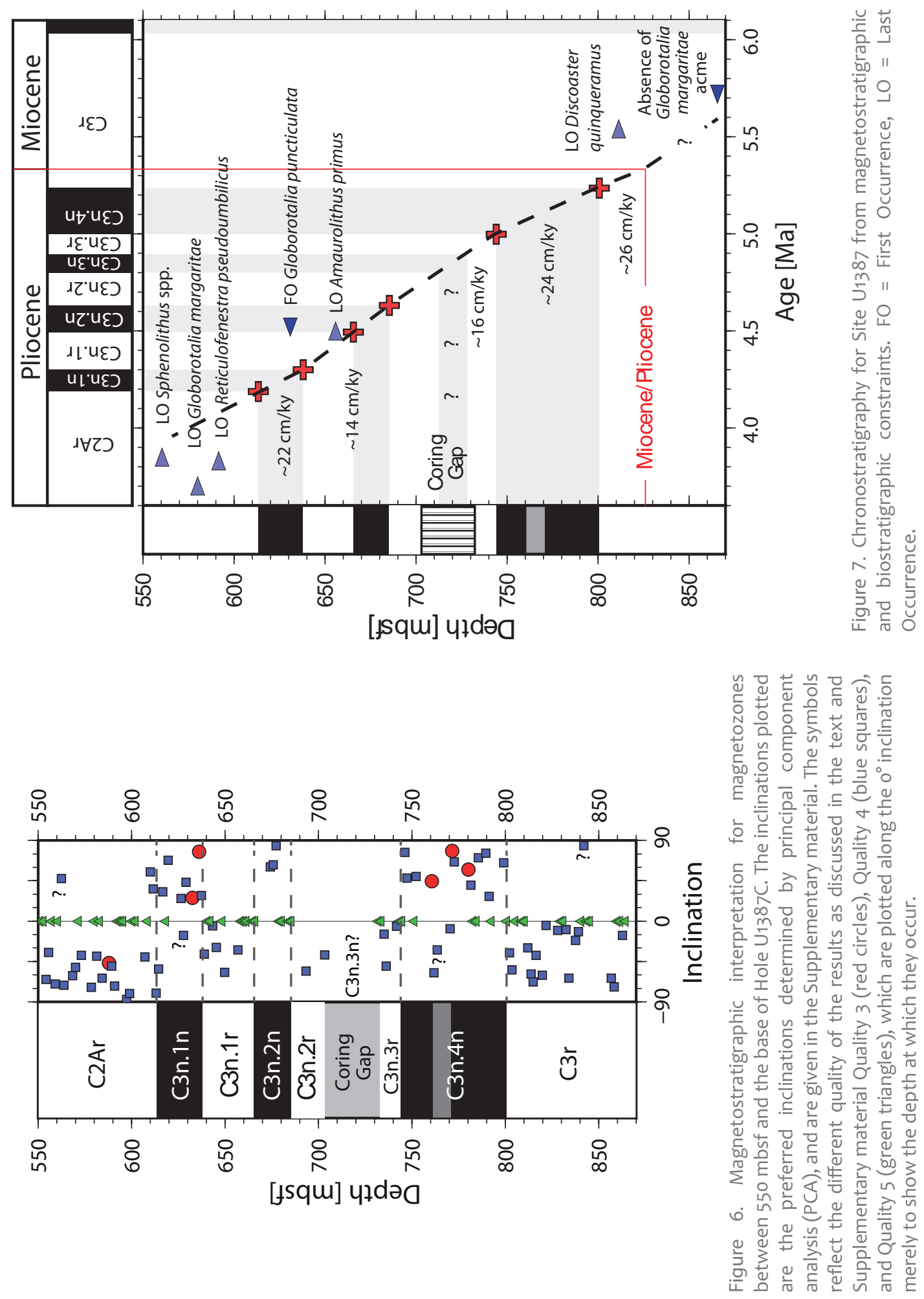


\subsection{Paleobathymetry estimations from benthic foraminiferal presence/absence data}

Presence/absence data of benthic foraminifers are provided in the Supplementary material. The studied samples frequently contain benthic foraminifers known to have their upper limit of bathymetric distribution at upper to middle bathyal water depths (e.g., C. pachyderma, Cibicidoides - wuellerstorfi, Laticarinina pauperata, Eggerella bradyi, Epistominella exigua, Fissurina spp., Gyroidinoides spp., Melonis spp., Oolina spp., Osangularia culter, Pullenia spp., Saracenaria spp.; Jones, 1994; Leckie and Olson, 2003; Van Morkhoven et al., 1986). Furthermore, the presence/absence data show taxa that characterize slope environments between 300 and $900 \mathrm{~m}$ water depth in the Gulf of Cadiz and the western Iberian Margin (e.g., Amphicoryna scalaris, Bigenerina nodosaria, Bulimina striata, Cibicidoides mundulus, Globocassidulina subglobosa, Planulina ariminensis, Uvigerina mediterranea, and U. pygmaea; Phipps et al., 2012; Schönfeld, 2002, 1997). A particularly interesting species among the bathyal taxa is L. pauperata, a cosmopolitan species that tolerates a wide range of environmental conditions at bathyal and abyssal water depths (Van Morkhoven et al., 1986). While other taxa limited to bathyal water depths are present in Interval I as well as Interval II and III, this species disappears from the record above $\sim 826$ mbsf. An upper depth limit at the middle to upper bathyal transition has been suggested for $L$. pauperata, and its disappearance may indicate a slight shallowing from middle to upper bathyal water depths comparable to today (Van Morkhoven et al., 1986).

Foraminiferal species restricted to neritic environments such as Ammonia spp., Asterigerinata spp., Cancris spp., and Elphidium spp. are increasingly present above 801 mbsf (Leckie and Olson, 2003; Mendes et al., 2012). These taxa occur throughout the record alongside bathyal species mentioned above and are thus considered allochthonous.

\section{Chronostratigraphic framework}

\subsection{Bio- and magnetostratigraphy}

\subsubsection{Planktic foraminifera}

Several planktic foraminiferal species provide constraints on the age of the basal part of IODP Hole U1387 (Table 1). These include the following:

1. The first occurrence of G. puncticulata (4.52 Ma; Lourens et al., 2004) which has been identified in IODP Hole U1387C at a depth of 630.82 mbsf (Expedition 339 Scientists, 2013a). The interval of interest ( 731.2 to 865.85 mbsf) is therefore entirely older than 4.52 Ma.

2. N. acostaensis which is abundant in upper Messinian to lower Pliocene sediments from this region and exhibits well-dated changes in predominant coiling direction and short time scale influxes of the inferior coiling direction (Krijgsman et al., 2004; Sierro et al., 2001; Lourens et al., 2004). Typically, assemblages strongly dominated by sinistral coiling 
N. acostaensis are found in sediments older than 6.37 Ma, while dextral coiling shells constitute the vast majority of specimens in sediments younger than $5.82 \mathrm{Ma}$ (Hilgen and Krijgsman, 1999; Krijgsman et al., 2004; Sierro et al., 2001). Quantitative assessment of the coiling direction of N. acostaensis in the lower part of Hole $\mathrm{U} 1387 \mathrm{C}$ shows that it is strongly dominated by dextral coiling forms (Fig. 5). Consequently, the base of the Hole is most likely younger than $5.82 \mathrm{Ma}$.

Two sinistral coiled influxes of N. acostaensis are found from 808.22 to 809.52 and at 841.80 mbsf (Fig. 5). In the Mediterranean Basin in the lower Pliocene, two sinistral influxes are reported and astronomically tuned in the Eraclea Minoa section to 5.30 and 5.32 Ma (Lourens et al., 1996). Equivalent influxes to these are described in precessional driven Cycles 2 and 3 immediately above the Miocene-Pliocene boundary in ODP Holes 974B and 975B (laccarino et al., 1999b).

3. A distinct high abundance interval, referred to as "acme", of G. margaritae has been described from several upper Miocene records from the Gulf of Cadiz, SW Spain and NW Morocco (Van den Berg et al., 2015; Krijgsman et al., 2004; Ledesma, 2000; Sierro et al., 1993, 1982). The "acme" has a relative abundance of $G$. margaritae that exceeds at least $10 \%$ of the total planktic foraminiferal assemblage. An interval of particular high abundance occurs in the Ain el Beida section (> $20 \%$; NW Morocco; Krijgsman et al., 2004) and the Montemayor-1 core (> 37\%; SW Spain; Van den Berg et al., 2015) between respectively, $\sim 5.75$ and $\sim 5.70 \mathrm{Ma}$ until $\sim 5.84 \mathrm{Ma}$ (both sites), where the "acme" coincides with glacial stages TG20 and TG22. Foraminiferal counts from the lower part of Hole U1387C show that only one sample contains > 10\% G. margaritae (805.42 mbsf; Fig. 5), indicating that this sedimentary succession does not overlap the high abundance "acme". The relative large time span of the "acme" seems to be too long to coincide within a coring gap (see Section 5.2.2). In addition, it is unlikely that the "acme" would be absent even though the sediments of this time-interval might have been covered, since it has always been found in Gulf of Cadiz succession. Since the coiling direction of N. acostaensis indicates that the studied sediments are most likely younger than $5.82 \mathrm{Ma}$, the $\mathrm{G}$. margaritae data further constrains the age of the sediments to being younger than $\sim 5.70$ 5.75 Ma. Outside the very high abundance interval, Krijgsman et al. (2004) included all samples with >5\% G. margaritae in the wider "acme" interval that spans 5.56 to $5.84 \mathrm{Ma}$. As our quantitative G. margaritae data typically varies between 2 and $10 \%$ (Fig. 5; Supplementary material), it is possible that these sediments at the base of IODP Hole U1387C overlap, at least in part, with the described 5.56 to 5.84 Ma interval.

4. An influx of G. menardii with a maximum relative abundance of $5.5 \%$ is recorded between 751.33 and 752.28 mbsf (Fig. 5; Supplementary material). Three similar influxes have been documented from the latest Messinian to earliest Pliocene in the Ain el Beida and Loulja sections in NW Morocco with astronomical ages of 5.55, 5.51 and 5.32 Ma'. Without more

${ }^{1}$ Please note that Krijgsman et al. (2004) incorrectly identify G. menardii pulses as Globorotalia miotumida. (Tulbure et al., in preparation), while they are referred to as $G$. menardii in van der Laan et al. (2006) (Van den Berg et al., 2015). 
robust age constraints the influx of G. menardii in IODP Site U1387 cannot be correlated to any of these.

In summary, planktic biostratigraphic results suggest that the interval from 731.20 to $865.85 \mathrm{mbsf}$ of IODP Hole U1387C is older than $4.52 \mathrm{Ma}$, the first occurrence of G. puncticulata (630.82 mbsf) and younger than the high abundance $G$. margaritae "acme" at 5.70-5.75 Ma.

\subsubsection{Calcareous nannofossils}

Characteristic calcareous nannofossil marker species from the latest Neogene are common with individuals of Amaurolithus primus, Discoaster surculus, Discoaster pentaradiatus and Discoaster quinqueramus as well as characteristic reticulofernestrids (Reticulofenestra pseudoumbilicus, Reticulofenestra minuta, Reticulofenestra minutula and Reticulofenstra rotaria), allowing to place the studied interval between biozones NN11 and NN15 spanning from 3.81 to 7.36 Ma (e.g. Young et al., 1994; Raffi et al., 2006). The presence of reworked specimens (e.g. Cyclicargolithus floridanus, Discoaster deflandei, Sphenolithus belemnos gr.), mainly of Paleogene and lower to middle Miocene varieties, is common (Raffi et al., 2006). Expedition 339 Scientists, (2013a) report the last occurrence of $D$. quinqueramus at $811.43 \mathrm{mbsf}$ what indicates an age younger than $5.54 \mathrm{Ma}$ (Raffi et al., 2006). However, this biostratigraphic event is hard to identify in such detail, because only a few specimens of $D$. quinqueramus are present and thus could easily be reworked. Also, a few specimens of $R$. rotaria are found in the studied interval which indicate an age range between 6.75 and 7.41 Ma (Flores et al., 2005; Lourens et al., 2004; Young et al., 1994). The planktic foraminiferal bio-events are clearly indicating late Messinian ages and not upper Tortonian to lower Messinian as indicated by $R$. rotaria. If $R$. rotaria and planktic foraminifers were in-situ, specimens of $G$. miotumida and continuous abundances of $G$. menardii 5 were expected (Lourens et al., 2004). The incompatibility of the nannofossil and foraminiferal data suggest that the few specimens of $D$. quinqueramus and $R$. rotaria are reworked.

\subsubsection{Magnetostratigraphy}

The paleomagnetic data is generally of low quality because the sediment magnetizations are relatively weak and the magnetization of the cores includes a significant drilling overprint that masks the original depositional magnetization. The overprint has a steep downward direction (positive inclinations) similar to that expected for normal polarity intervals. Hence, failure to remove the drilling overprint with magnetic cleaning, such as AF demagnetization, can bias the magnetic polarity interpretation significantly. This is particularly the case for the split-core sections, which give virtually only positive inclinations even in intervals that must be of reversed polarity. The 20-mT peak-field AF demagnetization used during Expedition 339 was clearly insufficient in removing the drilling overprint and resolving the original depositional magnetization, and thus no polarity could be determined from this data below 500 mbsf.

The discrete samples were subjected to much higher peak-field AF demagnetization, which was successful at removing the drilling overprint from many of the samples from Hole U1387C. Even though the quality of the samples is generally considered poor for resolving the ChRM fully, the polarity of the samples could be reasonably well estimated. This is illustrated in Figure 6 where the 
inclinations are shown for the interval from 550 mbsf to the base of the Hole, along with the interpretation of the magnetozones.

Most importantly for the present study is that the stratigraphic section below 800.65 mbsf is all reversely magnetized. Based on the biostratigraphic constraints, this magnetozone corresponds to Chron C3r (5.235-6.033 Ma; Lourens et al., 2004). The base of this magnetozone was not recovered, which is consistent with the biostratigraphic constraints that suggest the age of the bottom of the hole is $<5.75 \mathrm{Ma}$. The overlying normal polarity magnetozone spanning 743.99 to 800.65 mbsf corresponds to Chron C3n.4n (4.997-5.235 Ma; Lourens et al., 2004), indicating the boundary between the magnetozones at $800.65 \mathrm{mbsf}$ has an age of $5.235 \mathrm{Ma}$. The MiocenePliocene boundary is thus below $800.65 \mathrm{mbsf}$ and above the base of the Hole ( $865.6 \mathrm{mbsf}$ ). The sequence of magnetozones above Magnetozone C $3 n .4 \mathrm{n}$ fits well the general chron sequence of the geomagnetic polarity timescale and the depths and dates of the observed reversals agree well with biostratigraphic constraints and give sedimentation rates compatible with the other chronostratigraphic constraints (Fig. 7).

\subsection{Cyclostratigraphic constraints}

\subsubsection{Precessionally forced variations}

Benthic $\delta^{18} \mathrm{O}$ records in open ocean deep marine settings during the Pliocene-Pleistocene are mainly dominated by obliquity. However, the first $\sim 150 \mathrm{ky}$ at the base of the Pliocene show a strong precessional signal in the LR04 stack (Fig. 8B; Lisiecki and Raymo, 2005). In contrast, rhythmic sedimentary cycles, including resistivity, gamma ray and Ti/Al records from the Iberian and Moroccan Atlantic margins during the Messinian and Early Pliocene typically display a pronounced variability in response to precession (e.g. Hodell et al., 1994; Krijgsman et al., 2004; Pérez-Asensio et al., 2014, 2013; van der Laan et al., 2012, 2006, 2005; van den Berg et al., 2015). Precession continues to be dominant as astronomical forcing in IODP Sites drilled in the Gulf of Cadiz throughout the Pleistocene, including Site U1387 (Bahr et al., 2015; Lofi et al., 2015; Voelker et al., 2015b).

Precession and obliquity patterns are further investigated by comparing the $\delta^{18} \mathrm{O}$ of the Loulja section with obliquity and a combined record of normalized precession minus normalized tilt (obliquity), hereafter precession-tilt (Fig. 8A, 8B). Obliquity is expressed in precession-tilt by the enhancement of the amplitude of every other precession cycle. This distinct pattern is clearly visible in the Loulja $\delta^{18} \mathrm{O}$ record, for example around interglacial stage TG9 (5.45 Ma; Van der Laan et al., 2006). Here, the expression of TG9 is more pronounced due to increased influence of obliquity, while the precession cycles before and after TG 9 have lower amplitudes.

The discontinuous nature of the record in the studied interval of Hole U1387C makes it impossible to assess the oscillation patterns in the same way as can be achieved for continuous successions. However, in Interval I, a few continuous regular alternations are visible mainly in the $\delta^{18} \mathrm{O}$. Benthic $\delta^{18} \mathrm{O}$ oscillation patterns in Cores $61 \mathrm{R}, 59 \mathrm{R}$ and $58 \mathrm{R}$, show alternations of high and low amplitudes (Fig. 9), that are very similar to the typical interference patterns of obliquity and precession. To 
illustrate this, we show a comparison of the benthic $\delta^{18} \mathrm{O}$ with a theoretical cyclic precession-tilt curve (Fig. 9). A similar, close relationship between the $\delta^{18} \mathrm{O}$ benthic record and the precession-tilt curve is seen at the Loulja section (Fig. 8A, 8B).

In even more detail, Core $61 \mathrm{R}$ reveals three full regular alternations in the $\delta^{18} \mathrm{O}$ record, while the $\delta^{13} \mathrm{C}$ from the same foraminiferal specimens shows four regular alternations (Fig. 3, 9). Normally, ventilation patterns and organic carbon storage explain $\delta^{13} \mathrm{C}$ variations. In the Gulf of Cadiz $\delta^{13} \mathrm{C}$ variations have been explained as an expression of ventilation patterns linked to MOW during the Pleistocene with a strong precessional component (Voelker et al., 2006, 2015b), however, linking our data with these patterns without a definite understanding of Atlantic-Mediterranean exchange is problematic. Independently, other well-dated benthic Messinian to upper Pliocene benthic $\delta^{13} \mathrm{C}$ records in the area possess a precession component, i.e. Ain el Beida and Loulja sections (Van der Laan et al., 2012, 2006). Consequently, it is likely that the four $\delta^{13} \mathrm{C}$ regular alternations represent precession, while the long $\delta^{18} \mathrm{O}$ alternation from 856.68 to 860.80 is the expression of diminished precession under a strong influence of obliquity. This suggests that the short scale visible regular alternations of the $\delta^{18} \mathrm{O}$ record within Interval I are precession-induced cycles, with influence of other astronomical cyclicities.

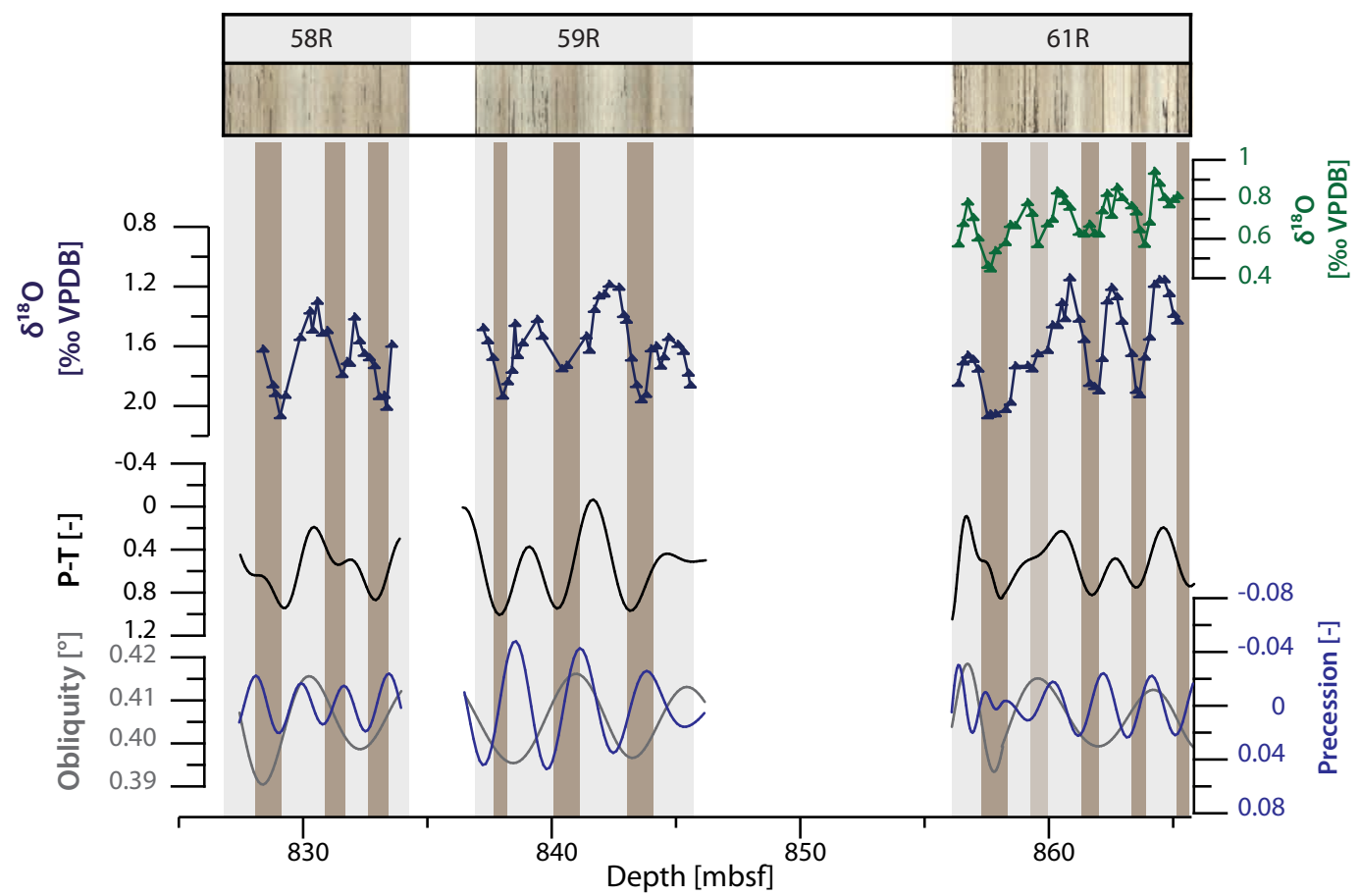

Figure 9. Close-up of $\delta^{18} \mathrm{O}$ (dark blue) and $\delta^{13} \mathrm{C}$ (green) of C. pachyderma together with colour changes (brown shades) from 827.20 to 865.85 mbsf (Cores 58R, 59R and 61R). A theoretical example of a corresponding precession-tilt curve (P-T; black) is displayed to show resemblance with $\delta^{18} \mathrm{O}$. This suggests the interference patterns of precession and obliquity in the $\delta^{18} \mathrm{O}$. The used obliquity (grey) and precession (light blue) curves are indicated below. Parts of the solution Lao 4 are used for all astronomical parameters $\left(65^{\circ} \mathrm{N}\right.$ summer insolation; Laskar et al., 2004). 
Regular alternations have larger wavelengths in Interval II and III, while coring gaps are still present. As a result, comparing cycle patterns as done for Interval I is impossible, because only one or two cycles can be recognized between gaps. We assume that the $\delta^{18} \mathrm{O}$ cyclic patterns are representing the same astronomical variations as in Interval I. Consequently, precessionally forced variability is assumed for the colour changes, $\mathrm{Zr} / \mathrm{Al}$ ratios and, to some extent, sand fraction analyses that have wavelengths consistent with the benthic $\delta^{18} \mathrm{O}$ record.

\subsubsection{Depositional time span}

If the cycles in IODP Hole U1387C are precessionally controlled, the depositional time span can be calculated given that the average duration of a precession cycle is $21.7 \mathrm{ky}$ (Berger, 1984) and using the same sedimentation rate for intervals where no core was recovered as is measured in the cores below and above. No significant stretching or shortening of the sediment inside the core pipe during drilling is anticipated because the sediment throughout the Hole is well compacted.

In Interval I, Cores 58R, 59R and 61R all show distinct colour and $\delta^{18} \mathrm{O}$ cycles with an average wavelength of $2.2 \mathrm{~m}$ per cycle (Table 2). Assuming this constant sedimentation rate, Interval I ( $38.68 \mathrm{~m}$ ) should equate to $\sim 18$ precession cycles, with an average sedimentation rate of about 10 $\mathrm{cm} / \mathrm{ky}$ and a time-span of $\sim 389 \mathrm{ky}$. The occurrence of two colour cycles and two carbon isotope excursions from 856.9 to 860.3 suggest the presence of two precession cycles during the long $\delta^{18} \mathrm{O}$ cycle (Fig. 3, 9).

In Interval II, cores with more continuous recovery (Cores $57 \mathrm{R}$ to $54 \mathrm{R}$ ) show an average thickness of $5.89 \mathrm{~m}$ per cycle (Table 2 ). Interval III appears too short to calculate an individual sedimentation rate in the same way, but it is clear that Core $48 \mathrm{R}$ has one long $\delta^{18} \mathrm{O}$-variation with a width of 5.71 $\mathrm{m}$, which is presumably representing nearly a full cycle. Uncertainty increases due to a possible additional, subtly expressed cycle in Core $48 \mathrm{R}$, as is hinted in the $\mathrm{Zr} / \mathrm{Al}$ oscillations. However, this still suggests that the sedimentation rate throughout Interval II and III remains relatively constant. Thus, the total thickness of Interval II and III (97.72 m) equates to $\sim 16$ precession cycles, with an average sedimentation rate of about $27.2 \mathrm{~cm} / \mathrm{ky}$ and a total depositional time span of $\sim 349 \mathrm{ky}$.

\subsection{Tentative working hypothesis on the age model for IODP Hole U1387C}

While individually, none of these different datasets provide robust age constraints, more confidence can be gained if the stratigraphic interpretation is compatible with all of them. Here, we explore the best possible stratigraphic fit between the data available.

Assuming, on the basis of the seismic correlation (Hernández-Molina et al., 2015), that the Miocene-Pliocene boundary occurs at the abrupt lithological change between Interval I and II (826 mbsf), the duration of the $\sim 18$ precession cycles ( $389 \mathrm{ky}$ ) in Interval I suggests that the age of the

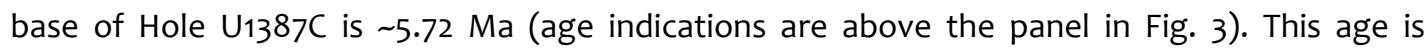
consistent with the absence of the G. margaritae "acme" which suggests that the base of the Hole must be younger than $\sim 5.70-5.75 \mathrm{Ma}$. The minimum timespan of the "acme" of at least 5 precession cycles makes it highly unlikely that the "acme" falls exactly in a coring gap. Within these age estimations, the two documented influxes of $G$. menardii are likely to be in the coring gap, 
within unrecovered Core 6oR (5.55 and 5.51 Ma; stratigraphic planktic foraminiferal influxes and coiling changes are represented in Fig. 8B).

The depositional time span calculated on the basis of precessional cycles of Interval II and III (16 precession cycles; $\sim 349 \mathrm{ky}$ ) suggests that, if the Miocene-Pliocene boundary is positioned right above Interval I, the age of the top of the studied interval is $\sim 4.98 \mathrm{Ma}$. The precession-constrained sedimentation rates can also be used to estimate the age of the normal polarity interval from 743.99 to 800.65 mbsf. This suggests an age range for the normal polarity interval from $\sim 5.04$ to $\sim 5.24$ Ma. This is in good agreement with the Chron C3n.4n (4.997-5.235 Ma; Lourens et al., 2004). The sinistral coiled influx of N. acostaensis from 808.22 to $809.52 \mathrm{mbsf}$ can be closely linked to the second reported dextral to sinistral coiling change reported at 5.30 $\mathrm{Ma}$ in the Mediterranean, three precession cycles above the Miocene-Pliocene boundary (laccarino et al., 1999b; Lourens et al., 1996). The influx of G. menardii between 752.4 and 751.3 mbsf, with its age estimation from this study of about 5.07 Ma, is thus younger than the influxes recorded in NW Morocco sections (5.31 Ma; Van der Laan et al., 2006; Fig. 8B). Planktic foraminiferal biostratigraphy of the equivalent section in Morocco (Loulja) has not been studied in detail and therefore the coiling changes in $\mathrm{N}$. acostaensis and influx of G. menardii may have been overlooked so far. The well-recorded influx of G. menardii at 5.32 Ma of the Loulja section (Van der Laan et al., 2006) is most likely lost in the coring gap just after the Miocene-Pliocene boundary (Fig. 8B).

In summary, the stratigraphic interpretation which places the Miocene-Pliocene boundary at the sharp sedimentological shift at about $826 \mathrm{mbsf}$, in accord with the seismic correlation (HernándezMolina et al., 2015), and using the precession-forced, sedimentary cycles to constrain the age above and below that point, provides an age model for the studied interval of Site IODP U1387. This age model is compatible with the available biostratigraphic and paleomagnetic data, which results in an age model with three tie-points: (1) an age of about 5.7 Ma at the base of the Hole, (2) the Miocene-Pliocene boundary (5.33 Ma) at about $826 \mathrm{mbsf}$ and (3) an age of about 5.0 Ma for the top of the studied interval at 731.20 mbsf. An uncertainty of two to three precessional cycles should be anticipated for the base and the top of the studied interval given the methods used to construct the age model.

\section{Discussion}

Hemipelagic nannofossil muds showing significant bioturbation and containing few lithic coarser particles characterize the Messinian part (Interval I) of IODP Hole U1387C. This, combined with the relatively low $\mathrm{Zr} / \mathrm{Al}$ ratios, which show no clear correlation with the precessional benthic $\delta^{18} \mathrm{O}$ record, indicate low energy depositional environment influenced by orbital variation (Bahr et al., 2014). Similar cyclicity is found in NW Morocco and the southern Iberian Margin, where clay-silt alternations result from orbitally-driven oscillations in detrital input (coast, riverine, or eolian; e.g. Sierro et al., 2000; van der Laan et al., 2012, Van den Berg et al., 2015). Above the Miocene-Pliocene boundary (Interval II and III), sedimentation rates are about three times higher than during the Messinian and the succession has higher Zr/Al values and sand content with more abundant lithic particles (Fig. 3). This suggests significant change in the depositional environment from quiet 
hemipelagic conditions to a higher energy environment including the presence of weak bottom currents.

\subsection{Bottom water flow strength indicators}

$\mathrm{Zr} / \mathrm{Al}$ ratios are relative high with large amplitude variations in Interval II and III. The sudden change in the appearance of the $\mathrm{Zr} / \mathrm{Al}$ record is therefore interpreted as a shift from a low energy hemipelagic setting in Interval I, to a higher energy environment controlled by bottom currents that are subject to particle sorting in Interval II and III (Fig. 3). The suggestion of increasing energy levels is consistent with the general increase in sand content in Intervals II and III relative to the base of the Hole, especially in sections where maximum $\mathrm{Zr} / \mathrm{Al}$ ratios coincide with maximum sand content (i.e. 788.80 to 803.68 mbsf; Fig. 4). Yet because of the absence of $\mathrm{Zr} / \mathrm{Al}$ data from the lowermost core of Interval II (Core 57R), we cannot determine with certainty from Zr/Al ratios only whether this transition occurs at the Miocene-Pliocene boundary or shortly thereafter. However, parallel behaviour between $\mathrm{Zr} / \mathrm{Al}$ ratios and $\delta^{18} \mathrm{O}$ immediately after the oldest measurement in Interval II and the abrupt sedimentation rate change reflected in benthic $\delta^{18} \mathrm{O}$, suggests an immediate change of depositional environment at the Miocene-Pliocene boundary.

In Interval II, two sandy beds show clear bigradational grading with tracers of bioturbation (Core 54R and 55R; 788.88 to 803.68 mbsf; Fig. 2C, D, 4). The patterns represents a coarsening upward sorting from homogenous muds with sparse bioturbation to more silty to sandy deposits until the facies succession reverses. These features are characteristic of contourites (Faugères et al., 1984; Gonthier et al., 1984; Rebesco et al., 2014). Similar sedimentary sequences to the two sandy beds are characterized as contourite sequences in the Faro Drift (Gonthier et al., 1984) and recently envisioned for the early Pleistocene for Site IODP U1386 in Alonso et al., (2016). These are distinctly different from the instantly deposited (un-bioturbated) turbiditic, normal grading, fining upward sequences (cf. Bouma et al., 1962). Discrimination between the sand grades $>63$ to $<150 \mu \mathrm{m}$ and $>150 \mu \mathrm{m}$ weight \% confirms the hypothesis of continuous sedimentary deposition under the influence of bottom water current flow. Therefore, the two sandy beds with bi-directional grading are interpreted as the earliest clear sandy contouritic deposits above the third precession cycle above the tentative Miocene-Pliocene boundary.

Seismic data imaging of the Early Pliocene shows features of slope instability on the Algarve Margin, north of IODP Site U1387 (Brackenridge et al., 2013; Hernández-Molina et al., 2015, 2014b; Martínez del Olmo, 2004; Roque et al., 2012). This sedimentary source may account for the tripling of the sedimentation rate that occurs at the Miocene-Pliocene boundary. However, the change in sedimentation rate is abrupt, rather than gradational, which is what would be expected if sedimentation rate changes as a result of progressive tectonic uplift of the margins and/or infilling of the basin, such as is seen in the Guadalquivir Basin (Van den Berg et al., 2015). There is also no evidence of significant shallowing of the depositional environment in Hole IODP U1387C during this period. The continuous presence of benthic foraminiferal taxa which have a bathyal upper depth limit, suggest a fairly constant bathymetry throughout Intervals I to III. The increasing presence of benthic foraminiferal species limited to neritic environments from about $801 \mathrm{mbsf}$ (i.e., in Interval II, $\sim 25 \mathrm{~m}$ above the Miocene-Pliocene boundary) upwards are interpreted as 
allochthonous. They always occur alongside species with a bathyal upper depth limit and are thus not indicative of a significant shallowing of the water depth at Hole U1387C. The shallower benthic foraminifers are probably introduced by pulses of episodic turbiditic-like downslope transport, resulting in the cm-scale sandy layers on the upper slope (Fig. 2D; 'sand influx' Fig. 4). In most cases, these thin turbiditic beds are almost destroyed by the combined action of bottom currents and macrobenthic communities that buried and excavate within the sediments (Dorador and Rodríguez-Tovar, 2016; Rodríguez-Tovar et al., 2015). Often only small patches of sand were preserved within a matrix of mud (Fig. $2 \mathrm{~F}$ ). If the increase in sedimentation rate was the result of instability on the Algarve Margin, then this shallow-water material likely resulted from direct downslope sediment transport. If, however, the abrupt sedimentation rate increase resulted from the onset or an increase of along-slope transport, then the shallow water material could derive from an up-current source. Most likely, a combination of the two processes has occurred; increased slope instability due to tectonic uplift causing increased sediment input from the margin, while along-slope flow provided suspended load from the distant Guadalquivir drainage basin, similar to the late Pleistocene described for IODP Sites U1387 and U1386 (Alonso et al., 2016). In addition, the along-slope suspended load may have been amplified due to suggested tectonic uplift from the early Pliocene (Hernández-Molina et al., 2014b). Interval III shows even higher grain size fractions $(>63 \mu \mathrm{m})$ than Interval II, suggesting increased influence of the alongand/or downslope processes. The possible increased terrigenous input from of the Guadalquivir and Guadiana rivers into the Gulf of Cadiz during the warm climate of the early Pliocene (Ducassou et al., 2015; Miller et al., 2005) may have amplified the along and/or downslope processes.

In summary, Hole U1387C shows features in Intervals II and III (lowermost Pliocene) that are consistent with transport and deposition by weak along-slope bottom water currents. These features are not present in Interval I (upper Miocene), that suggests low or absent influence of bottom current flow across Site U1387. Thus, either an increase or the onset of the bottom water current occurred immediately at or shortly after the Miocene-Pliocene boundary. The overall increase in sand content in Intervals II and III may reflect a further increase in flow strength during the earliest Pliocene. Likely, the increase in sedimentation rate at the Miocene-Pliocene boundary is the result of a combination of local instability of the margins and the onset of along-slope transport.

\subsection{Origin of bottom water current flow.}

MOW today is apparent as a warmer intermediate water mass along the margins of south west Iberia penetrating the Gulf of Cadiz from the Strait of Gibraltar (Hernández-Molina et al., 2014a). Consequently, if the Strait were closed, colder intermediate Atlantic waters would be expected at the same water depths in the Gulf of Cadiz. The temperature effect should be reflected in the benthic foraminiferal $\delta^{18} \mathrm{O}$, where colder conditions and decreased MOW result in an increase in the $\delta^{18} \mathrm{O}$ values. The benthic stable isotope records of NE Atlantic ODP Site 982 (1134 m water depth; Hodell et al., 2001) and onshore Ain el Beida (Krijgsman et al., 2004; van der Laan et al., 2005) and Loulja sections (Van der Laan et al., 2006) are compared with the benthic stable isotope record of Site $\mathrm{U} 1387$ in order to evaluate shorter scale patterns and relative off-sets (Fig. 8). The 


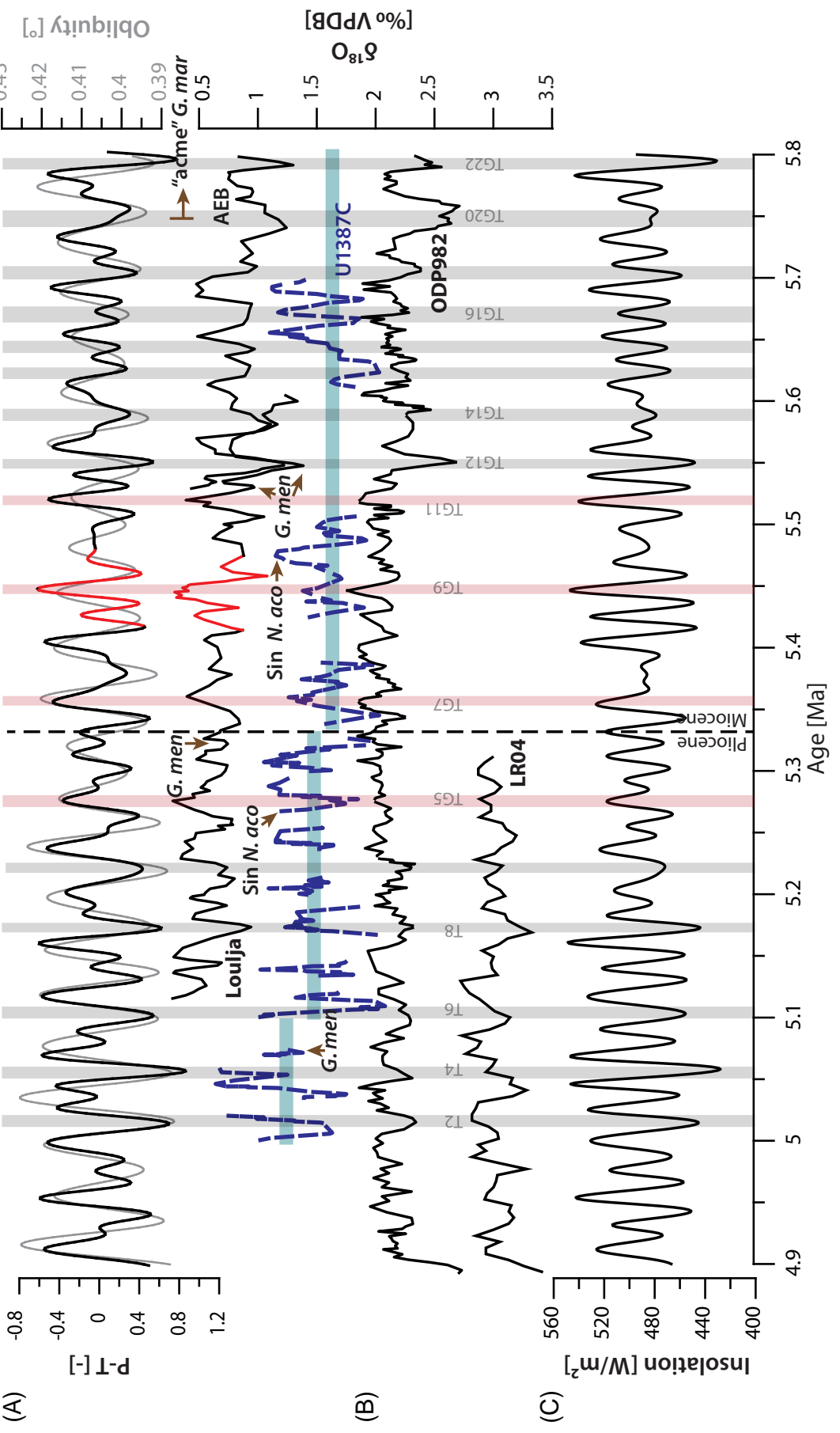

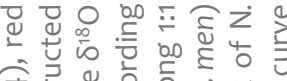

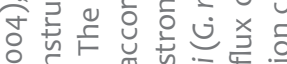

N $\overline{0} \dot{0} 0$ 元

iิ

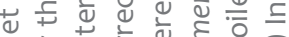

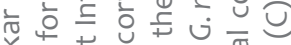

可 $\bar{v}$

능

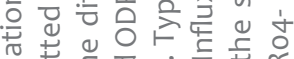

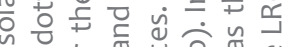

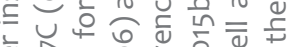

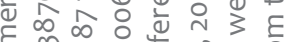

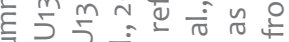

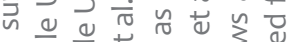

乙

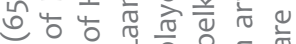

ᄃ

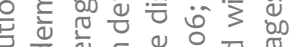

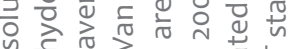

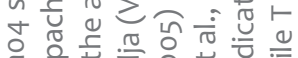

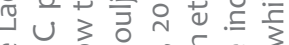

告

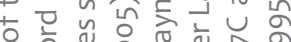

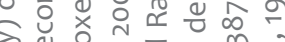

बิ

to 0 o

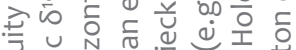

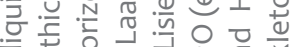

응

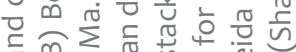

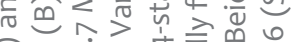

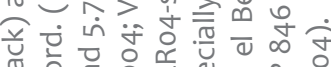

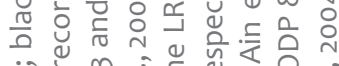

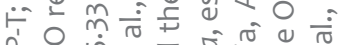

然

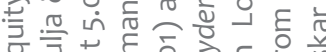

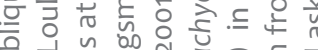

의 0

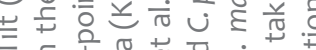

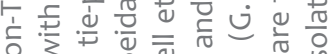

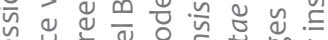

记 ᄃ

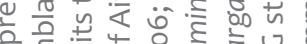

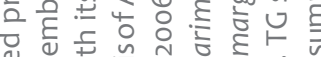

Nㅗㄴ

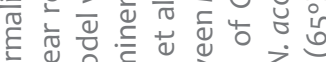

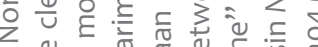

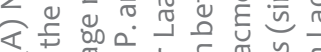

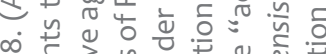

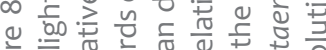

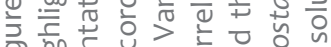

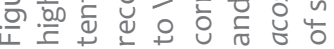


offset of about $1.2 \%$ between the benthic $\delta^{18} \mathrm{O}$ records from ODP Site 982 and NW Morocco has been interpreted as the temperature difference between cold Upper North East Atlantic Deep Water (UNEADW) at Site ODP 982 and warmer near-surface waters in NW Morocco in Van den Berg et al. (2015). The offset between the $U 1387 \mathrm{C}$ benthic oxygen isotope record and ODP 982 is smaller than its offset relative to NW Morocco, particularly during the Messinian (Fig. 8B). Ignoring the potential changes in the $\delta^{18} \mathrm{O}$ of the water, the reduced $\delta^{18} \mathrm{O}$-offset between Site ODP 982 and IODP U1387 can indicate that temperature of intermediate Atlantic waters in the Gulf of Cadiz was closer to that of UNEADW in the late Miocene. Counterintuitively, the $\delta^{18} \mathrm{O}$ of today's MOW is higher ( 0.5 to $1.1 \%$ ) compared to NEADW (-0.1 to $0.5 \%$ ), however, the temperature difference between these two water masses is between 8 and $10{ }^{\circ} \mathrm{C}$ (Voelker et al., 2015a). Hence the temperature effect on the shell of the benthic foraminifer $\delta^{18} \mathrm{O}$ is much higher than the effect of $\delta^{18} \mathrm{O}$ of the water (Epstein et al., 1953, 1951). This relation is evident during the transition from Marine Isotope Stage 32 to 31 in IODP Hole U1387, where an increase of MOW (high XRF scanning $\mathrm{Zr} / \mathrm{Al}$ ratios) results in lower benthic foraminiferal $\delta^{18} \mathrm{O}$ (Voelker et al., 2015b). Therefore, the observed decrease in benthic $\delta^{18} \mathrm{O}$ during the early Pliocene and its stepped divergence away from ODP 982 values suggests a gradual warming of intermediate Atlantic Waters near Gibraltar. This temperature increase over the studied period can be attributed to the absence or minor influence of warm MOW during the Messinian and the presence or increase of MOW during the Pliocene. Furthermore, increasing amplitudes that appear in Interval II and are even larger in Interval III may be attributed to increasingly fluctuating temperatures caused by varying influences of MOW over periods of insolation minima and maxima. Both arguments suggest that the increase or onset of bottom water current flow over the Miocene-Pliocene boundary can be attributed to MOW. A significant shallowing that would cause the change in bottom water temperatures at Site U1387C during the earliest Pliocene is excluded based on the benthic foraminiferal analyses.

Interestingly, amplitudes of benthic $\delta^{18} \mathrm{O}$ at Site U1387 do not only increase over the MiocenePliocene boundary, but also during the Messinian they are larger than amplitudes at Site ODP 982, Ain el Beida and Loulja. The Montemayor-1 core reveals the same feature as Hole U1387C (PérezAsensio et al., 2012; Van den Berg et al., 2015). The difference in amplitude of Hole U1387 and ODP 982 must be attributed to either a relative change of $\delta^{18} \mathrm{O}$ in the water mass or temperature. Increased amplitudes during the Pliocene can be attributed to fluctuations in MOW, however, it is thought that during the MSC MOW was either extensively reduced or even absent (Flecker et al., 2015; Roveri et al., 2014). Larger amplitudes due to larger temperature changes of shallower water depths can be excluded, because the shallower Loulja and Ain el Beida sections do not show the larger amplitudes. These successions are closer to the thermocline and thus more sensitive to temperature changes on glacial-interglacial cycles. One alternative, however speculative since there are no flow strength indicators observed in the sediments, is that the relatively high amplitude variations in benthic $\delta^{18} \mathrm{O}$ in $\mathrm{U} 1387 \mathrm{C}$ compared with both shallower and deeper locations hint towards the presence of weak MOW during the Messinian. 


\section{Conclusions}

We present evidence that the flow of Mediterranean-Atlantic bottom water began very shortly after the Messinian Salinity Crisis in the Gulf of Cadiz from IODP Site U1387. This study provides a chronostratigraphic framework for the lower part of IODP Site U1387C utilizing biostratigraphic, paleomagnetic, and cyclostratigraphic constraints. Our data suggest that the record extends into the latest Messinian and includes the Miocene-Pliocene boundary. Seismic data linking Site U1387C and the Algarve-2 well, as well as sedimentary changes in the sequence itself constrains the Miocene-Pliocene boundary at about 826 mbsf. Sediment deposition during the latest Messinian in the Gulf of Cadiz took place in a relatively quiet, hemipelagic environment driven by precessionally controlled Mediterranean monsoonal induced oscillations, with negligible evidence of bottom water flow strength. During the earliest Pliocene, an immediate decrease in the benthic $\delta^{18} \mathrm{O}$ may be the result from the direct warming of colder intermediate Atlantic waters due to increased Mediterranean-Atlantic exchange. The increase in sedimentation rate and as well as elevated variable XRF scanning Zr/Al ratios could have resulted from the onset of weak along-slope bottom water currents immediately at or right after the Miocene-Pliocene boundary. The occurrence of contouritic sedimentation in the Gulf of Cadiz results in two clear bigradational sandy beds above the third precession cycles after the Miocene-Pliocene boundary. Shallow water benthic foraminifers indicate that, besides along-slope transport, down-slope transport was present, redistributing shallow marine (continental shelf) particles to the upper slope.

\section{Acknowledgements}

We acknowledge the MEDGATE-team for passionate discussions and valuable comments on this study. David Hodell is thanked for the stable isotope analyses in the Godwin Laboratory for Palaeoclimate Research at the University of Cambridge and his valuable comments on the manuscript. This research used samples and data collected through the Integrated Ocean Drilling Program. Rocío Marino Ferrero and Jose Ignacio Martín Cruz are acknowledged for washing sediment samples. The research leading to these results has received funding from the People Programme (Marie Curie Actions) of the European Union's Seventh Framework Programme FP7/2007-2013/ under REA Grant Agreement No. 290201 MEDGATE, project P25831-N29 of the Austrian Science Fund (FWF), and NSF Grant OCE-1426132. The research was partially supported through Castilla y Leon project SA263U14 and CTM 2012-39599-C03, IGCP-619, and INQUA 1204 Projects. Research was conducted in the framework of the Continental Margins Research Group of the Royal Holloway University of London. We also thank A. Bahr and A. Voelker for full and constructive reviews that improved the manuscript.

\section{Author contributions}

M.v.d.S. picked foraminifera for stable isotopes, performed foraminiferal biostratigraphy, integrated the datasets, interpreted the results and wrote this manuscript with F.J.S., F.J.J-E provided the Zr/Al XRF core scanning data, R.F. assisted structuring the manuscript, F.J.H-M provided the seismic line to constrain the age model, J.A.F performed the nannofossil biostratigraphy, G.A. carried out the magnetostratigraphic analyses, M.G. assisted in publishing this work, P.G. and A.G-G provided the benthic foraminiferal paleobathymetric indications, N.A. carried out the stable isotope measurements. 


\section{Chapter 2.}

\section{Sedimentary cycles and oceanographic circulation under the influence of MOW over the Miocene- Pliocene boundary.}

Van der Schee, M., Sierro, F.J., Jiménez-Espejo, F.J., Flecker, R., Andersen, N.

To be submitted to Paleoceanography. 
Chapter Cover:

Miocene-Pliocene boundary with sharp transition from the Messinian Evaporites to Zanclean marls in the Eraclea Minoa section, Sicily, Italy. 


\title{
Sedimentary cycles and oceanographic circulation under the influence of MOW over the Miocene-Pliocene boundary in the Gulf of Cadiz
}

\author{
Marlies van der Schee ${ }^{(1)}$, F.J. Sierro(1), F.J. Jiménez-Espejo(2), R. Flecker(3), J.A. Flores ${ }^{(1)}$, N. \\ Andersen(4) $^{(4)}$ \\ (1) Dept. of Geology, University of Salamanca, Plaza de los Caídos s/n, 37008, Salamanca, Spain \\ (2) Dept. of Biogeosciences, JAMSTEC, Yokosuka 237-0061, Japan \\ (3) BRIDGE, School of Geographical Sciences, Cabot institute, University of Bristol, University Road, \\ Bristol, BS81SS, UK \\ (4) Leibniz-Laboratory for Radiometric Dating and Isotope Research, Christian-Albrechts-Universität \\ Kiel, Max-Eyth-Str. 11-13, 24118 Kiel, Germany
}

\begin{abstract}
Typical cyclic fluctuations are characteristic of the Miocene-Pliocene marine sediments recovered in IODP Hole U1387C. This succession records sedimentation in the Atlantic at the end of the Mediterranean's Messinian Salinity Crisis (5.33 to $5.97 \mathrm{Ma}$ ) and the onset of contourite deposition initiated by Mediterranean Outflow water (MOW) in the Gulf of Cadiz. Benthic and planktic $\delta^{13} \mathrm{C}$ and $\delta^{18} \mathrm{O}$, and elemental XRF data are used to assess the sedimentary patterns related to siliciclastic input, evaluate along-slope bottom water current strength and identify the origin of influencing water masses. During the Messinian, our results indicate that fluvial detrital input diluted biogenic carbonates. A higher siliciclastic component is found during insolation minima suggesting a precessional driver for this cyclicity. During the Pliocene, sedimentary cycles are overprinted by the influence of weak along-slope bottom water currents, coupling sedimentary variations with the benthic stable isotopes record. The current provides well-ventilated warmer waters and is attributed to MOW. In contrast, when grainsize data suggest that bottom water currents were sluggish or absent, the poorly ventilated, colder water mass is likely to have been Atlantic sourced water. Planktic $\delta^{18} \mathrm{O}$ and relative abundances of Globigerinoides gr. indicate sea surface temperature in this part of the Gulf of Cadiz warm at the same time as the bottom waters rapidly cool. This anomalous pattern of bottom and surface waters is attributed to changes in the water column either triggered by alternating anti-estuarine to estuarine circulations in the Mediterranean or by vertical shifts of settling depth of the MOW plume.
\end{abstract}




\section{Introduction}

Sediments in the Gulf of Cadiz and on the Moroccan and Iberian margins record the history of Mediterranean-Atlantic water exchange. Before, during and after the Messinian Salinity Crisis (MSC; 5.97 to $5.33 \mathrm{Ma}$ ) Mediterranean-Atlantic gateway configurations changed rapidly as a result of the restriction of the Betic and Rifian Corridors, which, in turn, modified the properties of the Mediterranean Outflow water (MOW) and its circulation pattern as it mixed with NE Atlantic waters (Flecker et al., 2015; Hernández-Molina et al., 2014a). During the MSC, water exchange must have been highly restricted to allow extreme variations in Mediterranean salinity to occur ranging from hypersaline conditions suitable for evaporite formation to the brackish Lago Mare phase (CIESM, 2008; Kuroda et al., 2016; Manzi et al., 2013; Roveri et al., 2008). A physical connection between the Mediterranean Basin and the open Atlantic Ocean was re-established through the

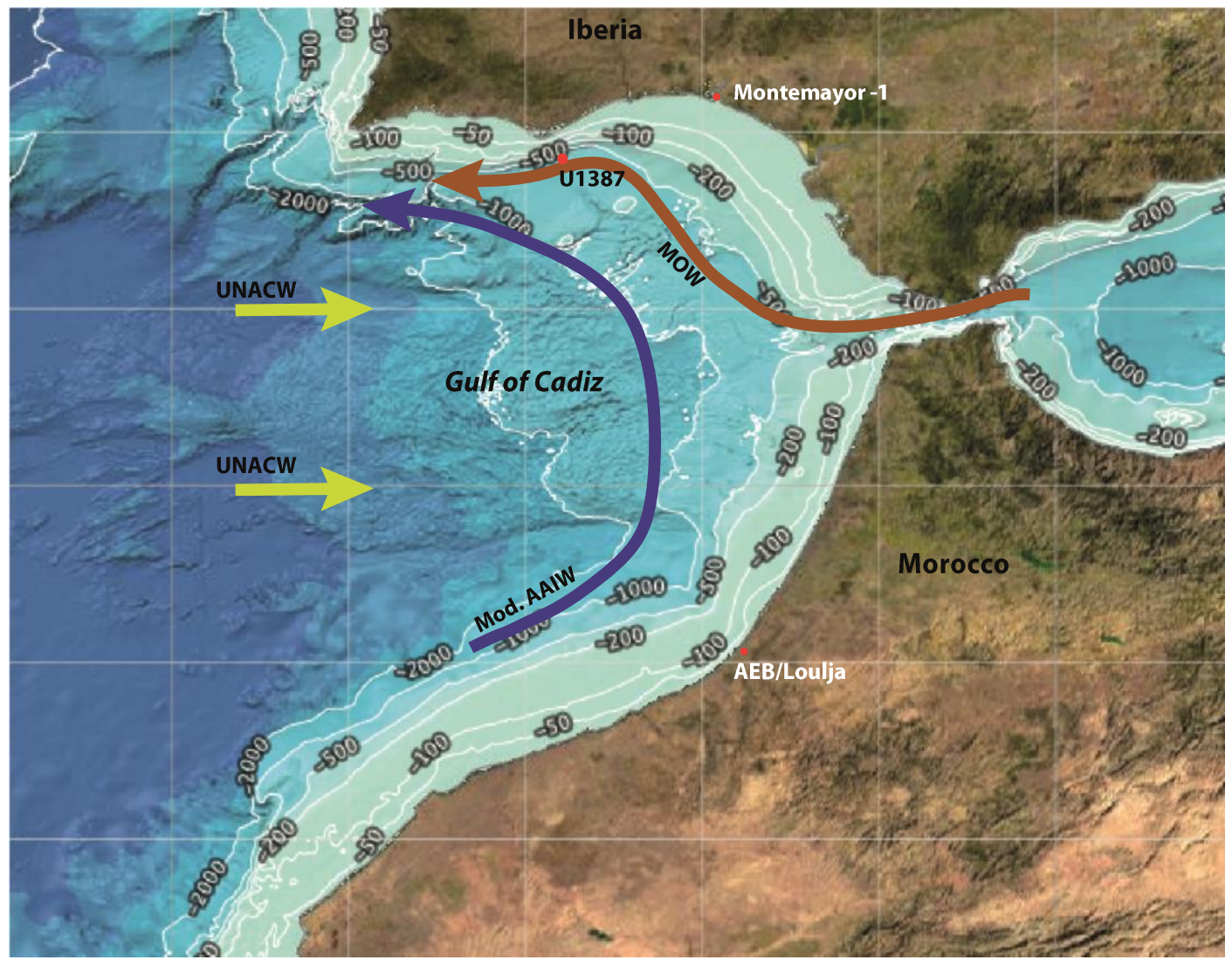

Figure 1. Locations of IODP Site U1387, the onshore Montemayor-1 core and Ain el Beida (AEB)/Loulja section. Modern day flow paths of the Mediterranean Outflow water (MOW), Upper North Atlantic Central water (UNACW) and modified Antarctic Intermediate water (mod. AAIW) are indicated. (Modified after Louarn and Morin, 2011). 
Gibraltar Strait marking the end of the MSC, and the Miocene-Pliocene boundary (5.33 Ma; Van Couvering et al., 2000). In the Gulf of Cadiz, contouritic sandy-layers, indicating weak along slope currents thought to derive from Mediterranean outflow, are found in the third precession cycle above the Miocene-Pliocene boundary (Chapter 1). However, detailed depositional environment and oceanographic changes in response to the onset of MOW at or just after the Miocene-Pliocene boundary are not well understood yet.

Sedimentary records suitable for the study of the development of MOW over the MiocenePliocene boundary are scarce in the region. The Guadalquivir Basin has a condensed interval with a glauconite layer just at the boundary (Fig. 1; Baceta and Pendón, 1999; CIESM, 2008; JiménezMoreno et al., 2013; Van den Berg et al., 2015), while a distinct hiatus towards the margins of the basin is present on the Algarve Margin (Hernández-Molina et al., 2016). On the Moroccan margin, the onshore Loulja section spans the boundary, but does not show a distinct change (Van der Laan et al., 2006) probably because sedimentary imprints of the initial weak MOW are expected to be less extensive on the southern margin as a result of MOW's northward flow path (HernándezMolina et al., 2003). Recently, Integrated Ocean Drilling Program (IODP) recovered deeper marine sediments from the Gulf of Cadiz that span the Miocene-Pliocene boundary (IODP Site U1387, 559 meter below sea level). This study along with other related research (Chapter 1 and García-Gallardo et al., in review; Hernández-Molina et al., 2016) are the first detailed investigations of these deeper marine sediments that allows us to reconstruct the nature of the onset of MOW after the MSC.

MOW intensity varies on a whole range of different time-scales including interannual and seasonal variability (Voelker et al., 2015a). Millennial scale environmental variation, such as Heinrich events in the late Pleistocene (Sierro et al., 2005) and astronomical induced glacial-interglacial variability over the last $\sim 1.8 \mathrm{Ma}$ are reported from multi-proxy datasets with stable isotopes, X-ray Fluorescence scanning data, Natural Gamma Ray downhole logs, etc. (e.g Bahr et al., 2015, 2014; Kaboth et al., 2016; Lofi et al., 2016; Voelker et al., 2015b). Further back in time, enhanced MOW is reported from 2.1 to $2.4 \mathrm{Ma}$ and 3.0 to $3.2 \mathrm{Ma}$, where increased water density at Site 548 in the North Atlantic is linked to profound hiatuses detected in seismic reflections in the Gulf of Cadiz (Hernández-Molina et al., 2014b; Khélifi et al., 2009). Persistent sequences of contourites seismic facies start at about 4.2-4.5 Ma indicating strong interaction between the Mediterranean and North Atlantic from that period on (Expedition 339 Scientists, 2012; Hernández-Molina et al., 2014b).

Messinian and early Pliocene orbitally-forced cyclic sedimentary successions have been well studied on the northern and southern margins of the Gulf of Cadiz during (Hilgen et al., 2000; Krijgsman et al., 2004; Pérez-Asensio et al., 2012; Sierro et al., 2000; Van den Berg et al., 2015; Van der Laan et al., 2012, 2006, 2005). Along the SW Iberian and NW Moroccan margins, regular alternations of detrital fluvial input to the basin are thought to have been the response to insolation-driven changes in precipitation. The deeper water cyclic sediments in Hole U1387C spanning the Miocene-Pliocene boundary provide insight into the forcing mechanisms of the sedimentary cycles and the initial influence on those of the MOW. 
In this study, we analyse upper Miocene to lower Pliocene (5.0 to 5.7 Ma) sediments from IODP Hole $\mathrm{U} 1387 \mathrm{C}$ and relate the sedimentary successions to paleoceanographic circulation patterns influence by the initiation of MOW. XRF scanning data are used to untangle cyclic sedimentary mechanisms, while benthic and planktic stable isotopes are used to trace the origin of water masses and insolation patterns. Our multi-proxy record is compared to other upper Miocene to lower Pliocene records onshore in the NE Atlantic, Mediterranean, and on the Iberian and Moroccan margins.

\section{Material and methods}

\subsection{Material and age model}

IODP Site U1387 was drilled during Expedition 339 in November to January 2011/2012, located on the upper slope of the Algarve Margin $\left(36^{\circ} 48.321^{\prime} \mathrm{N} ; 7^{\circ} 43.1321^{\prime} \mathrm{W}\right.$ at $559.1 \mathrm{~m}$ water depth; Stow et al., 2013; Fig. 1). This sedimentary succession is the only off-shore record reaching Miocene sediments in the Gulf of Cadiz to date. This research concentrates on the early Pliocene to Messinian interval located near the base of the Hole. The stratigraphic framework indicates a timespan from about 5.0 to 5.7 Ma, with the Miocene-Pliocene boundary ( $5.33 \mathrm{Ma}$ ) at about 826 mbsf (Hernández-Molina et al., 2016; Chapter 1).

\subsection{Methods}

\subsubsection{Carbon and oxygen isotopes}

Sample preparation for carbon and oxygen $\left(\delta^{13} \mathrm{C}, \delta^{18} \mathrm{O}\right)$ isotopic analyses on benthic Cibicidoides pachyderma species $>250 \mu \mathrm{m}$ are described and the $\delta^{18} \mathrm{O}$ published in Chapter 1 . In addition to the benthic stable isotopes, three to twenty planktic Globigerinoides obliquus $>250 \mu \mathrm{m}$ were selected for 291 samples. Specimens were washed with methanol, ultrasonicated for several seconds and dried for 24 hours to remove all liquids. All prepared samples were analysed in the LeibnizLaboratory for Radiometric dating and Isotope research at the Christian-Albrechts-University in Kiel with a MAT 253 mass spectrometer connected to a Kiel IV carbonate preparation device. The analytical precision of the international NBS-19 standard calibrated to laboratory-internal carbonate standards was better than $\pm 0.05 \%$ for $\delta^{13} \mathrm{C}$ and $\pm 0.08 \%$ for $\delta^{18} \mathrm{O}$. Samples with more than seven specimens were crushed to homogenise before analyses to obtain a representative subsample.

\subsubsection{XRF scanning data}

The XRF Core Scanner II (AVAATECH Serial No. 2) at the MARUM-University of Bremen was used to retrieve elemental ratios. XRF Core Scanner data were collected every $3 \mathrm{~cm}$ down-core over a $1.2 \mathrm{~cm}^{2}$ area with down-core slit size of $10 \mathrm{~mm}$ in three separate runs using generator settings of 10,30 , and $50 \mathrm{kV}$, and currents of $0.2,1.0$, and $1.0 \mathrm{~mA}$, respectively. Sampling time was set to $20 \mathrm{~s}$ and scanning took place directly at the split core surface on the archive half. The split core surface was covered with a $4 \mathrm{~cm}$ thin SPEXCerti Prep Ultralene1 foil to avoid contamination of the XRF 
measurement unit and desiccation of the sediment. The reported data have been acquired by a Canberra X-PIPS Silicon Drift Detector (SDD; Model SXD 15C-150-500) with 150 eV X-ray resolution and the Canberra Digital Spectrum Analyzer DAS 1000. The XRF II scanner is equipped with an Oxford Instruments 50W XTF5011. Core disturbance from drilling (biscuiting) may have significantly degraded the quality of measurements between 760.10 to 765.74 (Core $51 \mathrm{R}$ ) and inhibited measurements between 817.60 to 824.63 mbsf.

Raw total counts are normalized towards the total counts of the most important paleoproxy elements ( $\mathrm{Al}, \mathrm{Si}, \mathrm{S}, \mathrm{K}, \mathrm{Ca}, \mathrm{Ti}, \mathrm{Mn}, \mathrm{Fe}, \mathrm{Br}, \mathrm{Rb}, \mathrm{Sr}, \mathrm{Zr}, \mathrm{Ba}$ ) to circumvent the different refraction response of either silty or clayey intervals (Bahr et al., 2014 and references therein). Only $\mathrm{Al}, \mathrm{Si}, \mathrm{K}$ and $\mathrm{Ca}$ are displayed in this study, where $\mathrm{Ca}$ is used as a representation of $\mathrm{CaCO}_{3}$ - $\mathrm{Components}$ while $\mathrm{Al}$ and $\mathrm{K}$ represent the aluminosilicate component (clay) and Si the silicate component (sand). Thus, $\mathrm{Si} / \mathrm{K}$ ratios represent the relative proportion of silicate over aluminosilicate components within the siliciclastic component associated to riverine input (e.g. Holzwarth et al., 2010; Jiménez-Espejo et al., 2008) and current and/or water mass changes (e.g. Hodell et al., 2010). $\mathrm{Ti} / \mathrm{K}$ and $\mathrm{Zr} / \mathrm{Al}$ ratios are interpreted as representations of either bottom water current flow strength (Bahr et al., 2015, 2014; Kaboth et al., 2016; Voelker et al., 2015b) or as a proxy for dust (e.g Lourens et al., 2001; van der Laan et al., 2012). However, we use Ti/K rather than more conventional Ti/Al, because lower concentrations of $\mathrm{Al}$ are closer to the detection limit of the measurement device and the lighter elemental mass of Al obscures the emitted signal more easily (Tjallingii et al., 2007). The cross coefficient of Ca versus Sr is used to indicate that $\mathrm{Ca}$ is of biogenic origin (Hodell et al., 2008; Parra et al., 1981).

\subsubsection{Planktic foraminiferal warm water indicators}

Planktic foraminiferal quantitative analyses were performed in order to identify warmer intervals at the sea surface. Unbiased sample aliquots where obtained with a microsplitter until about 200300 planktic specimens remained in the $>150 \mu \mathrm{m}$ washed residue. Relative abundances of Globigerinoides quadrilobatus gr. (G. quadrilobatus, G. trilobus, G. inmaturus, G. sacculifer) and Globigerinoides obliquus gr. (G.bollii, G. cf. elongatus, G. extremus, G. obliquus) were grouped as warm-water, subtropical species (Bé, 1980; Curaso et al., 2002; Riforgiato, 2013; Van der Laan et al., 2012). Relative abundances of Globigerinoides are only counted for the Pliocene interval, since the Miocene sediments reveal strong parallel behaviour between the planktic and benthic $\delta^{18} \mathrm{O}$ records which allowed us to use these data as a reliable indicator of warmer and colder periods.

Figure 2 (next page). Paleoclimatic records, core recovery and core photographs of IODP Hole U1387C from 731.20 to 865.85 mbsf. The time-interval spanned from the latest Miocene to earliest Pliocene, Core number and photographs are indicated above the panel. (A) Relative abundances of Globigerinoides gr., warm-water species. Peaks in relative abundances are shaded vertically in the panel (black). (B) Planktic $\delta^{18} \mathrm{O}$ of G. obliquus (light blue). (C) Benthic $\delta^{18} \mathrm{O}$ of C. pachyderma (dark blue). (D) Benthic $\delta^{13} \mathrm{C}$ of the same specimens as for the $\delta^{18} \mathrm{O}$ (green). (E) $\mathrm{Ln}(\mathrm{Zr} / \mathrm{Al}$ ) XRF scanning ratios (purple) with its five-point running average (black). 


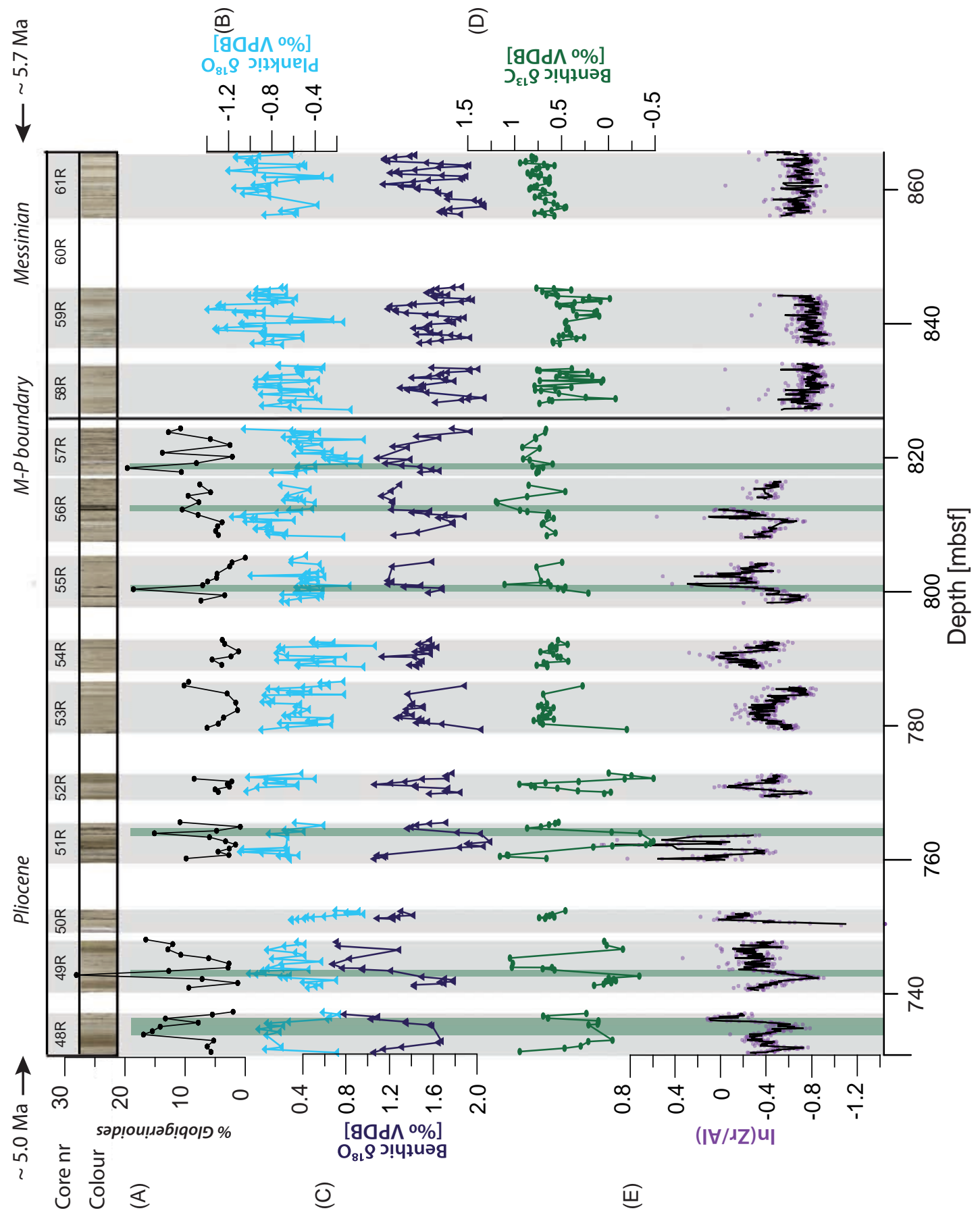




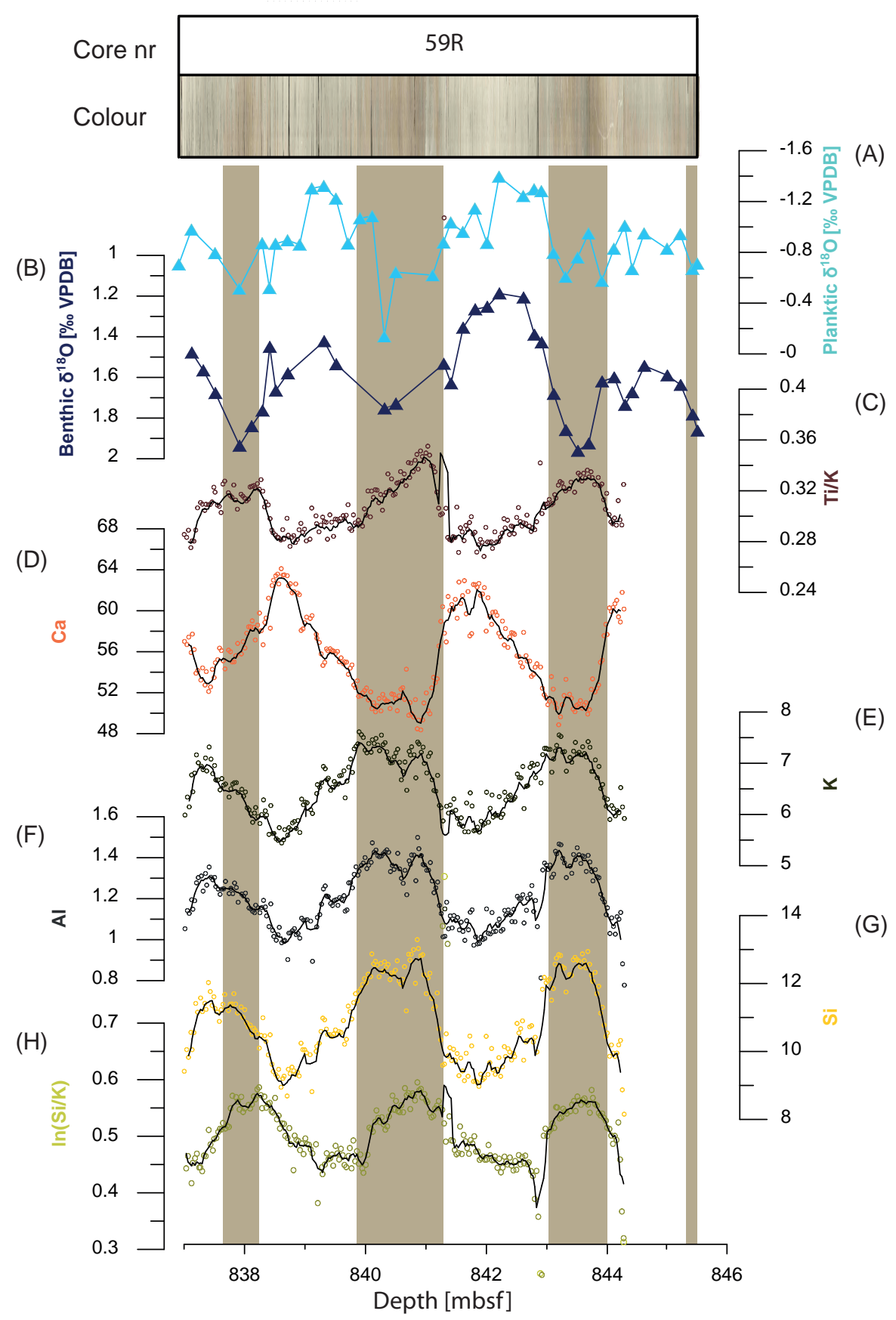

Figure 3. Detail of XRF scanning data zoomed into late Miocene sedimentary cycles compared to (A) planktic (light blue) and (B) benthic (dark blue) $\delta^{18} \mathrm{O}$ from 836.80 to $845.61 \mathrm{mbsf}$ (Core 59R). Darker intervals in core photographs are vertically highlighted (light brown). Elemental XRF scanning (C) Ti/K (brown) and (H) Si/K (green) ratios, and normalized elements of (D) Ca (orange), (E) K (grey), (F) Al (black) and (G) Si (yellow) (open circles; normalized elemental counts relative to the total counts of used elements (see section 2.2.2. for details), while the five-point running average are shown as a solid black line). 


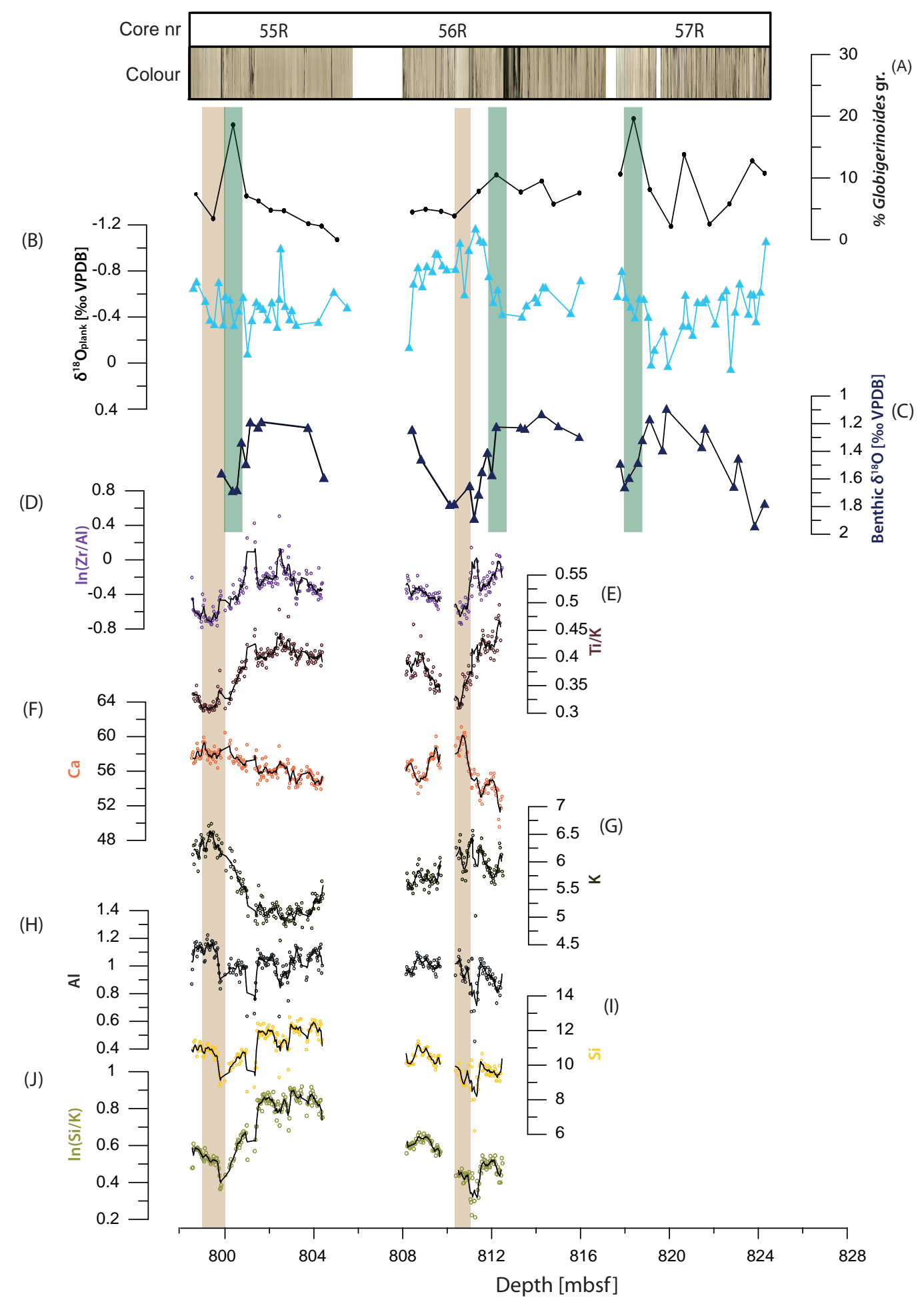

Figure 4. Detail of XRF scanning data to analyse Pliocene sedimentary cycles compared to (A) relative abundance of the Globigerinoidesgr, (B) planktic $\delta^{18} \mathrm{O}$ (light blue) and (C) benthic $\delta^{18} \mathrm{O}$ (dark blue) from 788.80 to 812.50 mbsf (Core $55 \mathrm{R}$ to $57 \mathrm{R}$ ). Vertically shaded are distinct lighter sediment colours (light pink) and relative abundance peaks of Globigerinoides(green). XRF scanning elemental (D) Zr/Al (purple), (E) Ti/Al (brown) and (F) Si/K (green) ratios are display, and normalized elements (F) Ca (orange), (G) K (grey), (H) Al (black), (I) Si (yellow) (open circles; normalized elemental counts relative to the total counts of used elements (see section 2.2.2. for details), while the five-point running average are shown as a solid black line). 


\section{Results}

\subsection{Stable isotope records}

Regular alternations are expressed in the stable isotope records (Fig. 2B, 2C and 2D). The most important observations are; 1 ) an increase of about $0.5 \%$ in the amplitude of the variations in the benthic $\delta^{13} \mathrm{C}$-record are found above $779.41 \mathrm{mbsf}$ with deviations mainly towards lower values; 2 ) general co-variations are recognizable. During the Pliocene, benthic $\delta^{18} \mathrm{O}$ and benthic $\delta^{13} \mathrm{C}$ records show in phase variations in opposite directions (Fig. $2 \mathrm{C}$ and $2 \mathrm{D}$; note that the axis in $2 \mathrm{C}$ is inverted). Parallel behaviour between benthic and planktic $\delta^{18} \mathrm{O}$ from 827.20 to $865.85 \mathrm{mbsf}$ is visible in the Messinian sediments (Fig. 2 and detailed Fig. 3; Core 59R). In contrast, rather unclear parallel behaviour is visible during the Pliocene between planktic and benthic $\delta^{18} \mathrm{O}$, although opposite behaviour can be detected from 731.20 to $737.50 \mathrm{mbsf}$ (Core 48R) and from 808.00 to $824.63 \mathrm{mbsf}$ (Core 56R and 57R; Fig. 4B and $4 \mathrm{C}$ ). Darker layers revealed in core photographs tend to be associated with heavy benthic $\delta^{18} \mathrm{O}$ (Figs. 3 and 4 , indicated with vertically shaded bands).

\subsection{X-ray fluorescence scanning analyses}

Ca and Sr are highly correlated $(R=0.93 P<0.005)$ over the studied interval (Fig. 5). This implies that variations in Ca mainly reflect changes in the biogenic carbonate content with only minor influence of detrital $\mathrm{Ca}$.

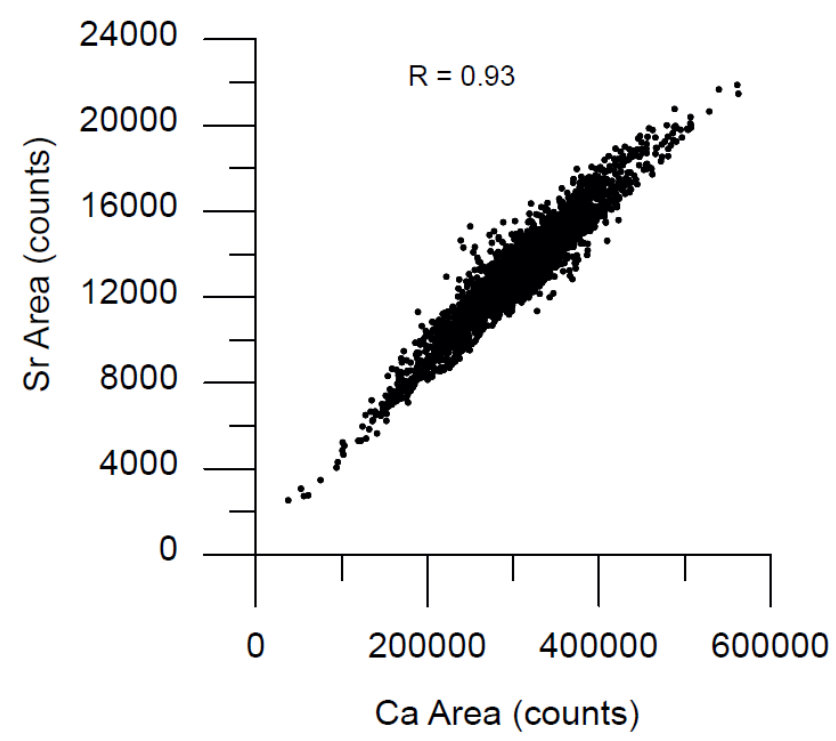

Figure 5. XRF scanning raw counts of Ca versus Sr for the interval of 731.20 to 865.85 mbsf at Site U1387C. High cross-correlations $(R=0.93 ; P<0.005)$ indicates the biogenic origin of $C a$. 


\subsubsection{Upper Miocene}

XRF analyses reveal regular alternations with a similar wavelength to the stable isotopes (Fig. 2, 3, $4,6)$. During the late Miocene, parallel behaviour of XRF elements is best expressed from 836.80 to $845.61 \mathrm{mbsf}$ (Core 59R) and therefore used to determine recurring patterns (Fig. 3). In general, $\mathrm{Al}$, Si and K, parallel one another and anti-correlate $\mathrm{Ca}$ (Fig. 3D, 3E, 3F and 3G). The siliciclastic intervals are associated with heavy planktic and benthic $\delta^{18} \mathrm{O}$ and darker sediment colours (Fig. $3 \mathrm{~A}$ and $3 \mathrm{~B}$ ). Si/K ratios mirror the Ti/K variability, and peaks in the siliciclastic beds (Fig. $3 \mathrm{C}$ and $3 \mathrm{H}$ ). This indicates a larger silicate component than aluminosilicate. The $\mathrm{Zr} / \mathrm{Al}$ shows rather low ratios that lack clear resemblance to the other well-expressed regular alternations (Fig. 6E).

\subsubsection{Pliocene}

Regular alternations in $\mathrm{Ca}, \mathrm{Al}, \mathrm{Si}$ and $\mathrm{K}$ and the parallel behaviour between these records is less well-developed during the Pliocene than the Miocene (Fig. 6). However, it is clear opposite behaviour is present mainly between $\mathrm{Ca}$ and $\mathrm{Si}$ (Fig. 4). Similar variations to the ones described for the Miocene, with highly variable $\mathrm{Ca}$ that negative parallels all siliciclastic elements are again present in the Pliocene from 731.20 to 737.50 mbsf (Core 48R). A notable overall increase in Ti/K, $\mathrm{Zr} / \mathrm{Al}$ and $\mathrm{Si} / \mathrm{Al}$ ratios is observed just above the Miocene-Pliocene boundary, as well as larger amplitude oscillations (Fig. 6A, 6B and 6H). Detailed parallel behaviour is most clearly visible from 812.50 to 798.40 mbsf (Core 55R and, in part, Core 56R; Fig. 4). Here, low Ti/K, Si/Al and Zr/Al ratios occur when $\mathrm{K}$ and $\mathrm{Al}$ are low and benthic $\delta^{18} \mathrm{O}$ is heavy. Besides, the earliest Pliocene sediments lack clear colour changes from 779.20 to 824.63 mbsf (Core 53R to 57R; Fig. 6). The higher resolution XRF scanning data reveal additional short time-scale regular alternations, for instance, from 731.20 to 748.19 mbsf (Core $48 R$ and $49 R$ ) and from 788.80 to 792.81 (Core 54R; Figs. 2, 6).

\subsection{Planktic foraminiferal warm water indicators during the earliest Pliocene} The relative abundance of warm-water planktic foraminiferal Globigerinoides species show regular alternations (Fig. 7). The high abundance peaks in this record occur at or just after the transition from light to heavy benthic $\delta^{18} \mathrm{O}$ (red arrows and green shaded area in Fig. 7) with increasing relative abundances during periods of light planktic and heavy benthic $\delta^{18} \mathrm{O}$, visible from 731.20 to 737.50 mbsf (Core 48R) and 808.00 to 824.63 (Core 56R and 57R).

\section{Discussion}

\subsection{Carbonate dilution cycles during the late Miocene in IODP Hole U1387C}

During the late Miocene, sedimentary cycles are well defined by regular alternations in sediment colour and the relative proportions of carbonate- $(\mathrm{Ca})$ and siliciclastic-associated elements ( $\mathrm{Si}, \mathrm{K}$, Al; Figs. 3D, 3E, 3F, 3G). The lighter colours in the core photographs are associated with intervals

Figure 6 (next page). XRF scanning data of the total studied interval from 731.20 to 865.85 mbsf compared with $(C)$ benthic $\delta^{18} \mathrm{O}$ (dark blue). The spanned time-interval is indicated above the panel, as well as core numbers and core photographs. Normalized XRF counts of (D) Ca, (E) K, (F) Al and (G) Si are displayed (see text for details), as well as elemental (A) Zr/Al (purple), (B) Ti/K (brown) and (H) Si/K (green) ratios (open circles), while five-point running averages are indicated with the continuous black line. 


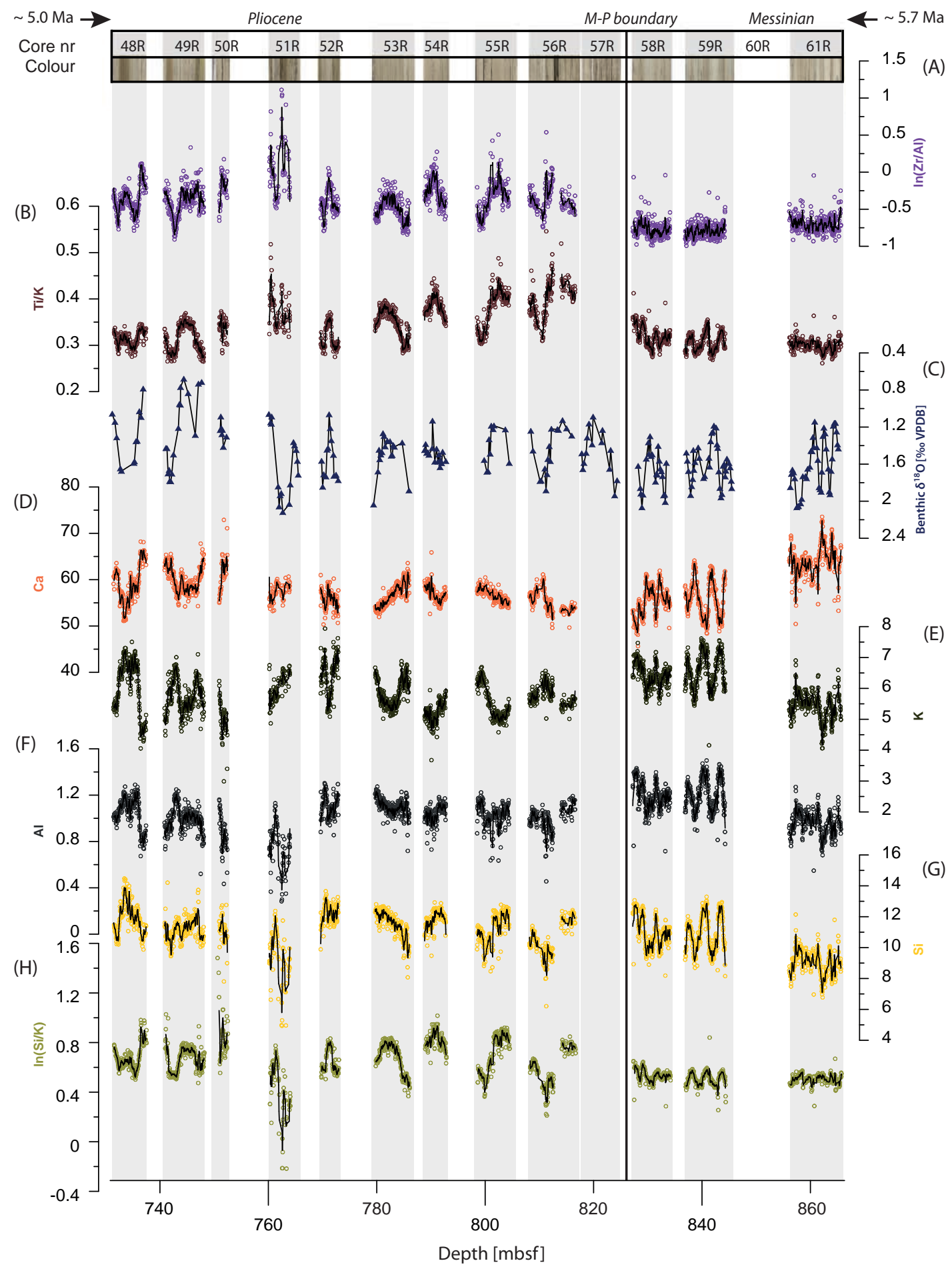



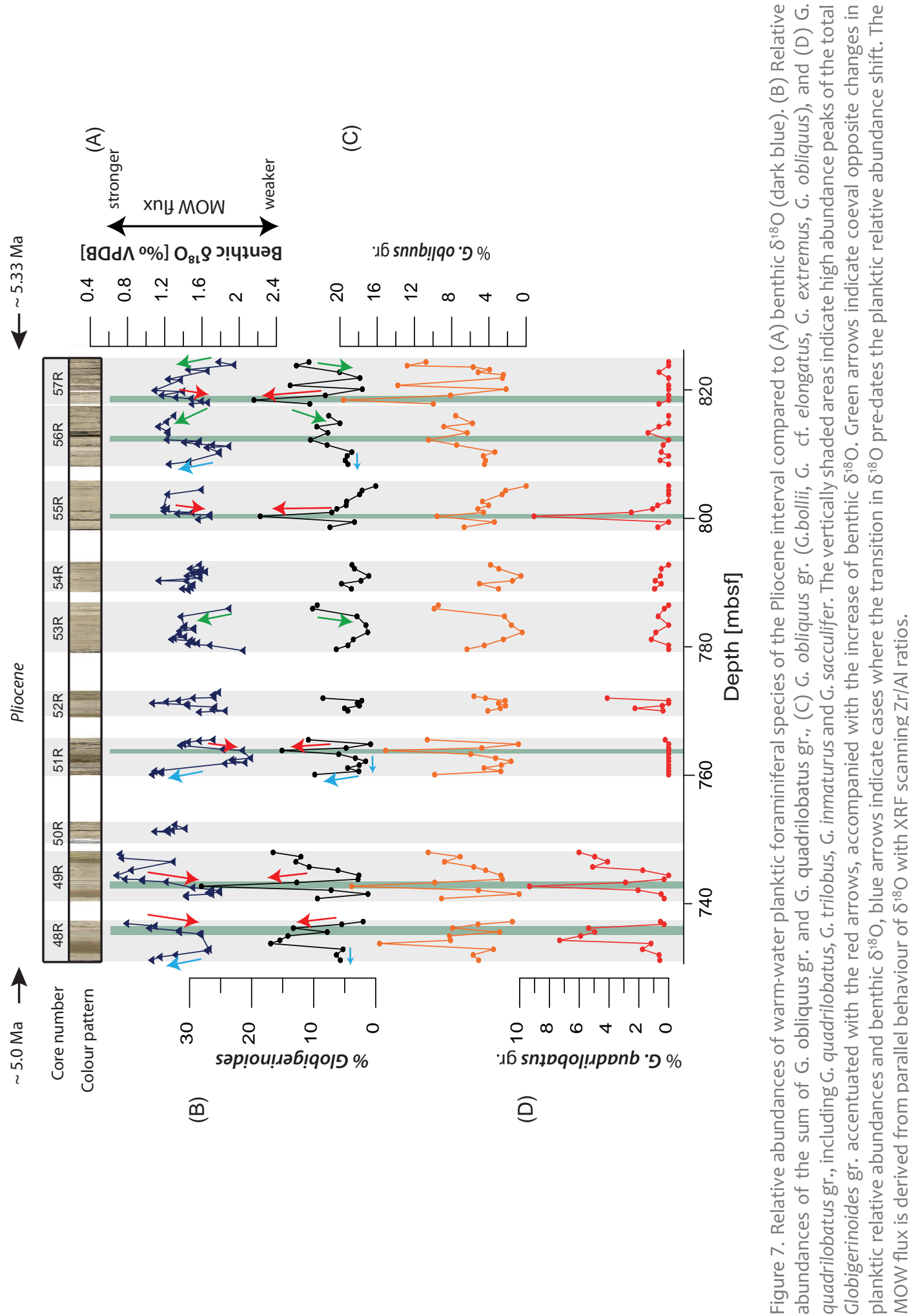
characterised by high $\mathrm{Ca}$ and low siliciclastic contents, and consequently are interpreted to be lighter in colour because of the higher concentration of whitish $\mathrm{CaCO}_{3}$. By contrast, darker greyish colours are related to intervals with a high siliciclastic content and little biogenic carbonate and are thought to result from increased detrital input. This suggests that sedimentary cycles during the Messinian are likely to be related to cyclical changes in the rate of sediment supply to the Gulf of Cadiz. It is assumed that changes in the primary production of calcium carbonate played a secondary role, as discussed in Thomson et al., (1999) for sediments from the last 150 ky on the Iberian Margin. Maximum detrital input occurred during intervals of heavy benthic and planktic $\delta^{18} \mathrm{O}$ (Fig. 3), where the planktic $\delta^{18} \mathrm{O}$ variability mirrors changes in SST and/or $\delta^{18} \mathrm{O}$ of the water $\left(\delta^{18} \mathrm{O}_{\mathrm{w}}\right)$. Consequently, we relate the heavy planktic and benthic $\delta^{18} \mathrm{O}$ to $65^{\circ}$ Northern Hemisphere summer insolation minima (hereafter; insolation minima), as has been done in sediment sequences at nearby locations spanning the same time period e.g. Loulja in NW Morocco (Van der Laan et al., 2006) and the Montemayor-1 borehole in SW Spain (Pérez-Asensio et al., 2013; van den Berg et al., 2015).

To investigate the relative contribution of the different types of siliciclastics further, especially the relative proportion of clay and silt, we used the $\mathrm{Si} / \mathrm{K}$ and $\mathrm{Ti} / \mathrm{K}$ ratios, assuming that $\mathrm{K}$ are more concentrated in clays. The relative proportion of clay within the siliciclastic component is larger (low $\mathrm{Si} / \mathrm{K}$ and $\mathrm{Ti} / \mathrm{K}$ ) when $\mathrm{Ca}$ is high at times of insolation maxima (Fig. 3C, 3D, $3 \mathrm{H}$ ). Consequently, we infer that the terrestrial input was relatively enriched in clay, even though the total detrital supply was smaller at these times. These cyclic sedimentary alternations observed in Hole U1387C during the Messinian are similar to the ones described in the Upper interval (60-178 mcd) of the Montemayor-1 borehole, where maximum detrital supply, with low clay content, is observed during insolation minima (Van den Berg et al., 2015). Onshore of the Guadalquivir Basin, these sedimentary cycles are up to $7 \mathrm{~m}$ thick and are explained by changes in erosion rates on the adjacent continent. It is thought that arid environmental conditions during insolation minima reduced the vegetation cover and favoured this erosion (Cerdan et al., 2010). This may have triggered rivers to transport and deliver a higher sediment load to the basinal margins with a relatively low clay content. During insolation maxima, fluvial discharge may have been higher, but total clay-rich suspended load was less as a result of more extensive vegetation in the hinterland. The thickness of more than seven meters for one precession cylce in the Montemayor-1 borehole and its position close to the coast makes it likely that the detrital input is mainly of fluvial origin. The strong similarities between the cyclic patterns in Hole $\mathrm{U} 1387 \mathrm{C}$ during the late Miocene with those reported for the northern Guadalquivir Margin at about the same time period (van den Berg et al., 2015) suggest that sedimentary cyclical changes in the Gulf of Cadiz are related to variations of over-land terrigenous input to the basin. In addition, IODP U1387C reveals clear asymmetric cyclicities, in which the base of each cycle is characterized by an abrupt increase of detrital material to the basin (Fig. 3). This is followed by a gradual decrease that culminates in another abrupt increase of detrital input at the onset of the next cycle. Such a pattern can be caused by rapid aridification causing the immediate increase of siliciclastic detrital input. Although sea-level changes during the late Miocene to early Pliocene are thought to have been relatively small 
(between 10-30 m; Aharon et al., 1993; Hodell et al., 2001), lower sea levels may have amplified the processes the enhancement of supply of coarser, siliciclastic material to the basin at times of insolation minima.

Alternatively, enhanced siliciclastic, silty material of eolian origin at times of dry and arid periods can also explain the sedimentary cycles and the low carbonate content during insolation minima. High Ti/K and Si/K ratios are consistent with a siliciclastic component poor in clay and dominated by silts as is usually the case for particles transported by wind (Lourens et al., 2001; Wehausen and Brumsack, 2000). However, an aeolian origin for the siliciclastic component as the major factor influencing sedimentary cyclicity should result in a clear in-phase relationship between detrital proxies and insolation forcing (Hodell et al., 2013). Here, the asymmetrical character of the cycles and phase lags between proxy records suggest dust is not the main source of detrital input. A minor aeolian influence must be considered however, since arid environmental conditions during the Messinian can be inferred from high Ti/Al ratios in the nearby Ain el Beida section (Van der Laan et al., 2012), pollen data (Fauquette et al., 2006; Jiménez-Moreno et al., 2010) and migratory movements of desert small mammals (García-Alix et al., 2016). In addition, apart from the conventional dust sources of the Sahara/Sahel area, it should be considered that Mediterranean sea-levels may have dropped substantially during the MSC (e.g. Flecker et al., 2015), exposing additional land surface that may have enhanced dust production in the Mediterranean area from exposed shelf and lacustrine basins under arid condition (Cornée et al., 2016).

Bottom water current flow can also explain the cyclical variation observed in Hole U1387C sediments. In such cases, finer/lighter clay-particles are preferentially removed leaving heavier, course grained siliciclastic material. However, Chapter 1 suggested that bottom water current flow was negligible during the Messinian in Hole U1387C, because grain size data do not show inphase behaviour with other proxy records.

\subsection{Sedimentation influenced by bottom water current flow during the early Pliocene}

During the early Pliocene, sedimentary cycles are present, but behave differently from those in the Miocene (Fig. 4 and 6). The less pronounced changes in Ca are reflected in the less pronounced colour alternations in core photographs during this interval (Fig. 6). Consequently, we conclude that cyclical changes of total detrital input to the Gulf of Cadiz are not as obvious.

However, regular alternations are clearly evident in the siliciclastic component with $\mathrm{Zr} / \mathrm{Al}, \mathrm{Ti} / \mathrm{K}$ and $\mathrm{Si} / \mathrm{K}$ ratios displaying cyclical patterns that are usually consistent with the benthic stable isotope record (Fig. 6A, 6B, 6C, 6H). Peaks in these elemental ratios indicate relatively low aluminosilicate (clay) and high silicate (silt) contents in the total siliciclastic (detrital) fraction. In combination with the $>63 \mu \mathrm{m}$ grain size fraction data (Chapter 1 ), these ratios are linked to increased bottom water current strength related to the onset of Mediterranean-Atlantic exchange immediately after the Miocene-Pliocene boundary. Consequently, sedimentary cycles with a higher silicate content 


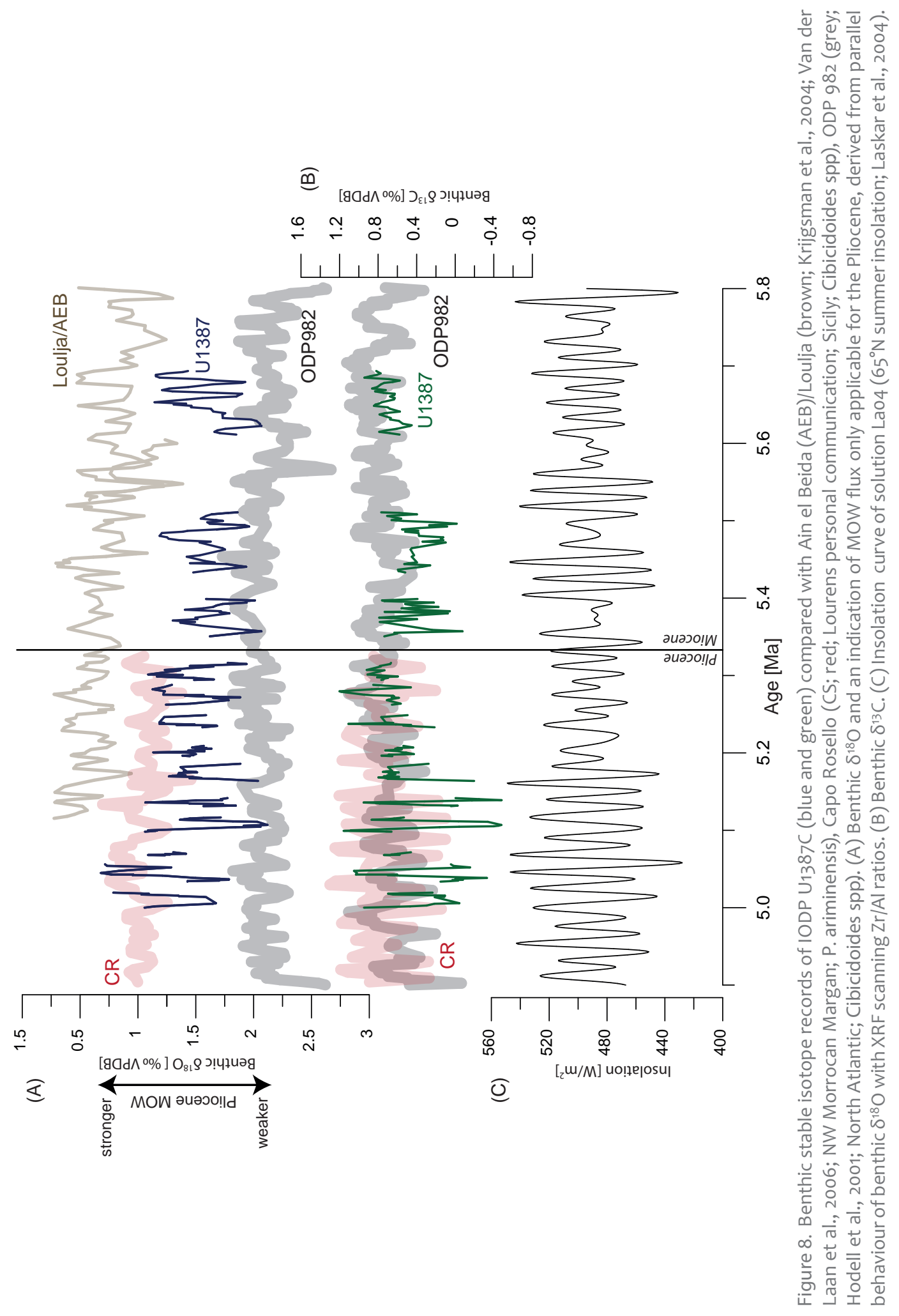


occur during intervals of stronger currents, while finer grained clay and carbonate deposition occurs at times of weak or absent bottom water activity. From 731.20 to 737.50 mbsf (Core 48R) in the Pliocene all mayor elements are again diluted by the Ca-signal, resembling the pattern observed during the Miocene (Fig. 6). This indicates that during this interval detrital input may have been more dominant.

\subsection{Mediterranean and Atlantic bottom water influences}

The Pliocene cyclicity in $\mathrm{Zr} / \mathrm{Al}, \mathrm{Ti} / \mathrm{K}$ and $\mathrm{Si} / \mathrm{K}$, are strongly coupled with the benthic stable isotopes. Heavy benthic $\delta^{18} \mathrm{O}$ and low $\delta^{13} \mathrm{C}$ are recorded in more muddy intervals, negatively paralleling $\mathrm{Zr} / \mathrm{Al}$ ratios for example (Fig. 2C, 2D, 2E). Consequently, we conclude that there is a strong coupling between benthic stable isotopes and bottom water currents.

The benthic $\delta^{18} \mathrm{O}$ record of $\mathrm{U} 1387 \mathrm{C}$ shows large amplitude variation by comparison with open ocean Atlantic records such as ODP 982 (Hodell et al., 2001), more shallow northern Moroccan sites (Krijgsman et al., 2004; Van der Laan et al., 2006) and Mediterranean unpublished Cibicidoides spp. from the earliest Pliocene from the Capo Rosello section (Sicily; Lourens personal communication; Fig. 8A). Benthic $\delta^{18} \mathrm{O}$ in Hole $\mathrm{U} 1387 \mathrm{C}$ reaches values comparable to time equivalent central Mediterranean average values when bottom water current flow was high ( $\mathrm{Zr} / \mathrm{Al}$ peaks, light benthic $\delta^{18} \mathrm{O}$; Fig. $8 \mathrm{~A}$ ). In contrast, when bottom currents are sluggish, benthic $\delta^{18} \mathrm{O}$ values in the Gulf of Cadiz are comparable to values obtained in ODP 982 (Fig. 8A)(Hodell et al., 2001). The unique large amplitude fluctuations of up to $1.1 \%$ in benthic $\delta^{18} \mathrm{O}$ in Hole U1387C are unlikely to have been caused by changes of $\delta^{18} \mathrm{O}$ of a single water mass, as similarly large variations are not observed either in the Upper North East Atlantic Deep Water (NEADW; ODP 982), in the Mediterranean (Fig. 8A) or Atlantic margins of Morocco and Spain (Ain el Beida/Loulja, Van der Laan et al., 2006, 2005; Montemayor-1, Pérez-Asensio et al., 2012; Van den Berg et al., 2015). Temperature is also unlikely to be able to account for these high amplitude changes in the Pliocene $\delta^{18} \mathrm{O}$ since today, mixing of warmer Mediterranean waters with colder Atlantic water at the Gibraltar Strait and beyond reduces the temperature of the MOW with about only $1{ }^{\circ} \mathrm{C}$ which equates to 0.2 per mil (Voelker et al., 2015a). One possible explanation for these large amplitude changes in benthic $\delta^{18} \mathrm{O}$ is a thorough switch from bottom currents flowing carrying warmer Mediterranean waters to sluggish conditions with weak or no bottom currents influenced strongly by colder intermediate Atlantic water.

The benthic $\delta^{13} \mathrm{C}$ record is consistent with the interpretation of switching Mediterranean and Atlantic bottom water influence at Site U1387. Throughout the Pleistocene, Mediterranean waters were characterized by high $\delta^{13} C_{D I C}(\mathrm{DIC}=$ Dissolved Inorganic Carbon), indicating well ventilated waters, especially during Northern Hemisphere summer insolation minima (Fig. 8C; Toucanne et al., 2015; Voelker et al., 2015b). North Atlantic intermediate waters on the eastern Atlantic margin usually exhibit low $\delta^{13} \mathrm{CDC}$, values, indicating less well ventilated waters because of the high oxygen consumption as a result of organic matter oxidation at upwelling zones which subsequently releases ${ }^{12} \mathrm{C}$ to the seawater (Voelker et al., 2015b). Site U1387C's varying bottom water $\delta^{13} C_{D I C}$ could result from mixing of the deeper, lower core of MOW (800-1500 m below sea level; lower 
$\delta^{13} C_{D I C}$ ) with deeper and better ventilated Upper NEADW (higher $\delta^{13} C_{D I C}$ ). Combining the two benthic stable isotope records of Hole $\mathrm{U} 1387 \mathrm{C}$ indicates that at times of light benthic $\delta^{18} \mathrm{O}$, suggesting warm bottom waters, well ventilated high benthic $\delta^{13} \mathrm{C}$ supports the interpretation of a Mediterranean origin of the water mass (Fig. $8 \mathrm{~B}$ ). In contrast, at times when benthic $\delta^{18} \mathrm{O}$ are heavy, indicating colder bottom waters, low benthic $\delta^{13} \mathrm{C}$ indicate more substantial influence of intermediate North Atlantic bottom waters with low benthic $\delta^{13} \mathrm{C}$.

Summarizing, at Site $\mathrm{U} 1387 \mathrm{C}$ during the early Pliocene, heavy benthic $\delta^{18} \mathrm{O}$ strongly suggest that periods of weak or absent bottom water activity are related to colder Atlantic bottom waters associated with abrupt drops in benthic $\delta^{13} \mathrm{C}$ (especially pronounced in the upper part of the record), indicating poorly ventilated waters. In contrast, periods with maximum current flow typically show light benthic $\delta^{18} \mathrm{O}$, which is probably driven by the influence of warm Mediterranean-derived bottom water temperatures, and high benthic $\delta^{13} \mathrm{C}$, reflecting MOW's well ventilated nature.

The Messinian benthic $\delta^{13} \mathrm{C}$ values are not as high as those from the Pliocene interval in Hole U1387C, (Fig. 8B). This suggests either the presence of poorly ventilated intermediate Atlantic waters in combination with weak or absent MOW or poorly ventilated MOW during the MSC in the Gulf of Cadiz. Negligible MOW is consistent with the hypothesis that evaporite precipitation in the Mediterranean during the MSC requires either highly restricted Mediterranean-Atlantic exchange, or one way flow of Atlantic water to the Mediterranean with no returning outflow (Flecker et al., 2015; Roveri et al., 2014). In addition, no evidence of MOW was found in previous multi-proxy studies on the margins of the Gulf of Cadiz (Pérez-Asensio et al., 2013; van den Berg et al., 2015; Van der Laan et al., 2012, 2006; Van der Schee et al., 2016). We therefore conclude that poorly ventilated intermediate Atlantic waters influenced the area around Hole U1387C in the Gulf of Cadiz during the MSC. This does not preclude the possibility that MOW flowed further offshore at the time.

\subsection{Surface versus deep water circulation during the earliest Pliocene}

Transitions from Mediterranean to Atlantic sourced bottom waters are synchronous with warming phases at the surface, recorded by peaks in the relative abundance of warm-water Globigerinoides species and/or lighter planktic $\delta^{18} \mathrm{O}$ (green shaded area and red arrows Fig. 7). By contrast, transitions from Atlantic to Mediterranean sourced bottom waters are either coeval with (green arrows Fig. 7A and 7B) or pre-date warming at the sea surface (blue arrows, Fig. $7 \mathrm{~A}$ and $7 B)$. When the Atlantic to Mediterranean sourced bottom water transition pre-dates the warming phase, the warming episodes at surface are short events that only occurred the time when Mediterranean intense bottom water was replaced by sluggish Atlantic bottom water. After maximum warming at the surface, waters cooled rapidly and both surface and bottom waters register colder conditions for a short period that continues until the advection warmer (probably Mediterranean) waters at the bottom. The consistent coupling between benthic $\delta^{18} \mathrm{O}, \mathrm{Zr} / \mathrm{Al}$, relative abundance of warm-water planktic foraminifers points to a coeval change in surface and bottom water circulation All this data show that, at least during these transitional phases, 
Mediterranean-Atlantic water exchange could have changed from an anti-estuarine to estuarine circulation.

\subsection{Short events of reversed Atlantic-Mediterranean circulation during the earliest Pliocene}

All hydrological settings at IODP Site U1387 presented above suggest that the flow of the MOW along the continental slope of the Gulf of Cadiz was repeatedly interrupted by Atlantic originated bottom waters during the earliest Pliocene. The parallel and often inverse changes points to reversed circulation in the Mediterranean Sea, with the presence of MOW during short time periods at the surface and Atlantic Inflow at depth (Fig. 9B). These short term reversals in Mediterranean circulation can be triggered by changes in the Mediterranean water budget, caused by periodic annual changes in precipitation and run-off associated with astronomical climate variations. Reversed circulation is triggered when precipitation and run-off exceeds water loss by evaporation in the Mediterranean, causing a positive fresh water budget. A hydrological model with reversed Mediterranean circulation is worth exploring, bearing in mind the sensitivity of the Mediterranean Basin to environmental change, especially immediately after the MSC with its last brackish water Lago Mare deposits (Clauzon et al., 1996; Krijgsman et al., 1999; Marzocchi et al., 2016). In addition, warmer climatic conditions (Fauquette et al., 2006; Miller et al., 2005) and unknown late Miocene to early Pliocene gateway depths (Flecker et al., 2015; Simon and Meijer, 2015) make alternative early Pliocene hydrological scenarios possible.

When environmental conditions are more arid at times of insolation minima, decreased precipitation and run-off enhances the Mediterranean's negative water budget, resulting in higher salinities. The larger Mediterranean-Atlantic density contrast can induce higher intensities of MOW along the Gulf of Cadiz, favouring the export of heat and salt to the Atlantic (Fig. 9A). However, this pattern may have changed abruptly when the Mediterranean environment became progressively wetter at times of insolation maxima. Increasing annual rainfall and fresh water input from Paratethys, the Nile and possibly Chad-derived rivers (Gladstone et al., 2007) reduced the density contrast at the Gibraltar Strait. At a certain threshold this may have triggered a reversed circulation in the Mediterranean (Fig. 9B). This is recorded in the Gulf of Cadiz by parallel warming at surface coinciding with pronounced cooling of bottom waters. The duration of the reversed circulation in the Mediterranean may have varied from one precession cycle to the other, causing the different patterns of bottom water warming and surface cooling. However, we want to stress that hydrographic conditions over precession cycles are highly variable, as also noted in Voelker et al., (2015b) in which from 1020 to 1135 ka at IODP Site U1387 showed that no glacial or interglacial period experienced the same conditions (Voelker et al., 2015b). The episodic reversals are more evident in the benthic $\delta^{13} \mathrm{C}$ record at Site U1387 about 100-kyr after the Miocene-Pliocene boundary. This coincides with the first high amplitude precessional variations during the $400-k y r$ eccentricity maximum (Fig. 8D). 

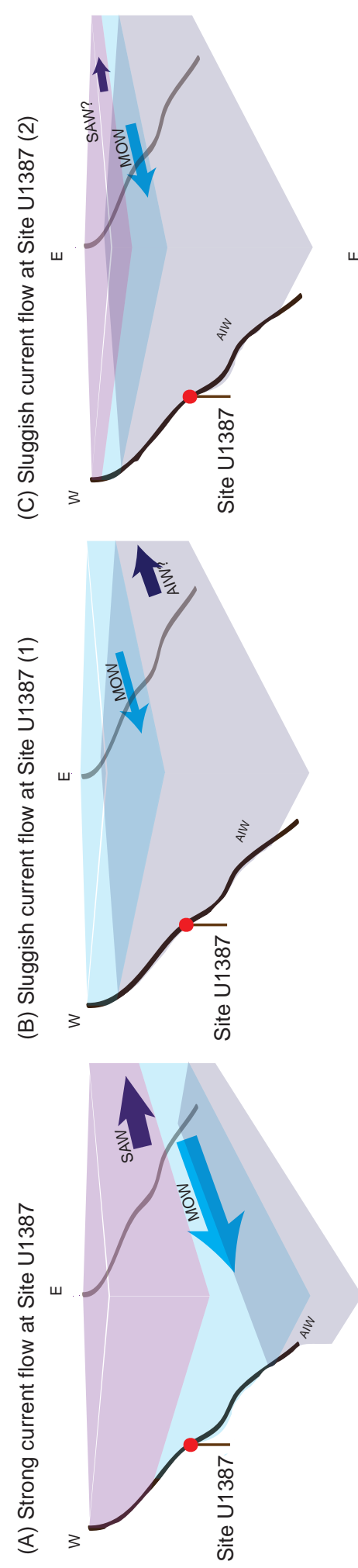

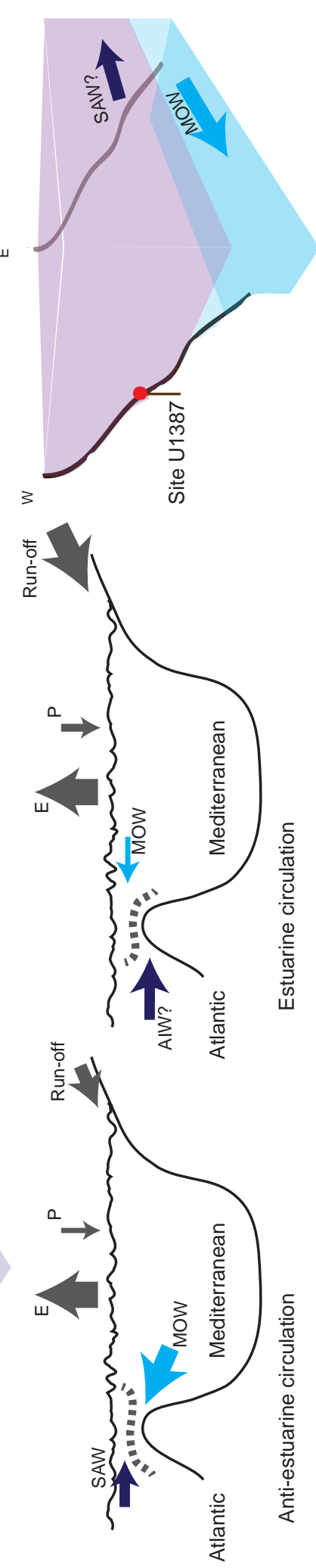

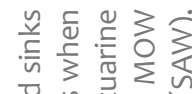

喜岀苟导

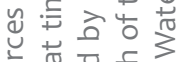

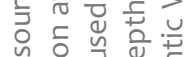

离离

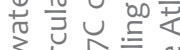

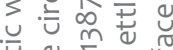

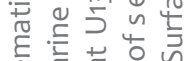

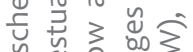

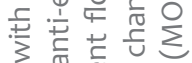

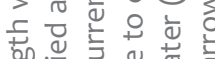

茄.

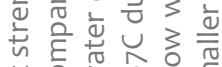

芒记

Uั

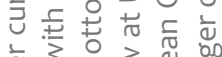

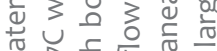

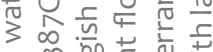

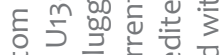

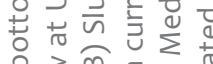

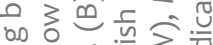

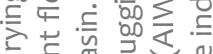

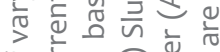

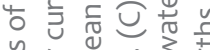

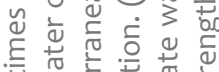

等

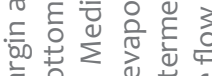

元

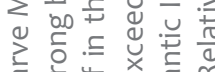

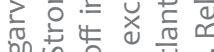

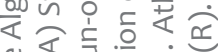

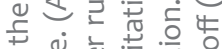

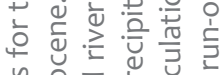
品음 든 이의

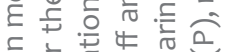

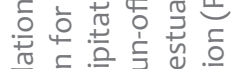
$\frac{\pi}{\overline{3}} \cdot \frac{\bar{n}}{\bar{n}} \cdot \frac{0}{\bar{v}}$

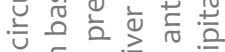
정 ฮ 诸议

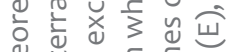
它 드으들

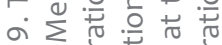

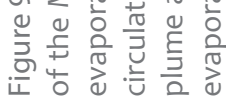


Phase relations with Northern Hemisphere insolation patterns are also suggested in the benthic $\delta^{13} \mathrm{C}$ record. High benthic $\delta^{13} \mathrm{C}$ plausibly have their origin in the Mediterranean (see section $4 \cdot 3$ ). However, such high values are only reached at times of insolation minima (Fig. 8B, Toucanne et al., 2015; Voelker et al., 2015b; Lourens personal communication). This could imply that during precession minima, reduced run-off and density difference between the Atlantic and Mediterranean Basin enhanced bottom water MOW in the Gulf of Cadiz. However, it remains unclear whether the colder temperatures at the sea surface are directly caused by decreased insolation or because of increased influence of colder Atlantic waters at the surface.

Evidence for a Mediterranean water budget that was at least less negative during the earliest Pliocene are found in oxygen isotope gradients between the Atlantic and the Mediterranean. Today, the $\delta^{18} \mathrm{O}$ water gradient between MOW (1.6\%) and intermediate Atlantic waters (0.6-0.8\%) is the result of the negative water budget of the Mediterranean (Voelker et al., 2015a). In the late Holocene, benthic foraminiferal $\delta^{18} \mathrm{O}$ inside the Mediterranean was $1 \%$ higher than benthic $\delta^{18} \mathrm{O}$ in the Gulf of Cadiz (Toucanne et al., 2015; Voelker et al., 2006). Because the temperature difference between the water masses is small, this gradient is mainly due to the difference in $\delta^{18} \mathrm{O}$ between the two. However, during the earliest Pliocene, the lightest benthic $\delta^{18} \mathrm{O}$ values recorded at Site U1387 are very similar to the average values inside the Mediterranean (Fig. 8A), suggesting the existence of a small $\delta^{18} \mathrm{O}$ gradient between the Atlantic and Mediterranean at those times (Rogerson et al., 2012). This reduction in $\delta^{18} \mathrm{O}$ difference could have been achieved either by higher Atlantic intermediate water temperatures or by a water budget in the Mediterranean that was less negative during the earliest Pliocene than in the Holocene.

Studies just above the Miocene-Pliocene boundary, combining benthic and planktic stable isotopes at high enough resolution to confirm or disprove the suggested positive Mediterranean water budget for the earliest Pliocene have yet to be generated. Global Circulation Model (GCM) studies are performed on the Mediterranean Sea and Paratethys for mean annual precipitation over a full precession cycle from 6.568 to 6.589 Ma (Marzocchi et al., 2016, 2015). At no point in the precession cycle, does the Mediterranean experience a positive freshwater budget according to these models (Marzocchi et al., 2016), but note that proxy records show wetter environmental conditions than the model suggests. GCM experiments performed with a positive Mediterranean water budget, indicating that brackish MOW could cause a total collapse of North Atlantic Deep Water (NADW) formation and shut-down of the Atlantic meriodial overturning circulation (AMOC; Ivanovic et al., 2014). However, if that model study is valid, benthic $\delta^{18} \mathrm{O}$ of ODP 982 , spanning the Messinian and early Pliocene interval, does not show such a clear response during the late Messinian, indicating that the model might exaggerate consequences regarding NADW formation and the AMOC shut-down (Fig. 8A).

\subsection{Variations in MOW plume settling depth}

The time periods of dominant Atlantic bottom waters at Site U1387 during the Pliocene can, in part, be explained by shallowing of MOW (Fig. 9C). This may also have forced Atlantic waters to move up towards the Site location of Hole $\mathrm{U} 1387 \mathrm{C}$, decreasing bottom water temperatures and 
benthic $\delta^{13} \mathrm{C}$. In this scenario, warm, low density surface Atlantic waters must have been present above the MOW, moving towards the Gibraltar Strait (Fig. 9C), somewhat comparable to the Pleistocene during glacial periods Marine Isotope Stages 10 and 12 when SST were cold, but intense deeper warm waters cause a pronounced lighter expression in benthic $\delta^{18} \mathrm{O}$ along the Portuguese margin (Voelker et al., 2010). If MOW settled at deeper depths, Site U1387C would have recorded colder Atlantic surface waters, however, this is incompatible with the synchronous, but opposite behaviour of warm-water planktic foraminiferal abundances (Fig. 9C). Settling depth and the flow path of MOW has been shown to be sensitive spatially in three dimensions in previous studies (Bahr et al., 2015; Lofi et al., 2016; Rogerson et al., 2005; Voelker et al., 2006, 2010).

\section{Conclusions}

Planktic and benthic stable isotopes and elemental XRF scanning data were generated for the Miocene-Pliocene boundary interval in the Gulf of Cadiz (IODP Hole U1387C). During the Messinian, sedimentation was mainly governed by precession-driven carbonate content diluted with terrigenous detrital input from the southern margin of the Iberian Peninsula.. Stable isotope data indicate that more detrital input, rich in silica, occurred during Northern Hemisphere summer insolation minima (arid periods) as a result of varying vegetation cover and associated fluctuations in erosion and sediment transport. During the Pliocene, sediment properties reflected in $\mathrm{Zr} / \mathrm{Al}, \mathrm{Si} / \mathrm{K}$ and $\mathrm{Ti} / \mathrm{K}$ ratios and grain-size fraction data were mainly driven by changes in bottom water current flow with the onset of MOW after the MSC. Light benthic $\delta^{18} \mathrm{O}$ and high $\delta^{13} \mathrm{C}$ suggest the advection of warmer, well ventilated bottom waters of Mediterranean origin when current flow is observe. Our results suggest that bottom water MOW was repeatedly interrupted and replaced briefly by colder, poorly ventilated Atlantic water, associated with more muddy sediments, indicative of sluggish bottom water currents. These events are marked by a rapid transition of light to heavy benthic $\delta^{18} \mathrm{O}$ parallel to drops in benthic $\delta^{13} \mathrm{C}$. Remarkably, surface waters also underwent profound changes that were, in part, coeval with these recorded changes to bottom water conditions. Significant warming of surface waters as indicated by higher relative abundances of warm-water species of Globigerinoides and, in some cases, lighter planktic $\delta^{18}$, occurs synchronously with a transition from active, warm MOW to sluggish, cold Atlantic bottom waters. This opposite behaviour, cooling of bottom water and surface warming, could be linked to a shift from anti-estuarine to estuarine circulation in the Mediterranean forcing cold Atlantic Inflow water over the sill of the Gibraltar Strait and warm MOW passing through at surface. Alternatively, the multi-proxy records may be explained by a shallowing of the MOW plume, resulting in warmer temperatures at the surface and increased influence of the colder Atlantic waters at depth.

\section{Acknowledgements}

All MEDGATE researchers are acknowledged for long discussions and their dedicated time to finish this work. This study uses samples provided by the Integrated Ocean Drilling Program, now International Ocean Drilling Program. Rocío Marino Ferrero and José Ignacio Martín Cruz are acknowledged for assisting in washing sediment samples and picking foraminifera. The research leading to these results has received funding from 
the People Programme (Marie Curie Actions) of the European Union's Seventh Framework Programme FP7/2007-2013/ under REA Grant Agreement No. 290201 MEDGATE and was partially supported through Castilla y Leon project SA263U14.

\section{Author contributions}

M.v.d.S. partly picked the foraminifers for stable isotope analyse, counted the planktic foraminiferal assemblages and wrote the manuscript. F.J.S. supervised this work. F.J.J-E. provided the XRF scanning data. R.F. edited the manuscript and gave scientific advice. N.A. measured the stable isotopes. 


\section{Chapter 3.}

Controls on authigenic $\mathrm{Nd}$ and $\mathrm{Pb}$ isotopes in Gulf of Cadiz sediments over the Miocene-Pliocene boundary.

In collaboration with;

M. Gutjahr, S. Modestou, S., F.J. Sierro. 
Chapter Cover:

Miocene sediments becoming weathered by the influence of the sea at Conil de la Frontera, where Mediterranean Outflow water baths offshore . 


\title{
Controls on authigenic $\mathrm{Nd}$ and $\mathrm{Pb}$ isotopes in Gulf of Cadiz sediments over the Miocene-Pliocene boundary
}

\author{
Marlies van der Schee( ${ }^{(1)}$, M. Gutjahr(2), S. Modestou(3), R. Flecker(4), F.J. Sierro(1). \\ (1) Dept. of Geology, University of Salamanca, Plaza de los Caídos s/n, 37008, Salamanca, Spain 2 \\ (2) GEOMAR Helmholtz Centre for Ocean Research Kiel, 24148 Kiel, Germany. \\ (3) SUERC, East Kilbride, G75 OQF, UK \\ (4) BRIDGE, School of Geographical Sciences, University of Bristol, University Road, Bristol, BS81SS, UK
}

\begin{abstract}
The re-establishment of the Mediterranean-Atlantic connection after a step-wise restriction during the Messinian Salinity Crisis in the Mediterranean has changed the influence of bottom water masses in the Gulf of Cadiz. This allows us to evaluate whether radiogenic neodymium (Nd) and lead $(\mathrm{Pb})$ isotopes on Fe-Mn oxyhydroxide sediment leachates can be reliably used as bottom water mass tracers for increased NE Atlantic influence during gateway restrictions and enhanced Mediterranean Outflow water (MOW) at times of increased Mediterranean-Atlantic exchange. First, regional endmember isotopic signatures are assessed in the NE Atlantic, for MOW and possible local influences from the Iberian Margins. For this, Fe-Mn crusts of various depths in the NE Atlantic corresponding to both water masses are compared with sediment leachates of the Alboran Sea, and for Nd only, modern river water signatures of the two most important rivers draining into the Gulf of Cadiz were measured. Secondly, sediment Fe-Mn oxyhydroxide leachates over the Miocene-Pliocene boundary were extracted from Gulf of Cadiz sediments and compared with the water mass endmembers. The Nd isotopic composition extracted from IODP Site U1387C Fe-Mn oxyhydroxides is more radiogenic than both MOW and NE Atlantic endmembers and likely dominated by mainly local inputs from coastal sections or riverine additions within the Gulf of Cadiz. Parallel orbital scale variations as XRF scanning Canorm hints towards a dominant influence from the release of Rare Earth Elements from suspended river sediments in a process called boundary exchange. On the other hand, $\mathrm{Pb}$ isotopic records might be influenced by changes in bottom water mass, however, due to inconsistent and insufficient data of the Fe-Mn crusts and Alboran Sea sediment leachates, this cannot be proven.
\end{abstract}

\section{Introduction}

The Mediterranean Sea and the Atlantic Ocean are connected to each other through the Gibraltar Strait. However, the corridor configuration was dramatically different in the late Miocene. During the late Tortonian, two gateways existed in southern Spain and northern Morocco (e.g. Benson et al., 1991). These corridors became successively restricted ultimately leading to the Messinian Salinity Crisis (MSC; 5.33-5.97 Ma) in the Mediterranean Sea causing the deposition of the Messinian evaporites (e.g. Hsu et al., 1973). The end of the Messinian is marked by a basin wide discontinuity in the Mediterranean marking a change from shallow to deep marine depositional 
environments, known as the Miocene-Pliocene boundary. These deposits are probably the clearest evidence for the re-established connection between the Mediterranean and Atlantic. After the onset of Mediterranean Outflow Water (MOW) in the Gulf of Cadiz, a large contourite depositional system developed as revealed in seismic 3D images from about 4.2-4.5 Ma (e.g. Expedition 339 Scientists, 2012; Hernández-Molina et al., 2006). Geochemical information towards regional circulation patterns during this major oceanographic reorganisation are rather sparse. For instance, on the Atlantic side of the Gibraltar Strait, radiogenic isotopic bottom water mass tracers have to date not been used to directly establish Mediterranean-Atlantic circulation dynamics during the initial stage of MOW formation.

Particularly over the last decade, the radiogenic neodymium isotopic composition $\left({ }^{143} \mathrm{Nd} /{ }^{144} \mathrm{Nd}\right)$ has been increasingly used to trace the origin of water masses (e.g. Böhm et al., 2015; Dausmann et al., 2015; Osborne et al., 2014). Neodymium isotopic compositions are usually given in $\varepsilon_{\mathrm{Nd}}$, where $\varepsilon_{\mathrm{Nd}}=\left(\left[\left({ }^{143} \mathrm{Nd} /{ }^{144} \mathrm{Nd}\right)_{\text {sample }} /\left({ }^{143} \mathrm{Nd} /{ }^{144} \mathrm{Nd}\right)\right.\right.$ chur $\left.]-1\right){ }^{*} 10000$ and $\left({ }^{143} \mathrm{Nd} /{ }^{144} \mathrm{Nd}\right)_{\text {chur }}=0.512638$ (Jacobsen and Wasserburg, 1980). Production of ${ }^{143} \mathrm{Nd}$ from its mother nuclide ${ }^{147} \mathrm{Sm}$ takes place with a half-live of $106 \mathrm{Ga}$. Furthermore, depending on lithology, continental sequences exhibit variable $\mathrm{Sm} / \mathrm{Nd}$, leading to variable $\varepsilon_{\mathrm{Nd}}$ on geological timescales. While old cratonic sequences yield the lowest $\varepsilon_{\mathrm{Nd}}$, representing the unradiogenic end of the spectrum, modern Mid-oceanic Ridge Basalts carry the most radiogenic Nd isotopic signatures. In the modern ocean, this results in North Atlantic deep waters mostly influenced by old geological terrains that are characterized by unradiogenic $\mathrm{Nd}$ with typically unradiogenic $\varepsilon_{\mathrm{Nd}}$ of up to -13.7 (Stichel et al., 2015) compared to those of the Pacific or the Southern Ocean (up to $-5.9 \varepsilon_{\mathrm{Nd}}$; Molina-Kescher et al., 2014) dominated by younger lithologies. Neodymium is transferred to the oceans in dissolved, colloidal, or particulate form via rivers or dust carrying the characteristic isotopic composition its source region (Frank, 2002). Away from ocean margins, $\mathrm{Nd}$ has a residence time of 200-1000 years (Tachikawa et al., 1999), below or on the order of the mixing time of the ocean, and is therefore considered a quasi-conservative proxy for changes in sources and mixing of water masses (Frank, 2002). Neodymium has been established as a powerful alternative geochemical proxy besides classical tracers such as stable carbon and oxygen isotopes $\left(\delta^{13} \mathrm{C}, \delta^{18} \mathrm{O}\right)$. While not affected by biological processes, $\mathrm{Nd}$ in places suffers from different caveats. For example, pre-formed Fe-Mn coatings on either fluvial or eolian detrital material can disturb the proxy as bottom water tracer (Bayon et al., 2004 and references therein). To circumvent these pitfalls, it is recommended to verify reductively extracted $\mathrm{Nd}$ isotope compositions from bulk sediment leachates with those of separated cleaned foraminiferal test fractions from within the same sediments (Tachikawa et al., 2014). Both mechanically cleaned foraminifera or alternatively fossil fish teeth/bones are thought to be insensitive to detrital contamination (Elmore et al., 2011; Palmer and Elderfield, 1985; Roberts et al., 2012, 2010) and serve as the best possible tool in ancient sedimentary settings to test whether reductively extracted bulk sediment ${ }^{143} \mathrm{Nd} /{ }^{144} \mathrm{Nd}$ indeed represent prevailing local pore water $\mathrm{Nd}$ isotope compositions (e.g. Blaser et al., 2016). In addition, the fundamental assumption that Nd isotopic compositions in the authigenic Fe-Mn oxyhydroxide fraction of sediments, foraminifera or fish teeth reflect the isotopic composition of regional bottom waters above sediment sites has been called into question (Abbott et al., 2015) and is commonly referred to in context of boundary exchange (cf. 
Lacan and Jeandel, 2005). Boundary exchange is a process that describes the partial dissolution of the particulate phase and isotopic exchange with dissolved $\mathrm{Nd}$ within the pore waters of marine sediments that is capable of altering the regional bottom water composition of water masses (e.g. Arsouze et al., 2007; Lacan and Jeandel, 2005; Tachikawa et al., 1999; Wilson et al., 2013, 2012). In such a scenario Rare Earth Elements (REE) released within marine sediments (e.g. Abbott et al. 2015 Geology; Abbott et al. 2016 EPSL) or from suspended river sediments can alter the bottom water Nd isotopic compositions (Rousseau et al., 2015).

Lead $(\mathrm{Pb})$ consists of four stable isotopes, of which three $\left({ }^{206} \mathrm{~Pb},{ }^{207} \mathrm{~Pb}\right.$ and $\left.{ }^{208} \mathrm{~Pb}\right)$ have also been produced by radiogenic decay from their mother nuclides ${ }^{238} \mathrm{U},{ }^{235} \mathrm{U}$ and ${ }^{232} \mathrm{Th}$, respectively. ${ }^{204} \mathrm{~Pb}$ is the only non-radiogenic (primordial) stable isotope. In addition to dissolved terrigenous input, $\mathrm{Pb}$ is also introduced in the ocean by hydrothermal activity and is most often of local importance (Barrett et al., 1987; Frank, 2002). Pb is removed from the water column within 10-100 years (Henderson and Maier-Reimer, 2002; Schaule and Patterson, 1981), hence significantly faster than $\mathrm{Nd}$. Particularly in the transition from physical glacial to chemical weathering regimes preferential dissolution of soluble accessory $\mathrm{U}$ - or Th-rich mineral phases can lead to the effect that the $\mathrm{Pb}$ isotopic runoff signal is more radiogenic than the bulk source composition (Crocket et al., 2012; Gutjahr et al., 2009; Kurzweil et al., 2010). In such cases, radiogenic $\mathrm{Pb}$ from accessory phases are preferentially released over stable ${ }^{204} \mathrm{~Pb}$ (Erel et al., 1994; Harlavan and Erel, 2002; Harlavan et al., 2009) and is commonly termed incongruent weathering. Whether such an effect may also occur under arid or semi-arid conditions in subtropical settings remains to be tested. The integrity of the $\mathrm{Pb}$ isotope proxy cannot be tested with core-top studies due to anthropogenically altered $\mathrm{Pb}$ isotopic signatures, however, mass balance calculations demonstrate that the $\mathrm{Pb}$ isotope signature of Fe-Mn coatings are not sensitive to detrital contamination on sediment cores at least along the Blake Ridge (Gutjahr et al., 2007). The best possible test is to compare ferromanganese crust-derived compositions with reductively leached Fe-Mn oxyhydroxides in marine sediment.

The $\mathrm{Nd}$ and $\mathrm{Pb}$ isotopic signatures are incorporated into various fossil archives, including Fe-Mn crusts (e.g. Abouchami et al., 1999; M. Frank, 2002; Muiños et al., 2013; Reynolds et al., 1999), reductively cleaned foraminifers (Ivanovic et al., 2013; Vance et al., 2004), authigenic Fe-Mn oxyhydroxides in marine sediments (Böhm et al., 2015; Pahnke et al., 2008; Piotrowski et al., 2005; Stumpf et al., 2010), uncleaned foraminifera (Huang et al., 2014; Noble et al., 2013; Roberts and Piotrowski, 2015; Tachikawa et al., 2014), fossil fish teeth and fish debris (Martin and Scher, 2004; Newkirk and Martin, 2009) and deep-sea corals (Van de Flierdt et al., 2006). Conversely, in contrast to $\mathrm{Nd}$, it is thought that $\mathrm{Pb}$ isotopic compositions in fish bones and teeth fragments are no reliable water mass tracers due to presence of initial $\mathrm{Pb}$, variable uptake and loss what leads to an open system behaviour (Basak et al., 2011). Archives of deep-sea corals and Fe-Mn crusts are not always available and high-resolution studies for handpicked foraminifera and fish teeth studies are time consuming. Sedimentary authigenic Fe-Mn oxyhydroxide leaching is a quick and - if done with great care - in many locations robust archive to reconstruct the isotopic evolution of bottom water masses in higher resolution studies, for both $\mathrm{Nd}$ and, although to date less extensively 
studied, Pb isotopes (Basak et al., 2011; Blaser et al., 2016; Gutjahr et al., 2009, 2007; Osborne et al., 2014).

Authigenic Fe-Mn oxyhydroxides form in the uppermost centimetres within marine pore waters (e.g. Haley et al., 2004), incorporating dissolved trace metals and particular $\mathrm{Nd}$ and $\mathrm{Pb}$ isotopic compositions of ambient bottom water. First, detrital particles from the continents and along marine continental margins release their easy leachable components to the seawater (Bayon et al., 2004, and references within). Afterwards, desorption of REE for the newly formed Fe-Mn coating on sediment particles occur on the seafloor scavenged from pore waters, where REE concentrations are highest (Haley et al., 2004). If isotopic signatures from specific water masses are known for a certain time, the radiogenic isotopic composition on the Fe-Mn coating allows the reconstruction of provenance of past bottom water mass. However, sediment leaching has not always appeared to provide a reliable reconstruction of seawater Nd (Blaser et al., 2016; Elmore et al., 2011; Roberts et al., 2010; Wilson et al., 2013), in which preformed Fe-Mn coatings before acquiring its isotopic signature at the sediment-water surface are troublesome for the purpose of the use of isotopic ratios as bottom water tracers.

In this study, we evaluate whether radiogenic $\mathrm{Nd}$ and $\mathrm{Pb}$ isotopic compositions can be reliably used as an appropriate bottom water mass tracer to enable isotope geochemical identification of the presence of MOW in the Gulf of Cadiz just after the MSC over NE Atlantic waters. The key challenge in this setting is the extraction of authigenic Fe-Mn oxyhydroxide compositions in relatively shallow water depth in a continental margin setting, a setting notoriously suspect for promoting boundary exchange for Nd (Lacan and Jeandel, 2005; Stichel et al., 2015). Both Nd and $\mathrm{Pb}$ isotopic compositions were measured on sediment leachates for a high resolution study. The sources for both radiogenic isotope systems can be of different sources and scavenging behaviour of $\mathrm{Nd}$ and $\mathrm{Pb}$ is not identical, thus measuring coupled $\mathrm{Nd}$ and $\mathrm{Pb}$ isotope compositions should provide a better understanding of key controls behind extracted radiogenic isotopic compositions in the marginal setting in the Gulf of Cadiz. Leachate bulk sediment oxyhydroxide results are compared to $\mathrm{Fe}-\mathrm{Mn}$ crust $\mathrm{Nd}$ and $\mathrm{Pb}$ isotope data to investigate characteristic isotopic compositions of both the MOW and NE Atlantic during the studied time period (Abouchami et al., 1999; Muiños et al., 2008). Finally, radiogenic isotopes presented here are compared with previously published foraminiferal benthic and planktic stable $\delta^{13} \mathrm{C}$ and $\delta^{18} \mathrm{O}$ and elemental XRF scanning data (Van der Schee et al., 2016).

\section{Material and Methods}

\subsection{Material and age constraints}

Sediments from Integrated Ocean Drilling Program (IODP) Site U1387 from 731.20 to 865.85 meter below sea floor (mbsf) are used to construct $\mathrm{Nd}$ and $\mathrm{Pb}$ isotope records ( $36^{\circ} 48.321^{\prime} \mathrm{N}$; $7^{\circ} 43.1321^{\prime} \mathrm{W}$ at 559 m water depth; Stow et al., 2013; Fig. 3 in Introduction). Today, Site U1387 is located in the less active Mediterranean Upper Water flow (Fig. 1 in Chapter 1; Cabeçadas et al., 2002; HernándezMolina et al., 2014). This sediment core is the only available spanning the Miocene-Pliocene 
boundary in a relatively deep marginal marine settings, but can be compared to onshore reference sediment cores and section in south west Spain (borehole Montemayor-1; Pérez-Asensio et al., 2014; Pérez-asensio et al., 2012; Pérez-Asensio et al., 2012; Van den Berg et al., 2015) and northwest Morocco (Loulja section; Van der Laan et al., 2012, 2006). The age model for IODP Hole U1387C was established combining bio-, magneto- and cyclostratigraphic methods (Van der Schee et al., 2016). Precise tuning to the insolation curve was not possible given numerous coring gaps. Analysed sediments were deposited between 5.7 to $5.0 \mathrm{Ma}$ (731.20 and $865.85 \mathrm{mbsf}$ ) and the Miocene-Pliocene boundary was identified at about 826 mbsf (Van der Schee et al., 2016).

If coring gaps allowed, sediment samples from continuous sections were taken every two metres. Consequently, a time resolution of about every $\sim 20$ ky for the Miocene and every $\sim 8$ ky for the Pliocene are obtained. In addition, three sedimentary cycles, interpreted as orbitally precessionally controlled, were sampled in higher resolution to disentangle millennial-scale natural variability. A sediment samples was taken from $0.41 \mathrm{mbsf}$ to compare sediment-derived authigenic $\mathrm{Nd}$ isotope signatures with today's MOW oceanographic signatures.

In addition to sediment samples from Hole U1387C, reference authigenic Fe-Mn oxyhydroxide radiogenic isotope compositions from ODP Site 978 from the eastern Alboran Sea $\left(36^{\circ} 13.87^{\prime} \mathrm{N}, 2^{\circ}\right.$ $3.42^{\prime} \mathrm{W}$ at $1929 \mathrm{~m}$ water depth) are used to evaluate the MOW endmember during the late Miocene and early Pliocene. In Hole ODP 978, two Pliocene samples were taken close to the planktic foraminiferal biostratigraphic events of the last common occurrence of Globorotalia margaritae (3.98 Ma; Lourens et al., 2004) and the first occurrence of Globorotalia puncticulata (4.52 Ma; Table 1; Lourens et al., 2004). Four samples containing nannofossil specimens of Retriculofenstra rotaria were dated as late Miocene with estimated ages between 6.79 and 7.41 Ma (Lourens et al., 2004).

The Guadalquivir and Guadiana Rivers were sampled to constrain the $\varepsilon_{\mathrm{Nd}}$ from the two most important rivers that drain in the Gulf of Cadiz from the Iberian Peninsula. The Guadalquivir River was sampled forty $\mathrm{km}$ from the Atlantic and at La Algaba, just north of Sevilla before the large agricultural area. The Guadiana River water samples were taken ten km for the Ocean and at Merida.

Table 1. Sample list for Site ODP 978 with accompanied depths and age estimates. Depths and used bioevents are from the (Shipboard Scientific Party, 1996), while ages of bio-events are from Lourens et al. (2004). $\mathrm{FO}=$ first occurrence, $\mathrm{LCO}=$ Last common occurrence and LO = last occurrence.

\begin{tabular}{|c|c|c|c|c|c|}
\hline \multirow[t]{2}{*}{ Sample ID } & \multirow{2}{*}{$\begin{array}{l}\text { Depth } \\
\text { [mbsf] }\end{array}$} & \multirow[t]{2}{*}{ Bio-Event } & \multicolumn{3}{|c|}{ Age [Ma] } \\
\hline & & & & $\min$ & $\max$ \\
\hline ODP 978 29R-6W $30-32 \mathrm{~cm}$ & 466.56 & LCO G. margaritae & $\sim 3.98$ & & \\
\hline ODP 978 35R-3W 65-67 cm & 518.85 & FO G. puncticulata & $\sim 4.52$ & & \\
\hline ODP 978 47R-1W $16-18 \mathrm{~cm}$ & 630.77 & Between FO and LO R. rotaria & & 6.79 & 7.41 \\
\hline ODP $97847 \mathrm{R}-3 \mathrm{~W} 122-124 \mathrm{~cm}$ & 634.99 & Between FO and LO R. rotaria & & 6.79 & 7.41 \\
\hline ODP 978 48R-1W 13-15 cm & 642.46 & Between FO and LO R. rotaria & & 6.79 & 7.41 \\
\hline ODP 978 48R-3W 121-123 cm & $644 \cdot 52$ & Between FO and LO R. rotaria & & 6.79 & 7.41 \\
\hline
\end{tabular}




\subsection{Sample preparation}

\subsubsection{Bulk sediment Fe-Mn oxyhydroxide extraction}

Bulk sediment samples were used to extract the authigenic Fe-Mn oxyhydroxide fraction according to a procedure modified from Gutjahr et al. (2007). Wilson et al., (2013) and Blaser et al., (2016) concluded that leaching of sediments without prior decarbonation leads to most reliable recovery of authigenic Nd compositions. Therefore, the decarbonation step is left out.

First, freeze-dried sediments (about $300 \mathrm{mg}$ ) were disintegrated overnight in deionised water (Milli-Q system) in $50 \mathrm{~mL}$ centrifuge vials. Subsequently samples were centrifuged and the supernatant discarded. Loosely adsorbed metals were removed using a $1 \mathrm{M} \mathrm{MgCl}_{2}$ solution, disintegrated, put on a shaker for $3 \mathrm{~h}$, and rinsed three times with approximately $35 \mathrm{~mL}$ deionised water to remove residual $\mathrm{MgCl}_{2}$. Sediments were thoroughly suspended with a vortex shaker following centrifugation and preceding each leaching and washing steps. The Fe-Mn oxyhydroxide fraction was leached in a $0.05 \mathrm{M}$ hydroxylamine hydrochloride $-15 \%$ distilled acetic acid $-0.01 \mathrm{Na}-$ EDTA solution, buffered to $\mathrm{pH} 4$ with $\mathrm{NaOH}$ on a shaker for $3 \mathrm{~h}$. Following centrifugation at 4000 rpm for $10 \mathrm{~min}$, the supernatant containing desired trace metals was extracted for further purification of $\mathrm{Nd}$ and $\mathrm{Pb}$ from the sample matrix. One total procedural blank was processed per batch of about 15 samples $\left(n_{(\text {TPB })}=5\right)$ as well as Fe-Mn nodule USGS standard reference materials NOD-A-1 and NOD-P-1 ( 10 mg; US Geological Survey).

\subsubsection{Foraminiferal $\mathrm{Nd}$ samples}

Sediment samples of $\sim 25 \mathrm{~g}$ were sieved through a $>150 \mu \mathrm{m}$ sieve and oven dried at $40^{\circ} \mathrm{C}$. For seven samples, a mixture of benthic and planktic foraminifers (20 mg) were handpicked and carefully crushed between two glass plates to open test-chambers. Other studies differentiate between planktic and benthic foraminifera, but a recent published study showed that all foraminiferal shells are dominated by a bottom water $\mathrm{Nd}$ isotope signature (Tachikawa et al., 2014). Foraminifera were rinsed in deionised water and methanol, and subsequently ultrasonicated multiple times until clean to remove any fine-grained particles. Efficacy of our cleaning procedure was verified under the microscope. The foraminiferal samples underwent reductive leaching steps to remove the Fe$\mathrm{Mn}$ coatings with the same prepared solutions and time intervals as used for bulk sediment samples and prepared for cation separation columns.

\subsubsection{Guadalquivir and Guadiana River water $\varepsilon_{\mathrm{Nd}}$}

The river water sample protocol is modified from previous studies approved by GEOTRACES for seawater measurements (Rickli et al., 2009; Stichel, 2010; Zimmermann et al., 2009). Two litres of water were filtered through a $0.45 \mu \mathrm{m}$ nitrocellulose membrane with use of acid-cleaned pesticide dispenser within 6 hours after collection. The samples were acidified to a pH of 2 with $4 \mathrm{~mL} 6 \mathrm{M}$ $\mathrm{HCl}$ and pre-concentrated by co-precipitation of the REE with Fe-chloride ( $5 \mathrm{mg}$ Fe per $\mathrm{L}$ filtrated water), in form of dissolved $\mathrm{FeCl}_{3}$ ( $\geq 99.99 \%$ pure on trace metal basis) in $6 \mathrm{M} \mathrm{HCl}$ and equilibration was allowed for $24 \mathrm{~h}$. The $\mathrm{pH}$ was brought back to 8 with an ammonia solution (25\% suprapure) to 
co-precipitate the dissolved trace metals with the $\mathrm{FeOOH}$. The supernatant was discarded, samples were dried and prepared for cation separation columns. While tubes, pumps and bottles of the samples were new and thoroughly cleaned in $\mathrm{HNO}_{3}$ at SUERC in Glasgow or Salamanca University laboratories, due to logistical problems the procedural blank was prepared in a bottle that was used once before, although left for two weeks in $1 \mathrm{M} \mathrm{HNO}_{3}$ and rinsed multiple times with deionised water. Therefore, the blank contribution might be unrealistically large. Still, a blank correction has been applied by subtracting the total weight of the Nd blank with respective $\varepsilon_{\mathrm{Nd}}$ of the total weight of $\mathrm{Nd}$ in the sample, shifting $\varepsilon_{\mathrm{Nd}}$ values not more than $0.6 \varepsilon \mathrm{Nd}$.

\subsection{Sample purification and mass spectrometric measurements}

$\mathrm{Pb}$ and $\mathrm{Nd}$ isotopes were isolated using standardised protocols. For $\mathrm{Pb}$ anion exchange columns (AG1-X8 resin) were employed. Cation exchange chromatography (Biorad 50W-X8 resin) and Eichrom Ln-spec ion column chemistry was used for $\mathrm{Nd}$ purification. Purified concentrations were determined on $10 \%$ of the purified sample on an Agilent Quadrupole MS preceding the isotopic measurements.

Isotopic compositions of the sediment leachates were measured on a Nu Plasma Multi Collector Inductively Coupled Plasma Mass Spectrometer (MC-ICP-MS) during six analytical sessions operated at the GEOMAR Helmholtz Centre for Ocean Research Kiel. The long-term external mass spectrometric reproducibility of standards are listed in Table 2 . The external $2 \sigma$ reproducibility is given, unless the internal errors were larger $(\mathrm{Nd}, \mathrm{n}=4$, of which 2 samples were repeated; $P b, n=0$ ). Afterwards, $\mathrm{Nd}$ isotopic data was corrected for post-depositional ${ }^{143} \mathrm{Nd}$ ingrowth with a half-live of ${ }^{147} \mathrm{Sm}$ of $1.06 * 10^{11} \mathrm{y}$ thereby deriving $\varepsilon_{\mathrm{Nd}(\mathrm{T})}$ from $\varepsilon_{\mathrm{Nd}(0)}$. $\varepsilon_{\mathrm{Nd}(\mathrm{T})}$ were calculated using the average ${ }^{147} \mathrm{Sm} /{ }^{144} \mathrm{Nd}$ of 0.13915 identically to the approach used by Ivanovic et al. (2013). Foraminiferal and river water samples containing only small amounts of $\mathrm{Nd}$ (within 2 and $10 \mathrm{ng}$ ) were measured on a Thermo Scientific Neptune Plus MC-ICP-MS at GEOMAR Kiel during two sessions. Blank contributions of the different sample types are listed in Table 3. The relatively large blank for the water samples will be further discussed in Section 4.1.1.

Table 2. The $2 \sigma$ reproducibility of Merck and SPEX standard solution ( 5 and $25 \mathrm{ppb}$, respectively) measured on the Thermo Neptune Plus. Standards JNDi-1 (Nd; 50 and 100 ppb), NIST NBS-982 (Pb; 40 ppb) and fully processed NIST NOD-A-1 and NOD-P-1 (50 ppb Nd; $40 \mathrm{ppb} \mathrm{Pb}$ ) through the leachate protocol are measured on the Nu Plasma MC-ICP-MS. The repetitions of measurements are given under ' $n$ '.

$\varepsilon_{\mathrm{Nd}} \quad \mathrm{n} \quad{ }^{208} \mathrm{~Pb} / 204 \mathrm{~Pb} \quad{ }^{207} \mathrm{~Pb} / 204 \mathrm{~Pb} \quad{ }^{206} \mathrm{~Pb} / 204 \mathrm{~Pb} \quad{ }^{208} \mathrm{~Pb} /{ }^{206} \mathrm{~Pb} \quad{ }^{207} \mathrm{~Pb} /{ }^{206} \mathrm{~Pb} \quad \mathrm{n}$

\section{Neptune Plus}

Merck $5 \mathrm{ppb}$

SPEX $25 \mathrm{ppb}$

$0.86 \quad 17$

0.3917

\section{Nu Plasma}

\begin{tabular}{|c|c|c|c|c|c|c|c|c|}
\hline $\begin{array}{l}\text { JNDi-1 (50 ppb Nd) } \\
\text { NBS-19 (40 ppb Pb) }\end{array}$ & 0.37 & 153 & 0.0162 & 0.00634 & 0.0121 & 0.000204 & 0.000049 & 102 \\
\hline $\begin{array}{l}\text { NOD-A-1 (50 ppb Nd) } \\
(40 \mathrm{ppb} \mathrm{Pb})\end{array}$ & 0.35 & 5 & 0.0157 & 0.00520 & 0.0064 & 0.000343 & 0.000110 & 9 \\
\hline $\begin{array}{l}\text { NOD-P-1 }(50 \mathrm{ppb} \text { Nd) } \\
(40 \mathrm{ppb} \mathrm{Pb})\end{array}$ & 0.53 & 9 & 0.0244 & 0.00992 & 0.0104 & 0.000654 & 0.000291 & 9 \\
\hline
\end{tabular}


Table 3. Individual and average total procedure blank concentrations, as well as maximum possible contribution to the samples. The total number of processed blanks are given under ' $n$ '.

\begin{tabular}{lcccc} 
& Weight (pg) & Average (pg) & Max contribution (\%) & $\mathrm{n}$ \\
\hline Nd & & & & \\
Sediment leachates & $53-201$ & 100 & 0.48 & 5 \\
Foraminifera & 68 & & 2.76 & 1 \\
River samples & 960 & & 37.55 & 1 \\
Pb & & & & \\
Sediment leachates & $43-326$ & 127 & 0.53 & 6
\end{tabular}

\section{Results}

\subsection{Fe-Mn oxyhydroxide $\mathrm{Nd}$ and $\mathrm{Pb}$ isotope records}

$\mathrm{Nd}$ isotopic compositions of bulk sediment leachates from Hole U1387C are strikingly invariable given measurement uncertainty over the Miocene-Pliocene boundary (Fig. 1). Compositions vary within -8.2 to $-9.4 \varepsilon_{\mathrm{Nd}(\mathrm{t})}$ and a clear long term trend is not apparent. The core top sample has a $\mathrm{Nd}$ isotopic composition of $-9.70 \varepsilon_{\mathrm{Nd}(0)}$ (Fig. 1). Resemblance to other proxy records from this core and time interval are not clearly apparent (Chapter 1 and 2). Rather than anything else, the Nd isotope record parallels Canorm of the XRF scanning data, best visible from 740.80 to 748.19 and 779.2 to 786.70 (Cores 49R and 53R) indicated with black arrows in Figure 1.

${ }^{206} \mathrm{~Pb} /{ }^{204} \mathrm{~Pb},{ }^{207} \mathrm{~Pb} /{ }^{204} \mathrm{~Pb}$ and ${ }^{208} \mathrm{~Pb} /{ }^{204} \mathrm{~Pb}$ show a tendency towards more radiogenic values from the late Miocene towards the earliest Pliocene, while ${ }^{207} \mathrm{~Pb} /{ }^{206} \mathrm{~Pb}$ and ${ }^{208} \mathrm{~Pb} /{ }^{206} \mathrm{~Pb}$ ratios decrease (Fig. 2). However, these longer term trends are not large given the large degree of shorter-term variability visible from 731.20 to 748.19 and 798.40 to 805.68 mbsf (Cores $48 R, 49 R$ and $53 R$ ). Parallel variation between all $\mathrm{Pb}$ isotopic ratios are apparent from 798.40 to $805.68 \mathrm{mbsf}$ (Core $55 \mathrm{R}$ ), while a distinct dissimilar pattern is visible in ratios ${ }^{206} \mathrm{~Pb} /{ }^{204} \mathrm{~Pb}{ }^{208} \mathrm{~Pb} /{ }^{206} \mathrm{~Pb}$ and ${ }^{207} \mathrm{~Pb} /{ }^{206} \mathrm{~Pb}$ from the ${ }^{207} \mathrm{~Pb} /{ }^{204} \mathrm{~Pb}$ and ${ }^{208} \mathrm{~Pb} / 204 \mathrm{~Pb}$ the 731.20 to $748.19 \mathrm{mbsf}$ (Core $48 \mathrm{R}$ and $49 \mathrm{R}$ ).

Early Pliocene samples from ODP Site 978 reveal isotopic compositions of $-9.2 \varepsilon \mathrm{Nd}(\mathrm{T}) \quad(2 \sigma \pm 0.51$; 3.98 Ma; $466.56 \mathrm{mbsf}$ ) and $-9.3 \varepsilon_{\mathrm{Nd}(\mathrm{T})}(4.52 \mathrm{Ma}$; 518.85), while the late Miocene samples range in $\varepsilon_{\mathrm{Nd}(\mathrm{T})}$ from -9.3 to -9.9 (Table 4; p. 82; Fig. 3). Pb isotopic compositions are listed in Table 4 and envisioned in Figure 3. For the $\mathrm{Pb}$ ratios, the sample located at $642.46 \mathrm{mbsf}$ (between 6.79 to 7.41 $\mathrm{Ma}$ ) deviates from the other samples. The other samples show rather steady compositions throughout the sampled interval.

\subsection{Foraminiferal $\mathrm{Nd}$ analyses}

Foraminifera-derived $\mathrm{Nd}$ isotope compositions are generally slightly more radiogenic than the bulk sediment leachates. The oldest six foraminiferal samples are within error of the leachates, while 


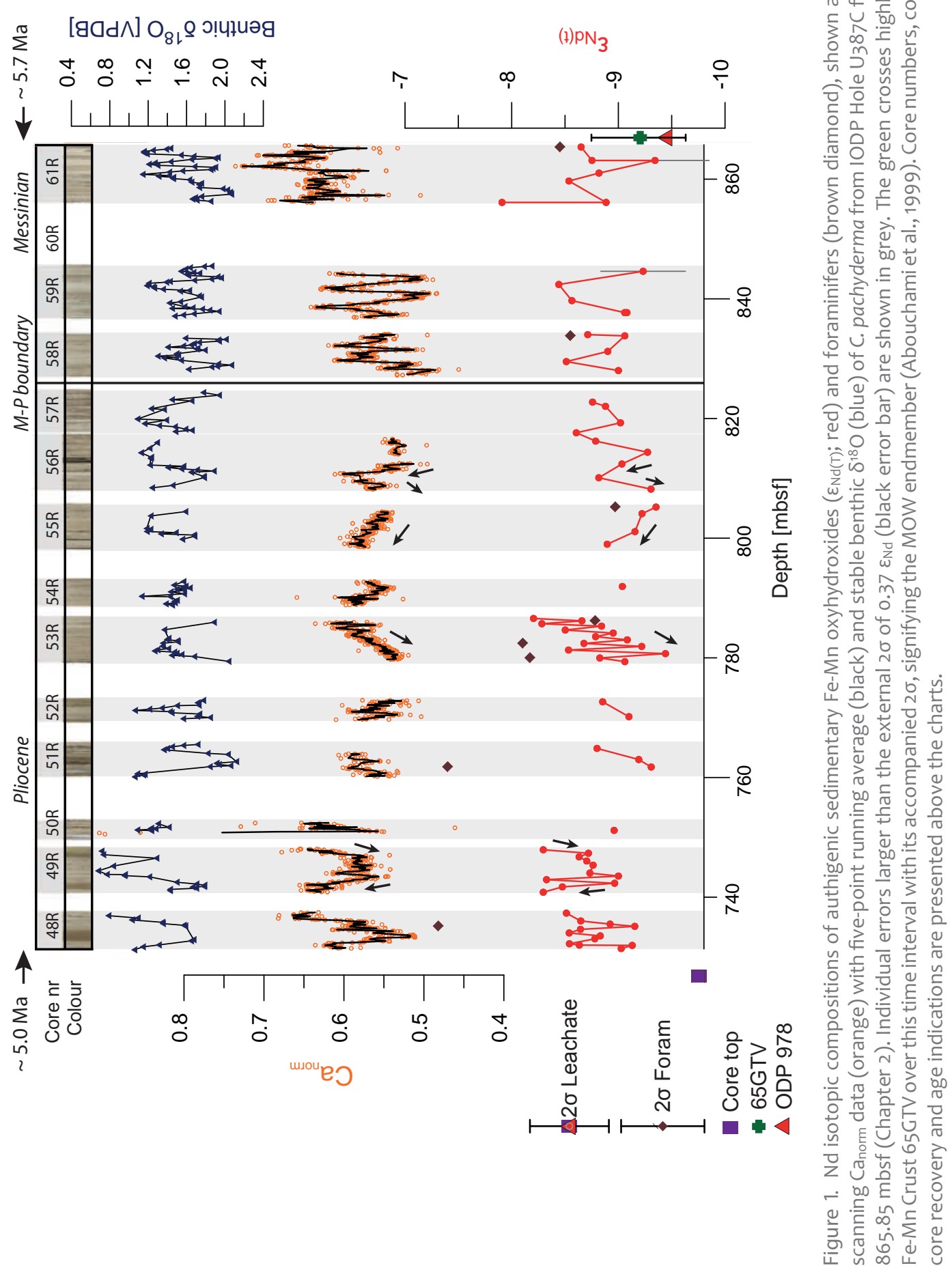


Table. 5. Nd isotopic results of river water samples of the south west Iberian Peninsula. Correction for the blank was applied due to apparently elevated blank levels.

\begin{tabular}{|c|c|c|c|c|c|c|}
\hline River & $\begin{array}{l}\text { Sample } \\
\text { location }\end{array}$ & $\varepsilon_{\mathrm{Nd}}$ & $\begin{array}{c}\text { Applicable } 2 \sigma \\
\text { in } \mathrm{e}_{\mathrm{Nd}}\end{array}$ & $\begin{array}{l}\text { Weight Nd } \\
\text { [ng] }\end{array}$ & $\begin{array}{c}\text { Blank } \\
\text { contribution [\%] }\end{array}$ & $\begin{array}{c}\varepsilon_{\mathrm{Nd}} \text { After blank } \\
\text { correction }\end{array}$ \\
\hline \multirow{2}{*}{ Guadalquivir } & La Algaba & -9.69 & 0.39 & 5.16 & 18.6 & -9.5 \\
\hline & Lebrija & -9.73 & 0.86 & 2.56 & 37.6 & -9.3 \\
\hline \multirow{3}{*}{ Guadiana } & Merida & -8.58 & 0.86 & 4.19 & 22.9 & -8 \\
\hline & Ayamonte & -7.83 & 0.39 & 6.21 & 15.5 & -7.4 \\
\hline & Blank & -10.4 & 1.56 & 0.96 & & \\
\hline
\end{tabular}

the youngest two samples are clearly more radiogenic with $\varepsilon_{\mathrm{Nd}(\mathrm{T})}$ values of up to -7.3 and deviate as much as $1.69 \varepsilon_{\mathrm{Nd}}$ from the bulk sediment-derived Fe-Mn oxyhydroxide fraction (Fig. 1).

\subsection{Guadiana and Guadalquivir River measurements}

River water results are presented in Table 5. The blank contribution is equivalent to 18.4 to $37.3 \%$ (Table 3). The Nd isotopic signature of the blank is less radiogenic than any of the water samples albeit with elevated uncertainty of $1.56 \varepsilon \mathrm{Nd}$ units. In Table 5 both originally measured as well as blank-corrected $\varepsilon_{\mathrm{Nd}}$ are presented. Blank-corrected $\varepsilon_{\mathrm{Nd}}$ of the Guadiana River is somewhat more radiogenic than the Guadalquivir River with $\varepsilon_{N d}$ values of about -8 and -9.5 , respectively.

\section{Discussion}

\subsection{Defining $\mathrm{Nd}$ and $\mathrm{Pb}$ isotopic endmembers for $\mathrm{MOW}$ and Atlantic waters during the Late Miocene-Early Pliocene}

Endmembers for MOW and NE Atlantic for the late Miocene to early Pliocene period are derived from previously published Fe-Mn crusts that are thought to correspond to the distinct water masses (Table 6). These are compared to Alboran Sea Fe-Mn sediment leachate isotopic compositions over the studied time period. The shallowest Crust 3514-1 most likely corresponds to a mixture of North Atlantic Central waters (NACW) influenced by the North Atlantic Current (NAC; which is a warm surface current transporting Gulf Stream waters to the eastern North Atlantic) and MOW. Crust 65GTV is considered to have developed in the flow path of MOW (Abouchami et al., 1999) that is derived from a mixture of Mediterranean and ambient Atlantic waters. Crust 35111 was suggested to have developed within the North East Atlantic Deep water (NEADW; Muiños et al., 2008). Isotopic signatures of the three water masses, as well as their spatial position may change over time, complicating the assignment of respective isotopic signatures to certain water masses in the past. As an example, the $\mathrm{Pb}$ isotopic ratios in crust 3511-1 deviate at $\sim 4 \mathrm{Ma}$ from older isotopic ratios towards more radiogenic values, which is interpreted as a stronger influence of radiogenic Labrador Sea water-derived $\mathrm{Pb}$ also tracing a secular $\mathrm{Pb}$ isotopic change of this water mass (Reynolds et al., 1999), and is not observed in the shallower crusts (Fig. 3; Muiños et al., 2008). In contrast, a shift of MOW to shallower depths may be represented in Crust 3514-6 from 


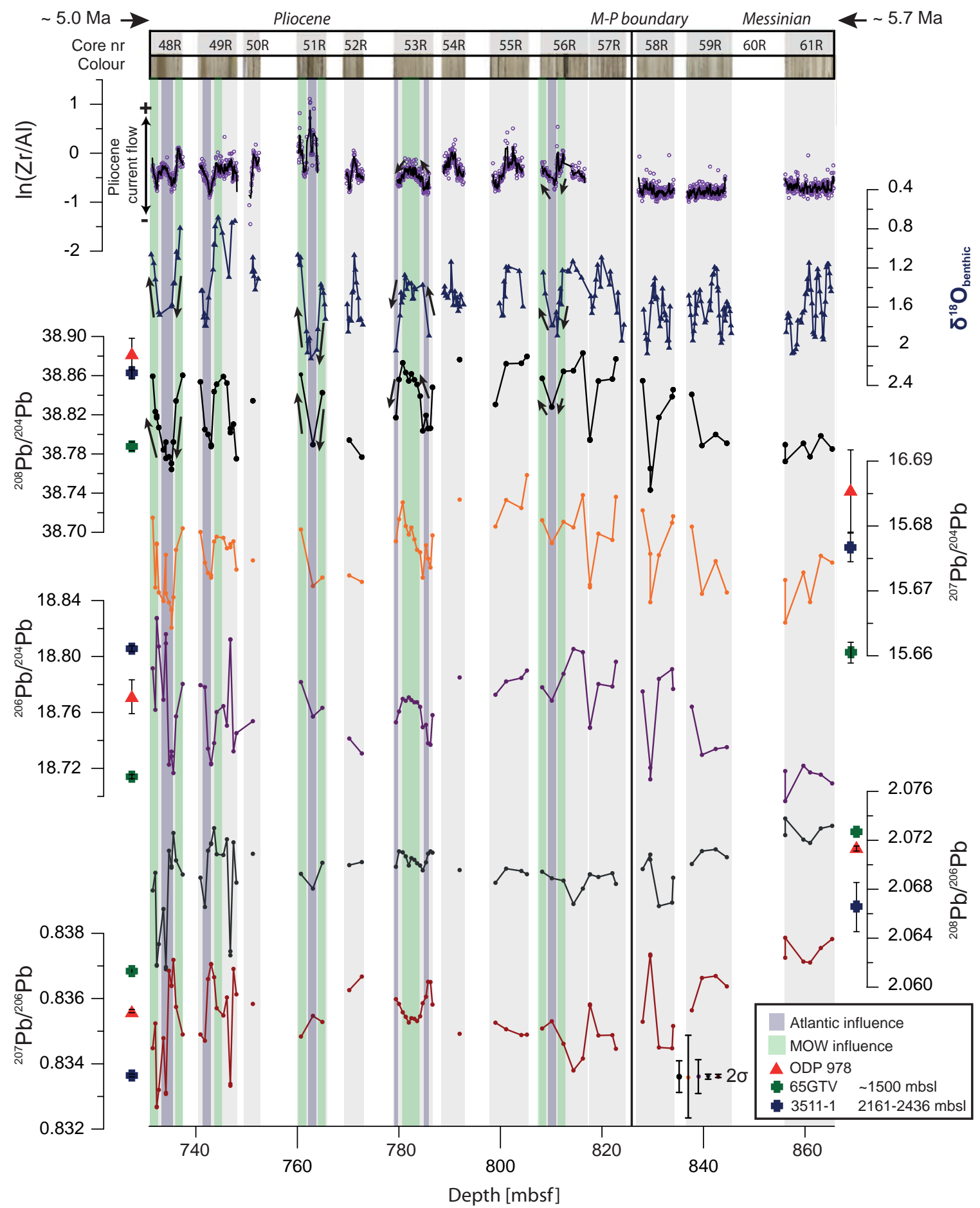

Figure 2. Fe-Mn oxyhydroxide-derived Pb isotopic compositions in IODP Hole U1387C (208Pb/204Pb (black), ${ }^{207} \mathrm{~Pb} / 204 \mathrm{~Pb}$ (orange), ${ }^{206} \mathrm{~Pb} / 204 \mathrm{~Pb}$ (purple), ${ }^{208} \mathrm{~Pb} /{ }^{206} \mathrm{~Pb}$ (grey) and ${ }^{207} \mathrm{~Pb} /{ }^{206} \mathrm{~Pb}$ (dark red). All error bars represent $2 \sigma$ external reproducibilities of repeated standard measurements. Bold crosses with accompanied $2 \sigma$ close to y-axes indicate the averages of Fe-Mn Crusts 65GTV (green) and 3511-1 (blue; Abouchami et al., 1999; Muiños et al., 2008). XRF scanning Zr/Al ratios (purple circles) with five-point running average (black) and benthic $\delta^{18} \mathrm{O}$ (dark blue) are compared with the newly retrieved data (Chapter 1). Core numbers, colour changes, core recovery and age indications are presented above the charts. 
Table 6. Locations and details of the used Fe-Mn Crusts.

\begin{tabular}{lccccl} 
Crust & Seamount & Latitude $(\mathrm{N})$ & Longitude $(\mathrm{W})$ & $\begin{array}{c}\text { Water depth } \\
{[\mathrm{mbsl}]}\end{array}$ & Reference \\
\hline $3514-6$ & Lion Seamount & $35^{\circ} 12.7-13.0^{\prime}$ & $15^{\circ} 42.03-42.36^{\prime}$ & $688-938$ & Muiños et al., 2008 \\
$65 \mathrm{GTV}$ & & $35^{\circ} 20^{\prime}$ & $15^{\circ} 20^{\prime}$ & $\sim 1500$ & Abouchami et al., 1999 \\
$3511-1$ & Josephine Seamount & $36^{\circ} 30.5-30.70^{\prime}$ & $14^{\circ} 12.48-13.04$ & $2161-2436$ & Muiños et al., 2008
\end{tabular}

$\sim 4 \mathrm{Ma}$, in which isotopic compositions in both $\varepsilon_{\mathrm{Nd}}$ and $\mathrm{Pb}$ ratios become more similar to compositions seen in Crust 65GTV. $\varepsilon_{\mathrm{Nd}(\mathrm{T})}$ shows signatures within error in Crust 65GTV and 3514-1 and distinct isotopic signatures 3511-1, Crusts 3514-6 and 3511-1 exhibit similar signatures for $\mathrm{Pb}$ isotopes prior to $4 \mathrm{Ma}$ (Figure 4). This might be explained by the shorter residence time of $\mathrm{Pb}$ compared to Nd, which is more efficiently mixed in the ocean (Muiños et al., 2008). Also, reversible scavenging of settling particles is more likely to occur for $\mathrm{Nd}$ than Pb isotopes (Frank, 2002), which can explain the discrepancy between the two records (e.g. Siddall et al., 2008; Tachikawa et al., 1999). Due to ongoing exchange in the water column between Fe-Mn coatings and surrounding water, this vertically mixes the isotope composition of the water column (Stichel et al., 2015).

Temporal resolution in the published Fe-Mn crusts $\mathrm{Nd}$ and $\mathrm{Pb}$ isotope records are quite low and age models have relatively large errors. However, the published records show small variations in isotopic compositions over the studied time interval. Therefore the average of the data points from the 4.59 to $6.06 \mathrm{Ma}$ interval from the Fe-Mn crusts are displayed in Figure 1 and 2 in comparison to the Hole $\mathrm{U} 1387 \mathrm{C}$ record (Table 7). Age models for the Fe-Mn crusts were adjusted using the newly published half-life of ${ }^{10} \mathrm{Be}$ after the publication of the crust records (Korschinek et al., 2010). In addition, the possible local signatures are derived from the river water samples and are interpreted from data that show severe offsets with the deeper marine records.

\subsubsection{Constraints towards Nd isotopic endmembers}

The core top sediment leachate sample with a $\varepsilon_{\mathrm{Nd}}$ of -9.7 is in good agreement with today's MOW of -9.4 $\varepsilon_{\mathrm{Nd}}$ (Stichel et al., 2015; Tachikawa et al., 2004). In addition, late Holocene foraminiferal coatings from the Alboran Sea indicate an $\varepsilon_{N d}$ of $-9.1 \pm 0.28$; Jiménez-Espejo et al., 2015). The small gradient that is found between the Alboran Sea and Gulf of Cadiz sites can be explained by mixing of more radiogenic Mediterranean water with a larger proportion of less radiogenic Atlantic waters of about $-11.5 \varepsilon_{\mathrm{Nd}}$ (Stichel et al., 2015).

During the late Miocene and early Pliocene, $\varepsilon_{\mathrm{Nd}}$ of ODP Site 978 are within error of the Fe-Mn crust 65GTV (Fig. 4). Therefore, given the good Nd isotopic agreement with Site ODP 978, Crust 65GTV is considered to represent a reliable Nd isotopic endmember for MOW and estimated to be about $-9.21 \pm 0.41 \varepsilon_{\mathrm{Nd}(\mathrm{T})}$ during the studied time period (Table 7). The Fe-Mn crusts in the flow path of NE Atlantic Deep Water show different isotopic signatures (Fig. 4). The NEADW has already been vigorous before 4.7 Ma (Bell et al., 2015) and most likely controlled the $\varepsilon_{\mathrm{Nd}}$ in the water depth of Crust 3511-1 since the Messinian with an $\varepsilon_{\mathrm{Nd}(\mathrm{T})}$ of about $-10.70 \varepsilon_{\mathrm{Nd}(\mathrm{T})}$. Fe-Mn crust 3514-1 shows an $\varepsilon_{\mathrm{Nd}(\mathrm{T})}$ between Crust 65GTV and 3511-1. This may indicate that both Crusts corresponds to a mixture 

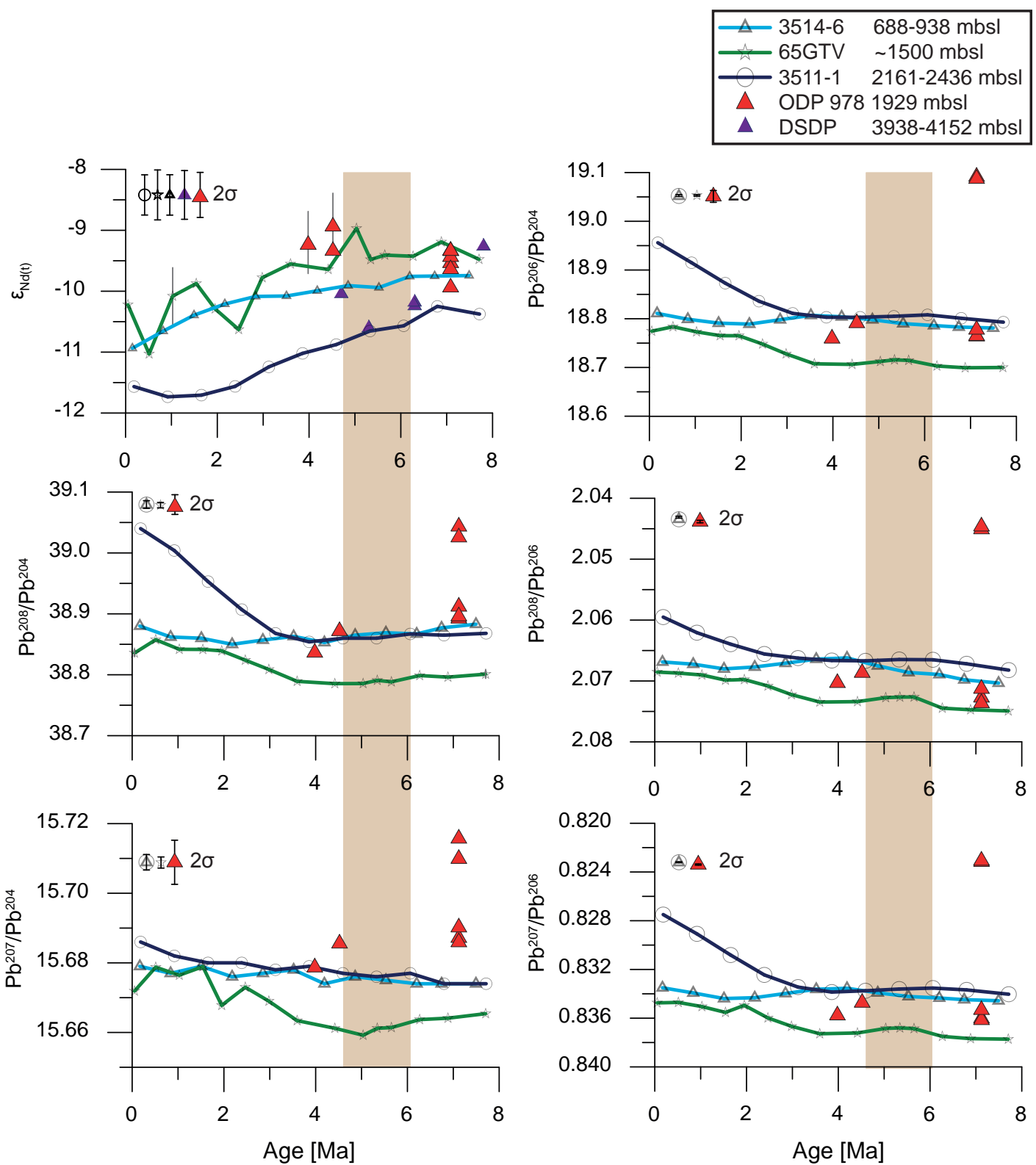

Figure 3. Comparison of published Fe-Mn crusts 3511-1 (dark blue), 3514-6 (light blue; Muiños et al., 2008) and 65GTV (green; Abouchami et al., 1999) with ODP 978 authigenic Fe-Mn oxyhydroxide-derived data (red triangles). $\varepsilon_{\mathrm{Nd}}$ bound fish remains of Atlantic DSDP 79-547 and DSDP 14-135 are indicated with purple triangles (Ivanovic et al., 2013). Grey error bars are for individual measurements if larger than the external $2 \sigma$ (black). The average of 3511-1 and 65GTV of the time interval from 4.59 to $6.06 \mathrm{Ma}$ is used as reference isotopic signatures for respectively NEADW and MOW (vertically shaded in brown). 


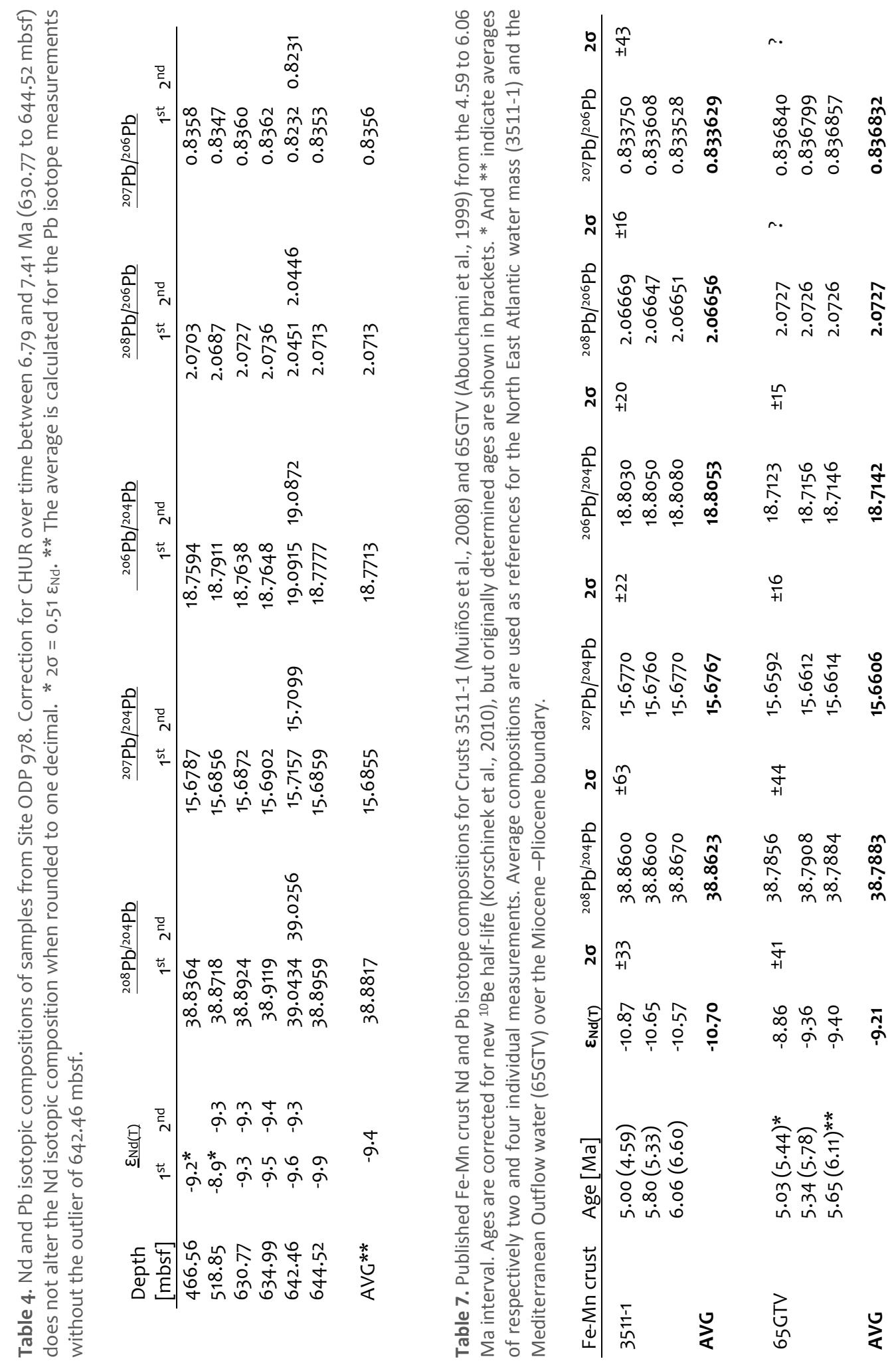


of Intermediate Atlantic water mass, similar to the NEADW, mixed with a proportion of MOW or NAC (Muiños et al., 2008). Concluding, if MOW would be of minor influence, $\varepsilon_{N d}$ are expected to be less radiogenic than about $-9 \varepsilon_{\mathrm{Nd}(\mathrm{T})}$ in the Gulf of Cadiz during the late Miocene and early Pliocene.

This $\varepsilon_{N d}$ for MOW is less radiogenic than late Miocene (7.20-7.22 Ma) Mediterranean $\varepsilon_{N d(T)}$ constraints presented in Ivanovic et al. (2013) for Mediterranean water based on two samples with reductively reductively cleaned fish remains from northern Morocco, suggesting an $\varepsilon_{\mathrm{Nd}}$ signature between -8.2 to -8.9 ( $\pm 0.4 \varepsilon_{N d}$ ). However, due to its good agreement with the ODP Site 978 leachates we consider the Fe-Mn Crust 65GTV more appropriate to use for this study. The sediment sites presented from Northern Morocco by Ivanovic et al. (2013) were located within the Rifian corridor that may have encountered significant boundary exchange thereby overprinting the regional water mass $\varepsilon_{N d}$ with a local $\mathrm{Nd}$ isotope composition via partial dissolution of the particulate phase within pore waters in Rifian corridor sediments (e.g. Abbott et al., 2016). The less radiogenic $\varepsilon_{N d}$ for NE Atlantic waters recorded in the deepest crust is in agreement with FeMn Crust MB1969.05 from the San Pablo seamount (1850 m water depth) providing NADW $\varepsilon_{N d(0)}$ compositions of -11.75 to $-11.49(n=3 ; 2 \sigma=\sim 0.35 \varepsilon N d$; Burton et al., 1999) and the 121DK Crust from the Tropic seamount with $\varepsilon_{N d(0)}$ from -11.24 to $-11.02 \varepsilon_{N d(0)}$ during the studied time interval $(n=2 ; 2 \sigma$ $=0.41 \varepsilon_{\mathrm{Nd}(0)}$; Abouchami et al., 1999). We cannot entirely exclude that $\mathrm{Nd}$ isotopic endmembers of the NE Atlantic and MOW may have been closer to each other than shown by the Fe-Mn crusts. More similar compositions are indicated by five chemically cleaned fish tooth and bone fragment samples from the late Miocene to early Pliocene from DSDP14-135 $\left(35^{\circ} 34.7^{\prime} \mathrm{N}, 10^{\circ} 42.5^{\prime} \mathrm{W} ; 4152 \mathrm{~m}\right.$ water depth) and DSDP $79-547\left(33^{\circ} 78^{\prime} \mathrm{N}, 9^{\circ} 35^{\prime} \mathrm{W} ; 3938 \mathrm{~m}\right.$ water depth) that show $\varepsilon_{\mathrm{Nd}(\mathrm{T})}$ between 9.26 and -10.60 ( $2 \sigma \pm \geq 0.4$; Ivanovic et al., 2013; Fig. 4). However, these deep marine DSDP sediments might be in turn influenced by radiogenic Antarctic Bottom water ( $\varepsilon_{N d}=-8.6$ to -9.6 ; Stichel et al., 2012) or a variation of modified AAIW (Louarn and Morin, 2011).

The local $\varepsilon_{N d}$ from the two most important rivers that drain into the Gulf of Cadiz yield isotopic compositions that are more radiogenic than estimates of the MOW or quite similar to MOW (after blank correction between -9.5 to $-7.4 \varepsilon \mathrm{Nd}(\mathrm{T})$ ), while the Guadalquivir River is less radiogenic than the Guadiana River. Although the performed measurements must be treated with caution due to the rather large blank contributions, it can be concluded that the local influence is more radiogenic than either MOW or NE Atlantic, with signatures of up to $-7.4 \varepsilon_{\mathrm{Nd}}$. Any bulk sediment leachate Nd isotope composition more radiogenic than the MOW endmember hence likely hints at significant contributions from the Gulf of Cadiz continental margins.

\subsubsection{Constraints towards $\mathrm{Pb}$ isotopic endmembers}

Site ODP $978 \mathrm{~Pb}$ isotopes do not compare well with the Fe-Mn crusts of $65 \mathrm{GTV}$; measurements are not within error of each other and various $\mathrm{Pb}$ isotope ratios of the Alboran sediment leachates, except for the ${ }^{208} \mathrm{~Pb} /{ }^{206} \mathrm{~Pb}$ ratio (Fig. 4). Even more, ratios are sometimes closer to the NE Atlantic Fe-Mn crusts 3511-1 than the one considered to represent MOW. The offset could be due to incompatibility of both proxy records, local weathering processes that influence the bulk 
sediment leachates or laboratory offsets. The final control causing this discrepancy remains unclear to us. Consequently, caution must be exercised when using any of these water mass endmembers. Local $\mathrm{Pb}$ isotopic ratios could not be measured on the river water samples since these would be overprinted by anthropogenic contributions (Alleman et al., 1999; Schaule and Patterson, 1981). Since the sediment samples were not decarbonated and hence the reductive leaching was carried out under buffered conditions (Bläser et al. 2016) we consider leaching artefacts as highly unlikely.

\subsection{Authigenic $\varepsilon_{N d}$ tracing local contributions in the Gulf of Cadiz}

The Fe-Mn oxyhydroxide-derived Nd compositions are slightly more radiogenic than constrained endmembers of the MOW and NE Atlantic water masses. This implies significant contributions from an additional source, hinting towards a local origin of the $\varepsilon_{\mathrm{Nd}}$. This local origin could either originate in (1) actually distinct bottom water $\varepsilon_{N d}$ at the sediment core site, (2) preferential extraction of preformed Fe-Mn oxyhydroxides present in the sediment during chemical sample purification, or (3) processes related to boundary exchange. Indeed, option (1) and (3) could occur in conjunction.

The oldest six foraminifera-derived $\mathrm{Nd}$ isotope signatures are within error of the sediment leachate compositions. This indicates that sediment leachates samples incorporated the same signal as the foraminiferal shells within the pore water at the sedimentation site. This suggests that the Fe-Mn coatings are not altered by preformed oxyhydroxides. In contrast, the youngest two foraminiferal measurements are significantly more radiogenic than the bulk sediment-derived authigenic $\mathrm{Nd}$ isotope record, with a maximum difference of $\sim 1.7 \mathrm{\varepsilon Nd}$. The discrepancy implies two different sources and thus, that at least one of the two proxy records does not record local bottom water compositions. Strikingly, the bulk sediment leachate compositions are closer to expected MOW than foraminiferal samples. Given the lack of further evidence, it remains unclear where the discrepancy originates from.

Observations from the Amazon plume in the Atlantic Ocean suggest that dissolved REE directly drained with river water discharge have little influence on the $\varepsilon_{\mathrm{Nd}}$, but that the release of REE from suspended river sediments dominate the signal (Rousseau et al., 2015). The parallel behaviour of $\varepsilon N d$ with XRF scanning Canorm hints towards a similar influence as from the Amazon plume (Fig. 1). Canorm is a representation of the raw counts of Ca normalized towards the total counts of the most important elements in the sediments, and is used as an inverse proxy for detrital input (Van der Schee et al., 2016b). Canorm is mainly of biogenic origin and therefore increased siliciclastic detrital input thus reduces the Canorm signal (Van der Schee et al., 2016b). Consequently variations in amount and possibly composition of the detrital input may have dominated the pore water $\varepsilon_{\mathrm{NC}}$ and thus the Fe-Mn oxyhydroxide sediment leachate record. However, the sediment leachate data and the modern river water samples from the Guadalquivir and Guadiana Rivers (about -7.4 to -9.5 $\left.\varepsilon_{N d(T)}\right)$ are isotopically relatively similar. This hints to a $\varepsilon_{N d}$ possibly influenced by regional river water input in the Gulf of Cadiz. 
In addition, our Nd isotope record apparently does not follow the XRF scanning Zr/Al pattern (Fig. 3). More specifically, parallel behaviour is clearly not observed between the $\mathrm{Nd}$ isotope record with $\mathrm{Zr} / \mathrm{Al}$ ratios from 779.20 to 786.70 (Core 53R; Fig. 3 and 4; $\mathrm{Zr} / \mathrm{Al}$ ratios is an indicator for flow strength in the early Pliocene of this record). From the multi-proxy study of stable isotopes and XRF scanning data, it is concluded that along slope current flow enhanced during periods with $\mathrm{Zr} / \mathrm{Al}$ peaks above the site location. Thus, if $\varepsilon_{\mathrm{Nd}}$ would have had responded to change in current flow, then the record must have shown isotopic variation paralleling $\mathrm{Zr} / \mathrm{Al}$ ratios. However, this is not the case. Consequently, the settle variation seen in our $\mathrm{Nd}$ isotope record is unlikely controlled by bottom water current flow variations related to MOW influence or overprinted by a secondary process.

\section{3. $\mathrm{Pb}$ isotopic record influenced by the origin of bottom waters?}

Orbital variations within the various $\mathrm{Pb}$ isotope records exhibit relatively large amplitudes, especially compared with other proxy records such as the benthic $\delta^{18} \mathrm{O}$ and XRF scanning $\mathrm{Zr} / \mathrm{Al}$ ratios. This strongly suggests that the records show real variations. In general, the $\mathrm{Pb}$ isotopic compositions fit well between the constrained Fe-Mn crusts 65GTV and 3511-1 (Fig. 3). However, to test this apparent agreement below the influence of MOW and Atlantic waters was also regarded from various XRF scanning-based proxy records (Fig. 3 shaded areas; Van der Schee et al., 2016b). Based on these independent lines of evidence it was concluded that during the Pliocene light $\delta^{18} \mathrm{O}$ were linked to increased MOW influences, while heavy $\delta^{18} \mathrm{O}$ were interpreted as influenced by enhanced Atlantic bottom waters. Zooming in from 779.2 to 786.70 mbsf (Core $53 \mathrm{R}$ ), if the Fe-Mn crust endmembers are reliable, this would lead us to interpret the record with opposite conclusions, causing strong scepticism to use the Fe-Mn crusts as reliable endmembers for this study. Interestingly, $\mathrm{Pb}$ isotope ratios of Hole $\mathrm{U} 1387 \mathrm{C}$ during the suggested increased MOW influence are consistently within error of the measured ODP 978 ratios for all isotope ratios. As a result the ODP 978 isotopic ratios may turn out to be useful as a reliable endmember for MOW, while the Fe-Mn crust derived information likely is not. However, this suggestion cannot be proven since a good reference for NE Atlantic waters is not available for the late Miocene to early Pliocene time interval. The establishment of a NE Atlantic endmember with only a few Fe-Mn sediment leachate samples that records the NE Atlantic of this age should help to resolve whether the constrained MOW endmember from ODP 978 is reliable.

Combining the radiogenic isotopic records, large variations over the studied time-period are not revealed. Both records seem to respond to changes in sedimentary depositional environment (Nd) and possibly oceanographic settings $(\mathrm{Pb})$ that, in turn, influence one another. The distinct observed patterns are related to different responses of local (reversed)-scavenging and changes of bottom water mass. The $\varepsilon_{\mathrm{Nd}}$ record shows a clear local signal, while it can neither be proven nor excluded that the $\mathrm{Pb}$ dataset traces the bottom water masses.

\section{Conclusions}

We present combined $\mathrm{Nd}$ and $\mathrm{Pb}$ isotopic ratios in Fe-Mn oxyhydroxide substrates from the Gulf of Cadiz over the Miocene-Pliocene boundary. The authigenic fraction in these sediments was 
analysed with the scope to unravel hydrographic conditions during the onset and development of Mediterranean Outflow water. It is thought that the leachates samples have acquired the isotopic signatures of bottom/pore water compositions, even though not all foraminifers Fe-Mn coating samples are within error of the sediment leachate samples. The $\varepsilon_{\mathrm{Nd}}$ data are more radiogenic than known Mediterranean and NE Atlantic endmember signatures and are most likely influenced by local sourcing within the Gulf of Cadiz. Given current understanding of the behaviour of $\mathrm{Nd}$ in the marine realm (e.g. Rousseau et al. 2015), the release of REE from suspended detrital sediments explains best the $\mathrm{Nd}$ isotopic composition.

NE Atlantic Fe-Mn crust data were incompatible with Alboran Sea sediment leachate samples for $\mathrm{Pb}$ isotopic compositions. Therefore it remains unclear whether $\mathrm{Pb}$ can be used as a bottom water tracers. However, good agreement of the sediment leachates from the Alboran Sea with the Gulf of Cadiz record at times when MOW was most likely present hints towards the usability of $\mathrm{Pb}$ as a reliable bottom water mass tracer. To a lesser extent influence of dust may have also influence the isotopic ratios, yet the ultimate control on the Gulf Cadiz $\mathrm{Pb}$ isotope composition in the studied water depth is currently underconstrained. Overall, isotope ratios seem to correspond to oceanographic and sedimentary configuration that in turn, influence one another. Despite a variety of proxies at hand at the sediment core site, no clear driver could be identified controlling the incorporated Fe-Mn oxyhydroxide signal.

\section{Acknowledgements}

All MEDGATE researchers are acknowledged for long discussions and their dedicated time to finish this work. Ana Kolevica and Tyler Goepfert provided excellent support in the GEOMAR laboratories during $\mathrm{Nd}$ and Pb sample processing. This study uses samples provided by the Integrated Ocean Drilling Program. The research leading to these results has received funding from the People Programme (Marie Curie Actions) of the European Union's Seventh Framework Programme FP7/2007-2013/ under REA Grant Agreement No. 290201 MEDGATE and was partially supported through Castilla y Leon project SA263U14.

\section{Author contributions}

M.v.d.S carried out the radiogenic analyses, wrote the manuscript and interpreted the data supervised by M.G.. S.M. helped carrying out the river sampling. F.J.S. helped interpreting the data from the perspective of the environmental setting in the Gulf of Cadiz. 


\section{Chapter 4.}

Improved biostratigraphic dating of upper Miocene sediments in the western Betics suggests late Tortonian closure of the Guadalhorce Corridor.

In collaboration with;

B.C.J. van den Berg, W. Capella, D. Simon, E. Dmitrieva, F.J. Sierro, W. Krijgsman, S. Vincent. 
Chapter Cover:

View towards Mirador and Embalse de la Tajo Encantada west of El Chorro, Spain.

Photography; Dirk Simon. 


\section{Improved biostratigraphic dating of upper Miocene sediments in the western Betics suggests late Tortonian closure of the Guadalhorce Corridor}

\section{Abstract}

Several gateways in the Betic Cordilleras connected the Mediterranean Sea with the Atlantic Ocean during the upper Miocene but the timing of closure and therefore their role prior and during the Messinian Salinity Crisis is still under debate. Especially the timing of closure of the Guadalhorce Corridor, which was probably the last existing branch connecting the Mediterranean with the Guadalquivir Basin is disputed. Difficulties assessing the timing and evolution of the Guadalhorce Corridor are caused by the lack of marine microfossils to constrain precise age determination through integrated stratigraphy. Therefore, we have to rely on dating of sediments of adjacent basins and assessing their possible relationship with this corridor. Here we present new biostratigraphic age constraints on the sediments of the Ronda Basin and Antequera region. These key areas formed the northern part of the gateway and both show a shallowing upward sedimentary succession from sandy marls to calcarenites. Planktonic biostratigraphic analyses of the marls revealed the presence of Globorotalia menardii, resulting in an age determination of late Tortonian ages, older than 7.58 Ma. This suggests that the Guadalhorce Corridor probably closed during the late Tortonian-early Messinian. Our observations are in line with results from the Arcos Basin and the previous published late Tortonian closure of the Granada Basin. This suggests that the late Tortonian period of tectonic uplift in the eastern Betics, closing the eastern branches of the Betic Corridor, was extended to the western Betics. This may have caused the observed shallowing upward environments and subsequently closed the western branches of this Corridor. This probably resulted in a late Tortonian to early Messinian closure of the Betic Corridor, well before the onset of the Messinian Salinity Crisis.

\section{Introduction}

The Betic Corridor connected the Mediterranean Sea with the Atlantic Ocean during the late Miocene and plays an important role in the history of the Mediterranean Basin. Stepwise restriction of this Corridor and the Rifian Corridor, located in northern Morocco, led to the extraordinary event of the Messinian Salinity Crisis (MSC; 5.97-5.332 Ma; Kouwenhoven et al., 2003; Roveri et al., 2014). However, the precise role of this Corridor on the onset and progress of the MSC has been under debate.

The western part of the Betic Corridor consisted of the Guadalquivir Basin, the foreland basin of the Betic Cordillera, which experienced continuous marine sedimentation from the middle to late Miocene up to the present day (González-Delgado et al., 2004; Salvany et al., 2011; Sierro et al., 
1996). The eastern part was divided in several sea branches (Fig. 2 in the Introduction), of which each closed separately due to sedimentary infill and tectonic uplift, gradually restricting Mediterranean-Atlantic exchange through southern Spain (Flecker et al., 2015; Martín et al., 2014). The most northerly branch, known as the North Betic strait, closed at 7.8 Ma (Krijgsman et al., 2000), while the branch passing through the Granada Basin closed around 7.3 Ma (Corbí et al., 2012). The youngest marine sedimentation in the Guadix Basin is dated at 7.85 Ma, even though subsequently a hiatus of more than $2 \mathrm{Ma}$ is present and therefore a later closure cannot be ruled out (Hüsing et al., 2010). It is suggested that the westernmost and probably last remaining branches known as the Guadalhorce Corridor (Martín et al., 2001) closed at 6.18 Ma (Pérez-Asensio et al., 2012). The timing of this closure, however, is based on indirect evidence through a change in benthic oxygen isotopes signatures in the Guadalquivir Basin from typical Mediterranean towards more Atlantic vales.

Difficulties assessing the timing and evolution of the Guadalhorce Corridor are caused by the lack of adequate sedimentary sequences to constrain precise dating through integrated bio-, magnetoand/or cyclostratigraphy. The sedimentary deposits in the Guadalhorce River valley are assigned on the geological map (MAGNA 50, $2^{\text {a }}$ Serie - IGME) as late Tortonian, based on regional lithostratigraphic correlations to nearby deposits close to Antequera, $12 \mathrm{~km}$ ENE of the Guadlahorce Corridor (López-Garrido and Sanz de Galdeano, 1999; Serrano Lozano, 1979). This location comprises marly intercalations with microfauna typical of the basal late Tortonian. However, Martín et al. (2001) attributes the sediments in the Guadalhorce gateway to the early Messinian (7.2-6.3 Ma), based on the occurrence of the planktic foraminiferal biostratigraphy in the Peñarrubia exposures (Fig. 1). This age is assigned mainly on the basis of the occurrences of Globorotalia miotumida, however, two influxes of G. miotumida are also known in the upper Tortonian (e.g. Krijgsman et al., 2000). To resolve these disputes, age determination on other laterally associated nearby outcrops and basins in this potential Corridor are essential.

The adjacently lying Ronda Basin is one of those associated basins and formed part of the Betic Corridor as a satellite basin of the Guadalquivir Basin (Gläser and Betzler, 2002). This Basin is located west of the Guadalhorce River valley, in the external zone of the Betic Cordillera, and is commonly assumed to have a Tortonian to early Messinian basin fill with a typical shallowing upwards sequence from deep marine marls to shallower marine calcarenites and limestones (Fig. 1; Gläser and Betzler, 2002; Rodríguez Fernández, 1982; Ruiz-Constán et al., 2009; Serrano Lozano, 1979). Dating of sediments in the Ronda Basin is mainly based on the biostratigraphic framework of Serrano Lozano (1979). However, that framework cannot be correlated to the presently used astronomically-tuned biostratigraphic framework of sections and boreholes in the Mediterranean and nearby Atlantic Margin (Krijgsman et al., 2004; Sierro, 1985; Sierro et al., 2000, 1996, 1993; Van den Berg et al., 2015; Van der Laan et al., 2006; Van der Schee et al., 2016). Therefore, verifying the age constraints with the current biostratigraphic framework of sedimentary sequences in the 


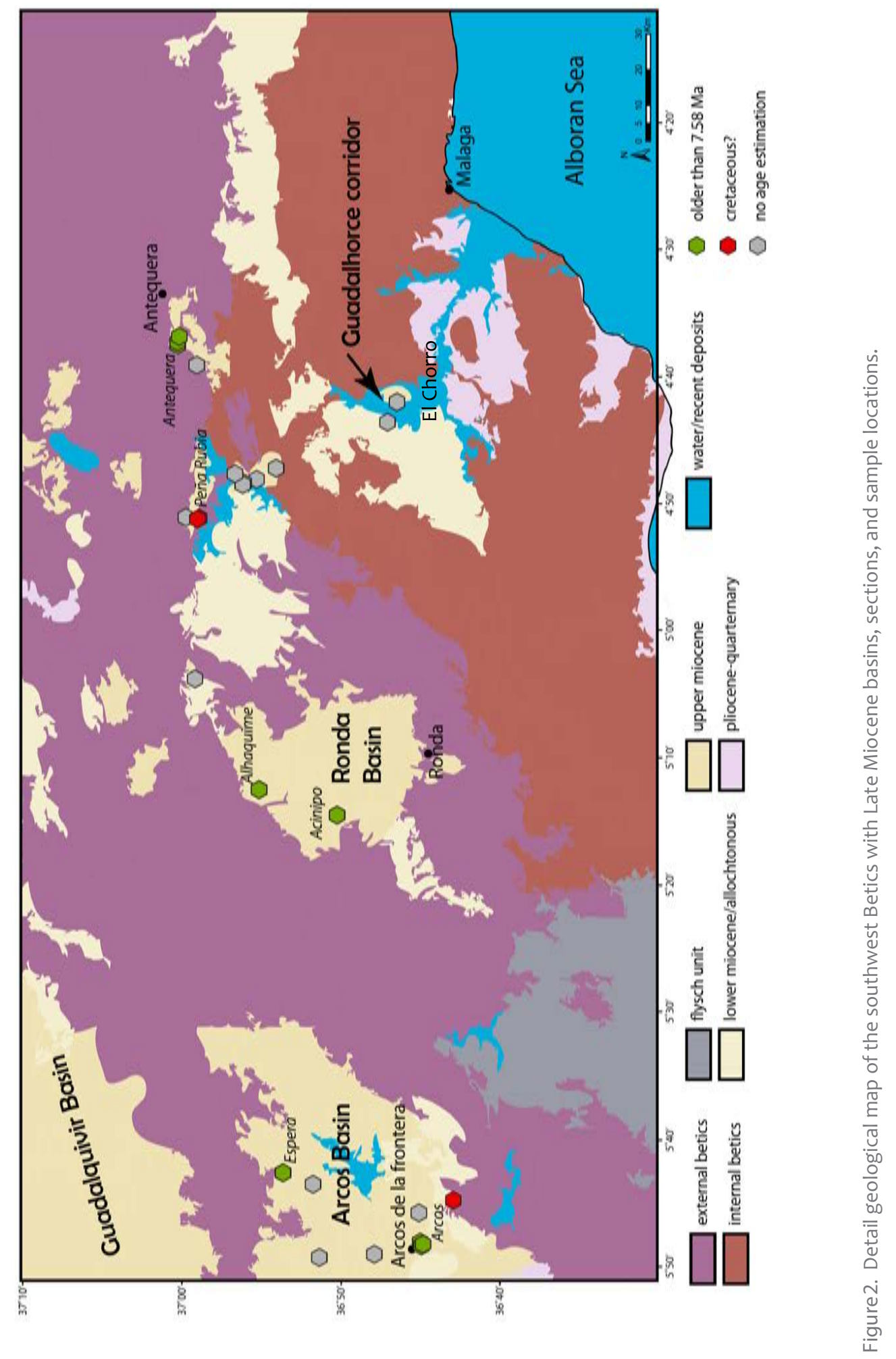


Ronda Basin and sediments associated with the Guadalhorce Corridor are essential to re-interpret the Betic Corridor evolution.

The area around Arcos de la Frontera, west of the Ronda Basin, was a satellite basin of the Guadalquivir Basin and contains a similar shallowing upwards sequence in the upper Miocene (Fig. 1). Also here, precise dating of sediments is lacking. Therefore, upper Miocene sediments from this area were dated to test consistency of changes in depositional environment in the South West Betic external zones throughout the late Miocene.

To summarize, we re-assess and improve the chronostratigraphy of sediments in the areas around Arcos de la Frontera, Antequera, the Guadalhorce River valley and Ronda Basin, based on the most up-to-date and detailed biostratigraphic framework of this region. Additionally, depositional environments are evaluated using sediment characteristics and structures. Subsequently, these findings are placed within the local geological framework and the evolution of the Betic Corridor.

\section{Methods}

We revisited the areas described above and investigated the outcrops and sections in areas marked as 'Tortonian', ‘Messinian' or 'Andalusian' on the MAGNA 50 ( 2 a Serie) - Mapa Geológico de España a escala 1:50.000 from the Instituto Geológico y Minero de España (IGME). 'Andalusian' is an obsolete geological stage used in the western part of the Guadalquivir Basin and considered to equal upper Miocene sediments (Berggren and Haq, 1976; Perconing, 1973).

The youngest sediments in the basins were targeted for qualitative biostratigraphic analyses, taking into consideration bedding planes and thus basin configurations. A total of 54 samples from sandy to silty marls were analyzed. If possible, these were carefully positioned at finer grained intervals to increase the probability of the presence of microfossils. Samples of about $100 \mathrm{~g}$ were disintegrated in water and washed over a >150 $\mu \mathrm{m}$ sieve. To date the Tortonian to Messinian sediments, biomarkers from the upper Tortonian until the lower Pliocene are reported. These include Globorotalia margaritae, Globorotalia miotumida, Neogloboquadrina acostaensis, Globorotalia menardii 4 and 5, Globorotalia scitula and Sphaeroidinellopsis with corresponding coiling directions.

\section{Results}

\subsection{Guadalhorce River valley}

The upper Miocene sequence in the Guadalhorce River valley start in the valley close to the village of El Chorro (Fig. 1) with coarse to very coarse grey sands and conglomerates with large scale erosional features (Fig. 2A). Lobes of grain-supported, boulder-bearing and more angular conglomerates are found within polymict, matrix-supported conglomerates alternating with sands. These attest to debris flows from the basin margins. Within the lower part of the sequence 
some centimeter to decimeter scale rip-up mud-clasts are found (Fig.2B). Towards the top, coarse sandstones show large scale cross-bedding, pointing predominantly to the NW (Martín et al. (2001). Despite the large amount of samples taken from outcrops within and just north of the Guadalhorce River valley, no planktic foraminiferal biomarkers were found. This is probably due to the coarse grained and shallow environmental character of the deposits found within this region.

\subsection{Ronda}

In the Ronda Basin, we studied the uppermost sequences of the late Miocene infilling. The Alhaquime section (Fig. 3) comprises of Fm. La mina (clay and marls) and Fm. De Setenil (Serrano Lozano, 1979) and are respectively marked Sequence 2 and 3 (equivalent to sections S13 and S14) in the lithostratigraphical subdivision presented by Gläser and Betzler (2002). The Acinipo section presented in this paper is equivalent to a combination of section S7 and S8 (Gläser and Betzler, 2002), and is referred to as Fm. Las Mesas by Lozano (1979). Sequence 2, at the lowest part of the Alhaquime section, consists of grey marls which become coarser-grained up sequence, forming lenses within the lowest calcarenitic layers (Fig. 3). An erosional surface, which marks the boundary between Sequence 2 and 3, is associated with a relative sea level lowering and a tectonic

(A)

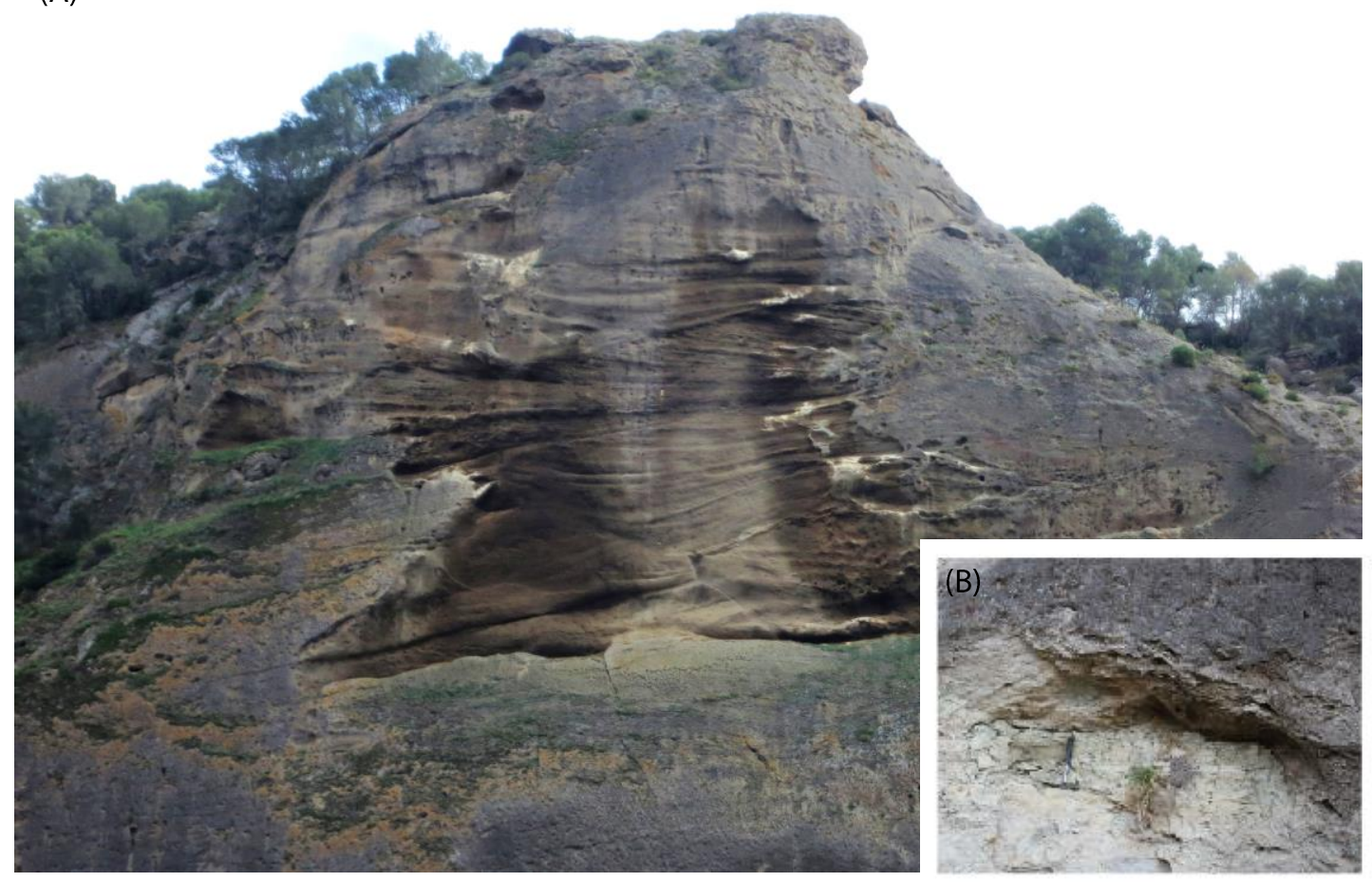

Figure 2. Photographs of the El Chorro exposure in the Guadalhorce River valley. (A) Trough cross-beds and overlying tabular cross-beds of the. Reactivation surfaces within sets of cross-bedding, with lateral spacing of some tens of meters, are present in the uppermost part of the tabular cross-bedded interval. (B) Example of a rip-up mud-clast two km west of El Chorro. 
event forming the anticline of the Sierra de las Salinas (Gläser and Betzler, 2002). Sequence 3 consists of increasingly thicker (up to $20 \mathrm{~m}$ ) deposits of sandy bryozoan calcarenites and brown to yellow siliciclastic sandstone intercalated with marls. In these sandy intervals both tabular-cross and trough-cross bedding were observed. Set thicknesses of the cross stratifications vary from $\sim 50 \mathrm{~cm}$ to $3 \mathrm{~m}$ and foreset planes dip towards the west and northwest (Fig. 3). Red algal limestones dominate Sequence 3 in the Acinipo section. Biostratigraphic samples were taken from the marls below and in between the calcarenitic alternations at Alhaquime, and just below the limestones at Acinipo. Only the samples in the marls of Sequence 2 contained planktonic foraminiferal biomarkers: G. menardii 4 sinistral, G. scitula sinistral/dextral and mainly sinistral coiling N. acostaensis.

\subsection{Antequera}

The lowest part of the Antequera sequence contains grey, fine grained to very sandy marls (Fig. 4A) which are subsequently replaced by sandy calcarenites with the marls containing microfossils, while the calcarenites show large bryozoan, ostracods, benthic foraminifera, red algae and shell fragments. The calcarenites of Antequera are more massive compared to the Ronda and Arcos basins; they show faint tabular bedding and only locally through-cross stratification. However, ubiquitous indicators of paleocurrent directions are generally lacking. The samples taken in the marls contain planktonic biomarkers G. menardii 4 sinistral, G. scitula sinistral/dextral and mainly sinistral coiling N. acostaensis.

\subsection{Arcos de la Frontera}

The lower part of the upper Miocene sequence found in the Arcos de la Frontera Basin is comprised of grey, fine to coarse grained marls, which are later replaced by sandy calcarenites. The marls contain microfossils, while the calcarenites are rich in bioclastic content, red algae, bryozoans and shell fragments. The calcarenites contain meter scale channels, tabular-cross and through-cross stratified sands. Some layers show intense bioturbation. Throughout the $\sim 50 \mathrm{~m}$ exposure at the Arcos section (Fig. 4B), a general trend is observed that the foreset-thicknesses decrease from several meters to few decimeters towards the top. Samples taken from grey, sandy marls just below the onset of the calcarenites at both Arcos and Espera contain the planktonic foraminiferal biomarkers G. menardii 4 sinistral, G. scitula sinistral/dextral and mainly sinistral coiling N. acostaensis.

\section{Discussion}

\subsection{Biostratigraphic dating}

\subsubsection{Late Tortonian age determination}

The preservation of the foraminifera is generally good, however, in many biostratigraphic samples microfauna is scarce or samples are sterile. Some samples did contain microfossils but no marker 

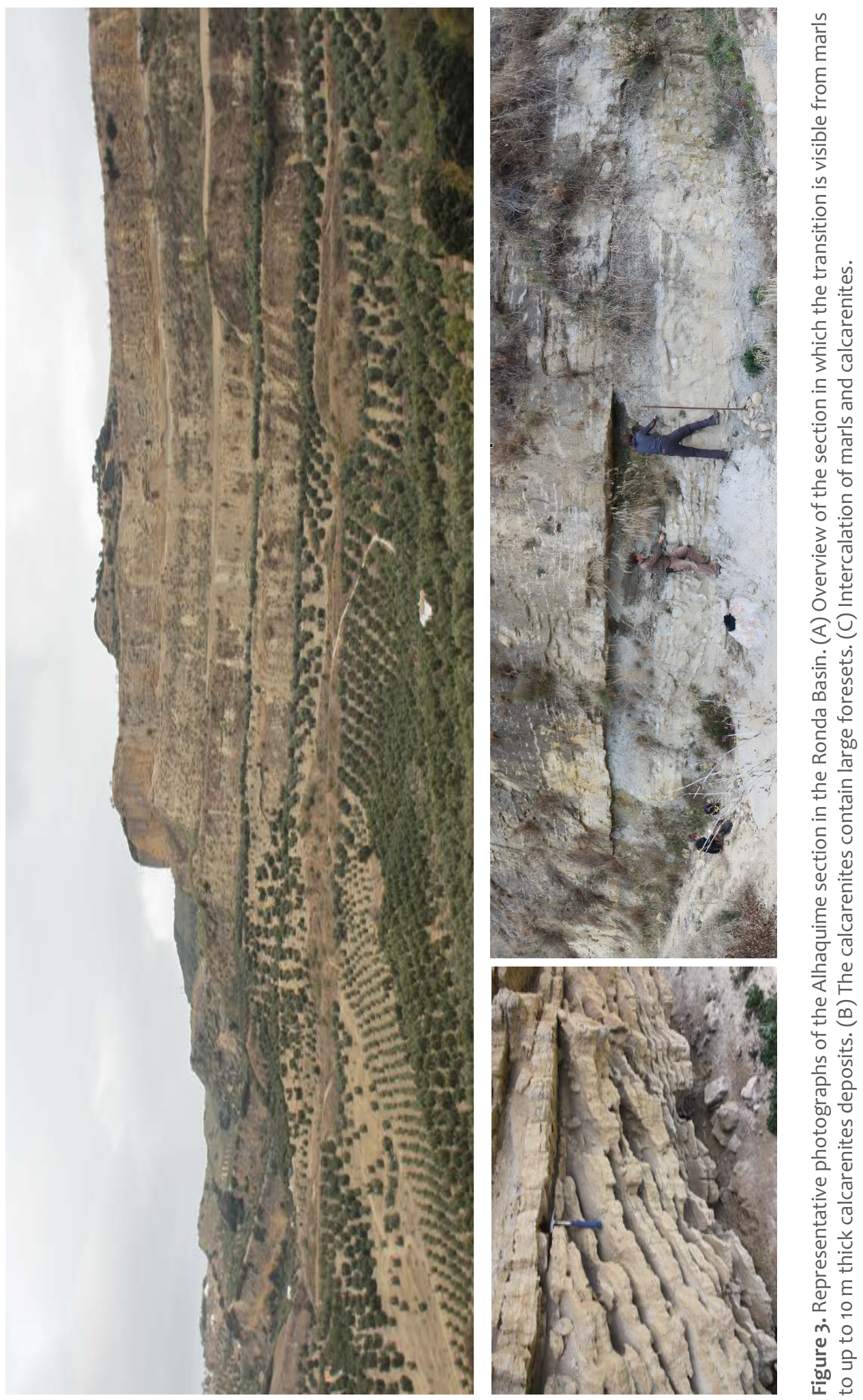
species were found. The matrix of the samples consists of, (rounded) quartz grains, silts, (secondary) gypsum, bioclastic fragments, (reworked) glauconite, detrital wood and shell fragments. These types of coarse-grained sediment severely limit the possibilities for reliable dating, due to the fact that the used biostratigraphic marker species generally live in deeper marine environments, while silty to sandy sediments are more often deposited in shallow and high energy environments, where these planktonic species do not dwell. This is evident from the amount of samples that are taken and unsuccessfully studied for age constraints (Fig. 1).

All samples that contain marker species consist of marls and sandy marls. The same planktonic biomarkers, i.e. G. menardii 4 sinistral, G. scitula sinistral/dextral and mainly sinistral coiling N. acostaensis were observed in these samples. This indicates that all these samples are older than the Last Common Occurrence (LCO) of G. menardii 4, dated at 7.58 Ma (Krijgsman et al., 1994; Lourens et al., 2004b; Sierro, 1985) and definitely older than the First Occurrence (FO) of G. menardii 5 (7.355 Ma; Hilgen et al., 1995; Krijgsman et al., 1994; Lourens et al., 2004). This is consistent with the first sinistral coiling of $N$. acostaensis, of which sinistral to dextral coiling changes are reported from around 6.35 Ma (Lourens et al., 2004b). Consequently, all the sediments in this study that were previously reported as 'Tortonian', 'Messinian' or 'Andalusian'

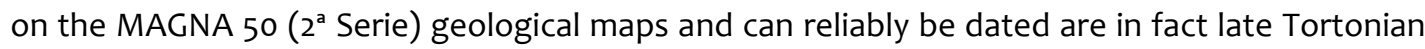
and no evidence is found for Messinian.

The dated marine silty marls in the Arcos and Ronda basins and Antequera region are subsequently replaced by calcarenites that can be in certain places up to 100 meters thick. Since there is no available method to reliably date these calcarenites, we cannot assess the exact time at which the observed marine sedimentation terminates in these basins. However, based on the fact that coarse grained deposits typically have high sedimentation rates and the reliable late Tortonian age determination of the deeper marine sediments below, the calcarenites are probably also deposited during the late Tortonian. We consider it as unlikely for the top of these sediments to reach up to an early Messinian age and highly unlikely that they are deposited during the Messinian Salinity Crisis. Unfortunately, it can neither be assessed how much (marine) sediment has been deposited and subsequently eroded on top of this late Tortonian sequence. Nonetheless, since Tortonian marine deposition is vast in the studied region, we find it unlikely that, in the case there was major Messinian marine sedimentation; all these sediments got completely eroded.

Despite age constraints based on planktonic foraminiferal biomarkers, we agree with LopezGarrido and Sanz de Galdeano (1999) that, based on their similarities in lithology, the Guadalhorce sandy deposits should be associated with the coarse-grained calcarenitic deposits in nearby regions like Ronda and Antequera. Since we assigned a late Tortonian age to these coarse grained sediments in these regions, probably the sediments within the Guadalhorce region were also deposited in the late Tortonian. 


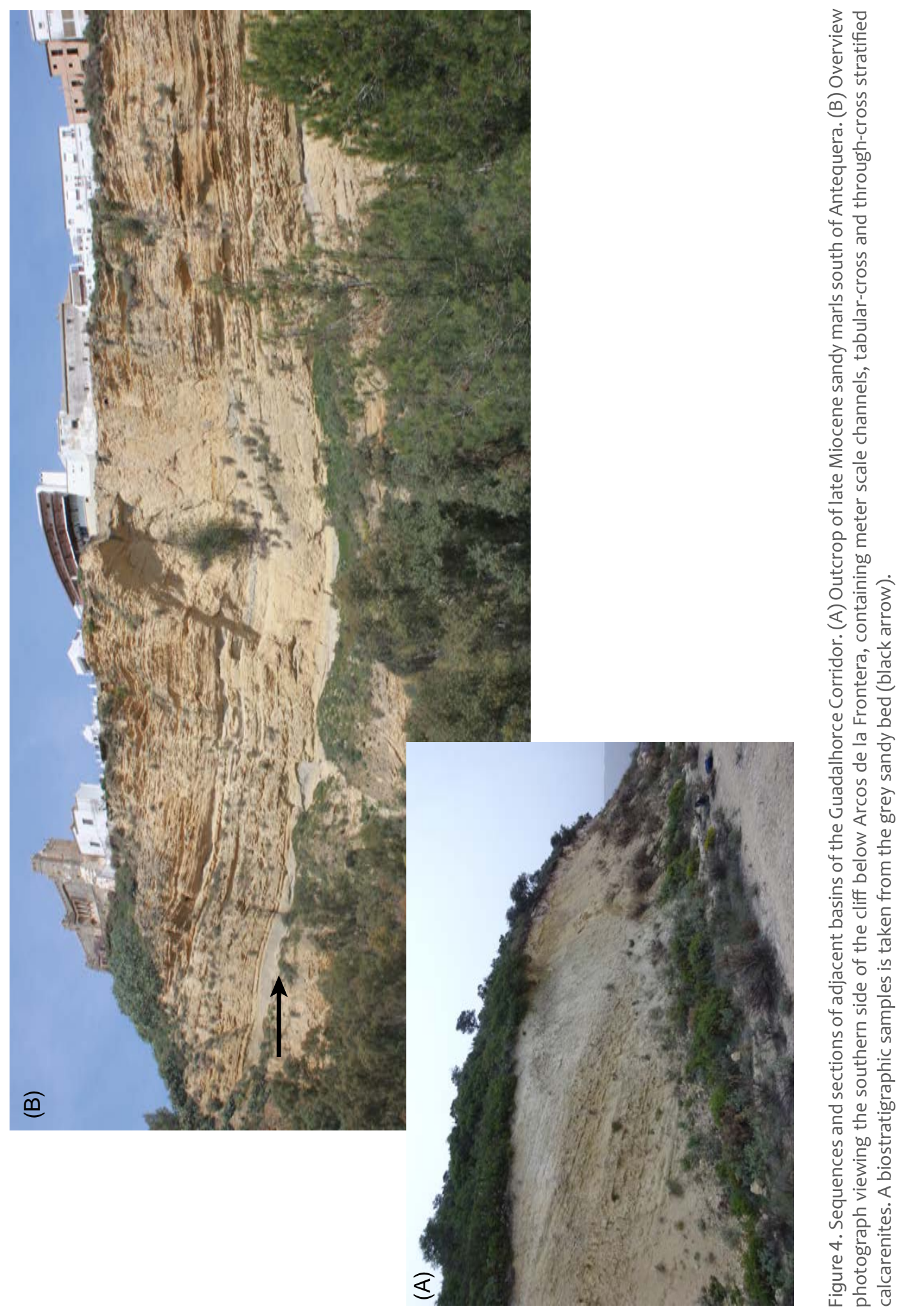




\subsubsection{Comparison with previous studies}

All datable samples indicate a late Tortonian age, older than 7.58 Ma. These samples were found in different basins and outcrops in the studied area, and should therefore represent well the ages of the deposition of Upper Miocene deep marine sediments north and west of the Guadalhorce Corridor. This is in contrast with the age determinations of previous studies done within this region (Gläser and Betzler, 2002; Martín et al., 2001; Serrano Lozano, 1979), which states that at least the upper part of the deep marine infilling was Messinian. Gläser and Betzler (2002) rely on the work of Serrano Lozano (1979) to assign a Tortonian-Messinian age to the deposits of the Ronda Basin. Martin et al., (2001) based their Messinian age determination for the Guadalhorce corridor on the occurrence of Globoratalia gr. miotumida, G. conomiozea and sinistral N. acostaensis in the Peñarrubia exposure. Despite extensive research and sampling in this area, we were not able to find a late Tortonian-early Messinian assemblage with planktonic foraminifera marker species in the same location. Also, we note that specimens of the group of G. miotumida and G. conomiozea have also been found during the late Tortonian well before the Tortonian-Messinian boundary, coexisting with sinistral N. acostaensis in the eastern Betic Lorca and Fortuna basins (Krijgsman et al., 2000).

\subsection{Sedimentological interpretation}

Regardless of smaller scale sea level fluctuations, e.g. in the Ronda Basin (Gläser and Betzler, 2002) within all basins and outcrops in the study area a change from deep marine marls, containing ample amount of benthic and planktonic foraminifera, towards coarse grained calcarenites with many shell fragments, algae and flow structures, and no, or only benthic foraminifera is observed, suggesting a general shallowing upwards trend. This is supported by evidence of very shallow environment depositions at the top of some sequences, with high percentages of benthic foraminifera and mollusk fragments. The youngest deep marine sediments in these basins and areas just north of the Guadalhorce River valley are dated as late Tortonian, older than 7.58 Ma, therefore this shallowing trend must have occurred around that same time period, resulting in a late Tortonian age estimation for the shallower marine calcarenites and probably also for the deposits within the Gaudalhorce River valley. The age of this shallowing trend leads to the suggestion that this branch of the Betic Corridor closed in the latest Tortonian instead of the Messinian, as suggested by previous studies (Martín et al., 2001; José N Pérez-Asensio et al., 2012). Due to the uncertainties described above it cannot be excluded that a restricted, shallow connection persisted after the major shallowing phase.

\subsection{Placement of the shallowing event within the tectonic context of the Betics}

The observed late Tortonian shallowing event in the western part of the Betics can be related to the regional tectonic uplift event which shallowed and subsequently closed the basins in the eastern Betics. The straits through the Lorca, Fortuna and Guadix basins probably all closed during the late Tortonian (Krijgsman et al., 2000; Martín et al., 2009; Betzler et al., 2006; Hüsing et al., 2010). The Granada Basin, just west of Antequera, closed in the latest Tortonian (7.3 Ma; Corbí et 
al., 2012). The late Tortonian age estimation for the observed shallowing trend, around the same time period as the eastern Betic range, implies a late Tortonian tectonic uplift over the entire Betic region. This uplift eventually has led to the complete closure of the Betic Corridor and might be related to the latest olistostrome emplacement in the Guadalquivir Basin around the TortonianMessinian boundary (Ledesma, 2000; Sierro et al., 1996), the first sign of restriction in the Mediterranean Basin in the form of reduced deep marine ventilation at 7.18 Ma (Kouwenhoven et al., 1999; Seidenkrantz et al., 2000) and results from the Huelva-1 record (chapter 3) suggesting earliest Messinian signs of Betic Corridor restriction.

\section{Conclusion}

The study area in south west Spain comprises four upper Miocene key sections or basins, i.e. Arcos de la Frontera, Ronda, Antequera, and Guadalhorce, all indicating a shallowing upward trend. At Ronda, Arcos and Antequera a regression from sandy marls to calcarenitic deposits is observed. Biostratigraphic dating of the marls resulted in all cases in a late Tortonian age, older than 7.58 Ma. The Guadalhorce Corridor consists of similar calcarenitic deposits as found above the marls in the other sections. A reliable age estimation for these deposits was not found. The observed late Tortonian regression is interpreted as a restriction and subsequent closure of the most western branch of the Betic Corridor. Due to dating difficulties of the overlying calcarenites, marking the shallow marine phase and uncertainties in erosion rates, the exact timing of cessation of marine sedimentation in this area cannot be pinpointed. However, based on typical sedimentation rates for calcarenites, marine sedimentation in this part of the Betic Corridor probably terminated in the late Tortonian-early Messinian. We suggest that the late Tortonian period of tectonic uplift in the Eastern Betics, which caused the closure of the eastern branches of the Betic Corridor, extended westward, uplifting the western Betics from the Granada Basin up to the Arcos Basin. This resulted in a late Tortonian-early Messinian closure of the Betic Corridor, well before the onset of the Messinian Salinity Crisis.

\section{Author contributions}

M.v.d.S analysed the biostratigraphy. M.v.d.S and B.v.d.B wrote the manuscript. B.v.d.B leaded the fieldwork and designed this study with F.JS.. W.C., D.S. and E.D. participated during fieldwork and brainstorm sessions. F.J.S., W.K. and S.W. supervised the MEDGATE-students in the field. 


\section{Conclusions}

This thesis demonstrates that gateway configurations influence ocean circulation patterns and depositional sedimentary successions. Also, environmental fluctuations of precipitation and runoff in the Mediterranean area play a major role on Mediterranean-Atlantic exchange regarding current speed and volume of Mediterranean Outflow. During the Messinian Salinity Crisis (MSC; 5.33-5.97 Ma), gateway connections between the Mediterranean and Atlantic became progressively restricted. The Miocene-Pliocene boundary marks the end of the Crisis by an abrupt shift from Messinian evaporites to Zanclean marls in the Mediterranean area, indicating deep marine settings and the re-establishment of the Mediterranean-Atlantic connection. Outside the Mediterranean in the Gulf of Cadiz, the gateway alteration immediately left an imprint in the sediment of IODP Hole U1387C.

\section{Stratigraphic framework}

The studied interval is located below the First Occurrence of Globorotalia puncticulata and above the First Occurrence of Globorotalia margaritae (Expedition Scientists, 2012). This gives an age estimation between 4.52 and 6.08 Ma (Lourens et al., 2004). The Miocene-Pliocene boundary is estimated to be at about 826 mbsf in Hernández-Molina et al. 2016 by correlating 2D and 3D

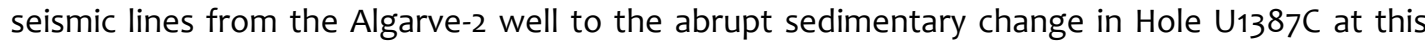
depth. The high abundance interval of $G$. margaritae has not been found in the sediments, indicating that the base of the Hole is most likely younger than $\sim 5.70 \mathrm{Ma}$. This is in agreement with the mainly dextral coiling of Neoglobquadrina acostaensis indicating an age likely younger than $\sim 5.82 \mathrm{Ma}$ (Sierro et al, 2001; Krijgsman et al., 2004). Regular alternations in benthic $\delta^{18} \mathrm{O}$ are interpreted as precession induced cyclicities due to the distinct amplitude enhancements of every other cycle, indicative of the influence of obliquity. Extrapolation of the average wavelengths over the coring gaps gives a depositional time span. If the Miocene-Pliocene boundary is positioned at about $826 \mathrm{mbsf}$, then the base of the Hole is about 5.7 Ma and the top of the studied interval 5.0 Ma. These three tie-points are in good agreement with Chron C3n.4n. (4.997-5.235 Ma; Lourens et al., 2004) of the poorly constrained paleomagnetic data and the influx of sinistral coiling Neogloboquadrina acostaensis at the third precession cycle above the Miocene-Pliocene boundary (laccarino et al., 1999b; Lourens et al., 1996).

\section{Onset of MOW}

Messinian sediments are deposited in a low energy hemipelagic setting, in which XRF scanning $\mathrm{Zr} / \mathrm{Al}$ ratios lack obvious regular alternations. Just above the Miocene-Pliocene boundary, $\mathrm{Zr} / \mathrm{Al}$ levels display high amplitude variations and above the third precession cycle, two course-grained contouritic bigradational sandy beds are revealed with tracers of bioturbation synchronous with Zr/Al peaks. Both features suggest the onset of weak along-slope bottom currents immediately at or right after the Miocene-Pliocene boundary. Linking benthic $\delta^{13} \mathrm{C}$ and $\delta^{18} \mathrm{O}$ with corresponding 
Mediterranean and NE Atlantic records let us conclude that the observed flow is of Mediterranean origin. Therefore we provide the oldest evidence of Mediterranean Outflow water (MOW) outside the Mediterranean after the MSC.

\section{Depositional environment}

Late Miocene sediments in Hole U1387C show typical carbonate cycles that result from variations in amount and composition of detrital siliciclastic input reaching the Gulf of Cadiz. Largest amounts of siliciclastics are present at times of Northern Hemisphere summer insolation minima. The fluctuations within the siliciclastic component are probably induced by precipitation patterns on the Iberia Peninsula influencing the vegetation cover on land and thus erosion rates. No evidence of bottom water current flow is found during the Messinian.

Sedimentation rate triples above the Miocene-Pliocene boundary. The presence of sporadic samples with shelf-dwelling benthic foraminifers suggest the temporal occurrence of downslope transport. Although centimetre-scale sandy layers of turbiditic origin were observed, in most cases, these layers were destroyed by the combined action of bioturbation by macrobenthic communities and bottom currents. A combination of tectonic uplift and the onset of along-slope currents may have provided suspended load from the distant up-current Guadalquivir drainage basin, explaining the tripled sedimentation rates over the Miocene-Pliocene boundary. XRF scanning data does not reveal regular alternations in the carbonate content, but cyclical patterns persists within the siliciclastic component induced by the weak current flow.

\section{Water mass circulation in the Gulf of Cadiz}

Like previous published studies, this multi-proxy record has not found any prove of MOW in upper Miocene sediments. Therefore, mainly Atlantic water was influencing the sediments in the Gulf of Cadiz. A slight decrease in benthic $\delta^{13} \mathrm{C}$ hints towards the presence of poorly ventilated Intermediate Atlantic waters. However, higher amplitudes than nearby records in benthic $\delta^{18} \mathrm{O}$ may speculatively hint to the presence of some MOW during the Messinian.

During the Pliocene, stable isotopes show striking coupling with the sedimentary cycles, indicating a strong relationship with the bottom water currents. Our results suggest that MOW was repeatedly interrupted by the influence of presumably cold, poorly ventilated Atlantic bottom waters at times when along slope currents were absent or sluggish. When cold Atlantic waters are recorded, coeval rapid shifts towards warmer surface waters are indicated by high relative abundances in warm-water planktic foraminifers. This opposite behaviour can be explained by shifts from a negative to a positive water budget in the Mediterranean, what would trigger cold Atlantic Inflow water into the Mediterranean over the sill of the Strait of Gibraltar and warm MOW at surface. After this either bottom waters warm synchronous with cooling at surface or the cooling at surface occurs quickly after its warmest interval and bottom and surface waters record colder conditions. In these cases, bottom water warming pre-dates the warming at the sea 
surface. The different scenarios can be explained by the direct and amount of MediterraneanAtlantic exchange and prevailing water masses in the Gulf of Cadiz. Alternatively, a pronounced shallowing in the settling depth of the MOW within the Atlantic can partially explain the micropaleontologic and stable isotope records.

\section{Controls on authigenic $\mathrm{Nd}$ and $\mathrm{Pb}$ isotopes}

Both $\mathrm{Nd}$ and $\mathrm{Pb}$ isotopes respond to changes in oceanographic and/or sedimentary settings in the Gulf of Cadiz over the Miocene-Pliocene boundary. The $\mathrm{Nd}$ isotopic compositions in the oxyhydroxide leachates was more radiogenic than the constrained MOW and NE Atlantic endmembers. Therefore, it is thought that the imprint must be of some local origin. Parallel behaviour with XRF scanning Canorm, an inverse measure for detrital input, hints towards a dominant influence on isotopic compositions from the release of Rare Earth Elements of suspended river sediments. $\mathrm{Pb}$ isotopic ratios hints to be dominantly controlled by the origin of the water mass, however, due to incompatible data to constrain the endmember compositions of Mediterranean and Atlantic water mass, this cannot be proven with to constrained dataset.

\section{Future research and remaining open questions}

This study is linked to the International Continental Scientific Drilling Program drilling proposal "Investigating Miocene Mediterranean-Atlantic Gateway Exchange" (IMAGE), in which it is targeted to drill several holes offshore along the Portuguese and Gulf of Cadiz Margins, and onshore in the Guadalquivir and south Rifian Basins. The main goal of this project, in combination with the IODP “Deep-Sea Record of Mediterranean Messinian Events" (DREAM) drilling proposal to drill inside the Mediterranean, is to investigate the evolution of Mediterranean-Atlantic water exchange during the late Miocene to early Pliocene and relate this to the main phases of the MSC.

Further evidence must be provided to prove the suggested time to time estuarine circulation in the Mediterranean. A high resolution multi-proxy record is needed from inside the Mediterranean by analysing planktic and benthic stable isotopes of, for instance, the lower part of the Capo Rosello section in Sicily. This would establish the exact timing that the Mediterranean water budget was evaporation-dominated only. This, in turn, could be used to improve global general circulation models that are performed on the Mediterranean area during this time period (e.g. Marzocchi et al., 2016).

$\mathrm{Pb}$ isotopic compositions of Fe-Mn authigenic oxyhydroxide leachates of NE Atlantic deep marine sediments of upper Miocene to lower Pliocene are needed to confirm that $\mathrm{Pb}$ isotopic ratios can be used as a bottom water mass tracer in the Gulf of Cadiz. The position of ODP 982 in the flow path of North East Atlantic Deep Water with robust age constraints is a good candidate to establish the NE Atlantic endmember. 
Chapter 4 suggests the closure of the Betic Corridor well before the MSC. However, the evaporite deposition proves a connection between the Mediterranean and the Open Ocean. This leaves us with the remaining question; if the Betic and Rifian Corridors ceased before the MSC, then where has been the last remaining gateway during the Crisis? Since there is no scientific prove that the Gibraltar Strait was closed before the Messinian, I would like to conclude this thesis by freely speculating on the possibility that Gibraltar has always been open. 


\section{Bibliography}

Abouchami, W.A., Aler, S.J.G.G., Oschinsky, A.K., 1999. Pb and Nd isotopes in NE Atlantic Fe - Mn crusts : Proxies for trace metal paleosources and paleocean circulation 63, 1489-1505.

Aharon, P., Goldstein, L.G., Wheeler, C.W., Jacobson, G., 1993. Sea-level events in the South Pacific linked with the Messinian salinity crisis. Geology 21, 771-775.

Alonso, B., Ercilla, G., Casas, D., Stow, D.A.V., Rodríguez-Tovar, F.J., Dorador, J., Hernández-Molina, F.-J., 2016. Contourite vs gravity-flow deposits of the Pleistocene Faro Drift (Gulf of Cadiz): Sedimentological and mineralogical approaches. Marine Geology 377, 77-94. doi:10.1016/j.margeo.2015.12.016

Ambar, I., Howe, M.R., 1979. Observations of the mediterranean outflow - II the deep circulation in the vicinity of the Gulf of Cadiz. Deep Sea Research Part A. Oceanographic Research Papers 26, 555-568. doi:10.1016/0198-0149(79)90096-7

Armi, L., Bray, N. a., 1982. A Standard Analytic Curve of Potential Temperature versus Salinity for the Western North Atlantic. Journal of Physical Oceanography. doi:10.1175/15200485(1982)012<0384:ASACOP>2.0.CO;2

Artale, V., Calmanti, S., Sutera, A., 2002. Thermohaline circulation sensitivity to intermediate-level anomalies. Tellus 54, 159-174. doi:10.1034/j.1600-0870.2002.01284.x

Baceta, J.I., Pendón, J.G., 1999. Estratigrafía y arquitectura de facies de la formación niebla, neógeno superior, sector occidental de la cuenca del guadalquivir. Revista de la sociedad geologica de España 12, 419-438.

Bahr, A., Jiménez-Espejo, F.J., Kolasinac, N., Grunert, P., Hernández-Molina, F.J., Rohl, U., Voelker, A.H.L., Escutia, C., Stow, D.A. V., Hodell, D.A., Alvarez-Zarikian, C.A., 2014. Deciphering bottom current velocity and paleoclimate signals from contourite deposits in the Gulf of Cádiz during the last 140 kyr: an inorganic geochemical approach. Geochemistry Geophysics Geosystems 18, 1-16. doi:10.1002/2014GC005356

Bahr, A., Kaboth, S., Jiménez-Espejo, F.J., Sierro, F.J., Voelker, A.H.L., Lourens, L., Röhl, U., Reichart, G.J., Escutia, C., Hernández-Molina, F.J., Pross, J., Friedrich, O., 2015. Persistent monsoonal forcing of Mediterranean Outflow Water dynamics during the late Pleistocene. Geology 43, 951-954. doi:10.1130/G37013.1

Baringer, M.O.N., Price, J.F., 1999. A review of the physical oceanography of the Mediterranean outflow. Marine Geology 155, 63-82. doi:10.1016/So025-3227(98)00141-8

Bé, A.W.H., 1980. Gametogenic calcification in a spinose planktonic foraminifer, Globigerinoides sacculifer (Brady). Marine Micropaleontology 5, 283-310. doi:10.1016/0377-8398(80)90014-6

Benson, H., Rakic-El Bied, K., Bonaduce, G., 1991. An important current reversal (influx) in the Rifian corridor (Morocco) at the Tortonian-Messinian boundary: The end of Tethys ocean. Paleoceanography 6, 164-192.

Berger, A., 1984. Accuracy and frequency stability of the Earth's orbital elements during the Quaternary, in: A. Berger, Imbrie, J., Hays, H., Kukla, G., Saltzman, B. (Eds.), Milankovitch and Climate: Understanding the Response to Astronomical Forcing. D. Reidel Publishing, Dordrecht, p. 3.

Berggren, W.A., Haq, B.U., 1976. The Andalusian stage (late Miocene): Biostratigraphy, biochronology and paaleoecology. Palaeogeography, Palaeoclimatology, Palaeoecology1 20, 67-129. 
Bertrand, S., Hughen, K.A., Sepúlveda, J., Pantoja, S., 2012. Geochemistry of surface sediments from the fjords of Northern Chilean Patagonia $\left(44-47^{\circ} \mathrm{S}\right)$ : Spatial variability and implications for paleoclimate reconstructions. Geochimica et Cosmochimica Acta 76, 125-146. doi:10.1016/j.gca.2011.10.028

Betzler, C., Braga, J.C., Martín, J.M., Sánchez-Almazo, I.M., Lindhorst, S., 2006. Closure of a seaway: Stratigraphic record and facies (Guadix basin, Southern Spain). International Journal of Earth Sciences 95, 903-910. doi:10.1007/s00531-006-0073-y

Blanc, P.-L., 2002. The opening of the Plio-Quaternary Gibraltar Strait: assessing the size of a cataclysm. Geodinamica Acta 15, 303-317. doi:doi:10.1016/So985-3111(02)01095-1

Bouma, A.H., Kuenen, P.H., Shepard, F.P., 1962. Sedimentology of some flysch deposits: a graphic approach to facies interpretation. Elsevier, Amsterdam.

Brackenridge, R., Stow, D.A.V., Hernández-Molina, F.J., 2011. Contourites within a deep-water sequence stratigraphic framework. Geo-Marine Letters 31, 343-360. doi:10.1007/s00367-0110256-9

Brackenridge, R.E., Hernández-Molina, F.J., Stow, D.A.V., Llave, E., 2013. A Pliocene mixed contourite-turbidite system offshore the Algarve Margin, Gulf of Cadiz: Seismic response, margin evolution and reservoir implications. Marine and Petroleum Geology 46, 36-50. doi:10.1016/j.marpetgeo.2013.05.015

Bradshaw, C.D., Lunt, D.J., Flecker, R., Salzmann, U., Pound, M.J., Haywood, A.M., Eronen, J.T., 2012. The relative roles of $\mathrm{CO}_{2}$ and palaeogeography in determining late Miocene climate: Results from a terrestrial model-data comparison. Climate of the Past 8, 1257-1285. doi:10.5194/cp-8-1257-2012

Cerdan, O., Govers, G., Le Bissonnais, Y., Van Oost, K., Poesen, J., Saby, N., Gobin, A., Vacca, A., Quinton, J., Auerswald, K., Klik, A., Kwaad, F.J.P.M., Raclot, D., Ionita, I., Rejman, J., Rousseva, S., Muxart, T., Roxo, M.J., Dostal, T., 2010. Rates and spatial variations of soil erosion in Europe: A study based on erosion plot data. Geomorphology 122, 167-177. doi:10.1016/j.geomorph.2010.06.011

Christensen, J.N., Halliday, A.N., Godfrey, L. V, Hein, J.R., Rea, D.K., 1997. Climate and Ocean Dynamics and the Lead Isotopic Records in Pacific Ferromanganese Crusts. Science 277, 913918. doi:10.1126/science.277.5328.913

CIESM, 2008. CIESM Workshop Monographs. The Messinian Salinity Crisis from mega-deposits to microbiology - A consensus report. CIESM workshop Monographs 33, 168 pages.

Clauzon, G., Suc, J., Gautier, F., Berger, A., Loutre, M., 1996. Alternate interpretation of the Messinian salinity crisis : Controversy resolved? Alternate interpretation of the Messinian salinity crisis: Controversy resolved? The Geological Society of America 846. doi:10.1130/0091-7613(1996)024<0363

Corbí, H., Lancis, C., García-García, F., Pina, J.A., Soria, J.M., Tent-Manclús, J.E., Viseras, C., 2012. Updating the marine biostratigraphy of the Granada Basin (central Betic Cordillera). Insight for the Late Miocene palaeogeographic evolution of the Atlantic - Mediterranean seaway. Geobios 45, 249-263. doi:10.1016/j.geobios.2011.10.006

Curaso, A., Sprovieri, M., Bonanno, A., Sprovieri, R., 2002. Astromonical calibration of the Serravallian/Tortonian case Pelacani section (Sicily, Italy). Rivista Italiana di Paleontologia e Stratigrafia 108, 297-306.

Curry, R., Dickson, B., Yashayaev, I., 2003. A change in the freshwater balance of the Atlantic Ocean 
over the past four decades. Nature 426, 826-829. doi:10.1038/nature02206

Dietrich, D.E., Tseng, Y., Medina, R., Piacsek, S.A., Liste, M., Olabarrieta, M., Bowman, M.J., Mehra, A., 2008. Mediterranean Overflow Water ( MOW ) simulation using a coupled multiple-grid Mediterranean Sea / North Atlantic Ocean model 113, 0-14. doi:10.1029/2006JC003914.1.

Dorador, J., Rodríguez-Tovar, F.J., 2016. High resolution digital image treatment to color analysis on cores from IODP expedition 339: Approaching lithologic features and bioturbational influence. Marine Geology 377, 127-135. doi:10.1016/j.margeo.2016.02.005

Ducassou, E., Fournier, L., Sierro, F.J., Zarikian, C.A.A., Lo, J., Flores, J.A., Roque, C., 2015. Origin of the large Pliocene and Pleistocene debris $\mathrm{fl}$ ows on the Algarve margin. Marine Geology (in press). doi:10.1016/j.margeo.2015.08.018

Duggen, S., Hoernle, K., Bogaard, P. van den, Rüpke, L., Morgan, J.P., 2003. Deep roots of the Messinian salinity crisis. Nature 422, 602-606. doi:10.1038/nature01551.1.

Epstein, S., Buchsbaum, R., Lowenstam, H. a, Urey, H.C., 1953. Revised Carbonate-Water Isotopic Temeprature Scale. Geological Society of America Bulletin 64, 1315-1325. doi:10.1130/00167606(1953)64

Epstein, S., Buchsbaum, R., Lowenstam, H.A., Urey, H.C., 1951. Carbonate-water isotopic temperature scale. Bulletin of the Geological Society of America 62, 417-426. doi:10.1017/CBO9781107415324.004

Esteras, M., Izquierdo, J., Sandoval, N., Bahmad, A., 2000. Evolución morfológica y estratigráfica plio-cuaternaria del Umbral de Camarinal (Estrecho de Gibraltar) basada en sondeos marinos. Revista de la Sociedad Geologica de España 539-50.

Expedition 339 Scientists, 2013a. Site U1387, in: Stow, D.A.V., Hernández-Molina, F.J., AlvarezZarikian, C.A., Expedition 339 Scientists (Eds.), Proceedings of the Intergrated Ocean Drilling Program. Integrated Ocean Drilling Program Management International, Inc, Tokyo. doi:10.2204/iodp.proc.339.105.2013

Expedition 339 Scientists, 2013b. Methods, in: Stow, D.A.V., Hernández-Molina, F.J., Alvarez Zarikian, C.A., Expedition 339 Scientists (Eds.), Proceedings of the IODP 339. Integrated Ocean Drilling Program Management International, Inc, Tokyo, pp. 1-5. doi:doi:10.2204/iodp.proc.339.102.2013

Expedition 339 Scientists, 2012. Mediterranean outflow: environmental significance of the Mediterranean Outflow Water and its global implications. IODP preliminary Report 339. doi:10.2204/iodp.pr.339.2012

Faugères, J., Gonthier, E., Stow, D.A.V., 1984. Contourite drift molded by deep Mediterranean outflow. Geology 12, 296-300. doi:doi: 10.1130/0091-7613(1984)

Fauquette, S., Suc, J.P., Bertini, A., Popescu, S.M., Warny, S., Bachiri Taoufiq, N., Perez Villa, M.J., Chikhi, H., Feddi, N., Subally, D., Clauzon, G., Ferrier, J., 2006. How much did climate force the Messinian salinity crisis? Quantified climatic conditions from pollen records in the Mediterranean region. Palaeogeography, Palaeoclimatology, Palaeoecology 238, 281-301. doi:10.1016/j.palaeo.2006.03.029

Flecker, R., Krijgsman, W., Capella, W., de Castro Martíns, C., Dmitrieva, E., Mayser, J.P., Marzocchi, A., Modestou, S., Ochoa, D., Simon, D., Tulbure, M., Van den Berg, B., Van der Schee, M., De Lange, G., Ellam, R., Govers, R., Gutjahr, M., Hilgen, F., Kouwenhoven, T., Lofi, J., Meijer, P., Sierro, F.J., Bachiri, N., Barhoun, N., Alami, A.C., Chacon, B., Flores, J., Gregory, J., Howard, J., Lunt, D., Ochoa, M., Pancost, R., Vincent, S., Yousfi, M.Z., 2015. Evolution of the Late 
Miocene Mediterranean-Atlantic gateways and their impact on regional and global environmental change. Earth-Science Reviews 150, 365-392. doi:10.1016/j.earscirev.2015.08.007

Flores, J.A., Sierro, F.J., 1997. A revised technique for the estimation of nannofossil accumulation rates. Micropaleontology 43, 321-324.

Flores, J.A., Sierro, F.J., Filippelli, G.M., Bárcena, M.Á., Pérez-Folgado, M., Vázquez, A., Utrilla, R., 2005. Surface water dynamics and phytoplankton communities during deposition of cyclic late Messinian sapropel sequences in the western Mediterranean. Marine Micropaleontology 56, 50-79. doi:10.1016/j.marmicro.2005.04.002

Frank, 2002. Radiogenic isotopes: tracers of past ocean circulation and erosional input. Reviews of Geophysics 40, 1-38.

Frank, M., Whiteley, N., Kasten, S., Hein, J.R., O'Nions, K., 2002. North Atlantic Deep Water export to the Southern Ocean over the past 14 Myr: Evidence from $\mathrm{Nd}$ and $\mathrm{Pb}$ isotopes in ferromanganese crusts. Paleoceanography 17, 1-9. doi:10.1029/2000PA000606

Ganeshram, R.S., Calvert, S.E., Pedersen, T.F., Cowie, G.L., 1999. Factors controlling the burial of organic carbon in laminated and bioturbated sediments off NW Mexico: Implications for hydrocarbon preservation. Geochimica et Cosmochimica Acta 63, 1723-1734. doi:10.1016/S0016-7037(99)00073-3

Garcés, M., Krijgsman, W., Agustí, J., 1998. Chronology of the late Turolian deposits of the Fortuna basin (SE Spain): Implications for the Messinian evolution of the eastern Betics. Earth and Planetary Science Letters 163, 69-81. doi:10.1016/So012-821X(98)00176-9

García Lafuente, J., Sánchez Román, a., Díaz del Río, G., Sannino, G., Sánchez Garrido, J.C., 2007. Recent observations of seasonal variability of the Mediterranean outflow in the Strait of Gibraltar. Journal of Geophysical Research 112, 1-11. doi:10.1029/2006JC003992

García, M., Hernández-Molina, F.J., Llave, E., Stow, D. a. V., León, R., Fernández-Puga, M.C., Diaz del Río, V., Somoza, L., 2009. Contourite erosive features caused by the Mediterranean Outflow Water in the Gulf of Cadiz: Quaternary tectonic and oceanographic implications. Marine Geology 257, 24-40. doi:10.1016/j.margeo.2008.10.009

García-Alix, A., 2015. A multiproxy approach for the reconstruction of ancient continental environments. The case of the Mio-Pliocene deposits of the Granada Basin (southern Iberian Peninsula). Global and Planetary Change 131, 1-10. doi:10.1016/j.gloplacha.2015.04.005

García-Alix, A., Minwer-Barakat, R., Martín Suárez, E., Freudenthal, M., Aguirre, J., Kaya, F., 2016. Updating the Europe-Africa small mammal exchange during the late Messinian. Journal of Biogeography 1-13. doi:10.1111/jbi.12732

García-Castellanos, D., Estrada, F., Jiménez-Munt, I., Gorini, C., Fernàndez, M., Vergés, J., De Vicente, R., 2009. Catastrophic flood of the Mediterranean after the Messinian salinity crisis. Nature 462, 778-81. doi:10.1038/nature08555

Gläser, I., Betzler, C., 2002. Facies partitioning and sequence stratigraphy of cool-water, mixed carbonate-siliciclastic sediments (Upper Miocene Guadalquivir Domain, southern Spain). International Journal of Earth Sciences 91, 1041-1053. doi:10.1007/s00531-002-0293-8

Gonthier, E., Faugères, J., Stow, D.A.V., 1984. Contourite facies of the Faro drift, Gulf of Cadiz. Geological Society, London, Special Publications1 15, 275-292.

González-Delgado, J., Civis, J., Dabrio, C., Goy, J., Ledesma, S., Pais, J., Sierro, F.J., Zazo, C., 2004. Cuenca del Guadalquivir, in: Vera, J.A. (Ed.), Geología de España. SGE-IGME, Madrid, pp. 543- 
500.

Gutjahr, M., Frank, M., Halliday, A.N., Keigwin, L.D., 2009. Retreat of the Laurentide ice sheet tracked by the isotopic composition of $\mathrm{Pb}$ in western North Atlantic seawater during termination 1. Earth and Planetary Science Letters 286, 546-555. doi:10.1016/j.epsl.2009.07.020

Harlavan, Y., Erel, Y., 2002. The release of $\mathrm{Pb}$ and REE from granitoids by the dissolution of accessory phases. Geochimica et Cosmochimica Acta 66, 837-848. doi:10.1016/So0167037(01)00806-7

Hecht, M., Holland, W.E., Artale, V., Pinardi, N., 1997. North Atlantic model sensitivity to Mediterranean waters, in: Howe, W., Henderson-Sellers, A. (Eds.), Assessing Climate Change: Results from the Model Evaluation Consortium for Climate Assessment1. Gordon \& Breach Science Publishers, Sydney, pp. 169-191.

Henderson, G.M., Maier-Reimer, E., 2002. Advection and removal of $210 \mathrm{~Pb}$ and stable $\mathrm{Pb}$ isotopes in the oceans: A general circulation model study. Geochimica et Cosmochimica Acta 66, 257272. doi:10.1016/S0016-7037(01)00779-7

Henry, F., Jeandel, C., Dupré, B., Minster, J.F., 1994. Particulate and dissolved Nd in the western Mediterranean Sea: Sources, fate and budget. Marine Chemistry 45, 283-305. doi:10.1016/0304-4203(94)90075-2

Hernández-Molina, F.J., Llave, E., Preu, B., Ercilla, G., Fontan, A., Bruno, M., Serra, N., Gomiz, J.J., Brackenridge, R.E., Sierro, F.J., Stow, D.A.V., Garcia, M., Juan, C., Sandoval, N., Arnaiz, A., 2014a. Contourite processes associated with the Mediterranean Outflow Water after its exit from the Strait of Gibraltar: Global and conceptual implications. Geology 42, 227-230. doi:10.1130/G35083.1

Hernández-Molina, F.J., Sierro, F.J., Llave, E., Roque, C., Stow, D.A.V., Williams, T., Lofi, J., Van der Schee, M., Arnaíz, A., Ledesma, S., Rosales, C., Rodríguez-Tovar, F.J., Pardo-Igúzquiza, E., Brackenridge, R.E., 2016. Evolution of the Gulf of Cadiz margin and southwest Portugal contourite depositional system: Tectonic, sedimentary and paleoceanographic implications from IODP expedition 339. Marine Geology 377, 7-39. doi:10.1016/j.margeo.2015.09.013

Hernández-Molina, F.J., Stow, D., Alvarez-Zarikian, C., Acton, G., Bahr, A., Balestra, B., Ducassou, E., Flood, R., Flores, J.A., Furota, S., Grunert, P., Hodell, D., Jimenez-Espejo, F., Kim, J.K., Krissek, L., Kuroda, J., Li, B., Llave, E., Lofi, J., Lourens, L., Miller, M., Nanayama, F., Nishida, N., Richter, C., Roque, C., Pereira, H., Go??i Fernanda Sanchez, M., Sierro, F.J., Singh, A.D., Sloss, C., Takashimizu, Y., Tzanova, A., Voelker, A., Williams, T., Xuan, C., 2013. IODP Expedition 339 in the Gulf of Cadiz and off West Iberia: Decoding the environmental significance of the Mediterranean outflow water and its global influence. Scientific Drilling 1-11. doi:10.5194/sd-16-1-2013

Hernández-Molina, F.J., Stow, D.A.V., Alvarez-Zarikian, C.A., Acton, G., Bahr, A., Balestra, B., Ducassou, E., Flood, R., Flores, J.A., Furota, S., Grunert, P., Hodell, D., Jimenez-Espejo, F., Kim, J.K., Krissek, L., Kuroda, J., Li, B., Llave, E., Lofi, J., Lourens, L., Miller, M., Nanayama, F., Nishida, N., Richter, C., Roque, C., Pereira, H., Sanchez Goñi, M.F., Sierro, F.J., Singh, a. D., Sloss, C., Takashimizu, Y., Tzanova, A., Voelker, A., Williams, T., Xuan, C., 2014b. Onset of Mediterranean outflow into the North Atlantic. Science 344, 1244-1250. doi:10.1126/science.1251306

Hernández-Molina, J., Llave, E., Somoza, L., Fernández-Puga, M.C., Maestro, A., León, R., Medialdea, T., Barnolas, A., García, M., Díaz del Río, V., Fernández-Salas, L.M., Vázquez, J.T., 
Lobo, F., Alveirinho Dias, J.M., Rodero, J., Gardner, J., 2003. Looking for clues to paleoceanographic imprints: A diagnosis of the Gulf of Cadiz contourite depositional systems. Geology 31, 19-22.

Hilgen, F.., Lourens, L.., Van Dam, J.A., 2012. The Neogene Period, in: Gradstein, F.M., Ogg, J.G., Schmitz, M., Ogg, G. (Eds.), The Geologic Time Scale. Elsevier, Amsterdam, pp. 923-978. doi:doi:10.1016/B978-0-444-59425-9.01001-5

Hilgen, F.J., Bissoli, L., laccarino, S., Krijgsman, W., Meijer, R., 2000. Integrated stratigraphy and astrochronology of the Messinian GSSP at Oued Akrech (Atlantic Morocco). Earth and Planetary Science Letters 182, 237-251.

Hilgen, F.J., Krijgsman, W., 1999. Cyclostratigraphy and astrochronology of the Tripoli diatomite formation (pre-evaporite Messinian, Sicily, Italy). Terra Nova 11, 16-22.

Hilgen, F.J., Krijgsman, W., Langereis, C.G., Lourens, L.J., Santarelli, A., Zachariasse, W.J., 1995. Extending the astronomical (polarity) time scale into the Miocene. Earth and Planetary Science Letters 136, 495-510. doi:10.1016/0012-821X(95)00207-S

Hodell, D. a., Channeil, J.E.T., Curtis, J.H., Romero, O.E., Röhl, U., Channell, J.E.T., Curtis, J.H., Romero, O.E., Röhl, U., 2008. Onset of “Hudson Strait" Heinrich events in the eastern North Atlantic at the end of the middle Pleistocene transition ( 640 ka)? Paleoceanography 23, 116. doi:10.1029/2008PA001591

Hodell, D., Crowhurst, S., Skinner, L., Tzedakis, P.C., Margari, V., Channell, J.E.T., Kamenov, G., Maclachlan, S., Rothwell, G., 2013. Response of Iberian Margin sediments to orbital and suborbital forcing over the past $420 \mathrm{ka}$. Paleoceanography 28, 185-199. doi:10.1002/palo.20017

Hodell, D.A., Curtis, J.H., Sierro, J., Raymo, M.E., 2001. Correlation of Late Miocene to Early Pliocene sequences between the Mediterranean and North Atlantic. Paleoceanography 16, 164-178.

Hodell, D.A.V., Benson, R.H., Kent, D. V, Boersma, A., Rakic-El Bied, K., 1994. Magnetostratigraphic, biostratigraphic, and stable isotope stratigraphy of an Upper Miocene drill core from the Salé Briqueterie (northern Morocco): A high-resolution chronology for the Messinian stage. Paleoceanography 9, 835-855.

Hsü, K.J., Montadert, L., Bernoulli, D., Cita, M.B., Erickson, A., Garrison, R.E., Kidd, R.B., Mèlierés, F., Müller, C., Wright, R., 1977. History of the Mediterranean salinity crisis. Nature 267, 399403.

Hsü, K.J., Ryan, W.B.., Cita, M.B., 1973. Late Miocene desiccation of the Mediterranean. Nature 242, 240-244.

Hüsing, S.K., Oms, O., Agustí, J., Garcés, M., Kouwenhoven, T.J., Krijgsman, W., Zachariasse, W.J., 2010. On the late Miocene closure of the Mediterranean-Atlantic gateway through the Guadix Basin (Southern Spain). Palaeogeography, Palaeoclimatology, Palaeoecology 291, 167-179. doi:10.1016/j.palaeo.2010.02.005

laccarino, S., Castradori, D., Cita, M., 1999. The Miocene/Pliocene boundary and the significance of the earliest Pliocene flooding in the Mediterranean. Memorie Società Geologica Italiana 54, 109-131.

laccarino, S.M., Cita, M.B., Gaboardi, S., Gruppini, G.M., 1999. High-resolution biostratigraphy at the Miocene/Pliocene boundary in Holes 974B and 975B, western Mediterranean. Proceedings of the Intergrated Ocean Drilling Program, Scientific Results 161, 197-221.

Iorga, M.C., Lozier, M.S., 1999. Signatures of the Mediterranean outflow from a North Atlantic 
climatology: 1. Salinity and density fields. Journal of Geophysical Research 104, 25.98526.009. doi:10.1029/1999JC900204

Ivanovic, R.F., Flecker, R., Gutjahr, M., Valdes, P.J., 2013. First Nd isotope record of MediterraneanAtlantic water exchange through the Moroccan Rifian Corridor during the Messinian Salinity Crisis. Earth and Planetary Science Letters 368, 163-174. doi:10.1016/j.epsl.2013.03.010

Ivanovic, R.F., Valdes, P.J., Flecker, R., Gutjahr, M., 2014. Modelling global-scale climate impacts of the late Miocene Messinian Salinity Crisis. Climate of the Past 10, 607-622. doi:10.5194/cp-10607-2014

Jacobsen, S.B., Wasserburg, G.J., 1980. Sm-Nd isotopic evolution of chondrites. Earth and Planetary Science Letters 50, 139-155. doi:10.1016/0012-821X(80)90125-9

Jiménez-Moreno, G., Fauquette, S., Suc, J.-P., 2010. Miocene to Pliocene vegetation reconstruction and climate estimates in the Iberian Peninsula from pollen data. Review of Palaeobotany and Palynology 162, 403-415. doi:10.1016/j.revpalbo.2009.08.001

Jiménez-Moreno, G., Pérez-Asensio, J.N., Larrasoaña, J.C., Aguirre, J., Civis, J., Rivas-Carballo, M.R., Valle-Hernández, M.F., González-Delgado, J.A., 2013. Vegetation, sea-level, and climate changes during the Messinian salinity crisis. Bulletin of the Geological Society of America 125, 432-444. doi:10.1130/B30663.1

Jones, R.W., 1994. The Challenger foraminifera. Oxford University Press, Oxford, New York.

Kaboth, S., Bahr, A., Reichart, G.-J., Jacobs, B., Lourens, L.J., 2016. New insights into upper MOW variability over the last 150kyr from IODP 339 Site U1386 in the Gulf of Cadiz. Marine Geology 377, 136-145. doi:10.1016/j.margeo.2015.08.014

Khélifi, N., Sarnthein, M., Andersen, N., Blanz, T., Frank, M., Garbe-Schonberg, D., Haley, B. a., Stumpf, R., Weinelt, M., 2009. A major and long-term Pliocene intensification of the Mediterranean outflow, 3.5-3.3 Ma ago. Geology 37, 811-814. doi:10.1130/G30058A.1

Khélifi, N., Sarnthein, M., Frank, M., Andersen, N., Garbe-Schönberg, D., 2014. Late Pliocene variations of the Mediterranean outflow. Marine Geology 357, 182-194. doi:10.1016/j.margeo.2014.07.006

Kirschvink, J.L., 1980. The least-squares line and plane and the analysis of paleomagnetic data. Geophysical Journal of the Royal Astronomical Society 62, 699-718. doi:10.1111/j.1365246X.1980.tbo2601.x

Kouwenhoven, T.J., Seidenkrantz, M.S., Van Der Zwaan, G.J., 1999. Deep-water changes: The nearsynchronous disappearance of a group of benthic foraminifera from the Late Miocene Mediterranean. Palaeogeography, Palaeoclimatology, Palaeoecology 152, 259-281. doi:10.1016/S0031-0182(99)00065-6

Krijgsman, W. et al, 1999. Late neogene evolution of the Taza-Guercif Basin (Ririan Corridor, Morocco) and implications for the Messinian salinity crisis.

Krijgsman, W., Gaboardi, S., Hilgen, F.J., laccarino, S., De Kaenel, E., van der Laan, E., 2004. Revised astrochronology for the Ain el Beida section (Atlantic Morocco): No glacio-eustatic control for the onset of the Messinian Salinity Crisis. Stratigraphy 1, 87-101.

Krijgsman, W., Garcés, M., Agustí, J., Raffi, I., Taberner, C., Zachariasse, W.J., 2000. The “Tortonian salinity crisis" of the eastern Betics (Spain). Earth and Planetary Science Letters 181, 497-511. doi:10.1016/So012-821X(00)00224-7

Krijgsman, W., Hilgen, F.J., Langereis, C.G., Zachariasse, W.J., 1994. The Age of the Tortonian Messinian Boundary. Earth and Planetary Science Letters 121, 533-547. doi:10.1016/0012- 


\section{X(94)90089-2}

Krijgsman, W., Hilgen, F.J., Raffi, I., Sierro, F.J., Wilson, D.S., 1999a. Chronology , causes and progression of the Messinian salinity crisis. Nature 400, 652-655.

Krijgsman, W., Langereis, C.., Zachariasse, W.., Boccaletti, M., Moratti, G., Gelati, R., laccarino, S., Papani, G., Villa, G., 1999b. Late Neogene evolution of the Taza-Guercif Basin (Rifian Corridor, Morocco) and implications for the Messinian salinity crisis. Marine Geology 153, 147-160. doi:10.1016/S0025-3227(98)00084-X

Krijgsman, W., Meijer, P.T., 2008. Depositional environments of the Mediterranean "Lower Evaporites" of the Messinian salinity crisis: Constraints from quantitative analyses. Marine Geology 253, 73-81. doi:10.1016/j.margeo.2008.04.010

Kuroda, J., Jiménez-Espejo, F.J., Nozaki, T., Gennari, R., Lugli, S., Manzi, V., Roveri, M., Flecker, R., Sierro, F.J., Yoshimura, T., Suzuki, K., Ohkouchi, N., 2016. Miocene to Pleistocene osmium isotopic records of the Mediterranean sediments. Paleoceanography 31, 148-166. doi:10.1002/2015PA002853

Lacan, F., Jeandel, C., 2005. Neodymium isotopes as a new tool for quantifying exchange fluxes at the continent-ocean interface. Earth and Planetary Science Letters 232, 245-257. doi:10.1016/j.epsl.2005.01.004

Lamy, F., Arz, H.W., Kilian, R., Lange, C.B., Lembke-Jene, L., Wengler, M., Kaiser, J., Baeza-Urrea, O., Hall, I.R., Harada, N., Tiedemann, R., 2015. Glacial reduction and millennial-scale variations in Drake Passage throughflow. Proceedings of the National Academy of Sciences of the United States of America 112, 13496-501. doi:10.1073/pnas.1509203112

Laskar, J., Robutel, P., Joutel, F., Gastineau, M., Correia, A.C.M., Levrard, B., 2004. A long-term numerical solution for the insolation. Astronomy \& Astrophysics 285, 261-285.

Leckie, R.M., Olson, H.C., 2003. Foraminifera as proxies for sea-level change on siliciclastic margins. In: Micropaleontologic Proxies for Sea-Level Change and Stratigraphic Discontinuities. SEPM Special Publication 75, 5-19.

Ledesma, S., 2000. Astrobiocronología y estratigrafía de alta resolución del neógeno de la cuenca del Guadalquivir-Golfo de Cádiz.

Li, L.Z.X., 2006. Atmospheric GCM response to an idealized anomaly of the Mediterranean sea surface temperature. Climate Dynamics 27, 543-552. doi:10.1007/s00382-006-0152-6

Lisiecki, L.E., Raymo, M.E., 2005. A Pliocene-Pleistocene stack of 57 globally distributed benthic $\delta$ 18 O records. Paleoceanography 20, PA1003. doi:10.1029/2004PA001071

Llave, E., Hernández-Molina, F.J., Somoza, L., Díaz-del-Río, V., Stow, D.A. V., Maestro, A., Alveriniho Dias, J.M., 2001. Seismic stacking pattern of the Faro-Albufeira contourite system ( Gulf of Cadiz ): a Quaternary record of paleoceanographic and tectonic influences 487-508.

Llave, E., Hernández-Molina, F.J., Stow, D. a. V., Fernández-Puga, M.C., García, M., Vázquez, J.T., Maestro, A., Somoza, L., Díaz del Río, V., 2007. Reconstructions of the Mediterranean Outflow Water during the quaternary based on the study of changes in buried mounded drift stacking pattern in the Gulf of Cadiz. Marine Geophysical Researches 28, 379-394. doi:10.1007/s11001-007-9040-7

Lofi, J., Gorini, C., Berné, S., Clauzon, G., Tadeu Dos Reis, a., Ryan, W.B.F., Steckler, M.S., 2005. Erosional processes and paleo-environmental changes in the Western Gulf of Lions (SW France) during the Messinian Salinity Crisis. Marine Geology 217, 1-30. doi:10.1016/j.margeo.2005.02.014 
Lofi, J., Voelker, A.H.L., Ducassou, E., Hernández-Molina, F.J., Sierro, F.J., Bahr, A., Galvani, A., Lourens, L.J., Pardo-Igúzquiza, E., Pezard, P., Rodríguez-Tovar, F.J., Williams, T., 2016. Quaternary chronostratigraphic framework and sedimentary processes for the Gulf of Cadiz and Portuguese Contourite Depositional Systems derived from Natural Gamma Ray records. Marine Geology 377, 40-57. doi:10.1016/j.margeo.2015.12.005

López-Garrido, A.., Sanz de Galdeano, C., 1999. Neogene Sedimentation and Tectonic-Eustatic Control of the Malaga Basin, South Spain. Journal of Petroleum Geology 22, 81-96.

Louarn, E., Morin, P., 2011. Antarctic Intermediate Water influence on Mediterranean Sea Water outflow. Deep-Sea Research Part I: Oceanographic Research Papers 58, 932-942. doi:10.1016/j.dsr.2011.05.009

Lourens, L.J., Antonarakou, A., Hilgen, F.J., Van Hoof, A.A.M., Zachariasse, W.J., 1996. Evaluation of the Plio-Pleistocene astronomical timescale. Paleoceanography 11, 391-413.

Lourens, L.J., Hilgen, F., Shackleton, J., Laskar, J., Wilson, J., 2004a. The Neogene period, in: Gradstein, F., Ogg, J., Simth, A. (Eds.), A Geologic Time Scale. Cambridge University Press, London, pp. 409-440.

Lourens, L.J., Hilgen, F., Shackleton, N.., Laskar, J., Wilson, J., 2004b. The Neogene Period, in: A Geologic Time Scale 2004. pp. 409-440.

Lourens, L.J., Wehausen, R., Brumsack, H.J., 2001. Geological constraints on tidal dissipation and dynamical ellipticity of the Earth over the past three million years. Nature 409, 1029-1033. doi:10.1038/35059062

Lozier, M.S., Sindlinger, L., 2009. On the Source of Mediterranean Overflow Water Property Changes. Journal of Physical Oceanography 39, 1800-1817. doi:10.1175/2009JPO4109.1

Lozier, M.S., Stewart, N.M., 2008. On the Temporally Varying Northward Penetration of Mediterranean Overflow Water and Eastward Penetration of Labrador Sea Water. Journal of Physical Oceanography 38, 2097-2103. doi:10.1175/2008JPO3908.1

Manzi, V., Gennari, R., Hilgen, F., Krijgsman, W., Lugli, S., Roveri, M., Sierro, F.J., Area, P., 2013. Age refinement of the Messinian salinity crisis onset in the Mediterranean MSC onset PREEVAPORITIC 1-8. doi:10.1111/ter.12038

Martín, J.M., Braga, J.C., Aguirre, J., Puga-Bernabéu, Á., 2009. History and evolution of the NorthBetic Strait (Prebetic Zone, Betic Cordillera): A narrow, early Tortonian, tidal-dominated, Atlantic-Mediterranean marine passage. Sedimentary Geology 216, 80-90. doi:10.1016/j.sedgeo.2009.01.005

Martín, J.M., Braga, J.C., Betzler, C., 2001. The messinian guadalhorce corridor: The last Northern, atlantic-mediterranean gateway. Terra Nova 13, 418-424. doi:10.1046/j.13653121.2001.00376.x

Martín, J.M., Puga-Bernabéu, A., Aguirre, J., Braga, J.C., 2014. Miocene Atlantic-Mediterranean seaways in the Betic Cordillera. Revista de la sociedad geológica de España 27, 175-186.

Martínez del Olmo, W., 2004. La exploración de hidrocarburos en el Terciario de España. Boletín Geológico y Minero 115, 411-426.

Marzocchi, A., Flecker, R., van Baak, C.G.C., Lunt, D.J., Krijgsman, W., 2016. Mediterranean outflow pump: an alternative mechanism for the Lago-Mare and the end of the Messinian Salinity Crisis. Geology 44, accepted. doi:10.1130/G37646.1

Marzocchi, A., Lunt, D.J., Flecker, R., Bradshaw, C.D., Farnsworth, A., Hilgen, F.J., 2015. Orbital control on late Miocene climate and the North African monsoon: Insight from an ensemble 
of sub-precessional simulations. Climate of the Past 11, 1271-1295. doi:10.5194/cp-11-1271-2015 Mauritzen, C., Morel, Y., Paillet, J., 2001. On the in influence of Mediterranean Water on the Central Waters of the North Atlantic Ocean. Deep-Sea Research Part I 48, 347-381.

McLennan, S.M., Hemming, S., McDaniel, D.K., Hanson, G.N., 1993. Geochemical approaches to sedimentation, provenance, and tectonics. Geological Society of America Special Paper 284, 21-40. doi:10.1130/SPE284-p21

Meijer, P.T., Krijgsman, W., 2005. A quantitative analysis of the desiccation and re-filling of the Mediterranean during the Messinian Salinity Crisis. Earth and Planetary Science Letters 240, 510-520. doi:10.1016/j.epsl.2005.09.029

Mendes, I., Alveirinho Dias, J.M., Schonfeld, J., Ferreira, J., 2012. Distribution of living benthic foraminifera on the northern Gulf of Cadiz continental shelf. The Journal of Foraminiferal research 42, 18-38. doi:10.2113/gsjfr42.1.18

Miller, K.G., Kominz, M.A., Browning, J. V, Wright, J.D., Mountain, G.S., Katz, M.E., Sugarman, P.J., Cramer, B.S., Pekar, S.F., 2005. The Phanerozoic Record of Global Sea-Level Change 310, $1293-1298$.

Muiños, S.B., Frank, M., Maden, C., Hein, J.R., van de Flierdt, T., Lebreiro, S.M., Gaspar, L., Monteiro, J.H., Halliday, a. N., 2008. New constraints on the Pb and Nd isotopic evolution of NE Atlantic water masses. Geochemistry Geophysics Geosystems 9, 1-18. doi:10.1029/2007GC001766

Ohneiser, C., Florindo, F., Stocchi, P., Roberts, A.P., DeConto, R.M., Pollard, D., 2015. Antarctic glacio-eustatic contributions to late Miocene Mediterranean desiccation and reflooding. Nature Communications 6, 8765. doi:10.1038/ncomms9765

Parra, M., Puechmaille, C., Carruesco, C., 1981. Strontium as a marker of the origin of biogenic and terrigenous materials and as a hydrodynamic tracer in the deep-sea North Atlantic area. Chemical Geology 34, 91-102.

Perconing, E., 1973. El Andaluciense, in: XII Coloquio Europeo de Micropaleontología. Empresa Nacional Adaro de Investigaciones Mineras, S.A., pp. 201-223.

Pérez-Asensio, J.N., Aguirre, J., Jiménez-Moreno, G., Schmiedl, G., Civis, J., 2013. Glacioeustatic control on the origin and cessation of the Messinian salinity crisis. Global and Planetary Change 111, 1-8. doi:10.1016/j.gloplacha.2013.08.008

Pérez-Asensio, J.N., Aguirre, J., Schmiedl, G., Civis, J., 2014. Messinian productivity changes in the northeastern Atlantic and their relationship to the closure of the Atlantic-Mediterranean gateway: implications for Neogene palaeoclimate and palaeoceanography. Journal of the Geological Society 171, 389-400. doi:10.1144/jgs2013-032

Pérez-Asensio, J.N., Aguirre, J., Schmiedl, G., Civis, J., 2012. Impact of restriction of the AtlanticMediterranean gateway on the Mediterranean Outflow Water and eastern Atlantic circulation during the Messinian. Paleoceanography 27, PA3222. doi:10.1029/2012PA002309

Pérez-Asensio, J.N., Aguirre, J., Schmiedl, G., Civis, J., 2012. Messinian paleoenvironmental evolution in the lower Guadalquivir Basin ( SW Spain ) based on benthic foraminifera. Palaeogeography, Palaeoclimatology, Palaeoecology 326-328, 135-151. doi:10.1016/j.palaeo.2012.02.014

Phipps, M., Jorissen, F.., Pusceddu, A., Bianchelli, S., de Stichter, H., 2012. Live benthic foraminiferal fauna along a bathymetrical transect $(282-4987 \mathrm{~m}$ ) on the Portuguese margin (NE Atlantic). Journal of Foraminiferal Research 42, 66-81. doi:doi: 10.2113/gsjfr.42.1.66 
Piepgras, D.J., Wasserburg, G.J., 1983. Neodymium in Waters of the North Atlantic 88, 5997-6006. Price, J.F., Baringer, M.O., Lueck, R.G., Johnson, G.C., Ambar, I., Parrilla, G., Cantos, A., Kennelly, M.A., Sanford, T.B., 1993. Mediterranean Outflow Mixing and Dynamics. Science (New York, N.Y.) 259, 1277-1282. doi:10.1126/science.259.5099.1277

Price, J.F., O’Neil Baringer, M., 1994. Outflows and deep water production by marginal seas. Progress in Oceanography 33, 161-200. doi:10.1016/0079-6611(94)90027-2

Raffi, I., Backman, J., Fornaciari, E., Pälike, H., Rio, D., Lourens, L., Hilgen, F., 2006. A review of calcareous nannofossil astrobiochronology encompassing the past 25 million years. Quaternary Science Reviews 25, 3113-3137. doi:10.1016/j.quascirev.2006.07.007

Raymo, M.E., Lisiecki, L.E., Nisancioglu, K.H., 2006. Plio-Pleistocene Ice Volume, Antarctic Climate, and the Global 8180 Record. Science 313, 492-495. doi:10.1126/science.aaa4019

Rebesco, M., Javier Hernández-Molina, F., Van Rooij, D., Wåhlin, A., 2014. Contourites and associated sediments controlled by deep-water circulation processes: State-of-the-art and future Considerations. Marine Geology 352, 111-154. doi:10.1016/j.margeo.2014.03.011

Reid, J.L., 1979. On the contribution of the Mediterranean Sea outflow to the NorwegianGreenland Sea. Deep Sea Research Part A, Oceanographic Research Papers 26, 1199-1223. doi:10.1016/0198-0149(79)90064-5

Riforgiato, F., 2013. Revision of the Messinian-Early Zanclean Sediments from ODP Hole $953 \mathrm{C}$ (Canary Island Archipelago, North-Eastern Atlantic): Biostratigraphy, Cyclostratigraphy, and Astronomical Tuning. Paleontology Journal 2013, 1-17. doi:10.1155/2013/947839

Robinson, S.A., Murphy, D.P., Vance, D., Thomas, D.J., 2010. Formation of "Southern Component Water" in the Late Cretaceous: Evidence from Nd-isotopes. Geology 38, 871-874. doi:10.1130/G31165.1

Rodríguez Fernández, J., 1982. El Mioceno del sector central de las Cordilleras Béticas. Universidad de Granada, Granada.

Rodríguez-Tovar, F.J., Dorador, J., Martin-Garcia, G.M., Sierro, F.J., Flores, J.A., Hodell, D.A., 2015. Response of macrobenthic and foraminifer communities to changes in deep-sea environmental conditions from Marine Isotope Stage (MIS) 12 to 11 at the "Shackleton Site." Global and Planetary Change 133, 176-187. doi:10.1016/j.gloplacha.2015.08.012

Rogerson, M., Bigg, G.R., Rohling, E.J., Ramírez, J., 2012a. Vertical density gradient in the eastern North Atlantic during the last 30,000 years. Climate Dynamics 39, 589-598. doi:10.1007/s00382-011-1148-4

Rogerson, M., Colmenero-Hidalgo, E., Levine, R.C., Rohling, E.J., Voelker, a. H.L., Bigg, G.R., Schönfeld, J., Cacho, I., Sierro, F.J., Löwemark, L., Reguera, M.I., de Abreu, L., Garrick, K., 2010. Enhanced Mediterranean-Atlantic exchange during Atlantic freshening phases. Geochemistry Geophysics Geosystems 11, 1-22. doi:10.1029/2009GC002931

Rogerson, M., Rohling, E.J., Bigg, G.R., Ramirez, J., 2012b. Paleoceanography of the AtlanticMediterranean exchange: Overview and first quantitative assessment of climatic forcing. Reviews of Geophysics 50, 1-32.

Rogerson, M., Rohling, E.J., Weaver, P.P.E., Murray, J.W., 2005. Glacial to interglacial changes in the settling depth of the Mediterranean Outflow plume. Paleoceanography 20, 1-12. doi:10.1029/2004PA001106

Roque, C., Duarte, H., Terrinha, P., Valadares, V., Noiva, J., Cachao, M., Ferreira, J., Legoinha, P., Zitellini, N., 2012. Pliocene and Quarternary depositional model of the Algarve margin 
contourite drifts (Gulf of Cadiz, SW Iberia): Seismic architecture, tectonic control and paleoceanographic insights. Marine Geology 303-306, 42-62.

Roveri, M., Flecker, R., Krijgsman, W., Lofi, J., Lugli, S., Manzi, V., Sierro, F.J., Bertini, A., Camerlenghi, A., De Lange, G., Govers, R., Hilgen, F.J., Hübscher, C., Meijer, P.T., Stoica, M., 2014. The Messinian Salinity Crisis: Past and future of a great challenge for marine sciences. Marine Geology 352, 25-58. doi:10.1016/j.margeo.2014.02.002

Roveri, M., Lugli, S., Manzi, V., Schreiber, B.C., 2008. The Messinian Sicilian stratigraphy revisited: new insights for the Messinian salinity crisis. Terra Nova 20, 483-488. doi:10.1111/j.13653121.2008.00842.x

Ruiz-Constán, A., Stich, D., Galindo-Zaldivar, J., Morales, J., 2009. Is the northwestern Betic Cordillera mountain front active in the context of the convergent Eurasia-Africa plate boundary? Terra Nova 21, 352-359. doi:10.1111/j.1365-3121.2009.00886.x

Ryan, W.B.., 1973. Geodynamic implications of the Messinian crisis of salinity, in: Messinian Events in the Mediterranean.

Salvany, J.M., Larrasoañañ, J.C., Mediavilla, C., Rebollo, A., 2011. Chronology and tectonosedimentary evolution of the Upper Pliocene to Quaternary deposits of the lower Guadalquivir foreland basin, SW Spain. Sedimentary Geology 241, 22-39. doi:10.1016/j.sedgeo.2011.09.009

Santisteban, C., Taberner, C., 1983. Shallow marine and continental conglomerates derived from coral reef complexes after desiccation of a deep marine basin : the Tortonian-Messinian deposits of the Fortuna Basin , SE Spain. Journal of the Geological Society of London 140, 401-411.

Schönfeld, J., 2002. Recent benthic foraminiferal assemblages in deep high-energy environments from the Gulf of Cadiz ( Spain ). Micropaleontology 44, 141-162.

Schönfeld, J., 1997. The impact of the Mediterranean Outflow Water (MOW) on benthic foraminiferal assemblages and surface sediments at the southern Portuguese continental margin. Marine Micropaleontology 29, 211-236. doi:10.1016/S0377-8398(96)00050-3

Seidenkrantz, M.-S., Kouwenhoven, T.., Jorissen, F.., Shackleton, N.., van der Zwaan, G.., 2000. Benthic foraminifera as indicators of changing Mediterranean-Atlantic water exchange in the late Miocene. Marine Geology 163, 387-407. doi:10.1016/So025-3227(99)o0116-4

Serrano Lozano, F., 1979. Los foraminíferos planctónicos del Mioceno superior de la cuenca de Ronda y su comparación con los de otras áreas de las Cordilleras Béticas. Universidad de Málaga.

Shackleton, N.J., Hall, M.A., Pate, D., 1995. Pliocene stable isotope stratigraphy of Site 846. Proceedings of the Intergrated Ocean Drilling Program 138, 337-355.

Sholkovitz, E., Szymczak, R., 2000. The estuarine chemistry of rare earth elements: Comparison of the Amazon, Fly, Sepik and the Gulf of Papua systems. Earth and Planetary Science Letters 179, 299-309. doi:10.1016/So012-821X(00)00112-6

Sierro, F.J., 1985. The replacement of the "Globorotalia merardii" group by the "Globorotalia Miotumida" group: an aid to recongnizing the Tortonian-Messinian boundary in the Mediterranean and adjecent Atlantic. Marine Micropaleontology 9, 525-535.

Sierro, F.J., Civis, J., González Delgado, J. a, 1982. Estudio de los Foraminíferos del Neogeno de Niebla (Huelva). Studia Geologica Salmanticensia 17, 67-87.

Sierro, F.J., Flores, J.A., Civis, J., González Delgado, J.A., Francés, G., 1993. Late Miocene 
globorotaliid event-stratigraphy and biogeography in the NE-Atlantic and Mediterranean. Marine Micropaleontology 21, 143-168.

Sierro, F.J., González Delgado, J.A., Dabio, C.J., Flores, J.A., Civis, J., 1996. S4 Late Neogene depositional sequences in the foreland basin of GuadaJquivir (SW Spain), in: Friend, P.F., Dabrio, C.J. (Eds.), Tertiary Basins of Spain: The Stratigraphic Record of Crustal Kinematics. pp. 339-345.

Sierro, F.J., Hilgen, F.J., Krijgsman, W., Flores, J.A., 2001. The Abad composite (SE Spain): a Messinian reference section for the Mediterranean and the APTS. Palaeogeography, Palaeoclimatology, Palaeoecology 168, 141-169.

Sierro, F.J., Hodell, D. a., Curtis, J.H., Flores, J. a., Reguera, I., Colmenero-Hidalgo, E., Bárcena, M. a., Grimalt, J.O., Cacho, I., Frigola, J., Canals, M., 2005. Impact of iceberg melting on Mediterranean thermohaline circulation during Heinrich events. Paleoceanography 20, n/an/a. doi:10.1029/2004PA001051

Sierro, F.J., Ledesma, S., Flores, J., Torrescusa, S., Olmo, M., 2000. Sonic and gamma-ray astrochronology: Cycle to cycle calibration of Atlantic climatic records to Mediterranean sapropels and astronomical oscillations. Geology 28, 695-698. doi:10.1130/0091$7613(2000) 28<695$

Simon, D., Meijer, P., 2015. Dimensions of the Atlantic-Mediterranean connection that caused the Messinian Salinity Crisis. Marine Geology. doi:10.1016/j.margeo.2015.02.004

Soria, J.M., Fernández, J., Viseras, C., 1999. Late Miocene stratigraphy and palaeogeographic evolution of the intramontane Guadix Basin (Central Betic Cordillera, Spain): Implications for an Atlantic-Mediterranean connection. Palaeogeography, Palaeoclimatology, Palaeoecology 151, 255-266. doi:10.1016/S0031-0182(99)00019-X

Spivack, A.J., Wasserburg, G., 1988. Neodymium isotopic composition of the Mediterranean outflow and the eastern North Atlantic * 4579.

Stow, D.A.V., Hernández-Molina, F.J., Alvarez Zarikian, C.A., Scientists, the E. 339, 2013. Proceedings IODP 339, Intergrated Ocean Drilling Program Management International. Tokyo. doi:doi:10.2204/iodp.proc.339.2013

Stow, D.A.V., Hernández-Molina, F.J., Hodell, D., Alvarez Zarikian, C.A., 2011. Mediterranean Outflow: environmental significance of the Mediterranean Outflow Water and its global implications. IODP Scientific Prospectus 339. doi:10.2204/iodp.sp.339.2011

Tachikawa, K., Jeandel, C., Roy-Barman, M., 1999. A new approach to the Nd residence time in the ocean: The role of atmospheric inputs. Earth and Planetary Science Letters 170, 433-446. doi:10.1016/So012-821X(99)00127-2

Tachikawa, K., Roy-Barman, M., Michard, a., Thouron, D., Yeghicheyan, D., Jeandel, C., 2004. Neodymium isotopes in the Mediterranean Sea: comparison between seawater and sediment signals. Geochimica et Cosmochimica Acta 68, 3095-3106. doi:10.1016/j.gca.2004.01.024

Thomas, D.J., Bralower, T.J., Jones, C.E., 2003. Neodymium isotopic reconstruction of late Paleocene-early Eocene thermohaline circulation. Earth and Planetary Science Letters 209, 309-322. doi:10.1016/S0012-821X(03)00096-7

Thomson, J., Schonfeld, J., Zahn, R., Grootes, P., Nixon, S., Summerhayes, C.P., 1999. Implications for sedimentation changes on the Iberian margin over the last two glacial/interglacial transitions from (230Th(excess))o systematics. Earth and Planetary Science Letters 165, 255- 
270. doi:10.1016/So012-821X(98)00265-9

Thunnel, R., Locke, S., Williams, D., 1988. Glacio-eustatic sea-level control on Red Sea salinity. Nature 334, 601-604. doi:10.1038/334601ao

Tjallingii, R., Röhl, U., Kölling, M., Bickert, T., 2007. Influence of the water content on X-ray fluorescence core-scanning measurements in soft marine sediments. Geochemistry, Geophysics, Geosystems 8, n/a-n/a. doi:10.1029/2006GC001393

Toucanne, S., Angue Minto'o, C.M., Fontanier, C., Bassetti, M.A., Jorry, S.J., Jouet, G., 2015. Tracking rainfall in the northern Mediterranean borderlands during sapropel deposition. Quaternary Science Reviews 129, 178-195. doi:10.1016/j.quascirev.2015.10.016

van Assen, E., Kuiper, K.F., Barhoun, N., Krijgsman, W., Sierro, F.J., 2006. Messinian astrochronology of the Melilla Basin: Stepwise restriction of the Mediterranean-Atlantic connection through Morocco. Palaeogeography, Palaeoclimatology, Palaeoecology 238, 1531. doi:10.1016/j.palaeo.2006.03.014

Van Couvering, J., Castradori, D., Cita, M.B., Hilgen, F.J., Domenico, R., 2000. The base of the Zanclean Stage and of the Pliocene Series. Episodes 23, 179-187.

Van den Berg, B.C.J., Sierro, F.J., Hilgen, F.J., Flecker, R., Larrasoaña, J.C., Krijgsman, W., Flores, J. a., Mata, M.P., Bellido Martín, E., Civis, J., González-Delgado, J. a., 2015. Astronomical tuning for the upper Messinian Spanish Atlantic margin: Disentangling basin evolution, climate cyclicity and MOW. Global and Planetary Change 135, 89-103. doi:10.1016/j.gloplacha.2015.10.009

van den Berg, B.C.J., Sierro, F.J., Hilgen, F.J., Flecker, R., Larrasoaña, J.C., Krijgsman, W., Flores, J.A., Mata, M.P., Bellido Martín, E., Civis, J., González-Delgado, J.A., 2015. Astronomical tuning for the upper Messinian Spanish Atlantic margin: Disentangling basin evolution, climate cyclicity and MOW. Global and Planetary Change 135, 89-103. doi:10.1016/j.gloplacha.2015.10.009

Van der Laan, E., Gaboardi, S., Hilgen, F.J., Lourens, L.J., 2005. Regional climate and glacial control on high-resolution oxygen isotope records from Ain el Beida (latest Miocene, northwest Morocco): A cyclostratigraphic analysis in the depth and time domain. Paleoceanography 20, 1-22. doi:10.1029/2003PA000995

Van der Laan, E., Hilgen, F.J., Lourens, L.J., de Kaenel, E., Gaboardi, S., laccarino, S., 2012. Astronomical forcing of Northwest African climate and glacial history during the late Messinian (6.5-5.5Ma). Palaeogeography, Palaeoclimatology, Palaeoecology 313-314, 107126. doi:10.1016/j.palaeo.2011.10.013

Van der Laan, E., Snel, E., de Kaenel, E., Hilgen, F.J., Krijgsman, W., 2006. No major deglaciation across the Miocene-Pliocene boundary: Integrated stratigraphy and astronomical tuning of the Loulja sections (Bou Regreg area, NW Morocco). Paleoceanography 21, 1-27. doi:10.1029/2005PA001193

Van der Schee, M., Sierro, F.J., Jiménez-Espejo, F.J., Hernández-Molina, F.J., Flecker, R., Flores, J.A., Acton, G., Gutjahr, M., Grunert, P., García-Gallardo, Á., Andersen, N., 2016. Evidence of early bottom water current flow after the Messinian Salinity Crisis in the Gulf of Cadiz. Marine Geology in press.

Van Morkhoven, F.P., Berggren, W.A., Edwards, A.S., Oertli, H.J., 1986. Cenozoic cosmopolitan deep-water benthic foraminifera. Bulletin des Centres de Recherches ExplorationProduction Elf-Aquitaine: Memorie 11, 68-70. 
Voelker, A., Lebreiro, S., Schonfeld, J., Cacho, I., Erlenkeuser, H., Abrantes, F., 2006. Mediterranean outflow strengthening during northern hemisphere coolings: A salt source for the glacial Atlantic? Earth and Planetary Science Letters 245, 39-55. doi:10.1016/j.epsl.2006.03.014

Voelker, A.H.L., Colman, A., Olack, G., Waniek, J.J., Hodell, D., 2015a. Oxygen and hydrogen isotope signatures of Northeast Atlantic water masses. Deep Sea Research Part II: Topical Studies in Oceanography 116, 89-106. doi:10.1016/j.dsr2.2014.11.006

Voelker, A.H.L., Rodrigues, T., Billups, K., Oppo, D., McManus, J., Stein, R., Hefter, J., Grimalt, J.O., 2010. Variations in mid-latitude North Atlantic surface water properties during the midBrunhes (MIS 9-14) and their implications for the thermohaline circulation. Climate of the Past 6, 531-552. doi:10.5194/cp-6-531-2010

Voelker, A.H.L., Salgueiro, E., Rodrigues, T., Jimenez-Espejo, F.J., Bahr, A., Alberto, A., Loureiro, I., Padilha, M., Rebotim, A., Röhl, U., 2015b. Mediterranean Outflow and surface water variability off southern Portugal during the early Pleistocene: A snapshot at Marine Isotope Stages 29 to $34(1020-1135 \mathrm{ka})$. Global and Planetary Change 133, 223-237. doi:10.1016/j.gloplacha.2015.08.015

Wehausen, R., Brumsack, H.J., 2000. Chemical cycles in Pliocene sapropel-bearing and sapropelbarren eastern Mediterranean sediments. Palaeogeography, Palaeoclimatology, Palaeoecology 158, 325-352. doi:10.1016/S0031-0182(00)00057-2

Young, J.R., Flores, J.A., Wei, W., 1994. A summary chart of Neogene Nannofossil magnetobiostratigraphy. Journal of nannoplankton research 16, 21-27. 


\section{Resumen}

La conexión marina entre el océano Atlántico y el mar Mediterráneo tiene un rol importante en los patrones de flujo de circulación oceánica. Sin embargo, durante el Mioceno más tardío, este intercambio de aguas Atlántico-Mediterráneas estuvo restringido o incluso ausente, conllevando a la precipitación de capas extensas de evaporitas en el Mediterráneo durante un evento conocido como la Crisis de Salinidad del Mesiniense (MSC; 5.33-5.97 Ma). El restablecimiento de la salida de masas de aguas Mediterráneas (conocidas en inglés como Mediterranean Outflow Water-MOW), ocurrió durante la transición Mio-Pliocena, cuando masas de aguas con características similares a las modernas fluyeron a través del Estrecho de Gibraltar hacía el Atlántico. Esta tesis doctoral está enfocada en estudiar el inicio y desarrollo de la masa de agua MOW en el Golfo de Cádiz.

Inicialmente, se construyó un modelo de edad combinando bio-, magneto-, y ciclo-estratigrafía para los sedimentos del sondeo U1387C, perforados sobre el talud superior ( $559 \mathrm{~m}$ ) en el Golfo de Cádiz, en el marco de la campaña 339 del programa Integrated Ocean Drilling Program (IODP). En este sondeo, el límite Mioceno-Plioceno está asociado con un cambio litológico abrupto, que se relaciona con cambios drásticos en los ambientes de depositación. Las secuencias hemipelágicas del Mioceno (i.e., Mesiniense más tardío) están formadas por ciclos sedimentarios de carbonato, originados por forzamiento orbitales. Las capas con mayores concentraciones de la fracción detrítica, dominada por silicatos, se depositaron durante periodos áridos de insolación mínima del Hemisferio Norte. Patrones sedimentarios similares han sido descritos para sedimentos más proximales recuperados en el sondeo Montemayor-1 en la cuenca del Guadalquivir; evidenciando que estos ciclos sedimentarios se formaron debido a variaciones en el aporte de material terrígeno hacía la cuenca. Durante las fases húmedas en los periodos de máxima insolación, la cobertera vegetal se extiende causando una reducción en el cantidad de material terrígeno disponible. En contraste, por encima del límite Mio-Plioceno, se encuentran dos niveles contorniticos bigradacionales de areniscas y además se observa un incremento abrupto en los valores de Zr/Al. Estos patrones sedimentarios se han relacionado con procesos de selección y sorteamiento del sedimento, y se han interpretado como evidencia directa de una corriente de fondo saliente, que habría iniciado en la transición del Mio-Plioceno o a la base del Plioceno.

Las semejanzas entre las variaciones de los registros sedimentarios y de los isótopos bentónicos $\left(\delta^{18} \mathrm{O}\right.$ y $\left.\delta^{13} \mathrm{C}\right)$ indican que las intensificaciones de las corrientes de fondo asociadas con el forzamiento orbital son probablemente resultado de procesos del Mediterráneo. Durante estos intervalos, la expresión isotópica del sondeo U1387C es similar a la de los registros de foraminíferos bentónicos del Mediterráneo, indicando la presencia de aguas bien oxigenadas y posiblemente más calientes. En contraste, cuando las corrientes de fondo se debilitan, o incluso son ausentes, hay un aumento en el contenido de aluminosilicatos en la fracción fina (>63 $\mu \mathrm{m}$ ), y los registros isotópicos difieren entre si. Durante estos intervalos, las corrientes de fondo que atraviesan la zona del sondeo serían más frías y poco ventiladas, y probablemente tendrían una mayor influencia de las corrientes de fondo del Atlántico. Mientras que las masas de aguas superficiales, reconstruidas a partir de los registros isotópicos planctónicos de $\delta^{18} \mathrm{O}$ y de las abundancias 
relativas de Globigerinoides, revelan cambios rápidos e isócronos pero opuestos en la temperatura. Es decir, cuando las masas de agua del fondo se enfrían, en superficie ocurre un calentamiento y viceversa. Este comportamiento opuesto se puede atribuir a la presencia de una circulación estuarina en el Mediterráneo, la cual se desarrolla cuando el balance hídrico de la cuenca es positivo o cuando hay la pluma de salida de la MOW se desplaza verticalmente hacía áreas más someras. Sin embargo, este desplazamiento vertical no explicaría los cambios rápidos e isócronos de la temperatura.

El origen de las masas de aguas profundas en el Golfo de Cádiz se estudió a través del uso de isotopos autigénicos de Neodimio ( $\mathrm{Nd}$ ) y Plomo ( $\mathrm{Pb}$ ). Las relaciones composicionales entre HierroManganeso (Fe-Mn) recuperadas en lixiviados de oxihidróxidos del sondeo $\mathrm{U}_{1387 \mathrm{C}}$, se compararon con los composiciones presentes en tres cortezas de Fe-Mn formadas a diferentes profundidades en el Noreste Atlántico (Abouchami et al., 1999; Muiños et al., 2008) y con lixiviados del Mar del Alborán (Mediterráneo Occidental), con el ánimo de definir las composiciones de MOW y de las aguas del NE Atlántico durante el Mio-Plioceno. La huella de los isotopos de Nd del sondeo $\mathrm{U} 1387 \mathrm{C}$ no se corresponde con ninguna señal isotópica, por lo que se considera que el registro de $\mathrm{Nd}$ esta controlado principalmente por procesos locales. Las relacione isotópicas del $\mathrm{Pb}$ son incompatibles con las señales de las cortezas de Fe-Mn del NE Atlántico, las cuales se basan en interpretaciones del isotopo estable más tradicional $\left(\delta^{13} \mathrm{C}, \delta^{18} \mathrm{O}\right)$. No obstante, los lixiviados de sedimentos del Mar de Alboran registran confiablemente las composiciones isotópicas de $\mathrm{Pb}$ de MOW, por tanto la composición de los lixiviados concuerdan con las interpretaciones del isotopo estable. Aunque el efecto de meteorización preferencial en el registro isotópico de $\mathrm{Pb}$ no puede ser excluido, estos resultados implican que la señal isotópica de Pb recuperada a partir de lixiviados de oxihidróxidos pueder ser potencialmente utilizada para rasterar masas de agua de fondo en ambientes marginales del Golfo de Cádiz.

Antes de la MSC, dos conexiones marinas conectaban el Atlántico y el Mediterráneo. El corredor Bético en el sur de España y el corredor Rifeño en el noroeste de Marruecos. Estos dos corredores se cerraron hacía el Mioceno tardío; sin embargo, aún se desconoce la fecha de exacta de cierre de estas conexiones. Hacía al margen occidental de las cordilleras Béticas, se preservan varias cuencas con sedimentos depositados durante el Mioceno tardío, incluyendo la cuenca de Ronda, Antequera y Arcos de la Frontera. Todas estas áreas potencialmente pueden ayudar a precisar la edad de cierre del corredor Bético, ya que son próximas al corredor Guadalhorce, el cual se considera fue la ultima extensión abierta de la corredor Bético. Las secuencias sedimentarias en estas cuencas están caracterizadas por un transición de margas arenosas de ambientes profundos a calcarenitas y calizas de ambientes someros. Diferentes análisis bioestratigráficos realizados en las margas infrayacentes indican que los sedimentos se acumularon antes de 7.58 Ma. Debido a la naturaleza de las calcarenitas y las calizas suprayacentes, no se pudo establecer ninguna datación bioestratigráfica confiable para estos niveles. No obstante, dadas las altas tasas de sedimentación típicas de estos depósitos es improbable que estos niveles someros sean significativamente más jóvenes que las capas de margas inferiores. En consecuencia, estos resultados implican que el corredor Guadalhorce probablemente se cerró durante el Tortoniense tardío o Mesiniense 
temprano. Adicionalmente, dadas las similitudes litológicas y en edades, es posible que la progresiva somerización de las secuencias del margen occidental del corredor Bético (cuencas de Ronda, Antequera y Arcos de la Frontera) corresponda con el mismo pulso tectónico que generó el cierre del margen oriental del corredor. 


\section{Conclusiones}

A través de esta tesis se demuestra que la configuración de las conexiones marinas influencia tanto los patrones de circulación oceánica como los procesos de sedimentación. Adicionalmente, se evidencia que los cambios en la precipitación y la descarga fluvial en el área del Mediterráneo juegan un papel fundamental en el intercambio de aguas Atlántico-Mediterráneas, dado que afectan la velocidad de las corrientes y el volumen de la masa de agua saliente del Mediterráneo. Durante la Crisis de Salinidad del Mesiniense (MSC; 5.33-5.97 Ma), la conexión entre el AtlánticoMediterráneo se redujo progresivamente. En el Mediterráneo, el límite Mio-Plioceno coincide con el fin de esta crisis, y corresponde con el paso de evaporitas del Mesiniense a margas del Zancliense. Esta transición indica el restablecimiento de condiciones marinas normales y de la conexión Atlántico-Mediterránea. Fuera del Mediterráneo, en el margen Atlántico a lo largo del Golfo de Cádiz, este cambio en la configuración de las conexiones marinas inmediatamente dejó una huella en la secuencia sedimentaria del sondeo U1387C de IODP.

\section{Marco estratigráfico}

De base a techo, el intervalo estudiado está localizado por encima de la primera ocurrencia de Globorotalia margaritae y por debajo de la primera ocurrencia de Globorotalia puncticulata (Expedition Scientists, 2012). Estos bioeventos indican una edad estimada entre 4.52 y $6.08 \mathrm{Ma}$ (Lourens et al., 2004). A través de la correlación de perfiles sísmicos que integran los sondeos Algarve-2 y U1387C, Hernández-Molina et al., (2016) han estimado que el límite Mio-Plioceno esta localizado a $826 \mathrm{~m}$ de profundidad, correspondiendo con un cambio sedimentario abrupto. El intervalo de altas abundancias de G. margaritae no se encontró en los sedimentos del sondeo U1387C, indicando que la base del sondeo es más joven de 5.70 Ma. Esta edad concuerda con la predominancia de Neoglobquadrina acostaensis dextralmente enrolladas, las cuales sugieren una máxima edad de $\sim 5.82 \mathrm{Ma}$ (Sierro et al, 2001; Krijgsman et al., 2004).

Las patrones alternantes presentes en el registro bentónico de $\delta^{18} \mathrm{O}$ son interpretadas como ciclicidades sedimentarias controladas por el forzamiento orbital (e.g., precesión, oblicuidad y excentricidad). La extrapolación de la longitud de onda promedio sobre las áreas sin recobro permitió estimar tiempos y tasas de sedimentación promedios. Si el límite Mio-Plioceno se encuentra a 826 mbsf, la base del sondeo tiene una edad estimada de $5.7 \mathrm{Ma}$, y la parte superior del intervalo estudiado tendría 5.0 Ma. Estos tres puntos de amarre concuerdan con la localización del Chron C3n.4n. (4.997-5.235 Ma; Lourens et al., 2004) y con el pico de abundancia de Neogloboquadrina acostaensis sinestralmente enrollada localizado tres ciclos de precesión por encima del límite Mio-Plioceno (laccarino et al., 1999b; Lourens et al., 1996).

\section{Inicio de la salida de aguas Mediterráneas (MOW)}

Los sedimentos del Mesiniense se depositaron en un ambiente de baja energía, en el cual la relación entre $\mathrm{Zr}$ y Al carece de una expresión clara. Inmediatamente por encima de la límite Mio- 
Plioceno, la relación $\mathrm{Zr} / \mathrm{Al}$ muestra variaciones de lata amplitud y por encima del tercer ciclo de precesión, dos niveles de areniscas contorníticas de grano gruesos muestran trazas de bioturbación isócrona con los picos de $\mathrm{Zr} / \mathrm{Al}$. Ambas características sugieren que una corriente débil que circulaba a lo largo de la plataforma, se formó bien durante el límite Mio-Plioceno o justo por encima de este nivel. La correlación entre registros isotópicos bentónicos de $\delta^{13} \mathrm{C}$ y $\delta^{18} \mathrm{O}$ con registros sedimentarios del Mediterráneo y el noreste Atlántico, permite concluir que el flujo observado es de origen mediterráneo. Por tanto, este registro se constituye en la evidencia más antigua de las masas de agua salientes del Mediterráneo (Mediterranean Outflow Water-MOW), fuera del Mediterráneo y después de la MSC.

\section{Ambientes de depositación}

Los sedimentos del Mioceno tardío del sondeo U1387C muestran ciclos de carbonato, formados por variaciones en la cantidad y composición del aporte de detritos siliciclásticos que llegan al Golfo de Cádiz. Mayores cantidades de siliciclásticos ocurren durante los periodos de máxima insolación de verano del Hemisferio Norte. Las fluctuaciones composicionales de la fracción siliciclástica son probablemente inducidas por cambios en los patrones de precipitación de la península Ibérica, los cuales controlan la extensión de la cobertera vegetal y las tasas de erosión. No se encontró evidencias que indiquen la presencia de masas de agua de fondo durante el Mesiniense.

La tasa de sedimentación se triplica por encima del límite Mio-Plioceno. La ocurrencia esporádica de muestras con foraminíferos bentónicos provenientes de la plataforma sugiere la presencia temporal de flujos de transporte de sedimentos hacía la cuenca. Aunque se observaron capas de areniscas centimétricas, en la mayoría de los casos, estas capas fueron destruidas por la acción combinada de la bioturbación por comunidades de macrobentos y las corrientes de fondo. El efecto conjunto de un levantamiento tectónico y de la aparición de corrientes a lo largo de la talud puede haber proporcionado aporte sedimentario provenientes de la cuenca hidrográfica del Guadalquivir, explicando las tasas de sedimentación triples presentes por encima del límite Mioceno-Plioceno. El registro de XRF no revela alteraciones regulares en el contenido de carbonato, no obstante los patrones cíclicos se evidencian dentro de la componente siliciclástica debidos a un flujo de corriente débil.

\section{Circulación de masas de aguas en el Golfo de Cádiz}

Tanto el registro sedimentario como los diferentes indicadores utilizados no muestran evidencia de la presencia de MOW para el Mioceno tardío, coincidiendo con estudios previamente publicados. En consecuencia, aguas Atlánticas principalmente influenciaron los procesos sedimentarios a lo largo del Golfo de Cádiz. Un ligero decrecimiento en los valores isotópicos de $\delta^{13} \mathrm{C}$ tomados en foraminíferos bentónicos sugiere la presencia de aguas Atlánticas intermedias poco ventiladas. No obstante, en comparación con registros cercanos, el sonde U1387C muestra 
una mayor variabilidad en las amplitudes del isotopos de $\delta^{18} \mathrm{O}$, lo que podría interpretarse como una señal de MOW durante el Mesiniense.

Durante el Plioceno, los valores de los isotopos estables se ajustan perfectamente a los patrones de los ciclos sedimentarios, indicando una fuerte relación con las corrientes de fondo. Los resultados presentados en esta tesis, indican que en algunos periodos las corrientes fluyendo a lo largo del talud se ralentizaron o estuvieron ausentes, lo cual sugiere que MOW estuvo interrumpida en múltiples ocasiones debido a la influencia de aguas profundas Atlánticas, probablemente, más frías y menos ventiladas. En los periodos donde se registran aguas frías Atlánticas, también se encuentran cambios rápidos e isócronos en las asociaciones cálidas de foraminíferos plantónicos, indicando la presencia de aguas de superficie más cálidas. Este comportamiento opuesto puede ser explicado a través de un cambio en el balance hídrico del Mediterráneo, pasando de valores negativos a positivos. Esta variación daría lugar a la entrada de aguas profundas frías del Atlántico en el Mediterráneo a través del Estrecho de Gibraltar, con aguas de MOW fluyendo en superficie. Seguidamente, bien habría un calentamiento de las aguas profundas sincrónico con un enfriamiento de las aguas superficiales, o bien habría un enfriamiento rápido de las aguas superficiales y así, tanto aguas profundas como de superficie registrarían condiciones más frías. En este último caso, el calentamiento de las aguas profundas antecedería el calentamiento en superficie. Estos diferentes escenarios pueden ser explicados por el intercambio directo entre aguas Atlántico-Mediterráneas y la cantidad de agua que prevalece en el Golfo de Cádiz. Alternativamente, los isotopos estables y la asociación micropaleontológica podrían ser parcialmente explicados por una somerización pronunciada en la profundidad de establecimiento de la MOW dentro del Atlántico.

\section{Controles sobre los isotopos autigénicos de $\mathrm{Nd}$ y $\mathrm{Pb}$}

Los isótopos de $\mathrm{Nd}$ y $\mathrm{Pb}$ responden a cambios en la configuración oceanográfica y/o sedimentaria en el Golfo de Cádiz durante el límite Mioceno-Plioceno. Las composiciones isotópicas de Nd en los lixiviados de oxihidróxido fue más radiogénica que los valores de referencia previstos para MOW y para el NE Atlántico. En consecuencia, se considera que los valores isotópicos de Nd registran una señal más local. El comportamiento paralelo de XRF Canorm, un indicador del aporte de detritos, sugiere que la composición isotópica tiene una influencia dominante de elementos de tierras raras proveniente de sedimentos fluviales en suspensión. Las relaciones isotópicas encontradas entre las especies de $\mathrm{Pb}$ parecen tener una relación directa con el origen de la masa de agua. Sin embargo, debido a la falta de datos compatibles para el Mediterráneo o Atlántico, no fue posible correlacionar las señales isotópicas de $\mathrm{Pb}$ con un origen particular.

\section{Futuras investigaciones y preguntas abiertas}

Este estudio esta enmarcado dentro de la propuesta de perforación de sedimentos del International Continental Scientific Drilling Program titulada "Investigating Miocene MediterraneanAtlantic Gateway Exchange” (IMAGE), a través de la cual se planteó estudiar diferentes secuencias 
sedimentarias offshore del margen portugués y del Golfo de Cádiz, y en tierra en las cuencas del Guadalquivir y del corredor Rifeño. El principal objetivo de este proyecto, en combinación con la propuesta IODP “Deep-Sea Record of Mediterranean Messinian Events" (DREAM), es investigar la evolución del intercambio de aguas Atlántico-Mediterráneas durante el Mioceno tardío y el Plioceno temprano, y su relación con las fases de la Crisis de Salinidad del Mesiniense.

Nuevos estudios y evidencias adicionales deben encontrarse para comprobar la existencia de periodos de circulación estuarina en el Mediterráneo. Se necesita un registro sedimentario continuo de alta resolución dentro del Mediterráneo (e.g., La sección Capo Rosello en Sicilia), que incluya isótopos planctónicos y bentónicos estables, para evaluar la evolución del balance hídrico dentro del Mediterráneo. Este tipo de registros, además, podrían ser usados para definir mejor las condiciones base en los modelos globales de circulación oceánica que se enfocan en el en estudiar la evolución del Mediterráneo durante el Mio-Plioceno (e.g. Marzocchi et al., 2016).

Para confirmar si las relaciones isotópicas de $\mathrm{Pb}$ se pueden usar como marcadores de aguas profundas en el Goldo de Cadiz, es necesario establecer las composiciones isotópicas en lixiviados de oxyhidróxido de Fe-Mn autigénicos provenientes de sedimentos profundos Mio-Pliocenos del NE Atlántico. El sondeo ODP-982 es un buen candidato para establecer los valores isotópicos de referencia para el Atlántico, debido a su localización sobre la trayectoria de flujo de las aguas profunda del NE Atlántico y a su robusto modelo de edad.

En el Capítulo 4 se sugiere el cierre del Corredor Bético mucho antes del inicio de la Crisis de Salinidad del Mesiniense. Sin embargo, la precipitación de extensas capas de evaporitas prueba la existencia de una conexión entre el Mediterráneo y el océano abierto. Lo cual permite plantear la siguiente interrogante: Sí los corredores Bético y Rifeño se cerraron mucho antes de la Crisis de Salinidad, entonces ¿Por dónde se estableció la conexión durante la Crisis? Dado que no hay evidencias científicas que soporten que el Estrecho de Gibraltar estuvo cerrado durante el Mioceno, me gustaría concluir esta tesis especulando libremente sobre la posibilidad de que el Estrecho de Gibraltar haya estado abierto antes del Plioceno. 


\section{Apendices.}

I. Objectives MEDGATE

II. Evolution of the Gulf of Cadiz Margin and southwest Portugal contourite depositional system: Tectonic, sedimentary and paleoceanographic implications from IODP Expedition 339.

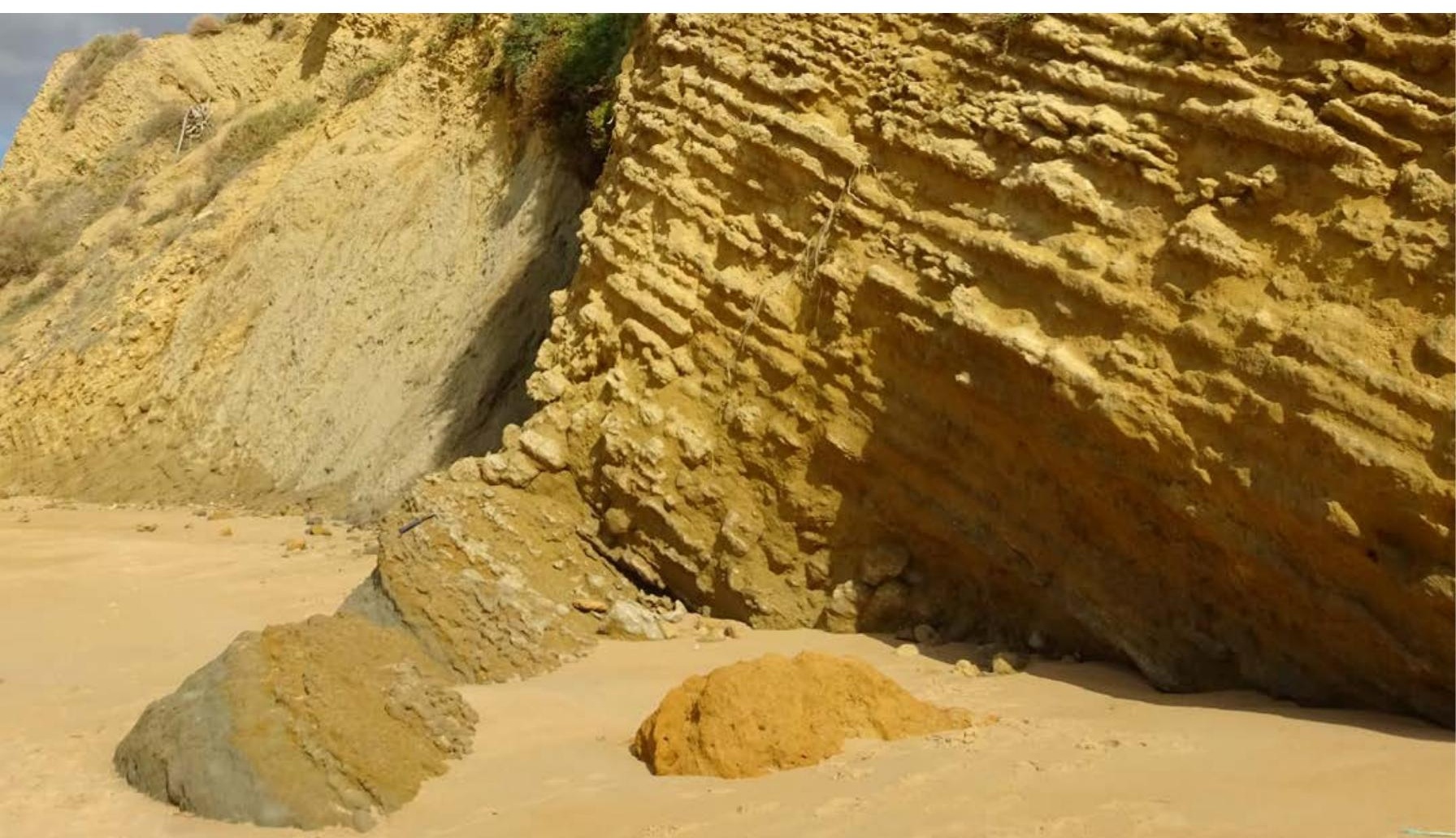




\section{Objectives of MEDGATE}

This PhD project was part of the International Training Network "Mediterranean Gateways" (MEDGATE), funded by Marie Curie Actions of the European Union. MEDGATE combined the expertise of 29 multidisciplinary geoscientists from oil industry and academia in six European countries and Morocco. Nine PhD students at four host-institution and one Post-Doc were trained for careers in either academia or industry. Individual projects were centered on the evolution of the marine corridors that linked the Mediterranean and Atlantic in the late Miocene. Each project used a different methodology to clarify the environmental impact of gateway exchange by approaching the scientific objectives from different angles. The PhD-students worked in four work package groups, including Geochemistry, Biostratigraphy, Paleogeography and Modelling. The groups organized training events, what gave a unique insight in their work to the other MEDGATE participants and provided the necessary knowledge to integrate the state-of-the-art technologies. Complimentary trainings, such as 'Train the trainer', 'Communicating science to the public' and a camera training were also delivered during these Network events. Acquired soft skills and scientific knowledge were used during the organization of the "RCMNS Interim Colloquium Mediterranean-Atlantic Gateways", which was held in collaboration with IODP Expedition 339 Scientists. The scientific sessions were structured and convened by the MEDGATE-students.

The training resulted in a common language for interdisciplinary debates between the ten MEDGATE researchers. New data was broadly discussed over the different fields of the four work packages and conceptual models were questioned early on with all participants. The fieldwork based Chapter 4 in this thesis is a good example of collaborations within MEDGATE, in which structural geological skills are combined with the biostratigraphic sample campaign. A conceptual modeler assisted in the field, immediately allowing discussions on water mass exchange through a possible gateway. All MEDGATE participants collaborated in a peer-reviewed publication in EarthScience Reviews. 


\title{
Evolution of the gulf of Cadiz margin and southwest Portugal contourite depositional system: Tectonic, sedimentary and paleoceanographic implications from IODP expedition 339
}

\author{
F.J. Hernández-Molina ${ }^{\text {a,* }}$, F.J. Sierro ${ }^{\text {b }}$, E. Llave $^{\text {c }}$, C. Roque ${ }^{\text {d }}$, D.A.V. Stow ${ }^{\text {e }}$, T. Williams ${ }^{\text {f }}$, J. Lofi ${ }^{g}$,
} M. Van der Schee ${ }^{\mathrm{b}}$, A. Arnáiz ${ }^{\mathrm{h}}$, S. Ledesma ${ }^{\mathrm{i}}, \mathrm{C}$. Rosales ${ }^{\mathrm{h}}$, F.J. Rodríguez-Tovar ${ }^{\mathrm{j}}$, E. Pardo-Igúzquiza ${ }^{c}$, R.E. Brackenridge ${ }^{\mathrm{k}}$

a Dept. Earth Sciences, Royal Holloway Univ. London, Egham, Surrey TW20 OEX, UK

b Dpto. de Geología, Univ. de Salamanca, Calle de los Caídos, 37008 Salamanca, Spain

Instituto Geológico y Minero de España (IGME), Ríos Rosas, 23, 28003 Madrid, Spain

d Instituto Dom Luiz-IDL, Lisboa, Portugal

e IPE, Heriot-Watt Univ., Edinburgh EH14 4AS, Scotland, UK

${ }^{\mathrm{f}}$ Lamont-Doherty Earth Observatory, Palisades, NY 10964, USA

${ }^{g}$ Géosciences Montpellier UMR 5243CC 060 - Bat. 22 Université de Montpellier 2 Place E. Bataillon, 34095 Montpellier Cedex 05, France

${ }^{\mathrm{h}}$ REPSOL, Méndez Álvaro 44, Edif. Azul 2 ${ }^{\mathfrak{a}}$ Planta, 28045 Madrid, Spain

' Gas Natural Fenosa, Avenida San Luis 77, 28033 Madrid, Spain

${ }^{j}$ Dpto. de Estratigrafía y Paleontología, Univ. Granada, 18002 Granada, Spain

${ }^{\mathrm{k}}$ Shell International Exploration \& Production B.V., Carel van Bylandtlaan 05.0B.03, 2596 HR The Hague, Netherlands

\section{A R T I C L E I N F O}

\section{Article history:}

Received 2 April 2015

Received in revised form 8 September 2015

Accepted 27 September 2015

Available online 9 October 2015

\section{Keywords:}

Neogene basins

IODP expedition 339

Contourites

Stratigraphy

Tectonic

Mediterranean outflow water

\begin{abstract}
A B S T R A C T
The contourite depositional system (CDS) along the southwestern Iberian Margin (SIM), within the Gulf of Cadiz and offshore areas of western Portugal bear the unmistakable signal of Mediterranean Outflow Water (MOW) exiting the Strait of Gibraltar. This locality records key information concerning the effects of tectonic activity on margin sedimentation, the effects of MOW dynamics on Atlantic circulation, and how these factors may have influenced global climate. Over the last four decades, numerous studies have been conducted on the late Miocene, Pliocene and Quaternary sedimentary stacking pattern of Neogene basins along the SIM for both academic and resources exploration purposes. However, understanding of the region rests primarily on basic seismic stratigraphy calibrated with limited data from only a few exploration wells. The Integrated Ocean Drilling Program (IODP) Expedition 339 recently drilled five sites in the Gulf of Cadiz and two sites on the western Iberian margin. The integration of core and borehole data with other geophysical databases leads us to propose a new stratigraphic framework. Interpretation of IODP Exp. 339 data along with that from industry sources and onshore outcrop analysis helps refine our understanding of the SIM's sedimentary evolution.

We identify significant changes in sedimentation style and dominant sedimentary processes, coupled with widespread depositional hiatuses along the SIM within the Cadiz, Sanlucar, Doñana, Algarve and Alentejo basins. Following the 4.5 Ma cessation of a previous phase of tectonic activity related to the Miocene-Pliocene boundary, tectonics continued to influence margin development, downslope sediment transport and CDS evolution. Sedimentary features indicate tectonic pulses of about 0.8-0.9 Ma duration with a pronounced overprint of 2-2.5 Ma cycles. These more protracted cycles relate to the westward rollback of subducted lithosphere at the convergent Africa-Eurasia plate boundary as its previous NW-SE compressional regime shifted to a WNWESE direction. Two major compressional events affecting to the Neogene basins at 3.2-3 Ma and 2-2.3 Ma help constrain the three main stages of CDS evolution. The stages include: 1) the initial-drift stage (5.33-3.2 Ma) with a weak MOW, 2) a transitional-drift stage (3.2-2 Ma) and 3) a growth-drift stage (2 Ma-present time) with enhanced MOW circulation into the Atlantic and associated contourite development due to greater bottom-current velocity. Two minor Pleistocene discontinuities at 0.7-0.9 Ma and 0.3-0.6 Ma record the effects of renewed tectonic activity on basin evolution, appearing most prominently in the Doñana basin. Several discontinuities bounding major and minor units appear on seismic profiles. Quaternary records offer the clearest example of this, with major units of about 0.8-0.9 Ma and sub-units of 0.4-0.5 Ma. Sedimentation is controlled by a combination of tectonics, sediment supply, sea-level and climate. This research identifies time scales of tectonic
\end{abstract}

\footnotetext{
* Corresponding author.

E-mail address: javier.hermandez-molina@rhul.ac.uk (F.J. Hernández-Molina).
} 
controls on deep-marine sedimentation, specifically over periods of 2.5->0.4 Ma. Shorter-term climatic (orbital) mechanisms control sedimentation at time scales of $\leq 0.4 \mathrm{Ma}$. The role of bottom water circulation and associated processes in shaping the seafloor and controlling the sedimentary stacking pattern on continental margins has to be seriously reconsidered in future multidisciplinary studies. This is not only because of the common occurrence of sandy contourite deposits in deep water setting and their economic interest for hydrocarbon exploration, but principally because they archive the heartbeat of the interior Earth and therefore have important sedimentary and paleoceanographic implications.

(c) 2015 The Authors. Published by Elsevier B.V. This is an open access article under the CC BY-NC-ND license (http://creativecommons.org/licenses/by-nc-nd/4.0/).

\section{Introduction}

From the middle Miocene through the Quaternary, Earth has experienced major plate tectonic, climatic and oceanographic shifts that along with orbital variations, have contributed to the present day global climate and ocean dynamics (e.g., Knutz, 2008; Potter and Szatmari, 2009). Global climate transitioned from more uniform Pliocene climates to dynamic glacial/interglacial cycles during the Quaternary (Sarnthein et al., 2009). Plate tectonics influence climate over a wide range of timescales due to horizontal and vertical displacements of lithosphere, which control continental distribution, atmospheric and oceanic circulation, and the location of continental ice sheets (Hay, 1996). The transition from warm greenhouse conditions during the Late Cretaceous and early Cenozoic, to a world influenced by the Northern Hemisphere glaciations (NHG) in the last 2.6 My, occurred in tandem with distinct phases of plate-tectonic reconfiguration (Hay, 1996; Zachos et al., 2001). The most significant topographic and bathymetric modifications of Earth's surface were the opening and closing of oceanic gateways, which exerted a pervasive influence on global ocean circulation and climate (Wright and Miller, 1996; Potter and Szatmari, 2009). Surface uplift at plate boundaries, or due to magmatic underplating and mantle plumes appear to be strongly time-dependent (Rudge et al., 2008; Lovell, 2010) and act as a mechanism for sea-level variation on geological time scales (Whyte and Lovell, 1997; Jones et al., 2012). Limited

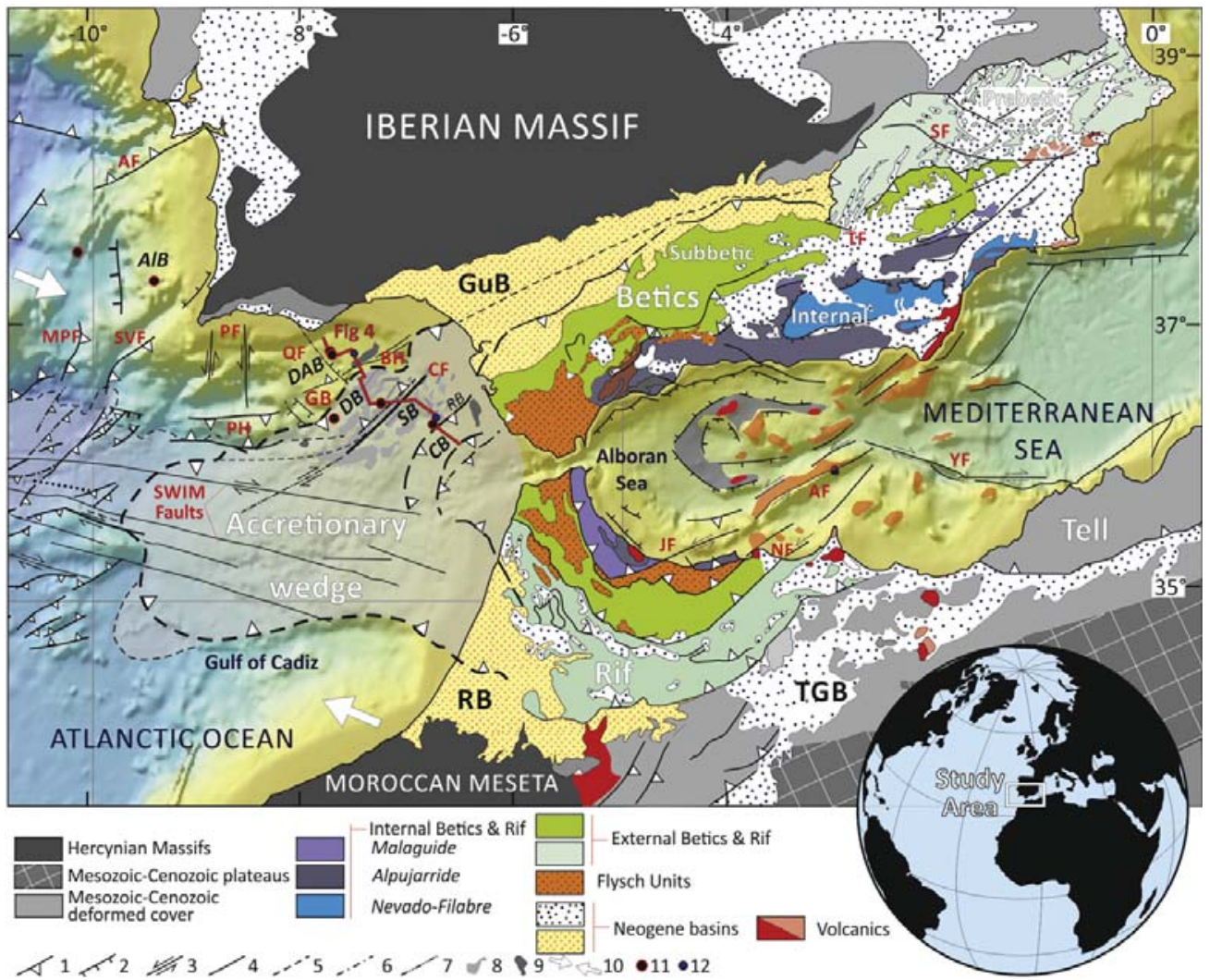

Fig. 1. Tectonic map showing principal structural units of the Betic-Rif Orogen and associated Neogene basins (originally from Iribarren et al., 2007 and Verges and Fernandez, 2012 , also including Gulf of Cadiz tectonic features described by Terrinha et al., 2002; Medialdea et al., 2004, 2009; Fernández-Puga et al., 2007; Roque et al., 2012 and Duarte et al., 2013). SF, Socovos Fault (Betics); TF, Tiscar Fault (Betics): JF, Jehba Fault (Rif); NF, Nekor Fault (Rif); AF, Alboran Ridge Fault (Alboran); and YF, Yusuf Fault (Alboran). CF, Cadiz Fault; OF, Ouarteira Fault; PH, Portimao High; BH, Basement High; SVF, San Vicent Fault; PF, Portimao Fault; MPF, Marquês de Pombal Fault; AF, Arrábida Fault. $1=$ reverse and thrust faults; 2 = normal faults; 3 = strike slip faults; $4=$ faults; $5=$ contact below sediment; $6=$ inferred/probable faults; $7=$ blind faults; $8=$ marly + salt diapirs (AUGC); $9=$ Salt diapirs; 10 : Nubia-Iberia plate convergence; $11=$ Sites from IODP Exp. 339; $12=2$ wells drilled by petroleum exploration companies. Legend for the sedimentary basins along the southern Iberian margin: $\mathrm{DAB}=$ Deep Algarve basin; $\mathrm{AlB}=$ Alentejo basin; $\mathrm{CB}=$ Cadiz basin; $\mathrm{DB}=$ Doñana basin; $\mathrm{RB}=$ Rota basin; $\mathrm{SB}=$ Sanlucar basin. 
evidence of sedimentary pulses ranging from 1 to $10 \mathrm{Ma}$ in duration (Rudge et al., 2008; Lovell, 2010) indicates that tectonics, climate and sea-level influence sedimentary stacking patterns on continental margins. More evidence concerning time-stratigraphic relationships between palaeoceanographic, environmental (climate and sea-level) and tectonic events is necessary to clarify specific cause-and-effect relationships among these factors, their relative importance, and specific time scales on which they operate (Hernández-Molina et al., 2014b).

The Gulf of Cadiz and offshore west Portugal (Fig. 1) along the southwestern Iberian margin (SIM), can help constrain some of these sedimentary pulses and their drivers. Previous research of these areas has primarily focused on the Mesozoic and Cenozoic history of the margin, especially the tectonic implications of convergence between the African and Eurasian plates in the middle and late Miocene (e.g., Maldonado et al., 1999; Gutscher et al., 2002; Alves et al., 2003; Gràcia et al., 2003; Terrinha et al., 2009; Medialdea et al., 2004; Iribarren et al., 2007; Zitellini et al., 2009; Duarte et al., 2011, 2013; Pereira et al., 2011; Vergés and Fernàndez, 2012 among others).

Several studies have described the evolution and stratigraphy of Pliocene and Quaternary offshore deposits (e.g., Faugères et al., 1985a, 1985b; Mougenot, 1988; Faugères et al., 1999; Maldonado et al., 1999; Llave et al., 2001, 2007a, 2011; Hernández-Molina et al., 2002, 2014a, 2014b; Marchès et al., 2010; Roque et al., 2012; Brackenridge et al., 2013). These studies identified various seismic units bound by regional discontinuities and interpreted them as significant changes in the stratigraphic stacking pattern of the slope. Age interpretations for these features, however, have been uncertain and controversial. Sediments from this region have only recently been sampled, and therefore the working model for the region's seismic stratigraphy was somewhat preliminary, having been calibrated with limited data from a few exploration wells drilled during the late seventies and early eighties. The stratigraphic model makes these basic assumptions about the study area: 1) sedimentation is continuous through time, although hiatuses may occur in the stratigraphic sequence, and 2) external processes such as glacioeustatic changes and climate variation are primary factors controlling sedimentation. Integrated Ocean Drilling Program (IODP) Expedition 339 drilled six sites within the contourite depositional system (CDS) along the SIM, from November 2011 to January 2012 (Fig. 2). Expedition results have allowed us to identify hiatuses and other major shifts in the sedimentary record through the late Miocene, Pliocene and Quaternary. This expedition provided the opportunity to interpret events occurring around the Strait of Gibraltar in terms of their impacts on regional basin evolution, global ocean circulation and climate. The main objectives of this contribution are: a) to establish a more robust stratigraphic model for the SIM based on the integration of IODP Exp. 339 data with onshore geology and petroleum industry borehole, core, 2D and 3D seismic data. The correlation between the IODP Exp. 339 sites and the seismic profiles is here presented by first time; b) to interpret major changes in

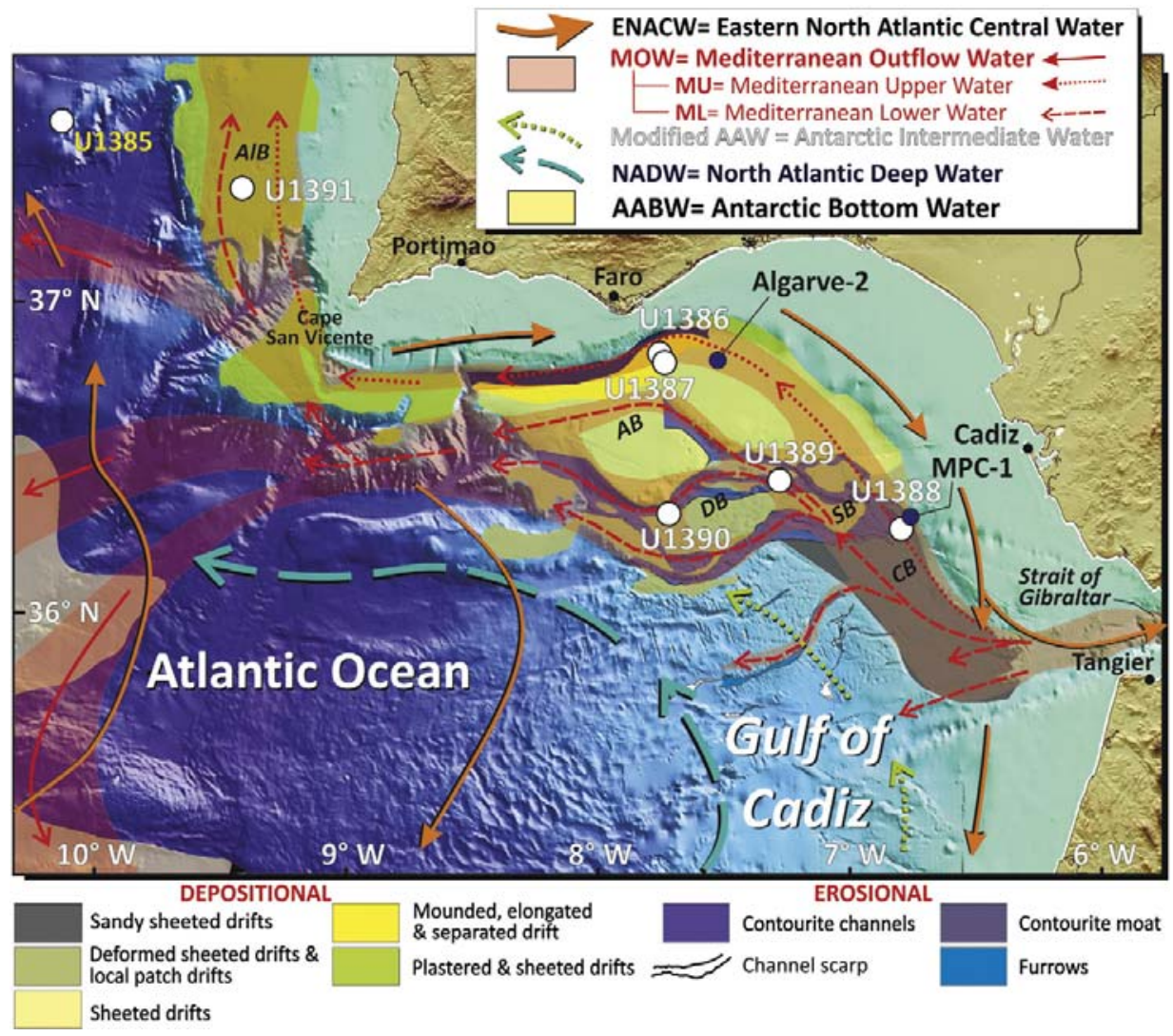

Fig. 2. Gulf of Cadiz showing the pathway of Mediterranean Outflow Water (MOW) after it exits Gibraltar Gateway, as well as the regional depositional and erosional features it generates along the mid-slope. IODP Exp. 339 sites shown as solid white circles and the two wells drilled by petroleum exploration companies are shown as blue circles. Bottom water masses and ocean currents are also shown. Legend for the sedimentary basins along the southern Iberian margin: $\mathrm{AB}=$ Algarve basin; $\mathrm{AlB}=\mathrm{Alentejo}$ basin; $\mathrm{CB}=\mathrm{Cadiz}$ basin; $\mathrm{DB}=\mathrm{Doñana}$ basin; $\mathrm{RB}=$ Rota basin; $\mathrm{SB}=$ Sanlucar basin. 
depositional style, sedimentation rates and margin evolution from the Pliocene through the Quaternary; and c) evaluate the broader tectonic, paleoceanographic and climatic implications of these events.

\section{Geologic framework}

The SIM is located near the Azores-Gibraltar Fracture Zone, a section of the convergent plate boundary between Eurasia (Iberia sub-plate) and Africa (Nubia sub-plate) (Fig. 1). The plates presently converge at a rate of $\sim 4-5 \mathrm{~mm} / \mathrm{y}$ in a WNW-ESE direction (Argus et al., 1989; Fernández-Ibánez et al., 2007). Counter-clockwise rotation along the margin is accommodated by a series of thrusts and dextral strike-slip faults, referred to as the SWIM faults (Fig. 1) (Zitellini et al., 2009) active since at least 1.8 Ma (Rosas et al., 2009; Duarte et al., 2011). Westward drift and collision of the Alboran Domain with the North African and south Iberian margins in the early to middle Miocene caused the formation of the Betic-Rif orogeny and the so-called Neogene basins, including the north Betic and south Riffian foredeeps. Westwards roll-back subduction of an oceanic lithosphere slab beneath the Gibraltar Arc and development of its accretionary wedge during the late Tortonian (Gutscher et al., 2002) caused radial emplacement of huge allochthonous masses evident as the "olistostrome unit" of the Guadalquivir basin (Iberian foreland), Rharb basin (North African foreland) and Gulf of Cadiz (Perconig, 1960-1962; Roberts, 1970; Flinch and Vail, 1998; Torelli et al., 1997; Maldonado et al., 1999; Terrinha et al., 2009). This unit, which marks the propagation of the Mediterranean Alpine collision belt into the Atlantic (Duarte et al., 2013), is specifically referred to as the allochthonous unit of the Gulf of Cadiz or AUGC (Medialdea et al., 2004). Structurally, the AUGC consists of a series of westwards imbricated thrusts cutting through an eastward-thickening package of sediments (up to $\sim 2.75 \mathrm{~km}$ ), which appear primarily as chaotic reflectors, numerous diffractions and hyperbolic reflections (Maldonado et al., 1999). Sediment includes Triassic, Cretaceous, Paleogene and Neogene units overlying Palaeozoic basement (Maldonado et al., 1999). Mud and salt diapirism affect Triassic salt units and uncompacted early to middle Miocene marls (Maestro et al., 2003).

The SIM divides into three major morpho-structural domains (Fig. 1) (Maldonado et al., 1999; Zitellini et al., 2009). These include: a) the Sudiberic paleomargin, which is part of the Iberian massif, b) Neogene basins, including the Guadalquivir and Rharb foreland basins and the Algarve basin, and c) the external front of the Betic-Rif collisional orogen, which represents the accretionary wedge or AUGC. Since the late Miocene, geodynamic evolution of the Neogene basins has been determined by oblique convergence between the Iberia and Nubian sub-plates (Zitellini et al., 2009; Duarte et al., 2011). This has been accommodated during distinct periods of crustal deformation and shortening phases, by fault reactivation, halokinesis and uplift of fault blocks (Maldonado et al., 1999; Gutscher et al., 2002; Alves et al., 2003; Gràcia et al., 2003; Maestro et al., 2003; Terrinha et al., 2003, 2009; García et al., 2009; Medialdea et al., 2004, 2009; Lopes et al., 2006; Fernández-Puga et al., 2007; Zitellini et al., 2009; Duarte et al., 2011; Pereira et al., 2011; Martínez-García et al., 2013). Latest Miocene to Pliocene deep and shallow marine deposits occur extensively within onshore basins (e.g., Martinez del Olmo et al., 1984; IGME, 1990, 1994; Sierro et al., 1991; Aguirre, 1995; Riaza and Martinez del Olmo, 1996; Ledesma, 2000), but are virtually absent onshore the Algarve basin (IGMP, 1998; Dias and Cabral, 1997), indicating that only the Guadalquivir, Rharb and the other basins around the Betic-Rif orogen were wider than their present expression (e.g., Michard et al., 2008; Salvany et al., 2011).

\section{Oceanographic setting}

The present-day circulation in the Gulf of Cadiz and along the western Portuguese margin is dominated by the exchange between the Atlantic and Mediterranean waters through the Strait of Gibraltar
(Fig. 2). Upon exiting the Strait of Gibraltar, the Mediterranean Outflow Water (MOW) cascades downslope in a northwesterly direction, at an overflow rate of $0.67 \pm 0.28 \mathrm{~Sv}$. MOW consist of relatively warm and highly saline water (Serra et al., 2010; Rogerson et al., 2012) that settle into an intermediate contour current within the mid-slope region, between 400 and $1400 \mathrm{~m}$ water depth (Ochoa and Bray, 1991; Baringer and Price, 1999). The Strait of Gibraltar physically moderates Mediterranean-Atlantic water-mass exchange, contributing warm and highly saline MOW to the Atlantic Ocean at 300-1400 m water depth (Borenäs et al., 2002). MOW input enhances North Atlantic density and helps drive deep convection. Estimates suggest that without MOW, the Atlantic Meridional Overturning Circulation (AMOC) would be reduced by $\sim 15 \%$ and North Atlantic sea surface temperatures would fall by up to $1{ }^{\circ} \mathrm{C}$ (Rogerson et al., 2012).

The MOW is a mixture of waters sourced from the Mediterranean Basin (Levantine Intermediate Water, LIW, and a small component of the West Mediterranean Deep Water, WMDW), a constricted basin under arid climate conditions that form warm, saline dense water averaging $13^{\circ} \mathrm{C}$ and $36.5 \%$ (Ambar and Howe, 1979; Bryden and Stommel, 1984; Bryden et al., 1994). The water mass accelerates through the narrow gateway of the Strait of Gibraltar, locally reaching velocities of up to $300 \mathrm{~cm} / \mathrm{s}$ (Ambar and Howe, 1979; Mulder et al., 2003) and moves north-westwards along the mid-continental slope of the Gulf of Cadiz, beneath the Atlantic Inflow Water (AIW) and above the North Atlantic Deep Water (NADW). The AIW consists of North Atlantic Superficial Water (NASW; surface to a depth of approximately $100 \mathrm{~m}$ ), and the Eastern North Atlantic Central Water (ENACW). It flows at depths between of 100 and $700 \mathrm{~m}$ and averages $12-16{ }^{\circ} \mathrm{C}$ and $34.7-36.25 \%$ 。 TDS. In the Gulf of Cadiz, the Modified Antarctic Intermediate Water (AAIW), which averages $\sim 10^{\circ} \mathrm{C}, \sim 35.62 \%$ o TDS and $\sim 4.16 \mathrm{ml} / \mathrm{l}$ dissolved oxygen (Louarn and Morin, 2011), has been identified as circulating above the MOW (Hernández-Molina et al., 2014a). The underlying NADW is a cold $\left(3-8{ }^{\circ} \mathrm{C}\right)$ and less saline (34.95-35.2\%o) water mass that flows at depths $>1500 \mathrm{~m}$ from the Greenland-Norwegian Sea region towards the south (Thorpe, 1975; Zenk, 1975; Gardner and Kidd, 1983; Ochoa and Bray, 1991; Baringer and Price, 1999; Serra et al., 2005). The MOW forms a $10 \mathrm{~km}$ (approximately) wide band as it accelerates through the Strait of Gibraltar, enters the Gulf of Cadiz at depths of $250-300 \mathrm{~m}$ and is then deflected to the west due to Coriolis effect (Ambar and Howe, 1979; Mulder et al., 2003). The MOW current velocity decreases immediately west of the Camarinal Sill within the Strait of Gibraltar, and continues to decline to $60-100 \mathrm{~cm} / \mathrm{s}$ further to the northwest (Cherubin et al., 2000). From there onwards, its volume transport increases by a factor of three to four (Serra et al., 2010; Rogerson et al., 2012). Density-driven descent and mixing with overlying Atlantic waters result in decreasing salinity along the margin in a SE to NW direction (Baringer and Price, 1997). Eventually, the MOW reaches a neutral buoyancy and leaves the seabed at a depth of $\sim 1400 \mathrm{~m}$ off Cape San Vicente, where it begins to raft above the NADW.

In the Gulf of Cadiz, the MOW pathway is influenced by the complex continental slope morphology and is locally enhanced where neotectonics have created diapiric ridges oblique to its flow direction (Fig. 2). These ridges are in part responsible for splitting the MOW into numerous distinctive cores, although vertical layering within the water core has also been proposed as a possible additional control (Millot, 2009; Copard et al., 2011). The main water cores consist of the Mediterranean Upper Core (MU) and the Mediterranean Lower Core (ML) (Madelain, 1970; Zenk, 1975; Ambar and Howe, 1979; Borenäs et al., 2002; Serra et al., 2005) (Fig. 2). The MU flows slope-parallel along southwestern Iberia at depths of 500-800 m with part of its flow captured by the Portimao Canyon at the Algarve margin (Marchès et al., 2007). Overall, the MU is warmer and less saline (13-14 ${ }^{\circ} \mathrm{C}$ and $35.7-37 \%$ ) relative to the $\mathrm{ML}\left(10.5-11.5{ }^{\circ} \mathrm{C}\right.$ and $36.5-37.5 \%$ ), which follows a general northwestern trend between 800 and $1400 \mathrm{~m}$ water depth, with an average velocity of $20-30 \mathrm{~cm} / \mathrm{s}$ (Llave et al., 2007a; García et al., 2009). The majority of the flow 
concentrates west of $7^{\circ} \mathrm{W}$ (Madelain, 1970). At $7^{\circ} \mathrm{W}$, a branch detaches from the southern part of the ML to veer off in a southwesterly direction. At $7^{\circ} 20^{\prime} \mathrm{W}$, the ML divides into three distinct branches with a general northwest direction: the southern branch (SB), the principal branch (PB) and the intermediate branch (IB). Both Portimão Canyon and Cape St. Vincent act as a source of meddies (Serra et al., 2005, 2010; Ambar et al., 2008). After exiting the Gulf of Cadiz, the MOW includes three principal branches. The main branch flows to the north along the middle slope of the Portuguese Margin, the second to the west, and the third to the south reaching the Canary Islands, before veering west (Iorga and Lozier, 1999; Slater, 2003).

Following the opening of the Strait of Gibraltar in the latest Miocene (Duggen et al., 2003; Roveri et al., 2014), the MOW generated one of the world's most extensive and complex Contourite Depositional System (CDS; Fig. 2) along the SIM during the Pliocene and Quaternary (e.g., Faugères et al., 1985a, 1985b; Nelson et al., 1999; Llave et al., 2001, 2007a, 2011; Habgood et al., 2003; Hanquiez et al., 2007; Hernández-Molina et al., 2003, 2006, 2011, 2014a; Marchès et al., 2007, 2010; García et al., 2009; Roque et al., 2012). Large depositional and erosional features within the CDS are used to define five morphosedimentary sectors (detailed in Hernández-Molina et al., 2003 and Llave et al., 2007a, 2007b). In general, the drifts consist primarily of muddy, silty and sandy sediments of mixed terrigenous and biogenic composition (Gonthier et al., 1984). Sand and gravel are found in the large contourite channels (Nelson et al., 1993, 1999; Stow et al., 2013a), and across the many erosional features (Stow et al., 2013a; Hernández-Molina et al., 2014a). In the proximal sector close to the Strait of Gibraltar, an exceptionally thick $(\sim 815 \mathrm{~m})$ sandysheeted drift occurs, with sand layers averaging thicknesses of 12-15 m (Nelson et al., 1993; Buitrago et al., 2001).

\section{Methodology}

This research has compiled and integrated extensive geophysical data and drill core records from late Miocene, Pliocene and Quaternary sediments. Results from the drillcore data acquired during IODP Exp. 339 aboard the R/V JOIDES Resolution have been correlated with petroleum industry drilling data from the margin (Fig. 3). Datasets were selected based on data coverage for the Pliocene and Pleistocene sections, which are not typically sampled by industry surveys.

IODP Exp. 339 aboard the R/V JOIDES Resolution drilled five sites in the Gulf of Cadiz and two sites off the west Iberian margin from 17 November 2011 to 17 January 2012 (Expedition 339 Scientists, 2012; Stow et al., 2013b; Hernández-Molina et al., 2013; Hodell et al., 2013). See details at http://iodp.tamu.edu/scienceops/expeditions/mediterranean outflow.html. Six of the sites (U1386-U1391, Fig. 3) were specifically selected in order to study MOW-generated CDS.

Drilling activities employed all three of the vessel's standard coring systems, which include an advanced piston corer (APC), an extended core barrel $(\mathrm{XCB})$, and a rotary core barrel (RCB). These allowed Exp. 339 to drill 19 holes (681 cores) in 46.1 days on site, with a penetration of $7857.4 \mathrm{~m}$ and $6301.6 \mathrm{~m}$ cored. In total, nearly $5.5 \mathrm{~km}$ of core were recovered, with an average recovery of $86.4 \%$ (Fig. 3). Stratigraphic correlation and specific age constraints were established onboard using: 1) lithostratigraphy, 2) biostratigraphy, 3) paleomagnetic data, 4) sediment core description, 5) geochemical analysis and 6) downhole measurements. Shipboard biostratigraphic dating was used to estimate regional correlations. Age data was essential for determining ages of key horizons (including several depositional hiatuses and stratigraphic boundaries) and sedimentary accumulation rates (for chronology details about the IODP sites, see Table S1 in Hernández-Molina et al., 2014b, and for the MPC-1 borehole, see Buitrago et al., 2001; Hernández-Molina et al., 2014a).

Preliminary onboard sedimentary facies description is reported in Stow et al. (2013b) and also integrated with seismo-acoustic and logging analysis in this work. We also report mineralogic and petrographic analysis of 32 samples of lower Pliocene sandstones from site U1387. Analysis, including SEM-EDS analyses, micro-X-ray fluorescence (micro-XRF), rare elements (REE) measurements and $\mathrm{C}$ and $\mathrm{O}$ stable isotope analysis was carried out by REPSOL (Caja et al., 2013).

Vertical seismic profiles (VSP) relating borehole depth to travel time in seismic reflection data (Fig. S1, in Supplementary material), have been critical for correlating IODP Exp. 399 results with regional multichannel seismic profiles. VSP were executed at sites U1386, U1387 and U1389. At sites U1390 and U1391 the depth to time conversion was based on the DSI sonic tool. Downhole logs were acquired with Schlumberger logging tools at five sites (U1386C, U1387C, U1389A, U1389E and U1391C, Fig. 3) following completion of coring operations. Log data was continuous with depth and measured in situ. Among the tools used during IODP Exp. 339, the Hostile Environment Natural Gamma Ray Sonde (HNGS) allowed us to continuously measure natural gamma radiation of sediment surrounding the open borehole. The HNGS signal primarily tracks clay content with high values generally identifying fine-grained deposits containing K-rich clay minerals that preferentially absorb $U$ and Th. Low values reflect quartz and calcite, which are unlikely to contain such high concentrations of radioactive elements. The High-Resolution Laterolog Array (HRLA) performs five measurements of formation resistivity with increasing penetration into the formation. The logs can be interpreted in terms of the stratigraphy, lithology and geochemical composition of the formation sampled. IODP Exp. 339 results have been correlated to industry wells referred to as Algarve-2 and MPC-1. Algarve-2 data was provided by DGGE (Direcção Geral de Geologia e Energia-Portugal) through the DPEP (Divisão para a Pesquisa e Exploração de Petróleo). The MPC-1 well was drilled by Esso in 1982 (Buitrago et al., 2001; Hernández-Molina et al., 2014a). These two sites have been very useful for correlating seismic data, lithologies and log data at a regional scale.

In order to evaluate cyclic patterns in the sedimentary record and GR logs, we performed spectral analysis on HSGR logs from sites U1386C and U1387C, using the Lomb-Scargle periodogram method (Scargle, 1982), to tract the record of low- and high (orbital-scale) variations in the sediment properties during the last $2 \mathrm{Ma}$ within the most depositional sector of the contourite depositional system. The age model for the last $2 \mathrm{Ma}$ at these sites is based on results from Lofi et al., 2015. The Lomb-Scargle periodogram method is the best methodology of spectral estimation and is particularly useful when conducting cyclostratigraphic analysis with uneven sampling data, even when dealing with short time series or with a discontinuous sedimentary record (i.e., missing data, minor hiatuses, bioturbation, etc.) (Pardo-Igúzquiza and Rodríguez-Tovar, 2011, 2012; Rodrigo-Gámiz et al., 2014). To evaluate the significance of the registered spectral peaks, the Lomb-Scargle periodogram is integrated with the implemented achieved significance level using the permutation test (see Pardo-Igúzquiza and Rodríguez-Tovar, 2000, 2005, 2006, 2011, 2012 for a detailed description). A first cyclostratigraphic analysis has been conducted to evidence any possible cyclicity at the Milankovitch frequency band. Then, a second study focused on the lower frequency band, to evaluate the possibility of any cycles with periodicities longer than those corresponding to the short-term eccentricity cycle ( $\geq 100 \mathrm{ky}$ ). This has been achieved by reducing the periodogram smoothing in the low frequencies in order to increase the spectral resolution at those low frequencies.

We constructed a large regional seismic compilation using data collected by industry and on several national and international research projects (Fig. 3). Multichannel 2-D seismic reflection profiles (MCS) used were: 1) the PD00 Survey acquired by TGS-NOPEC, 2000 (TGS, 2005; acquisition data reported in George, 2011; Llave et al., 2011; Brackenridge et al., 2013), 2) BIO Hespérides HE-91-3 cruise (acquisition data details in Maldonado et al., 1999), 3) BIO Hespérides TASYO 2000 cruise (acquisition data information in Medialdea et al., 2004, 2009), 4) IAM survey and the CSIC-Institut Jaume Almera (http://geodb.ictja. csic.es) and 5) S81, P74 and GC_d surveys by Repsol and Gas Natural- 


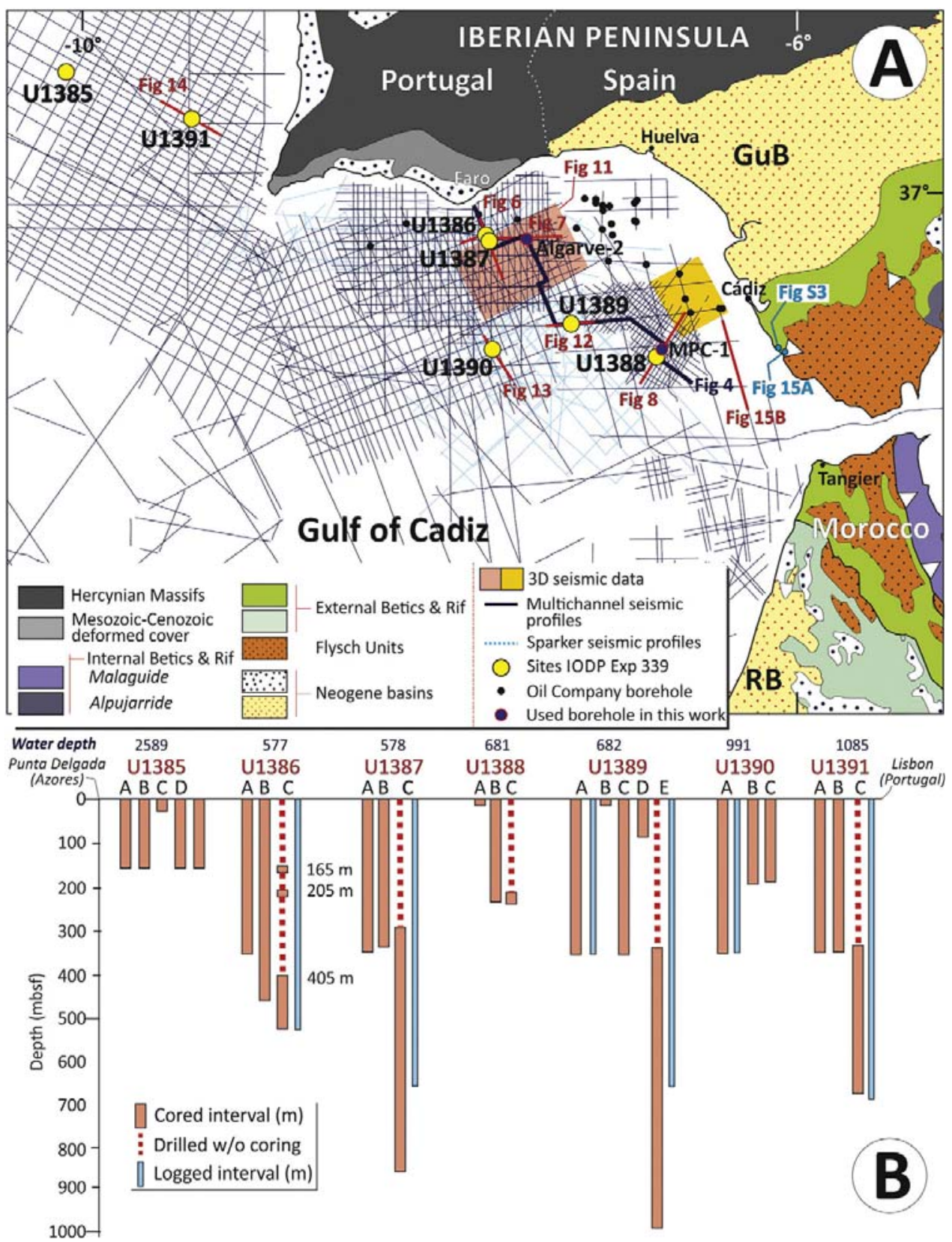

Fig. 3. A) Map locations of seismic profiles as well as sites drilled during IODP Exp. 339 and those sampled by previous drilling activity. Localities of outcrops reinterpreted by this study are also shown. B) Basic information on IODP Exp. 339 sites.

Fenosa. This study also incorporates additional MCS data from a 2012 3D seismic survey by Repsol, which covered Pliocene and Quaternary sediments, and included four amplitude anomaly maps. Several 2D seismic profiles of intermediate resolution were used for local analysis (Llave et al., 2001, 2006, 2007a, 2007b; Hernández-Molina et al., 2002, 2006). These were generated using Sparker 3000,4000 and $7500 \mathrm{~J}$ sources and obtained during research cruises FADO 9711, ANASTASYA
9909 and ANASTASYA 2000/09. The seismic, core and borehole data have been interpreted using the commercially available software package, Kingdom Suite ${ }^{\mathrm{TM}}$, which processes chronostratigraphical, sedimentological and log data. Depth and thickness from seismic profiles are expressed in seconds Two-Way Travel-Time (TWTT).

Major stratigraphic features of offshore deposits have been correlated with onshore outcrops based on published literature records as well 


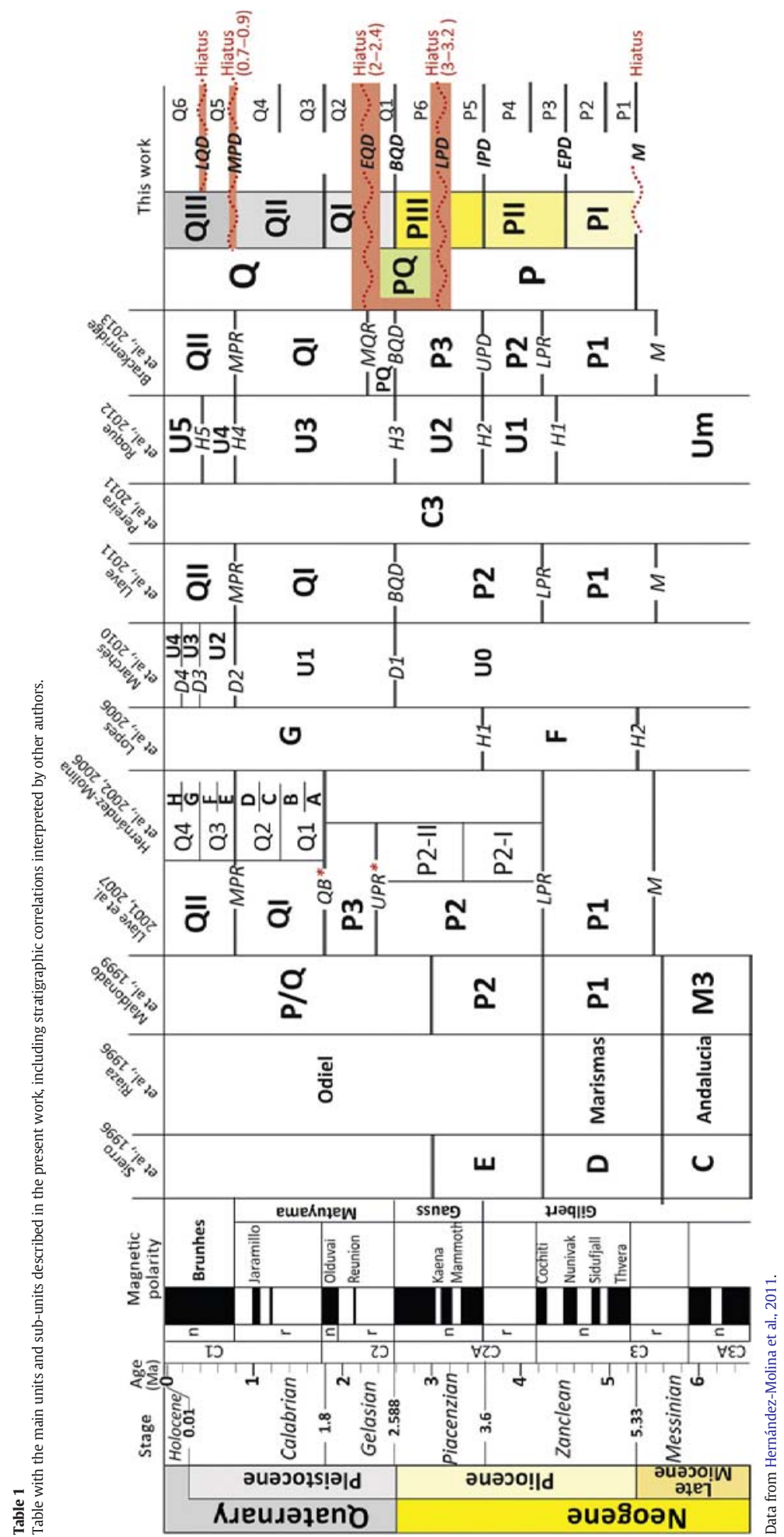


F.J. Hernández-Molina et al. / Marine Geology 377 (2016) 7-39

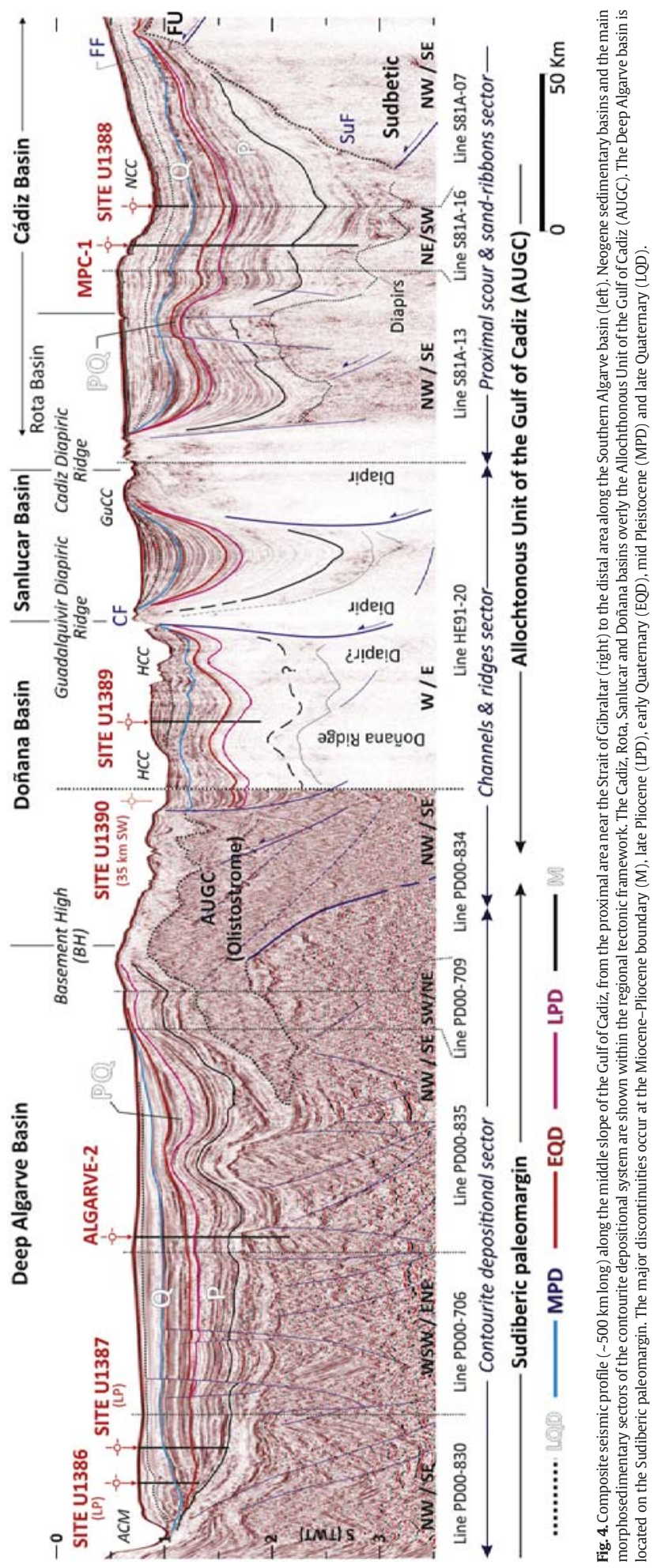




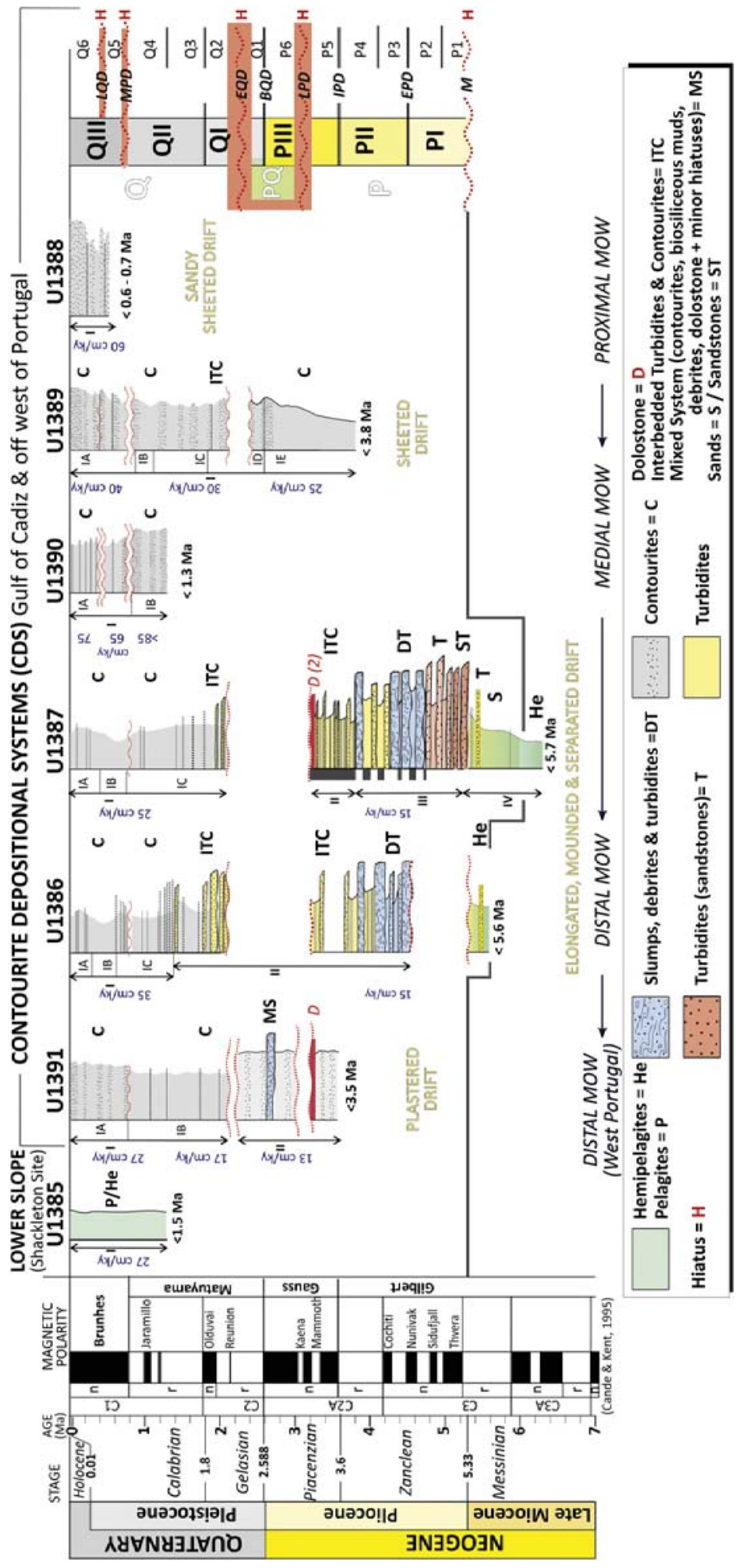

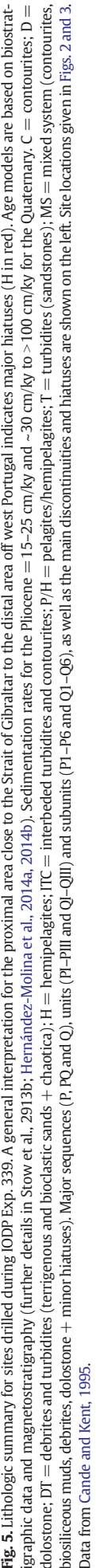




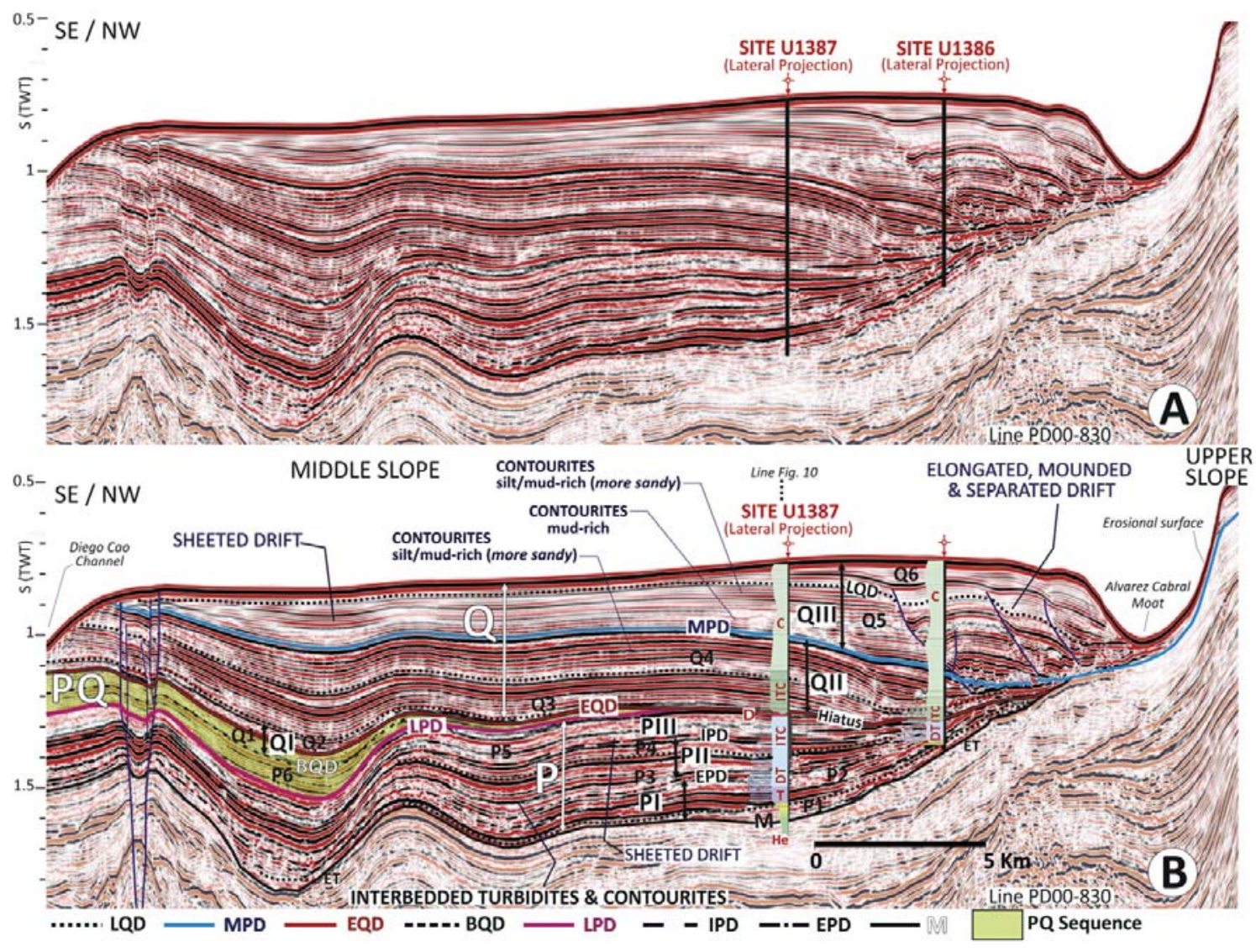

Fig. 6. Seismic profile (line PD00-830) of the Algarve basin showing the sedimentary stacking pattern for Pliocene sheeted drift to Quaternary separated drifts, based on correlations between sites U1386 and U1387. Both sites have been projected into this seismic profile. Site U1386 is place $1 \mathrm{~km}$ WSW from the line and Site U1387 is located $1.2 \mathrm{~km}$ ENW from the profile. Profile location given in Fig. 3. Major sequences (P, PQ and Q), units (PI-PIII and QI-QIII) and subunits (P1-P6 and Q1-Q6), as well as the main discontinuities and hiatuses are shown. See the text for further detail explanations (data courtesy of TGS-NOPEC Geophysical Company ASA). ET = Erosional truncation. Abbreviations for discontinuities (from bottom to top): M = Miocene-Pliocene boundary; EPD = early Pliocene discontinuity; IPD = intra Pliocene discontinuity; LPD = late Pliocene discontinuity; BOD = base of the Quaternary discontinuity; $\mathrm{EQD}=$ early Quaternary discontinuity, MPD = mid Pleistocene discontinuity; and LQD = late Quaternary discontinuity. Simplify sedimentary logs for U1386 and U1387 are included (see abbreviations in Fig. 5).

as recent re-analysis of the late Miocene, Pliocene and Quaternary onshore sections. Selected outcrops (Fig. 3) were specifically measured and re-sampled in order to date and characterize key stratigraphic horizons.

This paper updates and revises units, discontinuities and age assignments in the stratigraphic framework established by previous reports on the area. Inconsistencies in age assignments from previous works are a natural consequence of data processing methods as well as the different scales and resolution at which data was analyzed. Revisions also reflect recent modification of Quaternary chronostratigraphy by the International Commission on Stratigraphy (Mascarelli, 2009). The hierarchy of sedimentary units is described according to sedimentary sequences, units and subunits. The seismic-stratigraphic analyses were correlated with previous stratigraphic results from (Table 1): Sierro et al. (1996); Riaza and Martinez del Olmo (1996); Maldonado et al. (1999); Llave et al. (2001, 2007a, 2011); Hernández-Molina et al. (2002, 2006, 2014a, 2014b); Marchès et al. (2010); Roque et al. (2012); and Brackenridge et al. (2013). The term 'contourite' refers to sediments deposited or substantially reworked by the persistent action of bottom currents (e.g., Stow et al., 2002a; Rebesco, 2005; Rebesco and Camerlenghi, 2008). Contourites include a wide array of sediments that are affected to varying degrees by different types of currents (Rebesco et al., 2014). Thick, extensive sedimentary accumulations are referred to as contourite drifts or drifts. For the present work, we have adopted the classification of Faugères et al. (1999) (later updated by Faugères and Stow, 2008) and use the local and regional names for drifts described by previous authors (e.g., Faugères et al., 1985a, 1985b; Llave et al., 2007a; Hernández-Molina et al., 2003, 2014a; García et al., 2009; Marchès et al., 2007, 2010; Roque et al., 2012).

\section{Results}

A full assessment of the Neogene basins, the Late Miocene/Pliocene boundary, and the characteristics of the Pliocene to the Quaternary sedimentary record are outlined below. These are reported alongside the tectonic considerations of the results.

\subsection{Neogene basins}

Neogene basins in the study area include basins overlying the AUGC (Cadiz, Rota, Sanlucar and Doñana basins), a basin located on the Sudiberic paleomargin (Algarve basin) and the Alentejo basin off west 
F.J. Hernández-Molina et al. / Marine Geology 377 (2016) 7-39

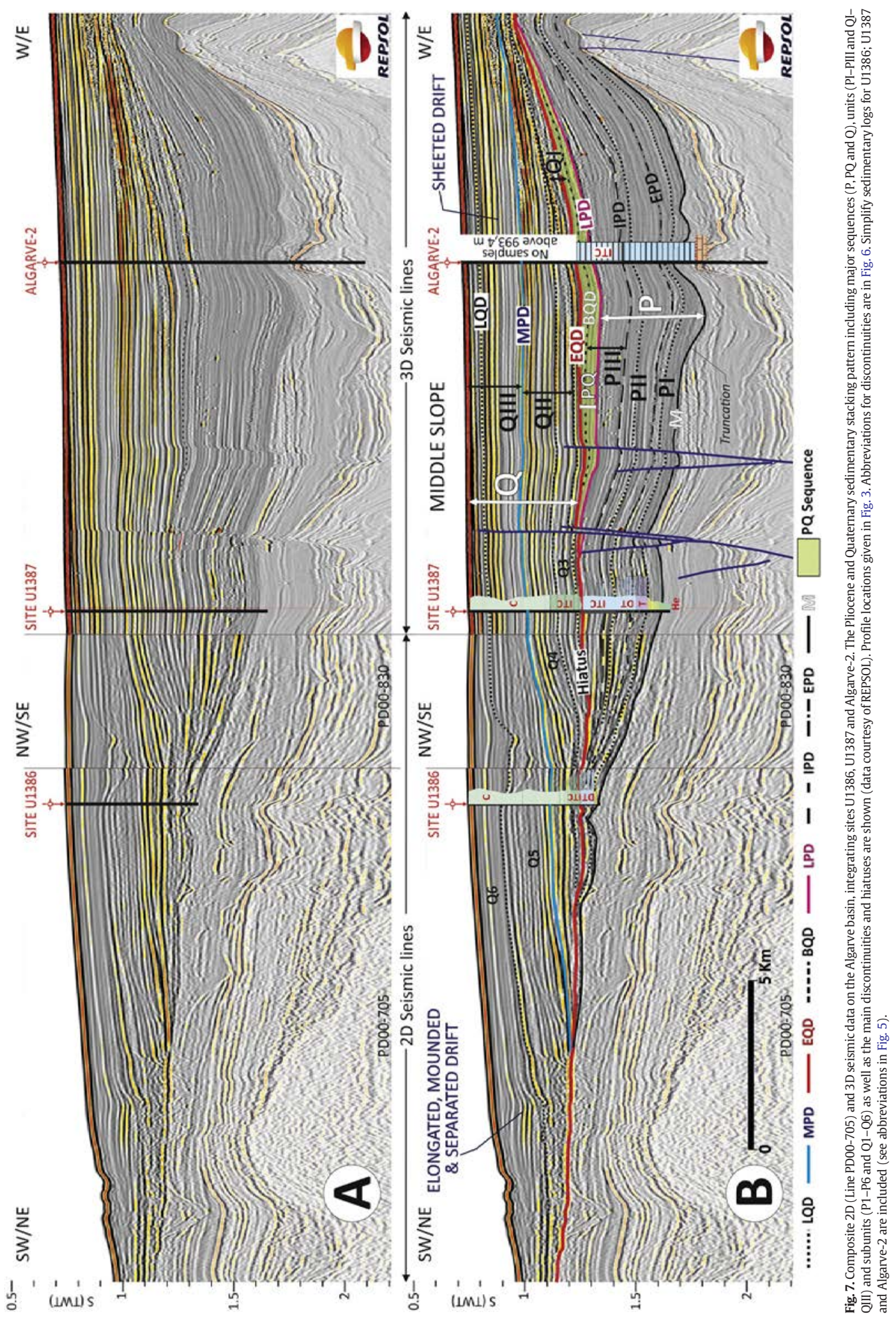




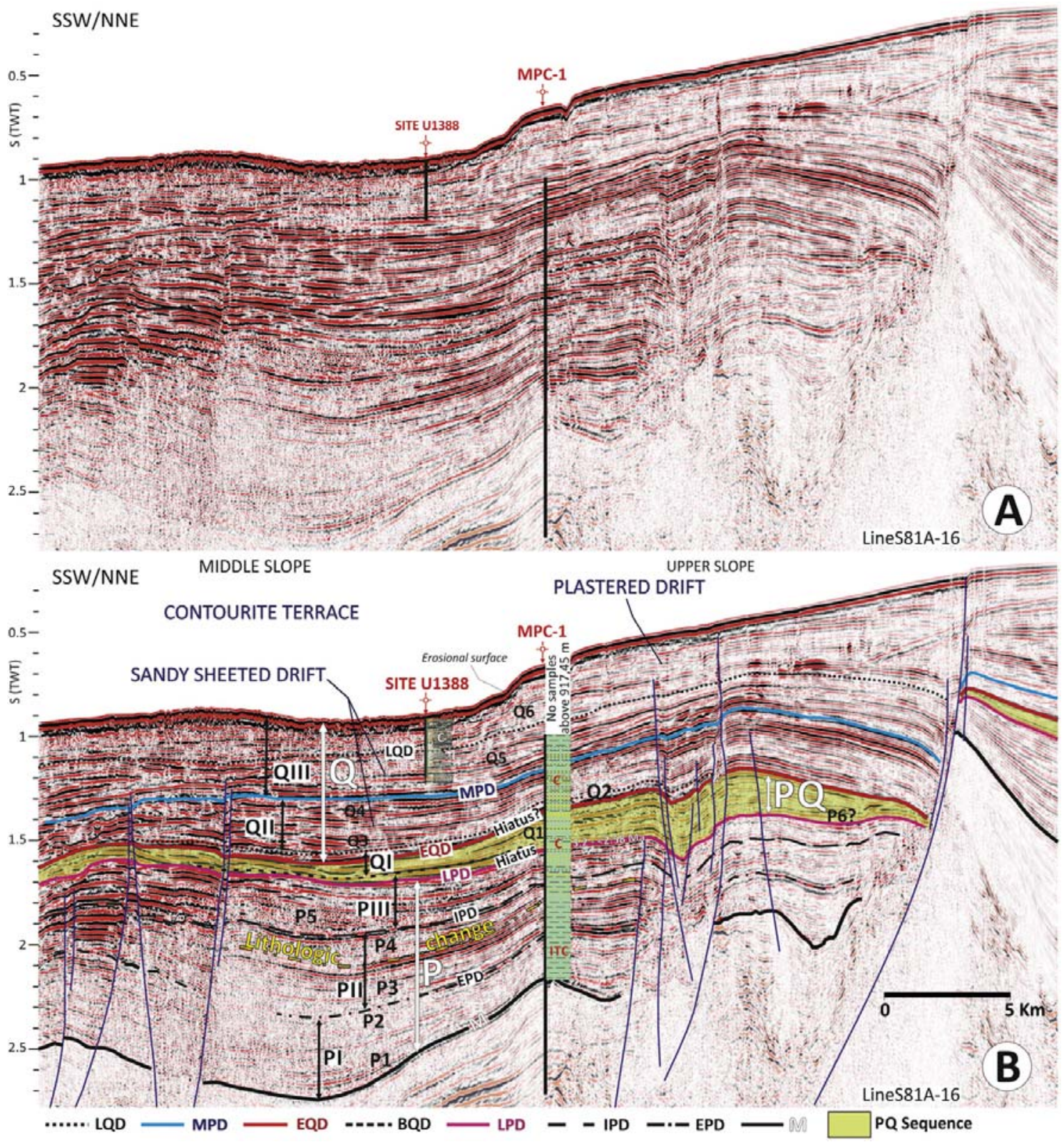

Fig. 8. Seismic profile (Line S81A-16) of the Cadiz basin across sites U1388 and MPC-1. Major sequences (P, PQ and O), units (PI-PIII and QI-OIII) and subunits (P1-P6 and Q1-O6), as well as the main discontinuities and hiatus are shown (Modified and updated from Hernández-Molina et al., 2014b). Profile location given in Fig. 3. Abbreviations for discontinuities are in Fig. 6. Simplify sedimentary logs for U1388 and MPC-1 are included (see abbreviations in Fig. 5).

Portugal (Fig. 1). Offshore slope areas of Algarve basin are considered as the Deep-Algarve basin. Tectonic features control the basins, their depocenter distribution and their main contourite sectors (1-5) described in Hernández-Molina et al. (2003, 2006) and Llave et al. (2007a, 2007b) (Fig. 4). The proximal scour and sand-ribbon sector (1) and the overflow sedimentary lobe sector (2) have developed within the Cadiz basin. The central channel and ridges sector (3) is found in the Sanlucar and Doñana basins and the main depositional sector (4) has formed within the Deep Algarve basin. The submarine canyon sector (5) covers the rest of the SIM westward including the Alentejo basin. Deformed sheeted drifts in the central sector coincide with the Doñana basin, which shows intensive recent and ongoing deformation.

Neogene Basins located in the Gulf of Cadiz are generally bound by westward thrusted Flysch and Subbetic material. The AUGC was thrust northwestwards into the Guadalquivir and Algarve basins. A set of 


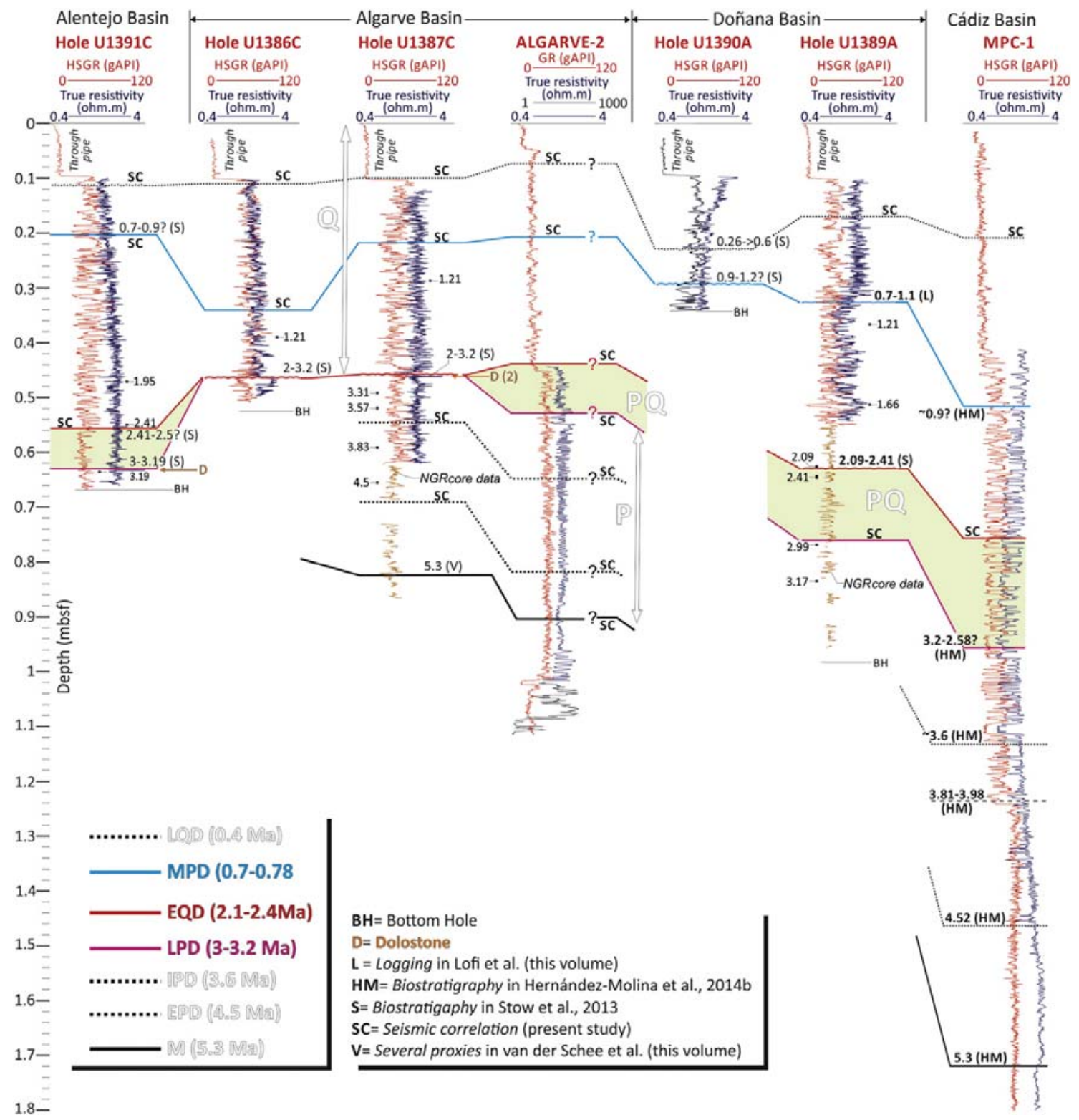

Fig. 9. Log data, gamma ray (HSGR) and resistivity, for IODP Exp. 339, Algarve-2 and MPC-1 boreholes shown with the main Pliocene and Quaternary discontinuities.

linear and segmented parallel ridges and highs trending in a NE-SW direction formed either exposed or buried structures, constructing the undulating sea-floor morphology that has been described by a number of works (e.g., Maldonado et al., 1999; Gutscher et al., 2002; Medialdea et al., 2004, 2009; Fernández-Puga et al., 2007; García et al., 2009). Diapirs appear as chaotic, highly diffractive bodies in seismic profiles (Fig. 4). Diapirs, as well as other highs and ridges are affected by SWIM strike-slip faults, which trend in a WNW-ESE direction, (Fig. 1) (Zitellini et al., 2009; Duarte et al., 2011). The influence of some of these structures on the Pliocene and Quaternary strata is shown in Figs. 4, 6-8 and 12-14.
The Cadiz basin occurs between frontal thrusted Flysch and Subbetic units (Fig. 4) and the Cadiz diapiric ridge (CDR). This basin trends in a NE-SW direction, and occupies an area $45 \mathrm{~km}$ wide and about $60 \mathrm{~km}$ in length, extending roughly to the present-day shelf break. The Pliocene and Quaternary sedimentary record is asymmetric and eastward thickening, with TWTTs of up to $1.7 \mathrm{~s}$. This section of the record was sampled at site U1388, where drilling reached Pleistocene units $(<0.6-0.7 \mathrm{Ma})$, and by the MPC- 1 borehole which extends to the late Miocene. The CDR trends in a NNE direction and resides at a water depth of $400-800 \mathrm{~m}$. It extends approximately $43 \mathrm{~km}$ in length, varies in width up to a maximum of $14 \mathrm{~km}$ and takes an asymmetric form. It 


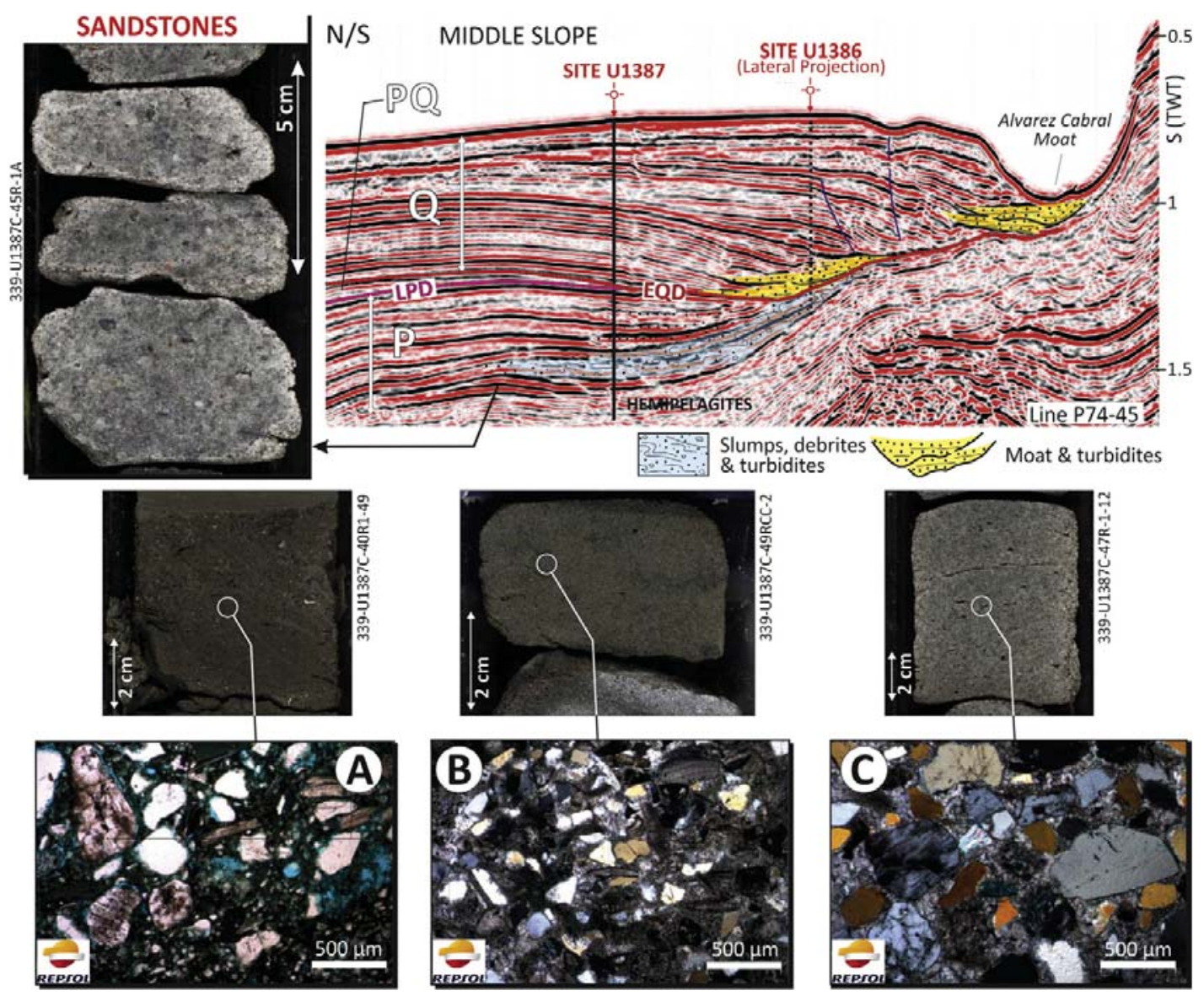

Fig. 10. Examples of early Pliocene sandstone petrofacies at site U1387C: A) petrofacies-1 with fine to very fine, very poorly sorted monocrystalline quartz sandstone (PP, plane polarized light.); B) petrofacies-2 with fine to very fine sandstone, moderate sorted and subrounded framework sandstone (XN, crossed nicols); and C) petrofacies-3 with well-rounded, poorly sorted sandstones $(\mathrm{XN})$

has gaps and is most strongly deformed along its eastern flank. The Rota basin is a smaller subordinate basin bounded by a diapiric structure and residing within the westernmost part of the Cadiz basin. It reaches widths of 20-25 km and thicknesses of approximately $1.5 \mathrm{~s}$ (TWTT).

The Sanlucar basin is of $25-30 \mathrm{~km}$ in width between the Cadiz and Guadalquivir diapiric ridges (GDR) (Fig. 4), and extends 70 km in length up to the shelf break. It has an asymmetric sedimentary thickness for the Pliocene and Quaternary section that reaches nearly $2 \mathrm{~s}$ (TWTT) along its eastern boundary. Although this basin was not sampled, upper slope and outer shelf deposits have been stratigraphically correlated with the adjacent Rota and Cadiz basins. The GDR trends in a NE-SW direction and reaches approximately $86 \mathrm{~km}$ in length. Its upper surface rests at water depths of 300-1100 m. This basin hosts the most extensive of the ridge systems found in the study area, and thus has a bathymetry characterized by numerous irregular highs, lows and gaps.

The Doñana basin is located to the west, between the Guadalquivir diapiric ridge and a set of elongated basement highs that trend in a NE-SW direction (Figs. 1 and 4). These occupy middle slope regions at 1200-1300 m depth and include the Guadalquivir bank (GB) and the Portimao and Albufeira basement highs ( $\mathrm{PH}$ and $\mathrm{AH}$, respectively). The Doñana basin is $25 \mathrm{~km}$ wide and extends $108 \mathrm{~km}$ in length up to the shelf break. It shows a Pliocene and Quaternary section of up to $\sim 1.5 \mathrm{~s}$ (TWTT). Two sites have been drilled in the Doñana basin, the site U1389 borehole in the east of the basin, which penetrates down to the early Pliocene $(<3.8 \mathrm{Ma})$ and the site U1390 borehole in a southwesterly area, which extends to the early Pleistocene $(<1.3 \mathrm{Ma})$. The Doñana basin is bisected by the Doñana dipiric ridge (DDR) which is a $53 \mathrm{~km}$ long feature located to the north, at water depths ranging from 500 to $1100 \mathrm{~m}$. This ridge outcrops in limited areas, and locally deforms the overlying sedimentary succession. The Guadalquivir bank (GB) is located in the southern part of the Algarve basin and represents a structural high located at water depths of around $300-500 \mathrm{~m}$. The GB represents south Portugal's Variscan rifted basement (Medialdea et al., 2004; Roque et al., 2012). Due to its tectonic inversion and recent uplift, the adjacent western sector of the basin suffered subsidence allowing the formation of a sedimentary depocenter.

The Deep Algarve basin resides between the Algarve upper slope and the aforementioned basement highs (Fig. 4). It extends $40-50 \mathrm{~km}$ in width and $114 \mathrm{~km}$ in length. Pliocene and Quaternary sedimentary thickness in the basin reach about $1.2 \mathrm{~s}$ (TWTT). Sedimentary thickness is irregular in the Deep Algarve basin but much more tabular than that previously described basins. The Deep Algarve basin was sampled at sites U1386, U1387 down to the late Miocene $(<5.75 \mathrm{Ma})$. The Algarve- 2 borehole was also drilled down to the late Paleocene and 


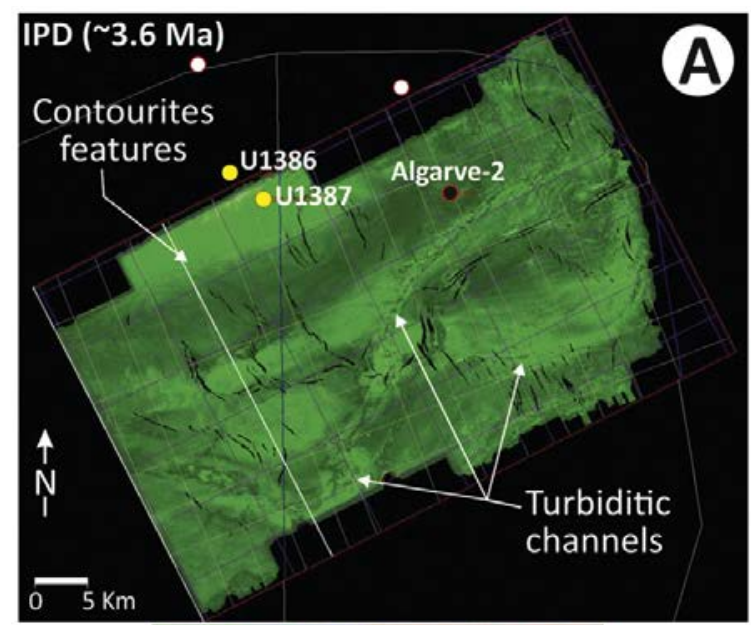

$-306.53$

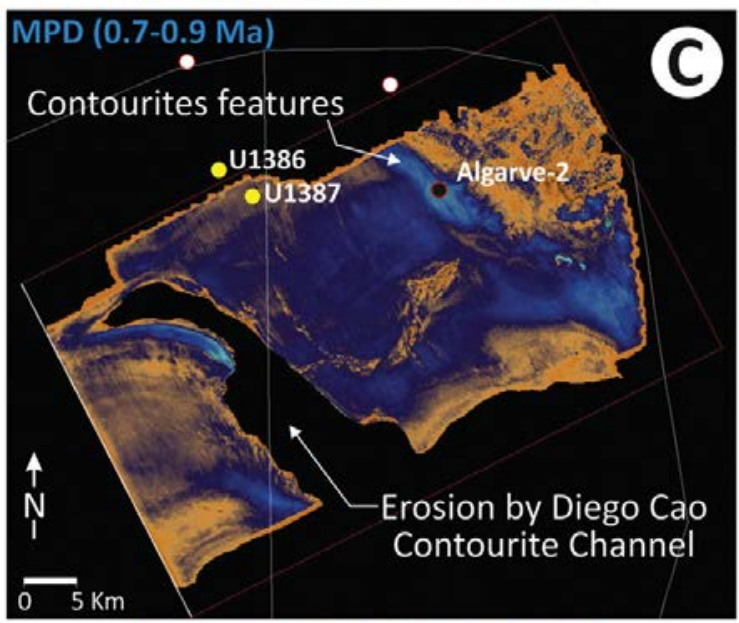

$-2805.10$

2604.81

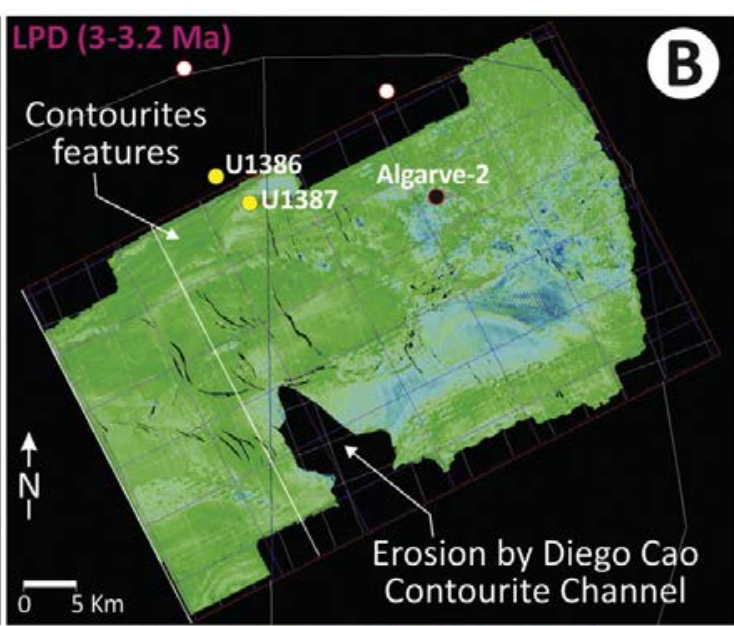

$626.54 \quad 2837.53$

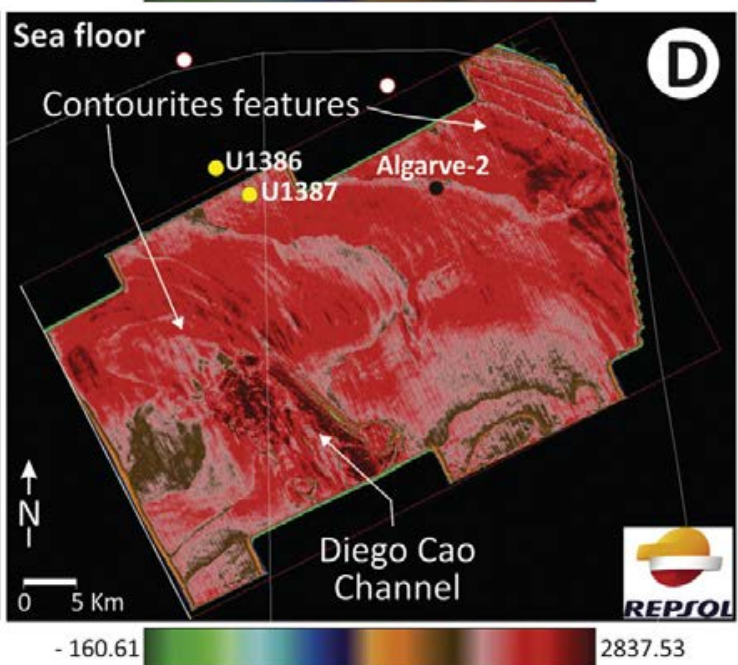

Fig. 11. Amplitude maps based on 3D seismic data from the Algarve basin (Fig. 3) for: A) Intra Pliocene Discontinuity ( 3.6 Ma); B) late Pliocene Discontinuity (3-3.2 Ma); C) mid Pleistocene Discontinuity (0.7-0.9 Ma); D) present day bathymetry of study area (data courtesy of REPSOL). Area location is provided by a red square in Fig. 3. These maps show the change from a system of mixed contourite and turbidite deposition in the early Pliocene to the dominant contourite system from the Pleistocene to the present.

Eocene sections, the later of which is unconformably overlain by Late Miocene-Pliocene sediments. This basin contains diapiric structures, which follow NE-SW trends and include late Triassic and early Jurassic evaporites. The frontal part of the AUGC also appears in this basin and pinches out within late Miocene sediments (Roque et al., 2012; Hernández-Molina et al., 2014b). Finally, the Alentejo basin trends in a $\mathrm{N}-\mathrm{S}$ direction between the San Vicente and Lisboa submarine canyons (Fig. 1) and hosts a Pliocene to Quaternary sediment thickness of $<0.9 \mathrm{~s}$ (TWTT). The borehole at site U1391 sampled this basin down to the early Pliocene $(<3.5 \mathrm{Ma})$.

Seismic and drilling results show significant spatial and vertical variation of sedimentary, seismic and logging facies along with numerous discontinuities in Neogene basins. The two most significant discontinuities (after the prominent Miocene-Pliocene boundary) occur at 3.2-3.0 Ma (late Pliocene Discontinuity, LPD) and 2.4-2 Ma (early Quaternary discontinuity, EQD) (Fig. 4) and divide the sedimentary record into three major sedimentary sequences of: Pliocene (P); Pliocene/Quaternary (PQ) and Quaternary $(\mathrm{Q})$ age. These sequences consist of six seismic units (PI-PIII and QI-QIII) bounded by minor discontinuities (Table 1), which appear as high-amplitude seismic reflections. The distribution of these reflections indicates that they represent erosional surfaces along basin margins that develop into conformable surfaces basinwards. Sedimentary facies for the Pliocene and Quaternary sections consist primarily of pelagites, hemipelagites, contourites, turbidites, debrites and slump deposits (Figs. 5 and S2). Dolomitic mudstone, dolostones and sandstones are rare, but also appear in drill core material associated with the aforementioned hiatuses. Contourites include sandrich, silt-rich and mud-rich contourites, and constitute about $50 \%$ of the recovered Pliocene core deposits, where debrites and turbidites are also common. Contourites predominate the sedimentary record Quaternary deposits (Fig. 5) above the $2.4-2$ hiatus (up to $95 \%$ of recovered core deposits). 


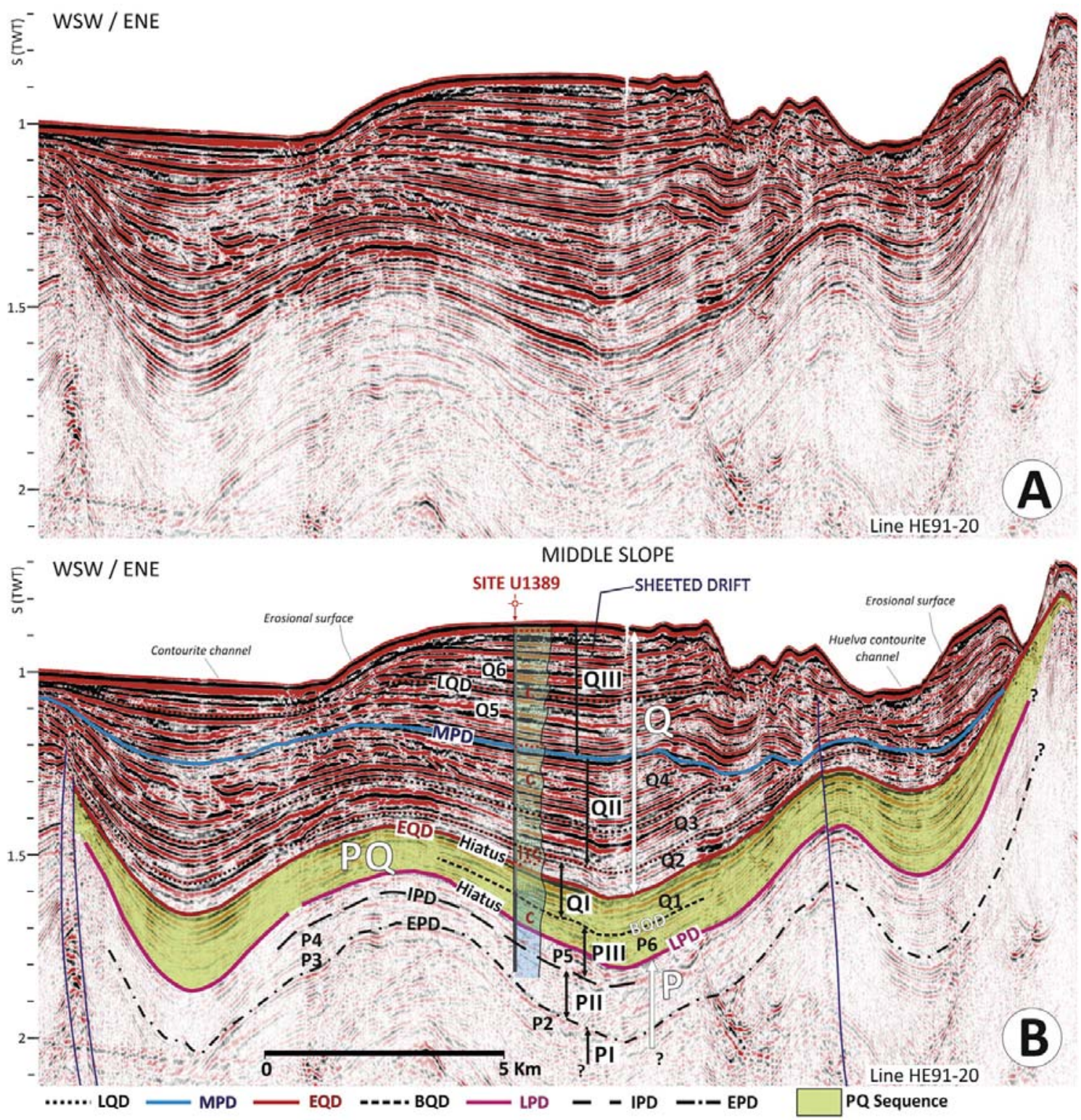

Fig. 12. Seismic profile (Line HE91-20) including site U1389 in the Doñana basin. Major sequences (P, PO and Q), units (PI-PIII and OI-OIII) and subunits (P1-P6 and O1-O6), as well as the main discontinuities and hiatus are shown. Profile location given in Fig. 3. Abbreviations for discontinuities are in Fig. 6. Simplify sedimentary log for U1389 is included (see abbreviations in Fig. 5).

\subsection{Late Miocene and Miocene/Pliocene boundary}

Seismic facies for the entire late Miocene appear as very weak to semi-transparent seismic reflections. Some seismic reflections suggest slope progradation in a seaward direction. Locally high amplitude reflections occur in lateral association with incised erosional surfaces and channelized features (Figs. 6 and 7). Being Messinian in age, these deposits appear in the Deep Algarve basin at sites U1387 and Algarve2 (Figs. 6 and 7) and in the Cadiz basin at the MPC-1 site (Fig. 8). The dominant regional sedimentary facies includes clays and marls with occasional layers of fine sand. This facies appears in the Deep Algarve basin at site U1387 as dark greenish to greenish, gray muds and muddy oozes with nannofossils. The facies forms in hemipelagic settings and shows subtle parallel lamination and pervasive bioturbation (Figs. S2-J). Siliciclastic abundances are up to 70\% and carbonate abundances are $15 \%-30 \%$.

The Miocene/Pliocene boundary (M) at 5.3 Ma was detected at borehole Algarve- 2 at around 1455-1460 mbsf in the Deep Algarve Basin (Figs. 5 and 7). The seismic reflector marking the boundary was traced from Algarve-2 to sites U1387 and U1386. The boundary appears in 


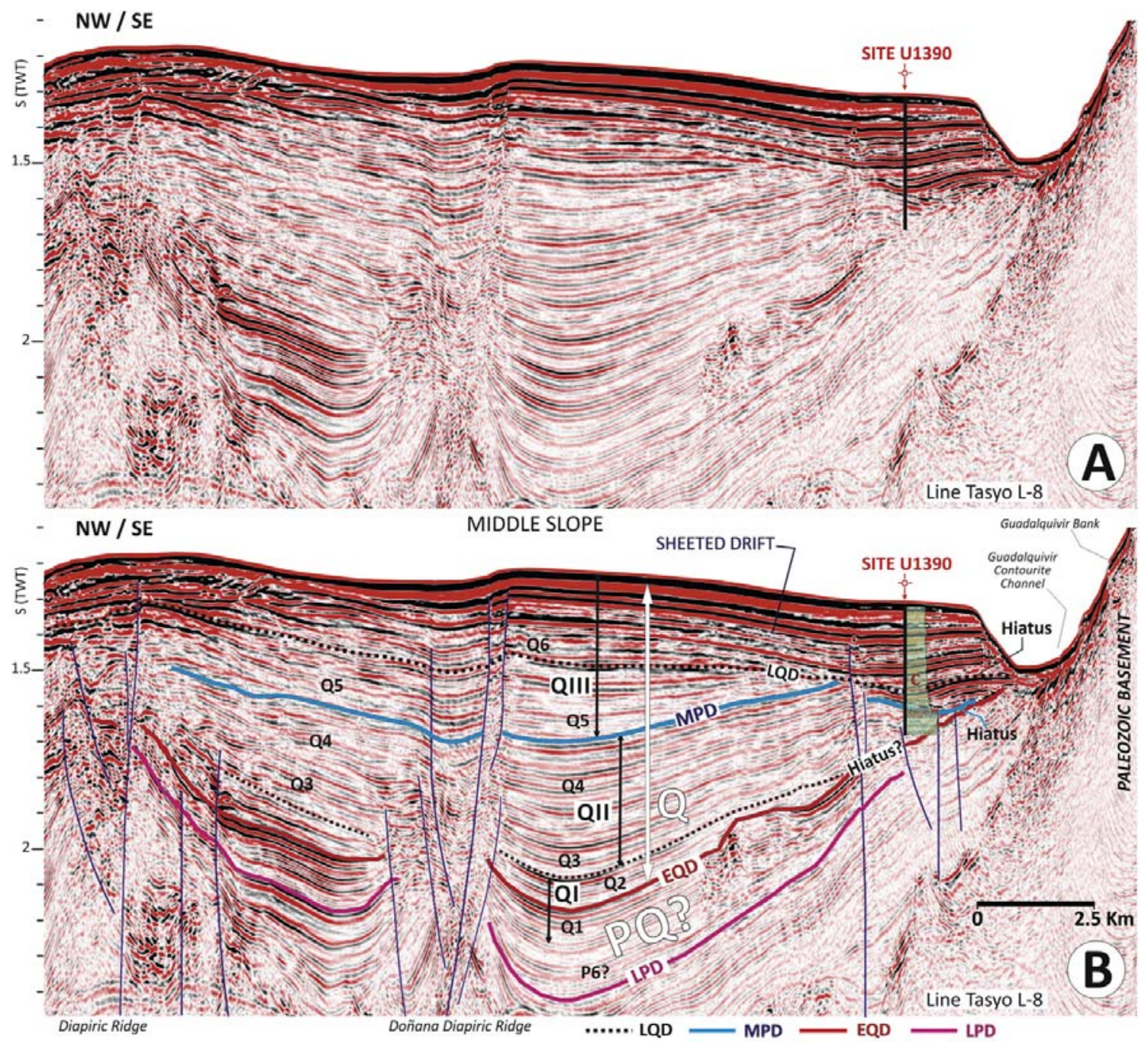

Fig. 13. Seismic profile (Line Tasyo L-8) of the Doñana basin across site U1390. Major sequences (P, PQ and Q), units (PI-PIII and QI-QIII) and subunits (P1-P6 and Q1-Q6), as well as the main discontinuities and hiatus are shown. Profile location given in Fig. 3. Abbreviations for discontinuities are in Fig. 6. Simplify sedimentary log for U1390 is included (see abbreviations in Fig. 5).

seismic profiles as an increase in reflection amplitudes (Fig. 7), which laterally correspond with an erosional surface along the axis of the Deep Algarve Basin (Figs. 6 and 7). These seismic characteristics also appear in profiles from the Cadiz, Rota and Sanlucar basins, but are less clear within the Doñana basin, due to its pervasive deformation. The transition does not appear in borehole log data (Fig. 9). The boundary at site U1387 is not consistently obvious in bio-, magneto- or cyclostratigraphic data. However Van der Schee et al. (2015) has recognized a significant change from hemipelagic muds to a sedimentary setting affected by bottom currents at around 826 mbsf in site U1387, which approximately coincides with the estimated depth for the aforementioned reflection. Above this boundary the sedimentation rate increases (from $~ 9.9$ to $27.2 \mathrm{~cm} / \mathrm{ky}$ in the Pliocene) and the sediment displays a greater relative siliciclastic component, an increase in the $>63 \mu \mathrm{m}$ grain size fraction, larger XRF Zr/Al ratios and lighter benthic oxygen isotope values.

\subsection{Pliocene}

The Pliocene succession was sampled at four sites from IODP Exp. 339 (U1386, U1387, U1389 and U1391, Fig. 5), as well as by the Algarve-2 and MPC-1 boreholes.

\subsubsection{Early Pliocene to late Pliocene}

Early Pliocene deposits appear as sheeted deposits with a general aggradational sedimentary stacking pattern and clear evidence of alongand across-processes interaction. These units correspond with the seismic units PI, PII and the lower part of PIII, which include a number of subunits (Table 1, Figs. 6-8). Seismic units vary between the Neogene basins in terms of seismofacies and sedimentation rates. In the Deep Algarve and Alentejo basins, these units exhibit well-stratified high amplitude reflections with good lateral continuity (PI and PII), which evolve 

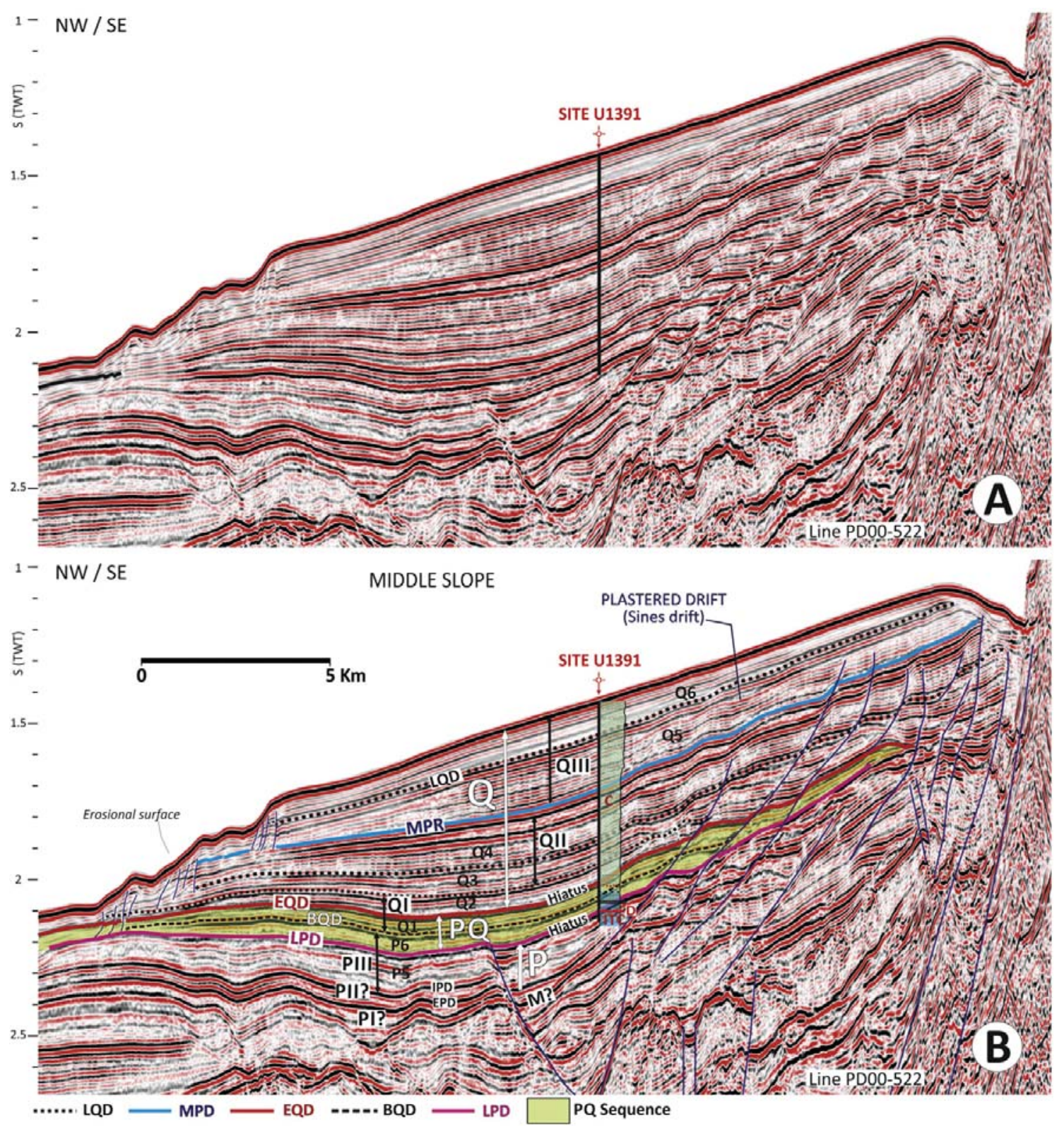

Fig. 14. Seismic profile (line PD00-522) of the Alentejo basin showing the Pliocene to Quaternary sedimentary record at site U1391. Major sequences (P, PQ and Q), units (PI-PIII and QIQIII) and subunits (P1-P6 and Q1-Q6), as well as the main discontinuities and hiatus are shown (data courtesy of TGS-NOPEC Geophysical Company ASA). Profile location given Fig. 3. Abbreviations for discontinuities are in Fig. 6. Simplify sedimentary log for U1390 is included (see abbreviations in Fig. 5).

upward into deposits with weaker acoustic response (PIII). In basins hosting the AUGC, the early Pliocene deposits generaly show the opposite seismofacies trend (Figs. 4 and 6-8), with a weak acoustic response at the base (PI and PII) strengthening progressively upward to PIII. Sedimentation rates are moderate in the Deep Algarve and Alentejo basins $(\sim 15 \mathrm{~cm} / \mathrm{ky})$, but higher in the Doñana basin ( $25 \mathrm{~cm} / \mathrm{ky}$; site U1389). A prominent precessional periodicity appears in log data from lower Pliocene records of the Gulf of Cadiz (Fig. 9). Sierro et al. (2000) first identified these cycles, being interpreted as rhythmic changes in clay content, reflecting precession-induced oscillations in annual rainfall. At sites U1386 and U1387, Pliocene logs record a strong lateral supply of terrigenous material.

The boundary between PI and PII represents an onlap surface (Fig. 6), referred to as the early Pliocene Discontinuity (EPD). Drilling data has constrained this surface to an age of ca. $4.5 \mathrm{Ma}$. This boundary correlates with the LPR horizon described in Llave et al. (2001, 

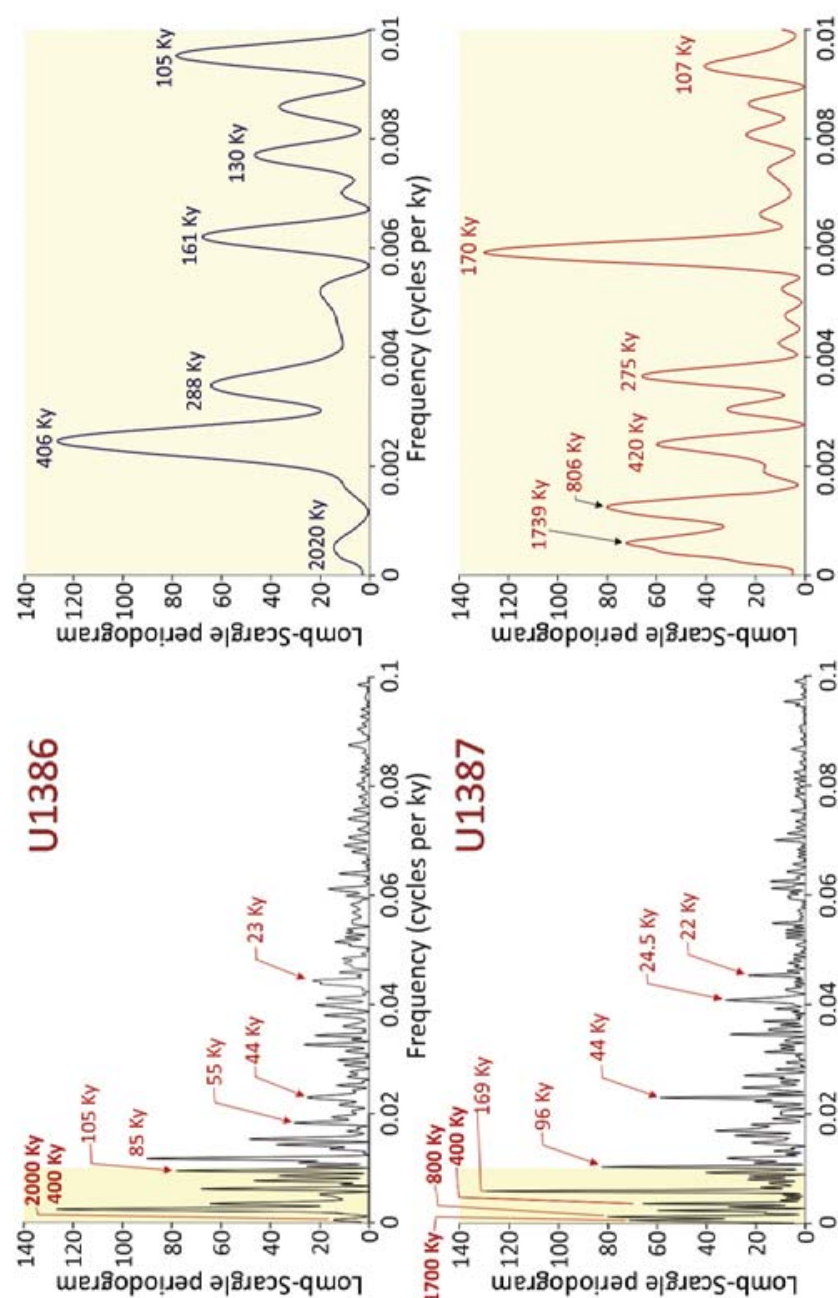

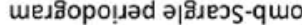
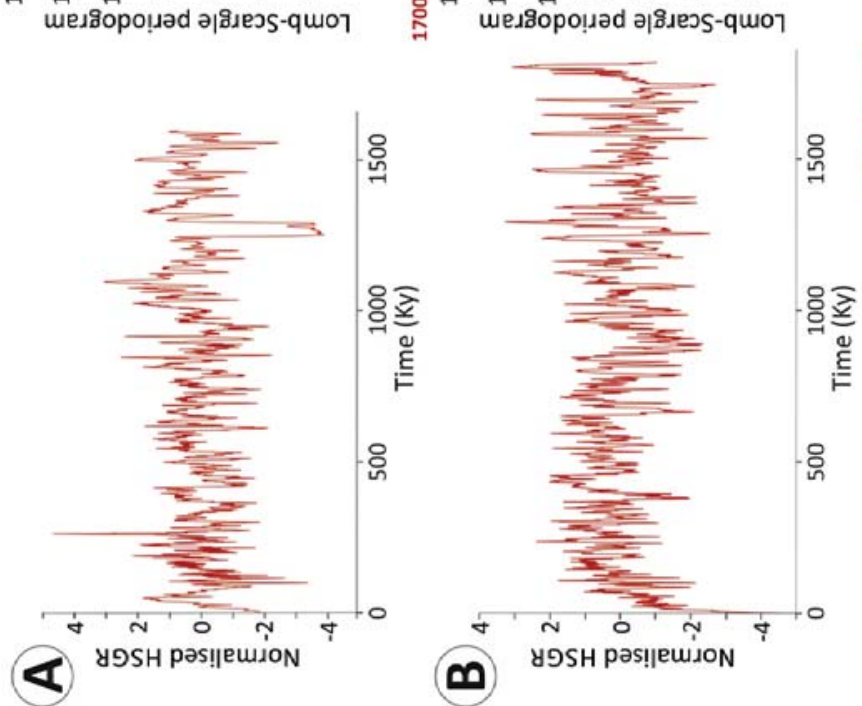

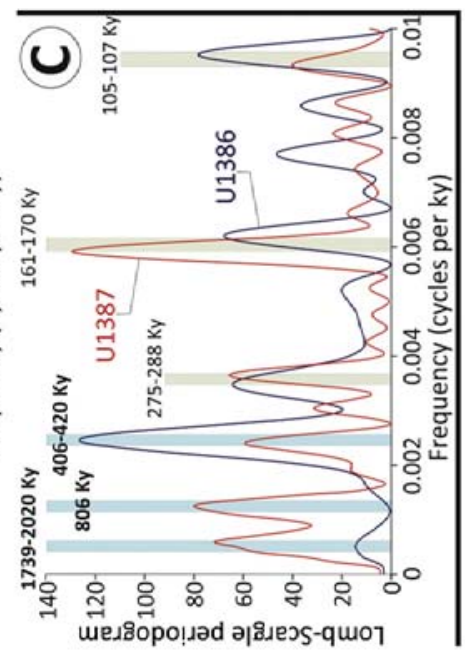


2007a, 2011); Hernández-Molina et al. (2002) and Marchès et al. (2010) and with the H1 discontinuity described in Roque et al. (2012) (Table 1).

Sub-unit PI has a basal tabular sub-unit (P1) that appears as moderate reflection amplitudes above the $\mathrm{M}$ discontinuity (Fig. 7). These deposits were drilled at site U1387. Although core recovery from this site was poor, core material exhibited thin sandy beds (silty sand and sand, Fig. S2-A), with common glauconite and dolomite, and was interbedded with nannofossil muds and occasional debrites. Above these sandy deposits, P2 occurs as a lobate to tabular shaped sub-unit with high to very high amplitude reflections at its base (Figs. 6 and 7). These seismofacies match the well-cemented, gray to dark greenish gray sandstones observed in core material from site U1387 (Fig. S2-B), which is interbedded locally with dark greenish gray, silty/muddy fine sands. Above the sandstones, chaotic seismic facies occur as tabular to wedge-shaped bodies (Fig. 6). These appear in drilling data from both U1386 and U1387, and correspond to thickly-bedded, chaotic, bioclastic debrites and slump deposits that reach thicknesses of up to $5 \mathrm{~m}$ (Figs. 5 and S2-C and D). These intervals appear as high resistivity values in borehole logs (Fig. 9, Ducassou et al., 2016).

The consolidated sandstone layers represent a shift in lithofacies at about $5 \mathrm{Ma}$, which corresponds to the marked change in seismofacies apparent in seismic profiles (Figs. 6 and 7). Sandstones show moderate to poor sorting and well-rounded grains of green glauconite but no bioturbation (Fig. 10). Sandstone clasts are supported by a matrix of clay and silt-sized carbonate, which is partly replaced by calcite cement. Silty material constitutes $30 \%$ of the matrix, siliciclastics make up $40 \%$ of the matrix (mostly quartz with trace feldspars, heavy minerals, and mica) and biogenic carbonate clasts makes up 30\% (foraminifers and shell fragments). Most of the quartz grains are angular, although some grains of rounded quartz, polycrystalline quartz, or quartzite are also present. Petrographic analysis of sandstone thin sections revealed grain-supported, medium-grained sand with calcite cement filling in pore spaces (Fig. 10). This sample had a high relative abundance of feldspathic material, reaching $25 \%$ in arkose samples, as reported by Stow et al. (2013b). Recent analysis by REPSOL using IODP samples (Caja et al., 2013) identified three petrofacies in these sandstones. Petrofacies 1 has variable rounded, medium-fine to very fine, very poorly sorted monocrystaline quartz sandstones containing bioclasts of foraminifera and coral material (Fig. 10A). Petrofacies 3 consists of medium grained, rounded to well-rounded, poorly sorted sandstones with very little matrix and dominantly containing monocrystalline and polycrystalline quartz (Fig. 10C). Petrofacies 2 represents an intermediate between petrofacies 1 and 3 (Fig. 10B). All petrofacies share basic compositions that include K-feldspars, plagioclase, foraminifera and minor components of intrusive igneous rock fragments, carbonate, muscovite, hornblende, tourmaline and glauconite clasts (Fig. 10).

PII consists of two subunits (P3 and P4, Table 1) bounded by an extensive, high-amplitude reflection surface dated at $\sim 3.8$ to $3.9 \mathrm{Ma}$ (Figs. 6 and 7). Within the AUGC, this horizon represents a lithologic shift in which sedimentary input to the Cadiz basin assumed a sandier composition (Hernández-Molina et al., 2014a) (Fig. 8). PIII and PII are separated by a high amplitude horizon dated at $~ 3.6-3.5 \mathrm{Ma}$ and interpreted as the intra Pliocene discontinuity (IPD) (Figs. 6, 7 and 8, Table 1). Above this surface, PIII assumes a sandier composition in the Cadiz basin (Fig. 8).

Nannofossil mud, silty mud and silty sand with biogenic carbonate comprise the dominant sedimentary facies found in PII and PIII core material from site U1387 (Figs. 5 and S2). The relative abundance of nannofossil mud decreases significantly through the early Pliocene up to unit PII. This compositional shift is manifested as a seismic amplitude increases for the overlying unit PIII in the Algarve basin. Interbedded turbidite and contourite deposits commonly appear as parallel- to slightly inclined-laminations with normally graded bedding (Fig. S2). For the intra Pliocene discontinuity (IPD), amplitude anomaly maps based on 3D seismic profiles of the Deep Algarve Basin, clearly show the common occurrence of turbiditic channels throughout the basin and their lateral association with contourite features (Fig. 11). Core material from PII and PIII subunits consists of cyclical alternation of sediments with light and dark layers of 1 to $5 \mathrm{~m}$ thickness (Figs. 5 and S2-H). The base of each cycle generally consists of light-colored silty sands with biogenic carbonate and normal graded bedding that passes upward into light- or dark-colored muds (Stow et al., 2013b). In general, the mud facies constitute $>80 \%$ of each cycle. The muds contain trace amounts of siliceous microfossils (e.g., radiolarians, diatoms, and sponge spicules). Lithologic contacts within a cycle are gradational or bioturbated, whereas the basal contact of the silty sands is sharp, erosional and sometimes bioturbated.

\subsubsection{The late Pliocene hiatus}

A regional discontinuity, termed the late Pliocene Discontinuity (LPD) appears as a laterally continuous, high amplitude reflection in the Deep Algarve basin (Figs. 6 and 7), basins covering the AUGC (Figs. 8, 12 and 13) and the Alentejo basin (Fig. 14). This discontinuity represents a local erosional surface with the hiatus increasing towards local highs. The hiatus appears at around 3.0-3.2 Ma in core material from site U1391, or as reduced rates of sedimentation at other sites. The amplitude anomalies map for the LPD in the Deep Algarve basin (Fig. 11) shows no turbiditic channels and an increase in reflectivity (associated to coarser grain sizes) in the southern part of the basin, near the basement highs. Dolostone deposits are closely linked to this hiatus (Figs. 5 and S2-I), indicating shallow diagenetic processes and appearing as high resistivity peaks in borehole logs (Fig. 9).

\subsection{The late Pliocene-Quaternary}

The Pliocene-Quaternary (PQ) sequence is bounded by the LPD at its base and by the early Quaternary discontinuity (EQD) along its upper surface. The sequence includes the upper part of the PIII seismic unit (P6) and the lower part of the QI seismic unit (Q1) (Table 1). PQ was sampled at sites U1389 and U1391 (Fig. 5), as well as by the Algarve-2 and MPC-1 boreholes, but did not appear in records from other sites. Sedimentation rates corresponding to this sequence reach $\sim 25 \mathrm{~cm} / \mathrm{ky}$ in the Doñana basin (site U1389) and $13 \mathrm{~cm} / \mathrm{ky}$ in the Alentejo basin (site U1391). On seismic profiles, the EQD completely erodes the PQ sequence in areas near the upper slope, diapirs and basement highs. The sequence is continuous in the deepest part of the basins (Figs. 6-8 and 12-14). Erosional processes have resulted in a wedge or lenticular shaped PQ sequence. Seismic profiles show PQ as high amplitude reflections indicating sheeted drift deposits and enhanced acoustic response in upper parts of the sequence, especially in areas adjacent to highs and banks. Borehole logs for this sequence show cyclic swings in amplitude that are generally lower than those observed for the Q sequence, except when sampling the most proximal site, MPC-1 (Fig. 9). Logs from site U1390 shows low amplitude variation for the lower part of the sequence, increasing to higher amplitude variation for the upper parts of the sequence.

Sedimentary facies for the latest Pliocene (P6) in the Doñana basin ( site U1389) consist of calcareous mud (Fig. S2-K). Bi-gradational sequences are scarce and normally graded bedding is absent. In the Alentejo basin (site U1391), above subunit P6, dominant calcareous muds alternate with biogenic muds (Fig. S2-L) and debrites. The earliest Pleistocene sedimentary record (Q1) is bounded at its base by a laterally extensive and high amplitude reflection, which corresponds to the basal Quaternary discontinuity (BQD). This surface correlates with the H3 discontinuity in Roque et al. (2012) and with horizons BQD and D1 in Llave et al. (2011) and Marchès et al. (2010), respectively (Table 1). Q1 is typically eroded by the EQD, but where observed, it appears as high- to very high-amplitude, laterally extensive seismic reflections that outline aggradational features and internal erosional truncations 
(Figs. 6-8 and 12-14). Core material revealed lithologies that include nannofossil muds, calcareous silty muds, and silty sands with biogenic carbonate (Figs. 5 and S2). There are frequent bioturbation structures throughout.

\subsubsection{The early Quaternary hiatus}

The early Quaternary discontinuity (EQD) is the most prominent discontinuity in the study area. This horizon marks a shift in the sedimentation pattern, a considerable increase in sedimentation rates and the onset of the present-day contourite depositional and erosional features. The surface appears as a high-amplitude reflection outlining a penetrative erosional truncation surface that is especially evident in areas near the upper slope and adjacent to relief (diapirs and basement highs) (Figs. 6-8 and 12-14). Core material shows the hiatus occurs at 2 and 2.4 Ma at different sites. The volume of sediment eroded varies, but increases considerably towards highs. The surface evolves to a more conformable horizon basinwards. Several well-cemented dolomite horizons occur below the EQD at site U1387, where beds appear as high resistivity peaks in borehole logs (Fig. 9). Dolostones consist of almost pure dolomite (3-10 $\mu \mathrm{m}$ dolomite grains) but contain a few quartz grains, opaque minerals, and ghosts of siliceous microfossils, including radiolarians and diatoms (Fig. S2-I). The dolomite beds are overlain by turbidite sands (Figs. 5-7).

\subsection{The Quaternary (<2 Ma)}

The Quaternary sequence $(\mathrm{Q})$ younger than 2 Ma consists of the upper part of the QI, as well as seismic units QII and QIII (Table 1). It unconformably overlies the Pliocene deposits and was sampled at all IODP Exp. 339 sites, partially by MPC-1, but did not appear at the Algarve-2 site. The primary contourite sedimentary facies include nannofossil mud, calcareous silty mud and silty bioclastic sand lithologies (Figs. 5 and S2). These three facies generally occur as bi-gradational sequences, the most complete of which coarsen upward from nannofossil muds to calcareous silty muds to silty bioclastic sands, and then fine upwards through calcareous silty mud to nannofossil mud (Fig. S2-N and O). Partial sequences are also common (Fig. S2-P and Q) and episodic turbidite intercalations with normally graded sequences occur at several sites (Fig. 5). As a result, some of the contourite muds retain a distinctive lamination, albeit discontinuous in character, whereas the thicker sands are especially clean and well sorted. The Q sequence appears in well logs from all sites. HSGR logs show the sequence as medium-amplitude cyclic swings, varying on decimeter to sub-meter scale, with no major steps in base levels (Fig. 9). High NGR values indicate layers with high clay content and low carbonate content, whereas lower NGR values indicate either the opposite and/or coarser grained clastic material characteristic of contourite beds. Prominent precessional and eccentricity periodicities appear in log data (Lofi et al., 2015. Fig. 9). HSGR log patterns correlate very well across sites sampled by IODP Exp. 339, enabling regional mapping of certain well expressed contourite beds (Lofi et al., 2015). Q1 sequences exhibit cycles consistent with orbital forcing at precessional and eccentricity-related timescales. The PQ and Pliocene intervals below also exhibit cyclic swings in both HSGR and resistivity logs, but with lower amplitude and at lower frequencies than those observed for the $\mathrm{Q}$ sequence (Fig. 9).

\subsubsection{From $2 \mathrm{Ma}$ to the middle Pleistocene}

The early and middle Pleistocene deposits (upper part of QI and Q2) are bound by the EQD at their base and by the Mid Pleistocene Discontinuity (MPD) along the upper surface. Internal discontinuities distinguish minor subunits (Q2, Q3 and Q4, Table 1). These deposits have middle to high amplitude acoustic response but occur as different seismic facies among the Neogene basins. In the basin covering the AUGC, these deposits appear as high to very high amplitude acoustic responses with a well-layered internal structure, indicating sheeted drifts in aggradational configuration. The facies show a few thin intervals of lateral progradation within the Cadiz and Doñana basins (Figs. 8, 12 and 13). In the Deep Algarve basin these deposits exhibit clear upslope progradation of certain well-stratified high amplitude and laterally continuous reflections (Figs. 6 and 7), which represent a mounded elongated and separated drift (Faro Drift). This mounded geometry evolves in a seaward direction to an aggradational geometry characteristic of a sheeted drift. A similar sequence of seismic facies appears within Q3 and Q4 in all the basins, wherein weak to transparent acoustic facies evolve upwards into a high-reflectivity facies truncated by a subtle erosional surface (Figs. 6-8 and 12-14).

Although these early and middle Pleistocene deposits are muddominated, they represent a period of increased sand and silt deposition and a marked increase in sediment supply to the slope (sedimentation rates of 25 and $40 \mathrm{~cm} / \mathrm{ky}$ ), relative to previous deposits (Fig. 5). Sedimentary facies of Q2 and Q3 record the interbedding of contourites with sandy and silty turbidites. The higher relative proportion of sand in contourites/turbidites explains the higher acoustic response of these subunits, especially in the Deep Algarve basin (Fig. 6). In the Doñana basin (sites U1389 and U1390) Q2 and Q3 are slightly enriched in the clay sized fraction (51\%) and the sandy mud with biogenic carbonate as a subordinate lithology. These horizons at site U1389 exhibit fewer and finer-grained contourite sequences, all without sand, and higher proportions of biosiliceous sediment (diatoms and sponge spicules). These sediment types indicate a low-energy depositional environment. Silty and sandy units are generally poorly sorted, with subrounded to rounded detrital siliciclastic material. Detrital carbonate grains are generally subrounded to subangular, many with abraded margins indicative of reworking.

\subsubsection{The mid Pleistocene discontinuity (MPD)}

Another important change in the sedimentary stacking pattern occurs at the mid Pleistocene discontinuity (MPD). This discontinuity correlates with the MPR discontinuity (Mid-Pleistocene Revolution) identified by Hernández-Molina et al. $(2002,2006)$; Llave et al. (2007a, 2007b, 2011); Marchès et al. (2010) and Roque et al. (2012). Although it is clearly evident in seismic profiles (Figs. 6, 7, 8, 12, 13 and 14) as an erosional surface in areas adjacent to diapirs and basement highs, core material from the Doñana basin ( sites U1389 and U1390) indicates it represents only a short hiatus of variable duration (around 0.7-0.9 Ma). In the Cadiz basin, the sheeted drifts become even sandier above the MPD. Thick sands also appear around this horizon in the Doñana basin (site U1390). The amplitude anomaly map for Deep Algarve basin (Fig. 11), show contourites features along slope in the vicinity of the MPD horizon.

\subsubsection{Middle Pleistocene to Holocene}

Middle Pleistocene to Holocene deposits (QIII, Table 1) overlie the MPD at their base and extend up to the present-day seafloor. In the seismic profiles, they exhibit different seismofacies across different Neogene basins (Figs. 6-8 and 12-14). In basins covering the AUGC, they appear as a sandy sheeted drift (Cadiz basin) that transitions to muddy sheeted and mounded drifts in a northwesterly direction. These are then incised by contourite channels in the Doñana and Deep Algarve basins. The deposits have a well-layered internal acoustic structure, very high to massive acoustic response (with a few very high reflections), aggradational seismic configuration and abundant internal erosional surfaces (Figs. 8 and 12-13). In the Deep Algarve basin, these deposits exhibit a weaker acoustic response, with a sigmoidal to oblique reflection configuration suggestive of upslope progradation in proximal areas of the slope, and parallel to sub-parallel reflectors, outlining enhanced mounded morphology (Figs. 6 and 7). Laterally, the mounds features transition into an aggradational pattern characteristic of a large sheeted drift. Sedimentation rates for these deposits are moderate $(\sim 30 \mathrm{~cm} / \mathrm{ky})$ in the Deep Algarve and Alentejo basins (sites U1386, U1387 and U1391), to extremely high in the Cadiz $(60 \mathrm{~cm} / \mathrm{ky}$ at site U1388) and Doñana basins, where the highest sedimentation 


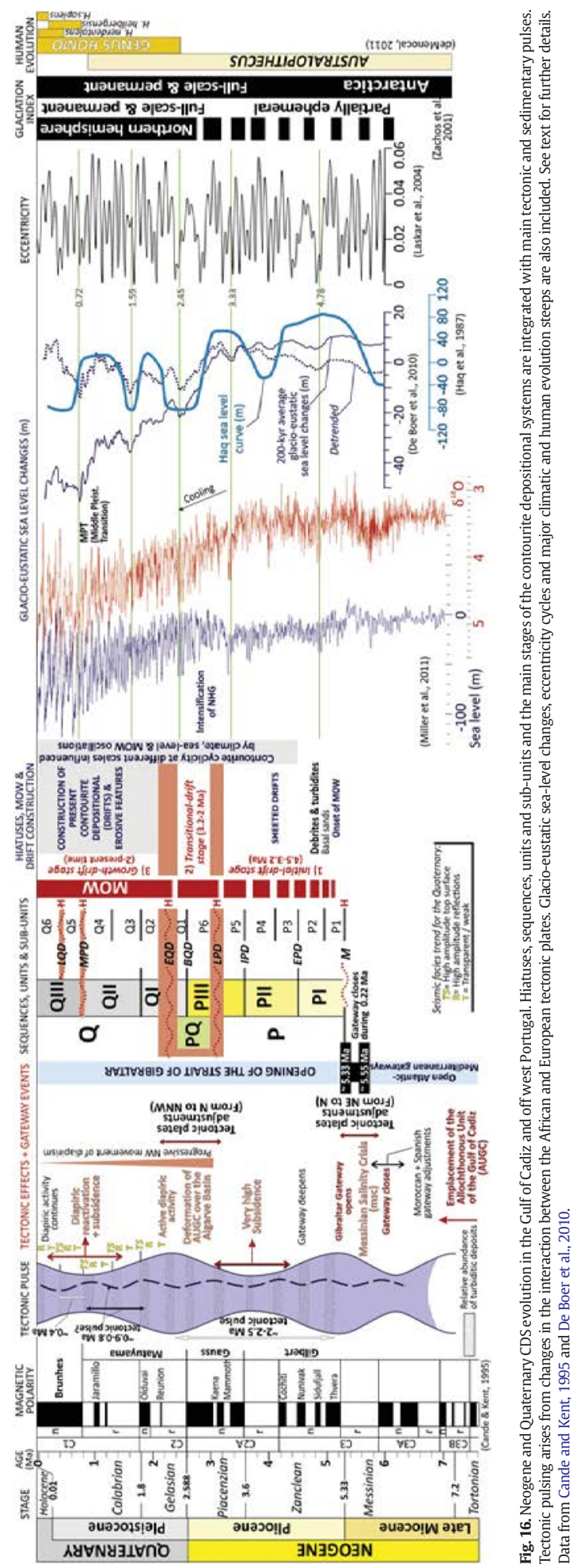



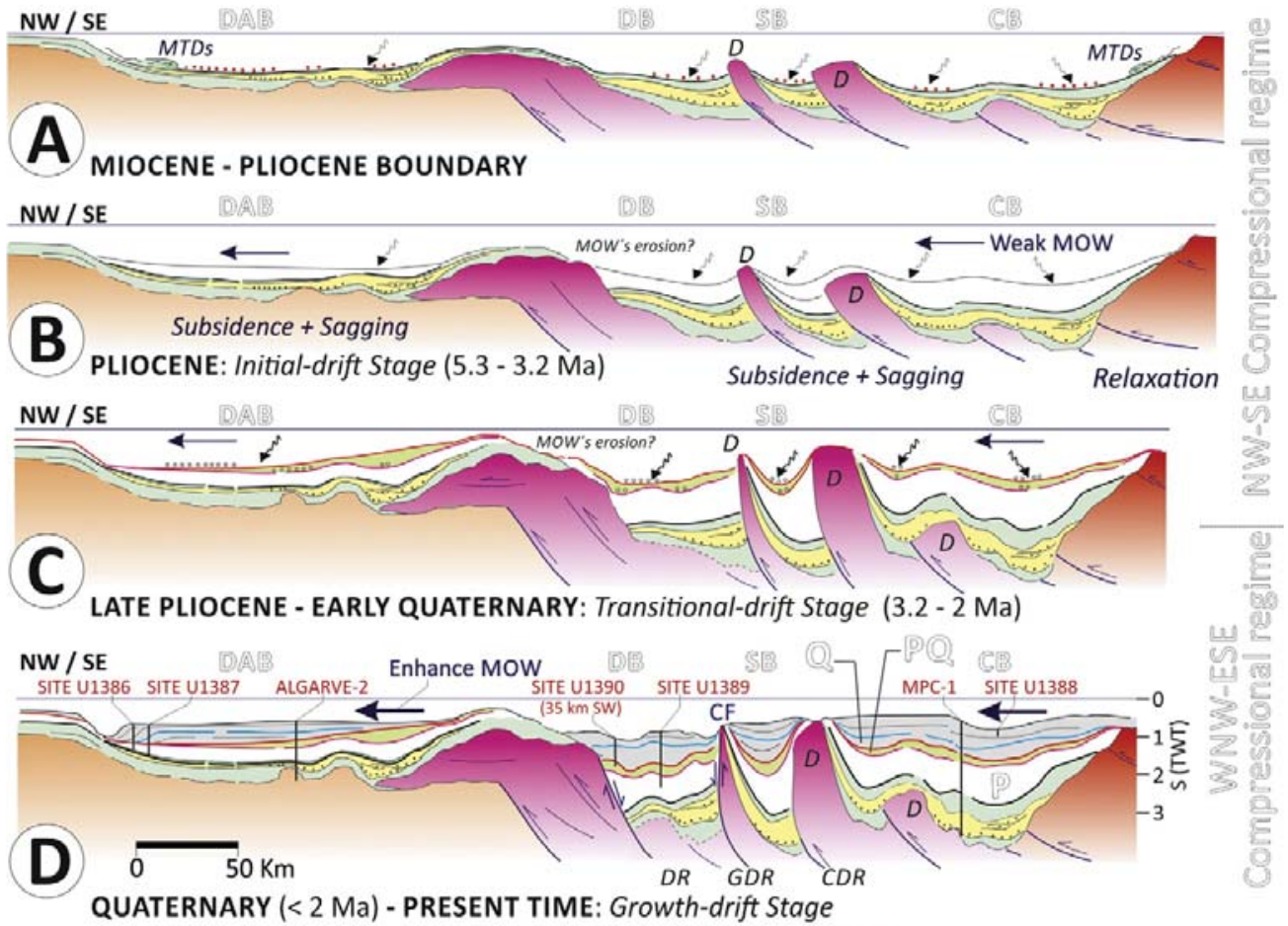

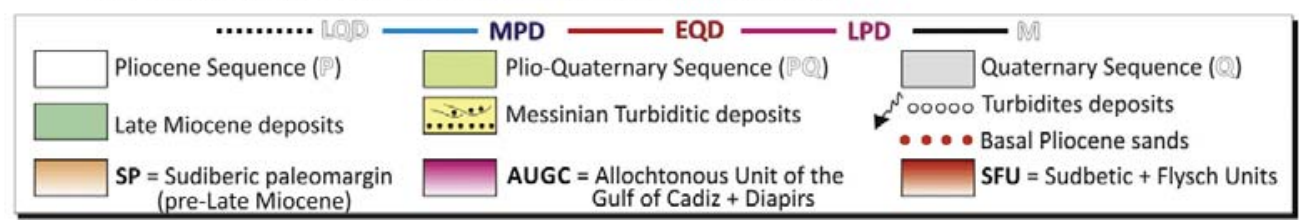

Fig. 17. Simplified evolutionary cartoons (not at scale) for the sedimentary evolution since the late Miocene to the present time of Neogene basins in the Gulf of Cadiz. After a compressional period associated with the late Miocene and early Pliocene ( $<4.5 \mathrm{Ma}$ ), two major compressional events affecting to the Neogene basins at 3.2-3 Ma and 2-2.3 Ma help constrain the three main stages of CDS evolution. The stages include: 1 ) the initial-drift stage (5.33-3.2 Ma) with a weak MOW, 2) a transitional-drift stage (3.2-2 Ma) and 3) a growth-drift stage (2 Mapresent time) with enhanced MOW circulation into the Atlantic and associated contourite development due to greater bottom-current velocity. See text for further details and discussion. Abbreviations for discontinuities are in Fig. 6 . CF, Cadiz Fault; D, Diapirs. Legend for the sedimentary basins: $\mathrm{DAB}=$ Deep Algarve basin; $\mathrm{CB}=\mathrm{Cadiz}$ basin; $\mathrm{DB}=\mathrm{Doñana}$ basin; $\mathrm{SB}=$ Sanlucar basin.

rates were observed ( $>100 \mathrm{~cm} / \mathrm{ky}$ at site $\mathrm{U} 1390)$. Sheeted drifts in the Doñana basin are highly deformed due to tectonic activity.

Internal discontinuities within QIII allow identification of two internal subunits (Q5 and Q6). These are bounded by the late Quaternary Discontinuity (LQD) discontinuity, locally identified as a short hiatus around 0.3-0.6 Ma in the Doñana basin (site U1390). A coarse layer is observed in association with the LQD in the Doñana basin, as is a shift from very poorly sorted below, to poorly sorted sediment above the discontinuity. The LQD correlates with the H5 discontinuity reported by Roque et al. (2012) and with the ID12 and D3 horizons identified by Llave et al. (2001, 2007a, 2011) and Marchès et al. (2010) (Table 1), respectively.

Sedimentary facies for QIII vary depending of the basin, with contourites as the dominant deposits, occurring as bi-gradational sequences, but also as top- and/or base-cut-out sequences (Fig. S2). Cadiz basin sediment from site U1388 shows sand, silty sand and silty muds as the principle lithologies from this horizon. Core material also includes numerous beds of calcareous sand and sand with biogenic carbonate (Fig. S2-R) reaching thicknesses of up to several meters. This subunit also includes many intervals of mud with biogenic carbonate that exceed thicknesses of $15 \mathrm{~m}$. In the Doñana basin, sedimentary facies consist primarily of calcareous mud, but also include silty mud, sandy mud, and silty sand with biogenic carbonate. In the Alentejo basin, sandy contourites and alternating reddish/brownish and greenish gray/greenish calcareous mud make up QIII. Subunits Q5 and Q6 exhibit sequences of seismic facies similar to those of Q3 and Q4, wherein weak to transparent acoustic facies transition upwards into high-reflectivity facies truncated by an erosional surface (Figs. 6-8 and 12-14). Drilling data from the Deep Algarve basin indicate that the weak to transparent seismic facies represent a mud dominated contourite succession that includes a higher proportion of nannofossil muds and calcareous silty muds. The greater reflectivity of overlying facies corresponds to increasing grain size and detrital content and to decreasing proportions of biogenic carbonate.

\subsubsection{Quaternary Cyclostratigraphic analysis}

A well-developed cyclostratigraphic pattern on normalized HSGR logs time-series is recognized in sites U1386 and U1387 
(Figs. 9 and 15), showing high-significant cycles (higher than 99\% $\mathrm{CL}$ ) at different frequencies and periods. In general both sites show similar, common peaks, located in the following four frequency bands (Fig. 15):

a) At the higher frequency band, two main peaks at $24.5 \mathrm{ky}$ and $22 \mathrm{ky}$ are registered in site U1387C that could be correlated with that at 23 ky in site U1386C (Fig. 15B).

b) At the middle frequency band, a common cycle at $44 \mathrm{ky}$ is observed, as well as one at $55 \mathrm{ky}$ in site U1386C (15A).

c) At the middle-lower frequency band, two main peaks at $85 \mathrm{ky}$ and 105 ky were registered at site U1386C that could be correlated with that at 96 ky in site U1387C (Fig. 15A).

d) At the lower frequency band several peaks from $0.4 \mathrm{Ma}$ to $2 \mathrm{Ma}$ are observed at both sites. The significant peak at $0.8 \mathrm{Ma}$ is only registered in site U1387 (Fig. 15C).

Detailed analysis of this cyclostragraphic results for site U1386 reveal slight differences in compared to site U1387 in all but the higher frequency bands. The Site U1386 records a reduced Quaternary sedimentary record since sub-unit Q3 pinches out close to the site and its younger record above the discontinuity MPD is affected by sinsedimentary faults (Fig. 15D).

\subsection{Tectonic considerations}

The late Miocene, Pliocene and Quaternary sediments are deformed by folding and faulting. Chronostratigraphic constraints presented in this work suggest asynchronous timing for such deformation events. At a local scale they are related mainly to 1 ) emplacement of the AUGC in the Gulf of Cadiz and Deep Algarve, 2) fault-activity, some of them bounding structural highs, 3) salt flowage. In fact, local deformation is evident from folding and faulting of late Miocene to Quaternary sedimentary cover overlying diapirs and structural highs. The structural grain of some of these features indicates continuous deformation up to present.

Late Miocene and Pliocene sediments overlying the AUGC are folded, in some cases slightly due to blind-thrust. These sediments are locally offset by the reactivation of the some AUGC imbricated thrust-faults (Fig. 4). Uplift of structural highs, such as the case of the Guadalquivir Bank, has also deformed the overlying sedimentary cover (Fig. 4). Basins covering the AUGC and Deep Algarve basin are faulted, primarily by NE and NW trending normal faults (Figs. 4, 6-8 and 12-13). Normal faults affecting the Alentejo basin trend primarily in a N-S direction (Fig. 14), cutting through the Pliocene and Quaternary. In this basin the sediments overlying LQD are underformed.

Salt flowage seems to be one of the main mechanisms leading to folding and faulting of the late Miocene through Quaternary in Deep Algarve, Doñana, Cadiz and Sanlucar basins. Inverted reactivated salt diapirs are found in the Algarve basin nearby the Diego Cão Channel (Fig. 6), probably induced either by regional shortening or local reactivation of a pre-existent normal fault of Mesozoic rifting phases. In the same basin, the presence of deeper salt domes is inferred from folded sediments, defining an asymmetrical anticline topped by EQD and a symmetrical one topped by MPD. Synkinematic sediments (seismic units P1-P5 and Q1) are thicker on the flanks than on the top of the salt dome indicating the upward movement of the salt. The associated rim syncline constituted a major local depocenter, and is generally thicker in the SE sector. Sediment folding has been attenuated since the deposition of unit Q2. In the Doñana Basin, sediments from Pliocene through Late Quaternary have been folded into symmetrical anticlines and synclines (Fig. 12). These structures are probably residual highs related to interdomal evolution occurring well below the Pliocene-Quaternary sequence, as there is no significant thickness variation of the seismic units. Contourite channels, such as the Huelva channel, have developed along the axis of the rim synclines. Diapiric ridge crests have been truncated by LQD, which marks the end of the folding phase, since younger sediments seem to be undeformed (Fig. 12). However, other NE-SW diapiric ridges are outcropping in the Doñana Basin, Sanlucar Basin and Cadiz Basin, such as the Guadalquivir and Cadiz Diapiric Ridges, suggesting a recent activity formed these structures. The upward salt flowage in the Doñana diapiric ridge occurred mainly between LPD and MPD. This induced compensatory subsidence and created rim synclines bounding the diapir, which acted as major depocenters during this phase (Fig. 4). Rising-up of salt in the Doñana diapiric ridge seems to have stopped, or at least decreased, during late Quaternary as marked by LQD (Fig. 12).

Two kinds of normal faults have been identified in close relation to diapiric domes and ridges: stretch faults and growth faults. In the Algarve basin the apex of salt diapirsm has been extended by stretching faults, which affected the entire Pliocene and Quaternary sedimentary column, and almost reached the seafloor. Several stretch faults developed in the apex of the Doñana diapiric ridge (Fig. 13) cutting through Pliocene and Quaternary sediments, although showing insignificant offsets. These extensional structures can be created by local stresses in the apex of diapirs due to salt flowage, independently of the regional tectonic regime. Some of these faults reached the seafloor and formed stair-step scarps (Fig. 13). The majority of stretch faults seem to be contemporaneous to diapir growth and sedimentation (e.g. Figs. 4 and 6) but some show evidences of posterior activity, cutting through undeformed sediments (e.g. Fig. 13). In the Cadiz basin, Quaternary sediments are locally affected by growth-faults, probably related to lateral salt flowage in a reactivated diapir (Fig. 8). Some of these faults are still active offsetting the present-day seafloor (Fig. 8). Growth-fault reactivation is recorded by EQD, with movement occurring largely until LQD and decreasing through present. Several episodes of fault movement created accommodation space in the SSW block, allowing the development of thicker Quaternary units.

Deformation of the early to late Pliocene $(\mathrm{P})$ sequence varies in different basins. Basins covering the AUGC primarily exhibit folding, due to the diapiric structures and uplift of highs (Figs. 12, 13 and 14).

Two deformation events related to the LPD and EQD also affected the late Pliocene to early Quaternary sequence $(\mathrm{PQ})$, mainly resulting in diapir growth and fault reactivation. Deformation appears as frequent faults and as reactivation of previous faults (evident from offset trends) and folds. Folded structures however are broader than those affecting early Pliocene sediments (Figs. 4, 6-8 and 12-14).

The Quaternary sequence $(Q)$ is also locally deformed, particularly in areas adjacent to structural highs and diapirs. These areas show folds, faults and features indicating reactivation of blind-thrusts (Figs. 4, 6-8 and 12-14). The major, active regional scale faults operating in the Gulf of Càdiz are the WNW-ESE SWIM faults, which apply dextral strike-slip or normal deformation to the seafloor, as well as their conjugates NE-SW structures. The Doñana basin records more intensive deformation of sediments deposited after the middle Pleistocene.

\section{Discussion}

\subsection{The Miocene-Pliocene boundary}

The Miocene-Pliocene boundary ( $\mathrm{M}$ discontinuity) represents a major stratigraphic surface within the Neogene basins along the SIM, but one whose expression varies laterally. Nelson et al. (1993) and Maldonado et al. (1999) described its basin-scale characteristics in basins covering the AUGC from single and multi-channel seismic profiles. In basins covering the AUGC, and in particular the Cadiz basin, this boundary forms a noticeable truncation surface clearly evident in seismic profile (Fig. 4). Along the flanks of the basement highs and diapirs it is very clear, but it become less obvious in central areas. Onshore (outcrop) expressions of this part of the basin show unconformable deposition of Pliocene sediments over late Miocene and AUGC sediments (IGME, 1990, 1994; Aguirre et al., 2010). The Fuente del Gallo north section (Cadiz, Spain; Figs. 3 and S3), provides a good example of this, 
wherein early Pliocene sands unconformably overly upper Miocene (Messinian) marls (Aguirre et al., 2010). Our analysis of marls below the unconformity identified abundant Globorotalia menardii form 4. The last common occurrence of this foram species was recorded in North Atlantic (Sierro et al., 1993) and Mediterranean sediments during the late Tortonian age (7.51 Ma; Hilgen et al., 1995). Other Tortonian species such as Globorotalia suterae are also present in marls beneath the unconformity. Horizons above the unconformity (Fig. S3) contain Globorotalia margaritae but not Globorotalia puncticulata. Because the first occurrence of $G$. puncticulata has been astrochronologically dated at 4.52 Myr (Lourens et al., 2004), we interpret these horizons to be early Pliocene in age, specifically dating between 5.33 (base of the Pliocene) and 4.52 Ma. However, a latest Messinian age cannot be entirely ruled out since G. margaritae was common at that time. The MiocenePliocene boundary is thus marked by a hiatus and lithological shift. Furthermore, Messinian deposits are all but absent from the section. A coeval lithological shift appears at the Miocene-Pliocene boundary in sediments from the Gulf of Cadiz continental shelf, where channelfilled turbidites are replaced by hemipelagites (Sierro et al., 2000, 2008). More inland, in the Guadalquivir basin the Miocene Pliocene boundary is identified by a pronounced reflector that separates Messinian seismic units with dominant northward progradation from Pliocene ones in a southward direction (Ledesma, 2000). The Miocene-Pliocene boundary is a conformable surface in the central part of the Deep Algarve basin at site U1387, only marked by local erosional along the axis of the basin and along its margins. The contact between the Cacela (marine) and Ludo (mainly fluvial) formations marks the approximate area of the Miocene-Pliocene boundary in Algarve basin outcrop (onshore). Moura and Boski (1999) and CachÃo and da Silva (2000) interpreted a hiatus of $2.5 \mathrm{Ma}$ and found the Messinian section absent from this part of the study area. The Miocene-Pliocene boundary has not yet been identified in the Alentejo basin, where the middle Miocene-Quaternary section consists of one big unit (C3) (Alves et al., 2009; Pereira et al., 2011; Pereira and Alves, 2013). In many areas of the Mediterranean continental margins, the Miocene-Pliocene boundary appears as a prominent erosive surface referred to as the ' $\mathrm{M}$ reflector' (Hsü et al., 1973; Ryan et al., 1973; Lofi et al., 2011). It is typically interpreted to represent penetrative desiccation and erosion during the Messinian salinity crisis (5.6-5.5 Ma) and the subsequent Zanclean flooding event (5.33 Ma) (e.g., Bache et al., 2009; Garcia-Castellanos et al., 2009; Estrada et al., 2011; Roveri et al., 2014; Flecker et al., 2015).

Above the Miocene-Pliocene boundary, fine sand deposits are found in units PI and PII. Onshore outcrops, adjacent to the Cadiz Basin, host extensive deposits of similar sands (e.g., see Fig. S3), which also appear regionally in the Neogene Guadalquivir foreland basin where they are described as glauconite and Huelva sands (Sierro et al., 1991, 1996; Gonzalez-Delgado et al., 2013), as well as in the basins covering the AUGC (IGME, 1990, 1994).

Several authors have interpreted the local erosional character of the Miocene-Pliocene boundary along the SIM as resulting from Messinian sea-level fall at about 5.5 Ma (Riaza and Martinez del Olmo, 1996; Nelson et al., 1993; Maldonado et al., 1999; Hernández-Molina et al., 2002). Hoddel et al. (2001) however demonstrated that sea-level began to rise below this boundary, and argued that the section lacked evidence of any other glacio-eustatic fall associated with the MiocenePliocene boundary. Sierro et al. (2008) and Flecker et al. (2015) found little evidence of major sea-level variations. These authors therefore proposed tectonic activity as a driving factor in boundary-related depositional changes. Results presented here support this hypothesis, as they describe compressional deformation of the AUGC and areas near the Strait of Gibraltar up until 4.5 Ma.

\subsection{Sedimentary stacking pattern}

The Pliocene to Quaternary sedimentary record in the Neogene basins shows a clear hierarchy of sedimentary units. Major sequences
PI-PII and QI-QIII units consist of P1-P6 and Q1-Q6 subunits, respectively. These subunits represent sedimentary cycles at different scales that are bounded by major and minor discontinuities. Seismic profiles show that the sedimentary thicknesses of Pliocene units and subunits are less than those of Quaternary units and subunits (Figs. 6-8 and 12-14). Shifts in sedimentary thickness coincide with major increases in sedimentation rates occurring above the early Quaternary discontinuity (EQD) at 2-2.4 Ma. A more pronounced change in sedimentary thickness occurred both above and below the Mid Pleistocene Discontinuity (MPD, Figs. 6-8 and 12-14). The estimated stratigraphic ages of around 0.8-0.9 Ma and 0.4-0.5 Ma for the subunits agrees well with cycles identified in the spectral analysis of HSGR logs (Fig. 15).

Cyclostratigraphic analysis of sites U1386 and U1387 evidences the incidence of an orbital control in the range of the Milankovitch temporal cycles (Berger, 1977, 1978; Berger et al., 1989). Thus, registered cycles at $22 \mathrm{ky}, 23 \mathrm{ky}$ and $24.5 \mathrm{ky}$ can be assigned to precession, those at $44 \mathrm{ky}$ and $55 \mathrm{ky}$ to the obliquity signal, while cycles of $85 \mathrm{ky}, 96 \mathrm{ky}$, and $105 \mathrm{ky}$ fit well with the short-term eccentricity. These data confirm the forcing of precession and eccentricity on deposition after the discontinuity MPD (as previously reported by Llave et al., 2001, 2007a and Hernández-Molina et al., 2002, 2006), and probably a comparatively minor incidence of the obliquity-induced cyclicity (Lofi et al., 2015).

In respect to the lower frequency band, that constitutes those cycles with a periodicity higher than that of the short-term eccentricity cycle (>100 ky), and orbital influence can be also envisaged. The common cycle at similar periods of $406 \mathrm{ky}$ and $420 \mathrm{ky}$, can be clearly correlated with the well-known long-term eccentricity cycle of approximately 0.4 Ma (Berger, 1977, 1978). These cycles show a high stability and have been used as a basic calibration period for cyclostratigraphy (Laskar et al., 2004, 2011; Hinnov and Hilgen, 2012). The peaks recognized around $2 \mathrm{Ma}$ (Fig. 15C), could be tentatively correlated with the approximately $2.4 \mathrm{Ma}$ eccentricity term. Modulation of the $0.4 \mathrm{Ma}$ components of the eccentricity shows actually a dominant component at a period of around 2.4 Ma related with Earth-Mars secular resonance (Laskar et al., 2004, 2011; Hinnov, 2000; Hinnov and Hilgen, 2012). This cycle has been also frequently identified in the geological record as a long-term cycle, from the Triassic, with periods of around 1.6 to $2 \mathrm{Ma}$ (see Boulila et al., 2012 and Ikeda and Tada, 2013 for recent reviews). However, differences in the periodicities corresponding to the modulated eccentricity at around $2.4 \mathrm{My}$, and those here registered at around $1.7 \mathrm{Ma}$ and $2.0 \mathrm{Ma}$ could reveal the incidence of different driving processes that induce new signals or distort the $2.4 \mathrm{Ma}$ orbital one. The cycle at around $0.8 \mathrm{Ma}$ registered in site U1387C has been related to a possible non linear combination of other periods or a double mode of the eccentricity period (Ripepe and Fischer, 1991; Kashiwaya et al., 1998). The absence of these cycles at site U1386 could be associated to local conditions disturbing its record (for example faulting, Fig. 6), although other global signals at higher (0.4 Ma) and lower (2 Ma) frequencies have been recognized.

These lower frequency cycles correspond with 3rd- and 4th-order asymmetric sequences identified in middle and high-resolution seismic profiles by Llave et al. (2001, 2007a) and Hernández-Molina et al. (2002, 2006). Sedimentary cycles can be identified regionally at seismic scale in all the Neogene basins. The Quaternary sequence shows the cycles more clearly than the Pliocene sequence, however. The cyclicity is evident as a consistent facies trend within each subunit that includes (a) a transparent zone at the base, (b) smooth, parallel reflectors of moderate-to-high amplitude in the upper section and (c) a continuous, high amplitude, erosive surface at the top (Fig. 6, 7 and 15D). This facies trend has previously been documented within the Faro-Albufeira Drift (Llave et al., 2001, 2006; Stow et al., 2002b), the Porcupine Drift (Van Rooij et al., 2003) and the Eirik Drift (Hunter et al., 2007). According to IODP Exp. 399 sampling, weak seismic facies at the unit scale ( 0.8-0.9 Ma) correspond to mud dominated sediments. The higher reflectivity facies above correspond to an increase in grain size and detrital content, and a decrease in biogenic carbonate. Most of the sandy 
turbidites deposits during the Quaternary are coincident with the upper reflective part in each sequence, but also with a higher number of coarser (sandy) contourites (Fig. 15D). Preliminary results from IODP Exp. 399 identify turbiditic deposits having similar periodicities (Stow et al., 2013b) in the upper and higher reflectivity part of the unit (Figs. 6 and 7). Whyte and Lovell (1997) described similar turbidite deposition cycles in North Sea deposits. Future works with higher resolution should clarify this interesting interrelation between along- and across sedimentary processes and products at these scales.

\subsection{The significance of hiatuses}

Regionally extensive erosional discontinuities are often used to identify contourites (Faugères et al., 1999; Rebesco et al., 2014). This is the case along the SIM, where discontinuities evident in seismic profiles as high amplitude reflections represent key, basin-scale stratigraphic horizons and important transitions in sedimentary staking patterns (Table 1 and Figs. 4, 6-8 and 12-14). The M, LPD and EQD in particular mark angular erosional unconformities along basin margins and areas surrounding highs and diapirs. Discontinuities grade laterally into conformable contacts towards the basin central areas. This demonstrates that the thickness eroded increases towards highs implicating uplift as a mechanism for erosion. In cases of more pronounced hiatuses, uplift appears to occur coeval to enhanced bottom current velocity. The association of hiatuses, discontinuities, correlative conformities and changes in sedimentation rate represents a major finding of IODP Exp. 339 (Stow et al., 2013b; Hernández-Molina et al., 2014b; Lofi et al., 2015). The two most significant discontinuities in the sedimentary record after the Miocene-Pliocene boundary $(\mathrm{M})$, are associated with LPD (3-3.2 Ma) and EQD (2-2.4 Ma) (Figs. 4, 6-8 and 12-14).

The late Pliocene hiatus, around 3-3.2 Ma (LPD), suggest a compressional tectonic event along the SIM. This coincides with an intraPliocene unconformity previously recognized in onshore outcrop of the Betic-Rif Cordillera (Montenat et al., 1990; Aguirre et al., 1995; Azdimousa et al., 2006), including sections between El Puntalejo and Cabo Roche adjacent to the Cadiz Basin (Cadiz, Spain; Fig. S4). The unconformity appears in this area between marine sands (Unit I) and the littoral Unit III, as defined by Aguirre $(1991,1992,1995)$ and Aguirre et al. $(1993,1995,2010)$. Our analysis showed that just beneath the unconformity, yellow sand deposits are found containing G. puncticulata and with G. margaritae, which constrains the sediment to a 3.81-4.52 Ma age range, based on the latest occurrence of G. margaritae, as astronomically dated by Lourens et al. (2004). The unconformity could thus correlate with a late Pliocene discontinuity, as has been proposed by Aguirre et al. $(1995,2010)$. The hiatus is coeval with tectonic activity in the Betic Cordillera (Montenat et al., 1990), but also with thrusting of the allochtonous unit on top of the Moroccan Meseta (Flinch and Vail, 1998), and the most intensive phase of AUGC emplacement in the Algarve basin (Hernández-Molina et al., 2014b). These events could also occur synchronously with uplift of the Serra do Caldeirão in the Algarve basin (Dias and Cabral, 1997, 2000).

For the early Quaternary, the EQD prominently marks a hiatus representing a major shift in sedimentation between 2 and $2.4 \mathrm{Ma}$ (Figs. 6-8 and 12-14), and the probable onset of a new compressional event. This hiatus appears in the Cadiz basin (Hernández-Molina et al., 2014a), and may correlate with the extensive erosional surface observed in adjacent onshore outcrops (Fig. S4). The onshore unconformity is overlain by extensive continental facies deposits (Zazo et al., 1985; IGME, 1990, 1994; Aguirre, 1991, 1992, 1995; Aguirre et al., 1993, 1995, 2010), and shows the end of sediment supply from any Guadalquivir river branch (Zazo et al., 1985; Aguirre, 1995) towards the Cadiz basin. The EQD also coincides with hiatuses observed in the northeast Atlantic between Gibraltar and equatorial areas. These form coevally with slump facies indicative of tectonic instabilities (Stein et al., 1986). In areas that experienced higher erosion, the EQD incised the entire late Pliocene section and base of the Quaternary. The only hiatus longer than the EQD in these regions is the interval spanning about 1.4 Ma, incising sediment from 3.4 to $2 \mathrm{Ma}$ in the Deep Algarve basin sections sampled at sites U1386 and U1387. A similar hiatus appears in the Alboran Sea section (Comas et al., 1996; Martínez-García et al., 2013).

Two other younger and minor discontinuities within the Quaternary record (Figs. 6-8 and 12-14) represent key stratigraphic horizons recording erosion and possible renewed tectonic activity at around 0.7-0.9 Ma for MPD (MIS 19-17) (Lofi et al., 2015) and between 0.3-0.6 Ma (MIS 11 and 13) for the LQD. Borehole log data record the MPD as a short hiatus within the Doñana basin that also affected the sedimentation rate at site U1391 (Lofi et al., 2015). A similar hiatus, coeval with tectonic activity occurs in sediments of the northeast Atlantic (Stein et al., 1986). The LQD corresponds to a hiatus in sediment from sites U1390 and U1391 (Lofi et al., 2015), and with a condensed interval in sediment from site U1385 (Hodell et al., 2015).

The aforementioned hiatuses coincide with sedimentary and paleoceanographic changes and regional tectonic activity. Conceptual depositional models for foreland basins (e.g., DeCelles and Giles, 1996; Einsele, 2000; Nichols, 2009) suggest that turbidites develop during initial stages after the thrusting. Messinian turbidites forming after the Tortonian emplacement of the AUGU likely reflect this phase of development (Riaza and Martinez del Olmo, 1996; Sierro et al., 1996; Ledesma, 2000). Hiatuses associated with turbidites demonstrate that similar sequences of events apparently occurred in the early Pliocene, late Pliocene and early Quaternary. These sedimentary features also indicate minor pulses of westward compression recorded in deformed wedges of the AUGC.

\subsection{Evolutionary model and paleoceanographic implications}

Neogene basins along the SIM record the complex interplay of tectonics, climate, sea-level and bottom current circulation from the latest Miocene to present-day. Around $50 \mathrm{~km}$ of convergence occurred in a NW direction between the Eurasian and African plates in the vicinity of the Alboran Sea and Gulf of Cadiz during this period (Dewey et al., 1989).

Neogene basin initiation began at the end of the early Miocene, as a consequence of downward flexure of pre-existing basement in response to loading of thrusted and imbricated overburden of Betic and Rif orogen (Sierro et al., 1996, 2008; Berástegui et al., 1998; Fernàndez et al., 1998; Maldonado et al., 1999; Ledesma, 2000; Roque, 2007; Terrinha et al., 2009; Vergés and Fernàndez, 2012). Tectonic inversion of Mesozoic extensional structures occurred simultaneously in the Deep Algarve and Alentejo basins (Terrinha et al., 2002; Roque, 2007). During the Tortonian, the regional compressional regime shifted towards a NW-SE direction, which remobilized the primarily westward emplacement of the AUGC (Maldonado et al., 1999; Medialdea et al., 2004; Sierro et al., 2008). Around the Tortonian-Messinian boundary $(\sim 7.2 \mathrm{Ma})$, regional tectonic activity caused narrowing of the Betic gateways (Fig. 16) between the Atlantic and Mediterranean (Sierro et al., 2008) and extensive turbidite deposition within Neogene basins (Riaza and Martinez del Olmo, 1996; Ledesma, 2000). Subsequent tectonic uplift in the Guadalquivir basin and Gibraltar area triggered the final closure of the Rifian and Iberian gateways ( $6 \mathrm{Ma})$, isolation of the Mediterranean Sea and onset of the Messinian Salinity Crisis at $5.55 \mathrm{Ma}$ (Hsü et al., 1973). This was a short-lived event that ended with opening of the Strait of Gibraltar at about 5.33 Ma (Duggen et al., 2003; Roveri et al., 2014; Flecker et al., 2015).

These events preceding Pliocene and Quaternary deposition conditioned the asymmetric shape of basins overlying the AUGC to an eastward deepening geometry. The results described here suggest this phase of tectonic activity was associated with the Miocene-Pliocene boundary and ended by $4.5 \mathrm{Ma}$. Younger Pliocene and Quaternary compressional events between 3.2-3 Ma and 2-2.3 Ma further pinpoint 
three stages of subsequent development and evolution of the contorite depositional systems (Figs. 16 and 17).

\section{Initial-drift stage (Pliocene, from 5.3-3.2 Ma);}

This stage began at the end of the compressional period associated with the late Miocene and early Pliocene. In the Deep Algarve basin, sandier deposits at the base of the Pliocene formed first, and were immediately followed by extensive mass transport deposits (MTDs). These included sands, sandstones, debrites and slumps. Based on sedimentologic and petrofacies analysis, the sandstones are categorized as turbidites and debrites. Like other MTDs, these derive primarily from the adjacent shelf and upper slope (Ducassou et al., 2016), which contributed quartz, lithics and carbonates. MTDs suggest resedimented facies and margin instability until $4.5 \mathrm{Ma}$ (Fig. 16). These deposits are coeval with early Pliocene debrites ( $>4.5 \mathrm{Ma}$ ) that outcrop in areas adjacent to the Cadiz basin (Fig. S3), and with gravitational collapse breccias described from the Strait of Gibraltar by Esteras et al. (2000) and Blanc (2002). Thrusting and westward compression of the frontal areas of deformed AUGC wedges compressed the basin during late Miocene and created several isolated basins (Cadiz, Sanlucar and Doñana). Regional depocenters migrated westward, and underwent subsidence, sagging and diapiric processes, as evidenced by morphological highs and diapiric ridges parallel to thrust structures. Fragmentation of Miocene basins into minor complex basins was by this point likely sufficient for development of piggyback basins (Figs. 16 and 17).

These events coincided with a major sea-level highstand (Haq et al., 1987; Raymo et al., 2011; Miller et al., 2011), evident from early Pliocene marine deposition in onshore localities (IGME, 1990, 1994; Sierro et al., 1996; Salvany et al., 2011). These events generated pronounced angular unconformities and a major hiatus between late Miocene and early Pliocene deposition near the Strait of Gibraltar (Figs. 4 and S3). This truncation may document folding and uplift due to the westward thrusting of Subbetic and Flysch units. Uplift occurred onshore, adjacent to the Algarve basin CachÃo and da Silva (2000), probably due to the regional forebulge position during this time. These events, along with widespread tectonic activity, compression and slope instability relate to late Miocene tectonic uplift in the Guadalquivir basin and Strait of Gibraltar area, the final closure of the Rifian and Betic gateways at $5.96 \mathrm{Ma}$, the Messinian Salinity crisis (MSC) (Duggen et al., 2003; CIESM, 2008; Flecker et al., 2015), and ultimately, the opening of the Strait of Gibraltar (Maldonado et al., 1999; Estrada et al., 2011), which caused the Zanclean flooding (Garcia-Castellanos et al., 2009; Estrada et al., 2011). Similar compressional stages have been determined in the Alboran Sea (Martínez-García et al., 2013) and other areas of the Mediterranean (Cloetingh et al., 1990). These events are attributed to a major reorganizational phase of the Africa-Eurasia plate boundary. During this time, compression shifted from NE to N (Duggen et al., 2003; Sierro et al., 2008), the Betic-Rif Cordillera basins experienced differential subsidence and the Gibraltar area was uplifted (Sierro et al., 2008).

These compressional events ( $>4.5 \mathrm{Ma}$ ) were followed by a period of relaxation, initiated by the elastic response to thrust loading. This period of sagging and high subsidence rates coincided with local extensional collapse affecting the AUGC (Maldonado et al., 1999; Medialdea et al., 2004, 2009), which likely deepened the Strait of Gibraltar.

The opening of the Strait of Gibraltar had major paleoceanographic implications. Bottom current indicators however show little evidence of this event. Indicators also suggest that MOW intensity was relatively weak during this time (Stow et al., 2013b; Hernández-Molina et al., 2014b, Van der Schee et al., 2015). The MOW strengthened progressively after $4.5 \mathrm{Ma}$ as indicated by the development of the large, muddy sheeted drifts in the Neogene basins recorded during PI, PII and the lower part of PIII units. Periodic turbidites are observed in these early Pliocene horizons (Roque et al., 2012; Brackenridge et al., 2013; Stow et al., 2013b). As the MOW developed into a source of intermediate water for the North Atlantic, its warm, saline outflow enhanced both the production of NADW and northward ocean heat transport in the Atlantic (Hay, 1996). Evidence for enhanced bottom current circulation in the early Pliocene (about 4.5 Ma) appears along the Porcupine margin (Van Rooij et al., 2003), north Atlantic (Hunter et al., 2007), continental margins of NW Europe (Laberg et al., 2005, Praeg et al., 2005; Stoker et al., 2005), Faeroe-Shetland Channel (Knutz and Cartwright, 2003) and south of the Greenland-Scotland Ridge (Wold, 1994). Evidence for enhanced MOW also occurs above the intra-Pliocene discontinuity (IPD) according to paleoceanographic proxies in the North Atlantic (Khélifi et al., 2011, 2014).

II. Transitional-drift stage (late Pliocene to early Quaternary, 3.2-2 Ma).

This stage documents the most important changes in the sedimentary stacking pattern and development of Neogene basins development, about $2.5 \mathrm{Ma}$ after late Miocene to early Pliocene events. The upper part of unit PIII (P6) and lower part of unit QI (Q1) consist of interbedded contourites and turbidites, with occasional debrites. Synsedimentary deformation, active halokinesis, lower subsidence rates, thrusting and folding occurred during a widespread phase of shortening affecting all basins. This phase began around the LPD (3-3.2 Ma) but ended with the EQD (2-2.4 Ma Ma) (Figs. 16 and 17). Hiatuses are accompanied by dolostones, debrite and more downslope sedimentation. Previous research has also detected the decrease in subsidence rates in the Gulf of Cadiz (Nelson et al., 1993; Maldonado et al., 1999; Maestro et al., 2003; Medialdea et al., 2004; Roque et al., 2012) and other areas of the North Atlantic (Cloetingh et al., 1990; Praeg et al., 2005; Stoker et al., 2005). Signs of continental deposition appear at the end of this stage, with the Guadalquivir basin (Salvany et al., 2011) and basins covering onshore AUGC units (Zazo et al., 1985; IGME, 1990, 1994; Aguirre et al., 1995, 2010), finalizing the separation of early Pliocene onshore units from Quaternary offshore marine basins. These events coincided with regional compression and deformation related to a directional change in the Iberia and Nubia convergent boundary from NW-SE to WNW-ESE (Zitellini et al., 2009; Duarte et al., 2013). The shift in convergence direction for the southwest Iberian margin coincided with a decline in westward migration and thrusting activity for the AUGC. Reactivated blind-thrusts accommodated shortening and thus exhibit only minor sedimentary subsidence (Gutscher et al., 2002). The oblique convergence between the sub-plates generated a new transpressional regime and reactivated WNW-ESE dextral strike-slip faults as well as shallower W-NW directed thrusts (Duarte et al., 2011). Evidence for compressional events around this age has been detected in the Betic (Viguier, 1974; Benkhelil, 1976), Rif (Guillemin and Houzay, 1982; Morel, 1988; Ait, 1991; Azdimousa, 1991), Alboran Sea (Bourgois et al., 1992; Martínez-García et al., 2013), easternmost Mediterranean (Cyprus) (Robertson et al., 1998; Kinnaird, 2008), Himalaya (Derbyshire, 1996), other areas of the Northern Hemisphere (Cloetingh et al., 1990) and offshore Central America (Vannucchi et al., 2013). These events are associated with global plate tectonic reorganization and final closure of the Central American Seaway, which led to the establishment of Northern Hemisphere glaciations and a shift to a globally cooler climate conditions (Zachos et al., 2001; Miller et al., 2011) coeval with the emergence of the genus Homo between 2.8-2.4 Ma (deMenocal, 2011; Villmoare et al., 2015) (Fig. 16).

The MOW progressively strengthened from 3.2 to $2 \mathrm{Ma}$ (Fig. 16), in tandem with enhanced deep-water convection in the Mediterranean Sea and with more active circulation in the North Atlantic (Khélifi et al., 2011, 2014). The MOW intensification contributed with saltwater to intermediate depths of northerly latitude Atlantic Waters, thus enhancing Thermohaline Circulation (THC), Atlantic Meridional Overturning Circulation (AMOC) and overall Northern Hemisphere deep-water formation (Hernández-Molina et al., 2014a). These changes coincided with long-term global cooling trends (Zachos et al., 2001) marked by the final NHG intensification (Bartoli et al., 2005). The shift 
included a decline in atmospheric $\mathrm{CO}_{2}$ levels, global cooling (Zachos et al., 2001) and sea-level fall (Miller et al., 2011). The 41 ky obliquity cycles replace the 23 ky precessional cycles as the primary orbital mechanism influencing climate. This shift is also associated with a progressive increase in the amplitude of Earth's orbital obliquity (Bartoli et al., 2005).

\section{Growth-drift stage (Quaternary, from 2 Ma to present).}

Over the last $2 \mathrm{Ma}$, the Quaternary section (upper part of unit QI and units II and III) exhibited major depositional changes with maximal sedimentation rates and a pronounced phase of contourite deposition and drift development throughout the Neogene basins. Interestingly, most of the North Atlantic contourite drifts show decreasing accumulation rates at this time (Knutz, 2008). Quaternary depocenters are located west of underlying sequences due to the displacement of preceding compressional stages. High sedimentation rates could arise from the combination of more vigorous bottom-current influence and substantially higher volumes of MOW input into the Atlantic, as well as from greater transport to offshore depocenters, due to the progradation of Guadalquivir and Rharb basin sediments into the Gulf of Cadiz (Sierro et al., 1991; Flinch and Vail, 1998; Riaza and Martinez del Olmo, 1996; Ledesma, 2000; Salvany et al., 2011).

Two phases of MOW and bottom current intensification (Fig. 16) led to the fully established MOW. We attribute its formation to tectonic constriction and deformation in the basins related to the mid Pleistocene discontinuity (MPD, 0.7-0.9 Ma, MIS 19-17) and LQD ( 0.4 Ma, between MIS 11 and 13). These events are especially evident in the Doñana basin, which experienced more deformation and the highest sedimentation rate observed from the MPD up to the present. The MPD represents the beginning of a new phase in the sedimentary stacking pattern of drifts, with enhanced upslope progradation and mounded drift morphologies (Llave et al., 2001, 2007a; Roque et al., 2012). Lateral migration of sandier deposits and of morphological features from proximal to central areas of the CDS co-occurred with MOW enhancement. Together these events coincide with a significant eustatic drop in sealevel (Miller et al., 2005; Rogerson et al., 2012), and intensification of the AMOC (Knutz, 2008). MOW density increased during subsequent glacial stages, as it did during the last glaciation when slope morphologies indicate that MOW flow rates were higher (Rogerson et al., 2012; Hernández-Molina et al., 2014a). The period between 0.9-0.7 Ma, coeval with the MPD, marked another important step in human evolution as pre-human primates disappeared (Fig. 16) and Homo heielbergensis, the ancestor of modern humans, emerged (deMenocal, 2011).

\subsection{Conceptual implications}

\subsubsection{Drift construction}

Contourite drift types are classified according to their external morphology (McCave and Tucholke, 1986; Faugères et al., 1999; Rebesco and Stow, 2001; Stow et al., 2002b; Nielsen et al., 2008; Rebesco et al., 2014). The three aforementioned evolutionary stages for the CDS imply the following phases of drifts. First, mixed drifts formed during the initial-drift stage (Pliocene) due to the interplay between acrossand along- slope processes, resulting in large sheeted drifts, which appear primarily as sub-parallel reflections onlapping previous relief. Second, a transitional-drift stage (Late Pliocene to the base of the Quaternary) began up-slope migration and moat development (nondeposition) marked by gently downlapping reflections in seismic profiles. Finally, a growth-drift stage (Quaternary, $<2 \mathrm{Ma}$ ) is dominated by contourite deposition. Drifts evolve into elongated mounds with a deep moat in the Deep Algarve and Alentejo basins and sandier sheeted drifts in the rest of the basins overlying the AUGC. Drifts therefore became more prominent high-relief features that regionally migrated up- and along-slope (downcurrent). When considered with the configuration of internal seismic units and dominant deposits, this shift in the drift's external geometry conceptually agrees with the vertical firstorder variation in drift evolution proposed by other authors (Faugères et al., 1985a; Stow et al., 2002b; Nielsen et al., 2008), demonstrating the case for intensified bottom-currents along the SIM during the last $2 \mathrm{Ma}$.

The same cyclicity in seismic facies trends is frequently found at different scales with (1) a transparent zone at the base, (2) smooth, parallel reflectors of moderate-to-high amplitude in the upper part, and (3) a continuous, high-amplitude erosional surface at the top. The integration of IODP Exp. 399 drilling data with multichannel seismic data presented here suggests that this cyclic pattern of seismic facies most likely represents repeated coarsening-upward sequences bounded by erosional surfaces at unit and sub-unit scales. The duration of these cycles identified in multichannel seismic is much greater (0.8-0.9 Ma and 0.4-0.5 Ma, Fig. 15) than cycles identified by Llave et al. (2001, 2006, 2007a) in sparker source seismic profiles. These authors demonstrated links between grain size variation, climate and MOW variability for the last eustatic/climate cycle, which experienced enhanced MOW during cold intervals. Additional research has corroborated these findings (Voelker et al., 2006; Toucanne et al., 2007; García et al., 2009; Rogerson et al., 2012; Bahr et al., 2014; Hernández-Molina et al., 2014a). Longer frequency cyclicities in seismic facies trends observable at seismic scales however raise questions as to whether differently scaled cycles arise from the same processes. The relative abundance of turbiditic deposits occupying upper sections of these cycles and their protracted periodicity, which resembles that of longer repetitions identified from IODP sites (Stow et al., 2013b), and their genetic relation to some of the short identified hiatus suggest that CDS reflect tectonic activity, relative sea-level change and margin instability rather than orbital-scale variation at these longer scales.

\subsubsection{Tectonics versus climate}

Eustatic sea-level variation occurs at different time scales (Vail et al., 1977) and exerts primary influence on sequence architecture and basin evolution (e.g., Coe, 2003; Catuneanu, 2006). However, the causes for eustatic variations are not fully understood (Lovell, 2010). Previous regional stratigraphic analysis of the SIM considered eustatic changes a primary depositional factor at unit and subunit scales (Flinch and Vail, 1998; Riaza and Martinez del Olmo, 1996; Llave et al., 2001, 2007a, 2011; Hernández-Molina et al., 2002, 2006; Marchès et al., 2010; Roque et al., 2012; Brackenridge et al., 2013). These studies linked prominent discontinuities to major sea-level drops, global cooling events and cyclic shifts in the climate system. In their interpretation, the continental margin (including contourite deposits) formed primarily by stacking of regressive and lowstand sedimentary deposits in every depositional sequence, and building its observed progradational morphology. Transgressive and highstand deposits are also present in each depositional sequence but occur as condensed sections. This interpretation is consistent with high-resolution seismic studies for the last eustatic hemicycle and last 4 th-order and 5 th-order sequences (Llave et al., 2001,2006) and with lithological changes observed in calypso piston and gravity cores (Llave et al., 2006, 2007a; Voelker et al., 2006; Toucanne et al., 2007; Bahr et al., 2014), and IODP Sites (Bahr et al., 2015).

The present work describes a clear and more protracted cyclicity in units and subunits of around 0.8-0.9 and 0.4-0.5 Ma (Fig. 15). These sedimentary cycles correspond with 3rd- and 4th-order asymmetric sequences identified in the region with mid- to high-resolution seismic profiles by Llave et al. (2001, 2007a) and Hernández-Molina et al. (2002, 2006). Results described here however indicate significant tectonic influence at long- and short-term scales, on margin development, downslope sediment transport and contourite drift evolution in Neogene basins. This activity also exerts primary influence on seafloor morphology, which in turn has determined MOW pathways and CDS 
architecture. According to the timing of these different events, we propose tectonic pulses of approximate $0.8-0.9$ Ma duration overprinted by more significant $2 / 2.5$ Ma compressive-flexural stress cycles, which caused uplift/compression or active subsidence (Fig. 16). Westward roll back of subducted oceanic lithosphere with simultaneous tectonic shortening and gravitational spreading in the Gulf of Cadiz (Gutscher et al., 2002, 2009; Duggen et al., 2003) provides a consistent explanation for these cycles. Compressional tectonic regimes along the northeast Atlantic margin apparently correlate with the development of major deep-sea unconformities (Andersen et al., 2000; Stoker et al., 2005) and sedimentary pulses (Whyte and Lovell, 1997; Lovell, 2010). Interestingly, compressional events similar to those described here also occurred in the Himalaya (Cochran, 1990; Derbyshire, 1996) and North Atlantic regions (Cloetingh et al., 1990; Knutz, 2008). Atlantic plate reorganization entailed similar tectonic cycles of compression and sagging related to episodic, small-scale convective flow in the upper mantle plume (Cloetingh et al., 1990; Whyte and Lovell, 1997; Praeg et al., 2005; Stoker et al., 2005). Convection in the Earth's mantle thus occurs in punctuated pulses on geologic times scales (Rudge et al., 2008; Lovell, 2010) and has been interpreted as "blobby" flow (Jones et al., 2012). Surface uplift due to plate interactions (subsidence, rift activity, etc.), magmatic underplating and plume activity also affects sea-level (White and McKenzie, 1989; Whyte and Lovell, 1997; Maclennan and Lovell, 2002; Lovell, 2010; Jones et al., 2012) on time scales of 2ndand 3rd order cycles from 2 to $4 \mathrm{Ma}$ down to $1 \mathrm{Ma}$ or less (Rudge et al., 2008; Lovell, 2010).

Consideration of these global cycles demonstrates that both tectonic and climatic factors determined sedimentary evolution of the Gulf of Cadiz and the margin off west Portugal. Changes in rates and geometries of plate boundaries as well as long-term plate reorganization lead to fluctuations in the magnitude of intraplate stresses. Modifications imparted by these factors on climate, relative sea-level and the seafloor morphology also affected bottom-current circulation. Tectonics thus influence deep-water sedimentation on geological scales of 2.5->0.4 Ma. Tectonic pulses occurring around 2-2.5 Ma and 0.8-0.9 Ma align with long-period variation in orbital (eccentricity) cycles as is reported above, and with 3rd-order (1-3 Ma) eustatic cycles (Lourens and Hilgen, 1997), but not with cycles operating on shorter time-scales (Fig. 16). Tectonic events could thus control 3rd-order cycles on time scales of about $0.8-2.5 \mathrm{Ma}$. We interpret variation occurring on significantly shorter time-scales in Quaternary contourites as related to climate variability, sediment supply and sea-level fluctuation. Sediments analyzed here also show evidence of orbital-scale effects (Fig. 15) as identified by other studies (Sierro et al., 1999, 2000; Hernández-Molina et al., 2014b; Lofi et al., 2015). Orbital cycles (variation in insolation) influences climate on shorter times scales $\leq 0.4 \mathrm{Ma}$ generating high to very high frequency (4th-order) depositional sequences of 0.1-0.2 Ma duration (Flinch and Vail, 1998) to submillennial scale variation in the sedimentary record (Schönfeld and Zahn, 2000; Llave et al., 2007a; Voelker et al., 2006; Toucanne et al., 2007; Rogerson et al., 2012; Bahr et al., 2014).

\section{Conclusion}

Semi-permanent bottom currents shape continental margin architecture and generate extensive contourite depositional systems (CDS). The large CDS along the Southwest Iberian margin (SIM) records unmistakable signs of Mediterranean Outflow Water (MOW) as it exits the Strait of Gibraltar, which reopened at the end of the Miocene. The SIM also records the pronounced effects of tectonic activity on margin sedimentation and evolution. The complexity of the SIM record results from the interaction of tectonic, climate and eustatic changes with additional bottom current circulation variations.

Integration of new core, borehole and outcrop data with previously collected seismic and drilling data revealed that significant changes in sedimentary style and processes often co-occurred with widespread depositional hiatuses. Tectonic influence on margin development, downslope sediment transport and sediment evolution began around the time of the narrowing of the Atlantic-Mediterranean gateways at $7 \mathrm{Ma}$ and opening of the Strait of Gibraltar (5.33 Ma). The periodicity of these different events suggests an $\sim 0.8-0.9$ Ma duration for tectonic pulsing. A pronounced overprint of $\sim 2-2.5$ Ma cycles related to the westward roll back of subducted lithosphere as the Africa-Eurasia collision transitioned from a predominantly NW-SE to WNW-ESE direction. Following the temporal decrease of tectonic activity near the MiocenePliocene boundary, major compressional events affecting Neogene basins between 3.2-3 Ma and 2-2.3 Ma differentiate three stages of CDS evolution. These include 1) an initial-drift stage (Pliocene, from 5.3-3.2 Ma) with a weak MOW and the formation of a mixed acrossand along slope deposits, 2) a transitional-drift stage (late Pliocene and early Quaternary, 3.2-2 Ma) and 3) a growth-drift stage (Quaternary, from 2 Ma to present) where the prevalence of contourites demonstrates increased bottom-current velocity due to a fully established MOW. Two younger and more minor Pleistocene discontinuities at 0.7-0.9 Ma and about 0.3-0.6 Ma in the Doñana basin record the effects of renewed tectonic activity.

A pronounced sedimentary cyclicity with a periodicity of about 0.8-0.9 Ma in sedimentary units, and 0.4-0.5 Ma sub-units appears throughout the sedimentary record, but is most clearly observed in the Quaternary section. Tectonics, sea-level and climate all exert primary external influence on sedimentation. The specific cause-and-effect relationships between them and their relative importance on temporal scales remain contentious. We propose that tectonic effects represent a long-term factor in controlling deep-marine sedimentation, especially at scales of 2.5->0.4 Ma, whereas climatic (orbital) variation constitutes a short-term factor clearly dominant at scales of $\leq 0.4 \mathrm{Ma}$

This work generally outlines the case for revisiting the role of bottom water circulation and associated processes in shaping the seafloor, controlling sedimentary stacking patterns on continental margins and influencing global climate. CDS preserve specific information on bottom-current circulation not available from other types of proxies. This information can be related to tectonic changes, climate and other sedimentary processes. High resolution, basin-level analysis of CDS requires integration of borehole, core and outcrop records with seismic data. Further research can help establish more refined interpretation of CDS, including their interaction with gravitational processes and their role in deep water systems. Refined interpretation workflows are necessary due to the common occurrence of sandy contourites in deep water settings with the potential of hydrocarbon resources and, most importantly, their role in recording Earth's paleoceanographic history.

Supplementary data to this article can be found online at http://dx. doi.org/10.1016/j.margeo.2015.09.013.

\section{Acknowledgments}

This research used samples and data collected through the Integrated Ocean Drilling Program (IODP). The research was partially supported through the CTM 2008-06399-C04/MAR, CTM 2012-39599-C03, CGL2011-26493, CTM2012-38248, SA263U14, IGCP-619, INQUA 1204 and FWF P25831-N29 Projects. Some data were collected with 941090-C03-03 (FADO) and MAR-98-0209 (TASYO) Projects. Research was conducted in the framework of the Continental Margins Research Group of the Royal Holloway University of London, People and the Program (Marie Curie Actions) of the European Union's Seventh Framework Program FP7/2007-2013/ under REA Grant Agreement No. 290201 MEDGATE'. We are very grateful to REPSeOL, TGS-NOPEC, and the CSIC-Institut Jaume Almera (http://geodb.ictja.csic.es) for allowing us to use an unpublished seismic data from the Gulf of Cadiz. We thank J. Aguire (UGR, Spain) for comments and suggestions concerning the Pliocene and Quaternary outcrops, B. van den Berg (USAL) for organizing a thought-provoking field-trip to Cadiz, Spain in November, 2014, M. Ángel Caja, L. García Diego, and J. Tritlla (REPSOL) for 
provenance and diagenetic analysis of early Pliocene sandstones and debrites, and L.J. Lourens (Utrecht University) for providing us the eccentricity and 200-Kys glacio-eustatic sea-level curves included in the Figure 16. Both Prof. D.A.V. Stow (Heriot-Watt Univ., UK) and F.J. Hernández-Molina (RHUL, UK), as the main co-proponents of the IODP Proposal 644 and the co-chiefs of the IODP Exp. 339, thanks to IODP, Exp. IODP 339 Scientists; JR crew and technicians, as well as all people, institutions and companies involved in making IODP a success since 2003. Finally, we also thank the editor, Gert J. De Lange and the reviewers T. Mulder (Bourdeaux Univ.); D. Van Rooij (Ghent Univ) and J. Duarte (Monash Univ.) for their very positive and helpful feedback and discussions in publishing this research.

\section{References}

Aguirre, J., 1991. Estratigrafía del plioceno de la Costa de Cadiz entre chiclana y conil. Geogaceta 9, 84-87.

Aguirre, J., 1992. Evolución de las asociaciones fósiles del plioceno Marino de cabo Roche (Cadiz). Rev. Esp. Paleontol. volumen Extra 3-10.

Aguirre, J., 1995. Implicaciones paleoambientales y paleogeográficas de dos discontinuidades estratigráficas en los depósitos pliocénicos de Cadiz (SW de españa). Rev. Soc. Geol. Esp. 8, 153-166.

Aguirre, J., Braga, J.C., Martín, J.M., 1993. Algal nodules in the late Pliocene deposits at the coast of Cadiz (S Spain). In: Barattolo, F., De Castro, P., Parente, M. (Eds.), Studies on fossil benthic algae: Bolletino della Societa Paleontologica Italiana Special Volume, pp. 1-7.

Aguirre, J., Castillo, C., Agustí, J., Férriz, F.J., Oms, O., 1995. Marine-continental magnetobiostratigraphic correlation of the dolomys subzone (middle of late Pliocene): implications for the late ruscinian age. Palaeogeogr. Palaeoclimatol. Palaeoecol. 117, 139-152.

Aguirre, J., Gibert, J.M., Puga-Bernabeu, A., 2010. Proximal-distal ichnofabric changes in a siliciclastic shelf, early Pliocene, Guadalquivir basin, southwest Spain. Palaeogeogr. Palaeoclimatol. Palaeoecol. 291 (2010), 328-337.

Aït, B.L., 1991. Tectoniques et états de contrainte récents du Maroc Nord. Résultats de la cinématique des plaques Afrique-Europe et du bloc d'Alboran. Univ. Mohammed V, Fac. Sci. Rabat (Thèse d'Etat). (252 pp.)

Alves, T.M., Gawthorpe, R.L., Hunt, D.W., Monteiro, J.H., 2003. Cenozoic tectonosedimentary evolution of the western Iberian margin. Mar. Geol. 195, 75-108.

Alves, T.M., Moita, C., Cunha, T., Ullnaess, M., Myklebust, R., Monteiro, J., Manuppella, G., 2009. Diachronous evolution of late Jurassic-cretaceous continental rifting in the northeast Atlantic (west Iberian margin). Tectonics 28, TC4003. http://dx.doi.org/ $10.1029 / 2008 T C 002337$ (32 pp.).

Ambar, I., Howe, M.R., 1979. Observations of the Mediterranean outflow-II. The deep circulation in the vicinity of the Gulf of Cadiz. Deep-Sea Res. 26 (A), 555-568.

Ambar, I., Serra, N., Neves, F., Ferraira, T., 2008. Observations of the Mediterranean undercurrent and eddies in the gulf of cádiz during 2001. J. Mar. Syst. 71 (1-2), 195-220.

Andersen, M.S., Nielsen, T., Sørensen, A.B., Boldreel, O.L., Kuijpers, A., 2000. Cenozoic sediment distribution and tectonic movements in the Faroe region. Glob. Planet. Chang. $24,239-259$.

Argus, D.F., Gordon, R.G., DeMets, C., Stein, S., 1989. Closure of the Africa-Eurasia-North America plate motion circuit and tectonics of the Gloria fault. J. Geophys. Res. 94, 5585-5602.

Azdimousa, A., 1991. La Géologie des Bordures Méridionales de la mer d'Alboran des Temsamane Jusqu'Au Cap des Trois Fourches (Rif Oriental, Maroc) (Thèse de 3ème Cycle), Université Mohammed 1, Fac. Sci. Oujda 219 pp.

Azdimousa, A., Poupeau, G., Rezqi, H., Asebriy, L., Bourgois, J., Ait Brahim, L., 2006. Géodynamique des bordures méridionales de la mer d'Alboran; application de la stratigraphie séquentielle dans le bassin néogène de Boudinar (Rif oriental, Maroc). Bulletin de l'Institut Scientifique, Rabat, section Sciences de la Terre n²8, pp. 9-18 Bulletin
(2006).

Bache, F., Olivet, J.L., Gorini, C., Rabineau, M., Baztan, J., Aslanian, D., Suc, J.-P., 2009. Messinian erosional and salinity crises: view from the Provence basin (gulf of lions, western Mediterranean). Earth Planet. Sci. Lett. 286, 139-157.

Bahr, A., Jiménez-Espejo, F., Kolasinac, N., Grunert, P., Hernández-Molina, F.J., Röhl, U., Voelker A Escutia, C Stow, D.A.V., Hodell, D. Alvarez-Zarikian, C.A. IODP Expedition 339 Scientists, 2014. Deciphering bottom current strength and paleoclimate signals from contourite deposits in the gulf of Cadiz during the last 140 kyr: an inorganic geochemical approach. G-Cubed 15 (8), 3145-3160.

Bahr, A., Kaboth, S., Jiménez-Espejo, F.J., Sierro, F.J., Voelker, A.H.L., Lourens, L., Röhl, U., Reichart, G.J., Escutia, C., Hernández-Molina, F.J., Pross, J., Friedrich, O., 2015. Persistent monsoonal forcing of Mediterranean Outflow dynamics during the late Pleistocene. Geology. http://dx.doi.org/10.1130/G37013.1 (in press).

Baringer, M.O., Price, J.F., 1997. Mixing and spreading of the Mediterranean outflow. J. Phys. Oceanogr. 27, 1654-1677.

Baringer, M.O., Price, J.F., 1999. A review of the physical oceanography of the Mediterranean outflow. Mar. Geol. 155, 63-82.

Bartoli, G., Sarnthein, M., Weinelt, M., Erlenkeuser, H., Garbe-Schönberg, D., Lea, D.W., 2005. Final closure of panama and the onset of northern hemisphere glaciation. Earth Planet. Sci. Lett. 237, 33-44

Benkhelil, J., 1976. Etude néotectonique de la terminaison occidental dans les Cordilléres Bétiques (Espagne) (Thése de 3em cycle), Univ. Nice (180 pp.).
Berástegui, X., Banks, C., Puig, C., Taberner, C., Waltham, D., Fernández, M., 1998. Lateral diapiric emplacement of Triassic evaporites at the southern margin of the Guadalquivir basin, Spain. In: Mascle, A, Puigdefa'bregas, C. Luterbacher, H.P. Fernández M. (Eds.), Cenozoic foreland basins of western Europe. Geol. Soc. London Spec. Publ. 134, pp. 49-68.

Berger, A., Loutre, M.F., Dehant, V., 1989. Milankovitch frequencies for pre-quaternary. Nature $342,133$.

Berger, A.L., 1977. Support for the astronomical theory of climatic change. Nature 269, $44-45$.

Berger, A.L., 1978. Long-term variations of daily insolation and Quaternary climatic changes. J. Atmos. Sci. 35, 2362-2367.

Blanc, P.-L, 2002. The opening of the plio-Quaternary Gibraltar strait: assessing the size of a cataclysm. Geodin. Acta 15 (5-6), 303-317.

Borenäs, K.M., Wahlin, A.K., Ambar, I., Serra, N., 2002. The Mediterranean outflow splitting- a comparison between theoretical models and CANIGO data. Deep-Sea Res. II 49, 4195-4205.

Boulila, S., Galbrun, B., Laskar, J., Pälike, H., 2012. A 9 myr cycle in Cenozoic $\delta^{13} \mathrm{C}$ record and long-term orbital eccentricity modulation: is there a link? Earth Planet. Sci. Lett. 317-318, 273-281.

Bourgois, J., Mauffret, A., Ammar, A., Demnati, A., 1992. Multichannel seismic data imaging of inversion tectonics of the alboran ridge (western Mediterranean sea). Geo-Mar. Lett. 12, 117-122.

Brackenridge, R.A., Hernández-Molina, FJ., Stow, D.A.V , Llave, R., 2013. A Pliocene mixed contourite-turbidite system offshore the Algarve Margin, Gulf of Cadiz: Seismic response, margin evolution and reservoir implications. Mar. Pet. Geol. 46: 36-50. doi.org/http://dx.doi.org/10.1016/j.marpetgeo.2013.05.015.

Bryden, H.L., Stommel, H.M., 1984. Limiting processes that determine basic features of the circulation in the Mediterranean sea. Oceanol. Acta 7, 289-296.

Bryden, H.L., Candela, J., Kinder, T.H., 1994. Exchange through the strait of Gibraltar. Prog. Oceanogr. 33, 201-248.

Buitrago, J., García, C., Cajebread-Brow, J., Jiménez, A.y., Martínez del Olmo, W., 2001 Contouritas: Un excelente almacén casi desconocido (Golfo de Cadiz, SO de España). 1er Congreso Técnico Exploración y Producción REPSOL-YPF, pp. 24-27 (Madrid).

CachÃo, M., da Silva, C.M., 2000. The three main marine depositional cycles of the neogene of Portugal. Ciênc. Terra (UNL). 14, 303-312.

Caja, M.A., Diego, L.G., Tritlla, J., 2013. Advance Provenance and Diagenetic Study for Algarve Turbiditic Systems Technical Report. REPSOL Technology - E\&P and Gas (42 pp.).

Cande, S.C., Kent, D.V., 1995. Revised calibration of the geomagnetic polarity timescale for the late cretaceous and Cenozoic. J. Geophys. Res. 100, 6093-6095

Catuneanu, O., 2006. Principles of Sequence Stratigraphy. Elsevier, Amsterdam.

Cherubin, L., Carton, X., Paillet, J., Morel, Y., Serpatte, A., 2000. Instability of the Mediterranean water undercurrents southwest of Portugal: effects of baroclinicity and topography. Oceanol. Acta 23 (5), 551-573.

CIESM, 2008. The Messinian Salinity Crisis from mega-deposits to microbiology - a consensus report. In: Biand, F. (Ed.), № 33 in CIESM workshop Monographs Monaco: (168 pp.).

Cloetingh, S., Gradstein, F.M., Kooi, H., Grant, A.C., Kaminski, M., 1990. Plate reorganization: a cause of rapid late neogene subsidence and sedimentation around the north Atlantic? J. Geol. Soc. Lond. 147, 495-506.

Cochran, J.R., 1990. Himalayan uplift, sea level, and the record of Bengal Fan sedimentation at the ODP Leg 116 sites. In: Cochran, J.R., Stow, D.A.V., et al. (Eds.), Proc. ODP Sci. Results 116. Ocean Drilling Program, College Station, TX, pp. 397-414.

Coe, A.L. (Ed.), 2003. The Sedimentary Record of sea-Level Change. Cambridge University Press, Cambridge.

Comas, M.C., Zahn, R., Klaus, A., et al., 1996. Proceedings of the Ocean Drilling Program, Initial Reports. vol. 161.

Copard, K., Colin, C., Frank, N., Jeandel, C., Montero-Serrano, J.-C., Reverdin, G., Ferron, B 2011. Nd isotopic composition of water masses and dilution of the Mediterranean outflow along the southwest European margin. Geochem. Geophys. Geosyst. 12, 864, Q06020.

De Boer, B., Van de Wal, R.S.W., Bintanja, R., Lourens, L.J., Tuenter, E., 2010. Cenozoic globa ice-volume and temperature simulations with 1-D ice-sheet models forced by benthic $\delta 180$ records. Ann. Glaciol. 51 (55), 23-33.

DeCelles, P.G Giles, KA 1996. Foreland basin systems. Basin Res 8, 05-123.

Derbyshire, E., 1996. Quaternary glacial sediments, glaciation style, climate and uplift in the Karakoram and nortwest Himalaya: review and speculations. Palaeogeogr. Palaeoclimatol. Palaeoecol. 120, 147-157.

Dewey, J.F., Helman, M.L., Turco, E., Hutton, D.H.W., Knott, S.D., 1989. Kinematics of the western Mediterranean. In: Coward, M. (Ed.), Alpine Tectonics. Spec. Publ. Geol. Soc., London 45, pp. 265-283.

Dias, R.P., Cabral, J., 1997. Plio-Quaternary crustal movements in southern Portugal-Algarve. IV Reunião do Quaternário Ibérico, pp. 61-68 Huelva.

Dias, R.P., Cabral, J., 2000. Deformações neotectónicas na região do Algarve. $3^{\circ}$ Simpósio da Margem Ibérica Atlântica, pp. 189-190 Faro.

Duarte, J.C., Rosas, F.M., Terrinha, P., Schellart, W.P., Boutelier, D., Gutscher, M.A., Ribeiro, A., 2013. Are subduction zones invading the Atlantic? Evidence from the southwest Iberia margin. Geology http://dx.doi.org/10.1130/G34100.1

Duarte, J.C., Rosas, F.M., Terrinha, P., Gutscher, M.-A., Malavieille, J., Silva, S., Matias, L., 2011. Thrust-wrench interference tectonics in the gulf of Cadiz (Africa-Iberia plate boundary in the north-east Atlantic): insights from analog models. Mar. Geol. 289, 135-149.

Ducassou, E., Fournier, L., Sierro, F.J., Alvarez Zarikian, C.A., Lofi, J., Flores, J.A., Roque, C. 2016. Origin of the large Pliocene and Pleistocene debris flows on the Algarve margin. Mar. Geol. 377, 58-76.

Duggen, S., Hoernle, K., van den Bogaard, P., Rüpke, L., Morgan, J.P., 2003. Deep roots of the Messinian salinity crisis. Nature (London, U. K.) 422 (6932), 602-606. 
Einsele, G., 2000. Sedimentary Basins. Evolution, Facies, and Sediment Budget, 2nd ed. Springer-Verlag, Berlin 792 pp.

Esteras, M., Izquierdo, J., Sandoval, N.G., Bahmad, A., 2000. Evolución morfológica y estratigráfica plio-cuaternaria del umbral de camarinal (estrecho de Gibraltar) basada en sondeos marinos. Rev. Soc. Geol. Esp. 13 (3-4), 539-550.

Estrada, F., Ercilla, G., Gorini, C., Alonso, B., Vázquez, J., García-Castellanos, D., Juan, C., Maldonado, A., Ammar, A., Elabbassi, M., 2011. Impact of pulsed Atlantic water inflow into the alboran basin at the time of the zanclean flooding. Geo-Mar. Lett. 31, 361-376.

Expedition 339 Scientists, 2012. Mediterranean outflow: environmental significance of the Mediterranean outflow water and its global implications. IODP Preliminary Report, p. 339 http://dx.doi.org/10.2204/ iodp.pr.339.2012

Faugères, J.-C., Stow, D.A.V., 2008. Contourite Drifts: Nature, Evolution and Controls. In: Rebesco, M., Camerlenghi, A. (Eds.), ContouritesDevelopments in Sedimentology 60. Elsevier, Amsterdam, pp. 257-288.

Faugères, J.-C., Cremer, M., Monteiro, H., Gaspar, L., 1985a. Essai de reconstitution des processus d'edification de la ride sedimentaire de faro (Marge Sud-portugaise). Bull Inst. Géol. Bassin Aquitaine 37, 229-258.

Faugères, J.-C., Frappa, M., Gonthier, E., Grousset, F., 1985b. Impact de la veine d'eau méditerranéenne sur la sedimentation de la Marge Sud et Ouest iberique au quaternaire recent. Bull Inst. Géol. Bassin Aquitaine 37, 259-287.

Faugères, J.-C., Stow, D.A.V., Imbert, P., Viana, A.R., 1999. Seismic features diagnostic of contourite drifts. Mar. Geol. 162, 1-38.

Fernàndez, M., Berástegui, X., Puig, C., García-Castellanos, D., Jurado, M.J., Torné, M., Banks, C., 1998. Geophysical and geological constraints on the evolution of the Guadalquivir foreland basin, Spain. In: Mascle, A., Puigdefâbregas, C., Luterbacher, H.P., Fernàndez, M. (Eds.), Cenozoic Foreland Basins of Western Europe: Geological Society Special Publications. 134, pp. 29-48.

Fernández-Ibánez, F., Soto, J.I., Zoback, M.D., Morales, J., 2007. Present-day stress field in the Gibraltar arc (western Mediterranean). J. Geophys. Res. 112, 1-25.

Fernández-Puga, M.C., Vázquez, J.T., Somoza, L., Díaz del Río, V., Medialdea, T., Mata, M.P. León, R., 2007. Gas-related morphologies and diapirism in the gulf of Cadiz. Geo-Mar. Lett. 27 (2-4), 213-221.

Flecker, R., Krijgsman, W., Capella, W., Martins, C., De, C., Demitrieva, E., Mayser, J.P., Marzocchi, A., Modestu, S., Ochoa Lozano, D., Simon, D., Tulbure, M., van den Berg, B., van der Schee, M., de Lange, G., Ellam, R., Govers, R., Gutjahr, M., Hilgen, F. Kouwenhoven, T. Lofi, J., Meijer, P. Sierro, FJ., Bachiri, N., Barboun, N., Chakor Alami, A., Chacon, B., Flores, J.A., Gregory, J., Howard, J., Lunt, D., Ochoa, M., Pancost, R., Vincent, S., Yousfi, M.Z., 2015. Evolution of the late Miocene MediterraneanAtlantic gateways and their impact on regional and global environmental Change. Earth-Sci. Rev. 150, 365-392.

Flinch, J.F., Vail, P.R., 1998. Plio-Pleistocene sequence stratigraphy and tectonic of the Gibraltar Arc. In: de Graciansky, P.C., Hardenbol, J., Jacquin, T., Vail, P.R. (Eds.), Mesozoic and Cenozoic Sequence Stratigraphy of European Basins SEM, Spec. Pub. vol. 60 pp. 199-208

García, M., Hernández-Molina, F.., Llave, E., Stow, D.A.V., León, R., Fernández-Puga, M.C., Díaz del Río, V., Somoza, L., 2009. Contourite erosive features caused by the Mediterranean outflow water in the gulf of Cadiz: Quaternary tectonic and oceanographic implications. Mar. Geol. 257, 24-40.

Garcia-Castellanos, D., Estrada, F., Jiménez-Munt, I., Gorini, C., Fernàndez, M., Vergés, J., De Vicente, R., 2009. Catastrophic flood of the Mediterranean after the Messinian salinity crisis. Nature (London, U. K.) 462 (7274), 778-781.

Gardner, J.V., Kidd, R.B., 1983. Sedimentary processes on the Iberian continental margin viewed by long-range side-scan sonar. 1: gulf of Cadiz. Oceanol. Acta 6 (3), 245-254.

George, D., 2011. TGS-Nopec's Portugal Survey Suspended. Oil and Gas Online.

Gonthier, E.G., Faugères, J.C., Stow, D.A.V. 1984. Contourite facies of the faro drift, gulf of Cadiz. En: Stow, D.A.V.,Piper, D.J.W. (Eds.), Fine-Grained Sediments, Deep-Water Processes and Facies. Geological Society Special Publication, 15: 275-292.

Gonzalez-Delgado, J.A., Dabrio, C.J., Sierro, F.J., Civis, J., 2013. The Neogene of Huelva (western Guadalquivir basin, SW Spain). Fieldtrip guide. STRATI 2013. 1st International Congress on Stratigraphy, Lisbon.

Gràcia, E., Danobeitia, J., Verges, J., Bartolome, R., 2003. Crustal architecture and tectonic evolution of the gulf of Cadiz, SW Iberia, at the convergence of the Eurasian and African plates. Tectonics $22(4), 1033$.

Guillemin, M., Houzay, J.-P., 1982. Le néogène post-nappes et le quaternaire du Rif Nord oriental. Stratigraphie et tectonique des bassins de Melilla, de kert, de boudinar et du piedmont des kebdana. Notes Mém. Serv. Géol. Maroc 314, 7-239.

Gutscher, M.-A., Dominguez, S., Westbrook, G.K., Gente, P., Babonneau, N., Mulder, T., Gontier, E., Bartolome, R., Luis, J., Rosas, F., Terrinha, P., Delila, T., Teams, D.S.I.S., 2009. Tectonic shortening and gravitational spreading in the gulf of Cadiz accretionary wedge: observations from multi-beam bathymetry and seismic profiles. Mar. Pet. Geol. 26, 647-659.

Gutscher, M.-A., Malod, J., Rehault, J.-P., Contrucci, I., Klingelhoefer, F., Mendes-Victor, L., Spakman, W., 2002. Evidence for active subduction beneath Gibraltar. Geology 30, 1071-1074.

Habgood, E.L., Kenyon, N.H., Masson, D.G., Akhmetzhanov, A., Weaver, P.P.E., Gardner, J., Mulder, T., 2003. Deep-water sediment wave fields, bottom current sand channels and gravity flow channel-lobe systems: gulf of Cadiz, NE Atlantic. Sedimentology 50, 483-510.

Hanquiez, V., Mulder, T., Lecroart, P., Gonthier, E., Marchès, E., Voisset, M., 2007. High resolution seafloor images in the gulf of Cadiz, Iberian margin. Mar. Geol. 28, 42-59.

Haq, B.U., Hardenbol, J., Vail, P.R., 1987. Chronology of fluctuating sea levels since the Triassic. Science 235, 1156-1167.

Hay, W.W., 1996, Tectonic and climate. Geol. Rundsch, v. 85, p. 409-437.

Hernández-Molina, F.J., Llave, E., Preu, B., Ercilla, G., Fontan, A., Bruno, M., Serra, N., Gomiz, J.J., Brackenridge, R.E., Sierro, F.J., Stow, D.A.V., García, M., Juan, C., Sandoval, N., Arnaiz, A., 2014a. Contourite processes associated to the Mediterranean outflow water after its exit from the Gibraltar strait: global and conceptual implications. Geology 42, 227-230.

Hernández-Molina, FJ Llave, E Somoza, L, Fernández-Puga, M.C. Maestro, A. León, R Barnolas, A., Medialdea, T., García, M., Vázquez, J.T., Díaz del Río, V., FernándezSalas, L.M., Lobo, F., Alveirinho Dias, J.M., Rodero, J., Gardner, J., 2003. Looking for clues to paleoceanographic imprints: a diagnosis of the gulf of Cadiz contourite depositional systems. Geology 31, 19-22.

Hernández-Molina, F.J., Llave, E., Stow, D.A.V., García, M., Somoza, L., Vázquez, J.T., Lobo, F.J., Maestro, A., Díaz del Río, V., León, R., Medialdea, T., Gardner, J., 2006. The contourite depositional system of the gulf of Cadiz: a sedimentary model related to the bottom current activity of the Mediterranean outflow water and its interaction with the continental margin. Deep-Sea Res. II 53, 1420-1463.

Hernández-Molina, F.J., Serra, N., Stow, D.A.V., Llave, L., Ercilla, E., Van Rooij, D., 2011. Along-slope oceanographic processes and sedimentary products around the Iberian margin. Geo-Mar. Lett. 31 (5-6), 315-341.

Hernández-Molina, F.J., Somoza, L., Vazquez, J.T., Lobo, F., Fernandez-Puga, M.C., Llave, E. Diaz-del Rio, V., 2002. Quaternary stratigraphic stacking patterns on the continental shelves of the southern Iberian peninsula: their relationship with global climate and palaeoceanographic changes. Quat. Int. 92, 5-23.

Hernández-Molina, F.J., Stow, D.A.V., Alvarez-Zarikian, C., Expedition IODP 339 Scientists, 2013. IODP expedition 339 in the gulf of Cadiz and off west Iberia: decoding the environmental significance of the Mediterranean outflow water and its global influence. Sci. Drill. 16, 1-11.

Hernández-Molina, F. Stow, D.A.V., Alvarez-Zarikian, C.A., Acton, G., Bahr, A., Balestra, B Ducassou, E., Flood, R., Flores, J.A., Furota, S., Grunert, P., Hodell, D., Jimenez-Espejo, F., Kim, J.K., Krissek, L., Kuroda, J., Li, B., Llave, E., Lofi, J., Lourens, L., Miller, M., Nanayama F., Nishida, N., Richter, C., Roque, C., Pereira, H., Sanchez Goñi, M.F., Sierro, F.J., Singh, A.D., Sloss, C., Takashimizu, Y., Tzanova, A., Voelker, A., Williams, T., Xuan, C., 2014b. Onset of Mediterranean outflow into the north Atlantic. Science 344, 1244-1250.

Hilgen, F.J., Krijgsman, W., Langereis, C.G., Lourens, L.J., Santarelli, A., and Zachariasse, W.J. 1995. Extending the astronomical (Polarity) time scale into the Miocene. Earth Planet. Sci. Lett., v. 136, p. 495-510.

Hinnov, L.A., 2000. New perspectives on orbitally forced stratigraphy. Annu. Rev. Earth Planet. Sci. 28, 419-475.

Hinnov, L.A., Hilgen, F.J., 2012. Cyclostrtaigraphy and Astrochronology. In: Gradstein, F.M., Ogg, J.G., Schmitz, M., Ogg, G. (Eds.), The Geologic Time Scale 2012. Elsevier, pp. 63-88.

Hoddel, D., Curtis, J.H., Sierro, F.J., Raymo, M.E., 2001. Correlation of late Miocene to early Pliocene sequences between the Mediterranean and north Atlantic. Paleoceanography 16 (2), 164-178.

Hodell, D., Lourens, L., Crowhurst, S., Konijnendijk, T., Tjallingii, R., the Shackleton Site Project Members, 2015. A reference time scale for Site U1385 (Shackleton Site) on the Iberian Margin.

Hodell, D., Lourens, L., Stow, D.A.V., Hernández-Molina, F.J., Alavarez-Zarikian, C.A., the Shackleton Site Project Members, 2013. The "shackleton site" (IODP site U1385) on the Iberian margin. Scientific Drilling. Sci. Drill. 16 (13-19), 2013. http://dx.doi.org/ 10.5194/sd-16-13-2013.

Hsü, K.J., Cita, M.B., Ryan, W.B.F., 1973. The Origin of the Mediterranean Evaporites. Initial Reports of the Deep Sea Drilling Project. U.S. Government Printing Office, Washington, DC, pp. 1203-1231.

Hunter, S.E., Wilkinson, D., Stanford, J., Stow, D.A.V., Bacon, S., Akhmetzhanov, A.M., Kenyon, N.H., 2007. The Eirik Drift: A Longterm Barometer of North Atlantic Deepwater Flux South of Cape Farewell, Greenland. In: Viana, A., Rebesco, M. (Eds.), Economic and Paleoceanographic Importance of Contourites. Geological Society of London Special Publication 276, pp. 245-263.

IGME, 1990. Mapa Geológico de España escala 1:50.000. Vejer de la Frontera. Instituto Tecnológico GeoMinero de España. Madrid.

IGME, 1994. Mapa Geológico de España. Escala 1:200.000. Hoja 86, 3-12. Instituto Geológico y Minero de España. Ministerio de Industria y Energía.

IGMP, 1998, Carta Geológica de Portugal (1:1 000 000) Instituto Geológico e Mineiro, Portugal.

Ikeda, M., Tada, R., 2013. Long period astronomical cycles from the Triassic to Jurassic bedded chert sequences (inuyama, Japan); geologice evidences for the chaotic behavio of solar planest. Earth Planets Space 65, 351-360.

Iorga, M., Lozier, M.S., 1999. Signatures of the Mediterranean outflow from a north Atlantic climatology. 1. Salinity and density fields. J. Geophys. Res. 194 25985-26029.

Iribarren, L., Vergés, J., Camurri, F., Fullea, J., Fernàndez, M., 2007. The structure of the Atlantic- Mediterranean transition zone from the alboran sea to the horseshoe abyssal plain (Iberia- Africa plate boundary). Mar. Geol. 243, 97-119.

Jones, S.M., Lovell, B., Crosby, A.G., 2012. Comparison of modern and geological observations of dynamic support from mantle convection. J. Geol. Soc. 169, 745-758.

Kashiwaya, K., Ryugo, M., Sakai, H., Kawai, T., 1998. Long-term climate-limnological oscillation during the past .2-.5 million years printed in lake Baikal sediments. Geophys. Res. Lett. 25, 659-662.

Khélifi, N., Sarnthein, M., Andersen, N., Blanz, T., Frank, M., Garbe-Schönberg, H., B.A., Stumf, R., Einelt, M., 2011. A major and long-term Pliocene intensification of the Mediterranean outflow, 3-5-3.3 Ma ago. Geology 37, 811-814.

Khélifi, N., Sarnthein, M., Frank, M., Andersen, N., Garbe-Schönberg, D., 2014. Late Pliocene Variations of the Mediterranean Outflow. Mar. Geol. 357, 182-194.

Kinnaird, T.C., 2008. Tectonic and Sedimentary Response to Oblique and Incipient Continental - Continental Collision the Easternmost Mediterranean (Cyprus) (Thesis submitted for the degree of Doctor of), Philosophy University of Edinburgh (380 pp.).

Knutz, P.C., 2008. Palaeoceanographic significance of contourite drifts. In: Rebesco, M, Camerlenghi, A. (Eds.), ContouritesDevelopments in Sedimentology 60. Elsevier, Amsterdam, pp. 511-535. 
Knutz, P.K., Cartwright, J., 2003. Seismic stratigraphy of the west Shetland drift: implications for Late Neogene paleocirculation in the Faeroe-Shetland gateway. Paleoceanography 18, 1093. http://dx.doi.org/10.1029/2002PA000786.

Laberg, J.S., Stoker, M.S., Torbjørn Dahlgren, K.I., De Haas, H., Haflidason, H., Hjelstuen, B.O., Nielsen, T., Shannon, P.M., Vorren, T.O., Van Weering, T.C.E., Ceramicola, S., 2005. Cenozoic alongslope processes and sedimentation on the NW European Atlantic margin. Mar. Pet. Geol. 22, 1069-1088.

Laskar, J., Fienga, A., Gastineau, M., Manche, H., 2011. La2010: a new orbital solution for the long term motion of the earth. Astron. Astrophys. 532. http://dx.doi.org/10. 1051/0004-6361/201116836.

Laskar, J., Robutel, P., Joutel, F., Gastineau, M., Correia, A.C.M., Levrard, B., 2004. A long term numerical solution for the insolation quantities of the earth. Astron. Astrophys. Paris $428\left(n^{\circ} 1\right), 261-285$.

Ledesma SM (2000) Astrobiocronología y estratigrafía de alta resolución del Neógeno de la Cuenca del Guadalquivir-Golfo de Cadiz. (PhD Thesis), University of Salamanca, Salamanca. Unpublished, (464 pp.)

Llave, E., Hernández-Molina, F.J., Somoza, L., Stow, D.A.V., Díaz del Río, V., 2007a. Quaternary evolution of the contourite depositional system in the gulf of Cadiz. In: Viana, A., Rebesco, M. (Eds.), Economic and Paleoceanographic Importance of Contourites. Geol Soc London Sp Publ 276, pp. 49-79.

Llave, E., Hernández-Molina, F.J., Stow, D., Fernández-Puga, M.C., García, M., Vázquez, J.T., Maestro, A., Somoza, L., Díaz del Río, V., 2007b. Reconstructions of the Mediterranean outflow water during the Quaternary since the study of changes in buried mounded drift stacking pattern in the gulf of Cadiz. Mar. Geophys. Res. 28, 379-394.

Llave, E., Hernández-Molina, F.J., Somoza, L., Díaz-del-Río, V., Stow, D.A.V., Maestro, A., Alveirinho Dias, J.M., 2001. Seismic stacking pattern of the faro-albufeira contourite system (gulf of Cadiz): a Quaternary record of paleoceanographic and tectonic influences. Mar. Geophys. Res. 22, 487-508.

Llave, E., Matias, H., Hernández-Molina, F.J., Ercilla, G., Stow, D.A.V., Medialdea, T., 2011. Pliocene-Quaternary contourites along the northern gulf of Cadiz margin : sedimentary stacking pattern and $46 \mathrm{lim}$ adu distribution. Geo-Mar. Lett. 31 (5/6). http://dx. doi.org/10.1007/s00367-011-0241-3.

Llave, E., Schönfeld, J., Hernández-Molina, F.J., Mulder, T., Somoza, L., Díaz del Río, V., I. Sánchez-Almazo, I. 2006. High-resolution stratigraphy of the Mediterranean outflow contourite system in the gulf of Cadiz during the late Pleistocene: the impact of Heinrich events. Mar. Geol., 227: 241-262.

Lofi, J., Déverchère, J., Gaullier, V., Gillet, H., Gorini, C., Guennoc, P., Loncke, L., Maillard, A. Sage, F., Thinon, I., 2011. Atlas of the "Messinian Salinity Crisis" seismic markers in the Mediterranean and Black seas. CCGM \& Mém. SGF n.S., t.179, (72 pp.).

Lofi, J., Voelker, A.H.L, Ducassou, E., Hernández-Molina, F.J., Sierro, F.J., Bahr, A., Galvani, A., Lourens, L.J., Pardo-Igúzquiza, E., Rodríguez-Tovar, F..., William, T., 2015. Quaternary record in the gulf of Cádiz and Portuguese contourite depositional systems. Mar. Geol. (in this volume).

Lopes, F.C., Cunha, P.P., Le Gall, B., 2006. Cenozoic seismic stratigraphy and tectonic evolution of the Algarve margin (offshore Portugal, southwestern Iberian peninsula). Mar. Geol. 231, 1-36.

Louarn, E., and Morin, P., 2011, Antarctic intermediate water influence on Mediterranean sea water outflow, Deep-Sea Res. I Oceanogr. Res. Pap., v. 58, p. 932-942, doi:http:// dx.doi.org/10.1016/j.dsr.2011.05.009.

Lourens, LJ., Hilgen, FJ. 1997. Long-periodic variation in the earth's obliquity and their relation to third-order eustatic cycles and late neogene glaciations. Ouat. Int. 40, 43-52.

Lourens, L.J., Hilgen, F.J., Shackleton, N.J., Laskar, J., Wilson, D., 2004. The Neogene Period. In: Gradstein, F.M., Ogg, J.G., Smith, A.G. (Eds.), Geological Time Scale 2004. Cambridge University Press, Cambridge, UK, pp. 409-440

Lovell, B., 2010. A pulse in the planet: regional control of high-frequency changes in relative sea level by mantle convection. J. Geol. Soc. 167, 637-648.

Maclennan, J., Lovell, B., 2002. Control of regional sea level by surface uplift and subsidence caused by magmatic underplating of earth's crust. Geology 30 (8), 675-678.

Madelain, F., 1970. Influence de la topographie du fond sur l'ecoulement méditerranéen entre le Detroit de Gibraltar et le cap saint-Vincent. Cah. Oceanogr. 22, 43-61.

Maestro, A., Somoza, L., Medialdea, T., Talbot, C.J., Lowrie, A., Vázquez, J.T., Díaz-del-Río, V., 2003. Large-scale slope failure involving triassic and middle Miocene salt and shale in the gulf of Cadiz (Atlantic Iberian margin). Terranova 15, 380-391.

Maldonado, A. Somoza, L., Pallares, L., 1999. The betic orogen and the Iberian-African boundary in the gulf of Cadiz, geological evolution central north Atlantic. Mar. Geol. 155, 9-43.

Marchès, E., Mulder, T., Cremer, M., Bonnel, C., Hanquiez, V., Gonthier, E., Lecroart, P., 2007. Contourite drift construction influenced by capture of Mediterranean outflow water deep-sea current by the portimao submarine canyon (gulf of Cadiz, south Portugal). Mar. Geol. 242, 247-260.

Marchès, E., Mulder, T., Gonthier, E., Cremer, M., Hanquiez, V., Garlan, T., Lecroart, R., 2010. Perched lobe formation in the gulf of Cadiz: interactions between gravity processes and contour currents (Algarve margin, southern Portugal). Sediment. Geol. 229, 81e94.

Martinez del Olmo, W., Garcia-Mallo, J., Leret, J., Serrano-Oñate, A., Suarez-Alba, J., 1984. Modelo tectosedimentario del bajo Guadalquivir. I Congreso Español de Geologia. Tomo I, 199-213.

Martínez-García, P., Comas, M., Soto, J.I., Lonergan, L., Watts, A.B., 2013. Strike-slip tectonics and basin inversion in the western Mediterranean: the post-messinian evolution of the alboran sea. Basin Res. 25, 361-387. http://dx.doi.org/10.1111/bre. 12005.

Mascarelli, A.L., 2009. Quaternary geologists win timescale vote. Nature 459, 264.

McCave, I.N., Tucholke, B.E. 1986. Deep current controlled sedimentation in the western North Atlantic. En: Vogt, P.R., Tucholke, B.E. (Eds.), The Geology of North America, vol. M, The Western North Atlantic Region. Geological Society Am Boulder (CO), pp 451-468

Medialdea, T., Somoza, L., Pinheiro, L.M., Fernández-Puga, M.C., Vázquez, J.T., León, R., Ivanov, M.K., Magalhaes, V., Díaz-del-Río, V., Vegas, R., 2009. Tectonics and mud volcano development in the gulf of cádiz. Mar. Geol. 261, 48-63.
Medialdea, T., Vegas, R., Somoza, L., Vazquez, J.T., Maldonado, A., Díaz-del-Río, V., Maestro, A., Córdoba, D., Fernández-Puga, M.C., 2004. Structure and evolution of the "olistostrome" complex of the Gibraltar arc in the gulf of Cadiz (eastern central Atlantic): evidence from two long seismic cross-sections. Mar. Geol. 209, 173-198.

deMenocal, P.B., 2011, Climate and human evolution. Science, V. 331(6017), p. 540-542 Michard, A., Saddiqi, O., Chalouan, A., Frizon de Lamotte, D. (Eds.), 2008. Continental Evolution: The Geology of Morocco: Structure, Stratigraphy and Tectonics of the AfricaAtlantic-Mediterranean Triple Junction. Springer-Verlag, Berlin Heidelberg (424 pp.).

Miller, K.G., Kominz, M.A. Browning J.V., Wright, J.D., Mountain, G.S. Katz, M.E. Sugarman, P.J., Cramer, B.S., Christie-Blick, N., Pekar, S.F., 2005. The phanerozoic record of global sea-level change. Science 310, 1293-1298.

Miller, K.G., Mountain, G.S., Wright, J.D., Browning, J.V., 2011. A 180-million-year record of sea level and ice volume variations from continental margin and deep-sea isotopic records. Oceanography 24 (2), 40-53. http://dx.doi.org/10.5670/oceanog.2011.26.

Millot, C., 2009. Another description of the Mediterranean outflow. Prog. Oceanogr. 82 (2), 101-124.

Montenat, C., Ott d'Estevou, P., De La Chapelle, G., 1990. Le bassin de nijar-carboneras et le couloir du bas-andarax. In: Montenat, C. (Ed.), Les bassins néogènes du domaine bétique oriental (espagne). tectonique et sédimentation darts un couloir de décrochement. Doc. Trav. IGAL. 12-13, pp. 129-164.

Morel, J.-L., 1988. Evolution récente de l'orogène rifain et de son avant-pays, depuis la fin de la mise en place des nappes (Rif, maroc). Mém. Géodiffusion 4 (226 pp.).

Mougenot, D., 1988. Geologie de la Marge Portugaise VI. Univ. Pierre et, Marie Curie, Paris Thése 3éme Cicle. 259 pp.

Moura, D., Boski, T., 1999. Unidades litostratigráficas do pliocénico e plistocénico no Algarve. Commun. Inst. Geol. Min. 86, 85-106.

Mulder, T., Voisset, M., Lecroart, P., Le Drezen, E., Gonthier, E., Hanquiez, V., Faugères, J.-C. Habgood, E., Hernández-Molina, F.J., Estrada, F., Llave, E., Poirier, D., Gorini, C., Fuchey, Y., Volker, A., Freitas, P., Lobo Sanchez, F., Fernandez, L.M., Morel, J., 2003. The gulf of Cadiz: an unstable giant contouritic levee. Geo-Mar. Lett. 23 (1), 7-18.

Nelson, C.H., Baraza, J., Maldonado, A., 1993. Mediterranean undercurrent sandy contourites, gulf of Cadiz. Spain. Sediment. Geol. 82, 103-131.

Nelson, C.H., Baraza, J., Rodero, J., Maldonado, A., Escutia, C., Barber Jr., J.H., 1999. Influence of the Atlantic inflow and Mediterranean outflow currents on late Pleistocene and Holocene sedimentary facies of gulf of Cadiz continental margin. Mar. Geol. 155, 99-129.

Nichols, G., 2009. Sedimentology and stratigraphy. 2nd ed. Wiley-Blackwell (419 pp.)

Nielsen, T., Knutz, P.C., Kuijpers, P.C.A., 2008. Seismic expression of contourite depositional systems. In: Rebesco, M., Camerlenghi, A. (Eds.), ContouritesDevelopments in Sedimentology 60. Elsevier, Amsterdam, pp. 301-322.

Ochoa, J., Bray, N.A., 1991. Water mass exchange in the Gulf of Cadiz. Deep-Sea Research 38 (1), S465-S503.

Pardo-Igúzquiza, E., Rodríguez-Tovar, F.J., 2000. The permutation test as a non-parametric method for testing the statistical significance of power spectrum estimation in cyclostratigraphic research. Earth Planet. Sci. Lett. 181, 175-189.

Pardo-Igúzquiza, E., Rodríguez-Tovar, F.J., 2005. MAXENPER: a program for máximum entropy spectral estimation with assessment of statistical significance by the permutation test. Comput. Geosci. 31, 555-567.

Pardo-Igúzquiza, E., Rodríguez-Tovar, F..., 2006. Maximum entropy spectral analysis of climatic time series revisited: assessing the statistical significance of estimated spectral peaks. J. Geophys. Res. 111, D10102. http://dx.doi.org/10.1029/2005JD006293.

Pardo-Igúzquiza, E., Rodríguez-Tovar, F.J., 2011. Implemented lomb-scargle periodogram: a valuable tool for improving cyclostratigraphic research on unevenly sampled deep sea stratigraphic sequences. Geo-Mar. Lett. 31, 537-545.

Pardo-Igúzquiza, E., Rodríguez-Tovar, F.J., 2012. Spectral and cross-spectral analysis of uneven time series with the smoothed lomb-scargle periodogram and Monte Carlo evaluation of statistical significance. Comput. Geol. 49, 207-216.

Perconig. E. 1960-1962. Sur la constitution ge'ologique de l' andalousie occidentale, en particulier du bassin du Guadalquivir (espagne meridionale). livre me'moire du professeur Paul fallot. Mem. Hors-Ser. Soc. Geol. Fr. 1, 229-256.

Pereira, R., Alves, T.M., 2013. Margin segmentation prior to continental break-up: a seismic-stratigraphic record nof multiphased rifting in the north Atlantic (southwest Iberia). Tectonophysics 505, 17-34.

Pereira, R., Alves, T.M., Cartwright, J., 2011. Post-rift compression on the SWIberian margin (eastern north Atlantic): a case for prolonged inversion in the ocean-continent transition zone. J. Geol. Soc. 168, 1249-1263.

Potter, P.E. and Szatmari, P., 2009, Global Miocene tectonics and the modern world. Earth Sci. Rev., v.96, p. 279-295

Praeg, D., Stoker, M.S., Shannon, P.M., Ceramicola, S., Hjelstuen, B., Laberg, J.S., Mathiesen, A., 2005. Episodic Cenozoic tectonism and the development of the NW European "passive" continental margin. Mar. Pet. Geol. 22, 1007-1030.

Raymo, M.E., Mitrovica, J.X., O'Leary, M.J., DeConto, R.M., Hearty, P.J., 2011. Departures from eustasy in Pliocene sea-level records. Nat. Geosci. 4, 328-332.

Rebesco, M., 2005. Contourites. En: Richard, C., Selley, R.C., Cocks, L.R.M., Plimer, I.R. (Eds.), Encyclopedia of Geology, vol. 4. Elsevier, London, pp. 513-527.

Rebesco, M., Camerlenghi, A. (Eds.), 2008. ContouritesDevelopments in Sedimentology vol. 60. Elsevier, Amsterdam.

Rebesco, M., Stow, D., 2001. Seismic expression of contourites and related deposits: a preface. Mar. Geophys. Res. 22, 303-308.

Rebesco, M., Hernández-Molina, F.J., Van Rooij, D., Wåhlin, A., 2014. Contourites and associated sediments controlled by deep-water circulation processes: state of the art and future considerations. Mar. Geol. 352, 111-154.

Riaza, C., Martinez del Olmo, W., 1996. Depositional model of the Guadalquivir-Gulf of Cadiz tertiary basin. In: Frien, P.F., Dabrio, C.J. (Eds.), Tertiary Basins of Spain: The Stratigraphic Record of Crustal Kinematics. Cambridge University Press, Cambridge, pp. 330-338.

Ripepe, M., Fischer, A.G., 1991. Stratigraphic rhythms synthesized from orbital variations. In: Franseen, K., Watney, W.L., Kendall, C.G., St., C., Ross, W. (Eds.), Sedimentary 
Modelling: Computer Simulations and Methods for Improved Parameter Definition. Kansasa state geol. Surv. Bull. 233, pp. 335-344.

Roberts, D.G, 1970. The Rif-betic orogen in the gulf of Cadiz. Mar. Geol. 9, M31-M37.

Significance of lower pliocene mass-flow deposits for the timing and process of collision of the Eratosthenes seamount with the Cyprus active margin. In: Robertson, A.H.F., Emeis, K.-C., Richter, C., Camerlenghi, A. (Eds.), Proceedings of the Ocean Drilling Program, Scientific Results. vol. 160, pp. 465-481.

Rodrigo-Gámiz, M., Martínez-Ruiz, F., Rodríguez-Tovar, F.J., Jiménez-Espejo, F., PardoIgúzquiza, E., 2014. Millennial- to centennial-scale climate periodicities and forcing mechanisms in the westernmost Mediterranean for the past 20,000 years. Quat Res. 81, 78-93.

Rogerson, M., Rohling, E.J., Bigg, G.R., and Ramirez, J., 2012, Paleoceanography of the AtlanticMediterranean exchange: Overview and first quantitative assessment of climatic forcing: Rev. Geophys., v. 50, RG2003, doi:http://dx.doi.org/10.1029/2011RG000376.

Roque, C., 2007. Tectonostratigrafia do Cenozóico das Margens Continentais Sul e Sudoeste Portuguesas: um Modelo de Correlação Sismostratigráfica. Departamento de Geologia, Universidade de Lisboa.

Roque, C., Duarte, H., Terrinha, P., Valadares, V., Noiva, J., Cachão, M., Ferreira, J., Legoinha, P., Zitellini, N., 2012. Pliocene and Quaternary depositional model of the Algarve margin contourite drifts (gulf of Cadiz, SW Iberia): seismic architecture, tectoni control and paleoceanographic insights. Mar. Geol. 303-306, 42-62.

Rosas, F.M., Duarte, J., Terrinha, P., Valadares, V., Matias, L., Gutscher, M.A., 2009. Major bathymetric lineaments and soft sediment deformation in NW gulf of Cadiz (Africa-Iberia plate boundary): new insights from high resolution multibeam bathymetry data and analogue modelling experiments. Mar. Geol. 261 (1-4), 33-47.

Roveri, M., Flecker, R., Krijgsman, W., Lofi, J., Lugli, S., Manzi, V., Sierro, F.J., Bertini, A., Camerlenghi, A., De Lange, G., Govers, R., Hilgen, F.J., HÅNubscher, C., Meijer, P.T., Stoica, M., 2014. The Messinian Salinity Crisis: Past and future of a great challenge for marine sciences. Mar. Geol. 352, 25-58.

Rudge, J.F., Shaw Champion, M.E., White, N., McKenzie, D., Lovell, B., 2008. A plume model of transient diachronous uplift at the earth's surface. Earth Planet. Sci. Lett. 267, $146-160$.

Ryan, W.B.F., Hsü, K.J., Cita, M.B., Dumitrica, P., Lort, J., Maync, W., Nesteroff, W.D., Pautot, G., Stradner, H., Wezel, F.C., 1973. Western Alboran Basin-Site 121. In: Initial Reports of the Deep Sea Drilling Project. (Ed. by W.B.F. Ryan \& K.J. Hsu“" al.), 13, 43-89. Govt. Printing Office, Washington D.C.

Salvany, J.M., Larrasoaña, J.C., Mediavilla, C., Rebollo, A., 2011. Chronology and tectonosedimentary evolution of the upper Pliocene to Quaternary deposits of the lower Guadalquivir foreland basin, SW Spain. Sediment. Geol. 241, 22-39.

Sarnthein, M., Bartoli, G., Prange, M., Schmittner, A., Schneider, B., Weinelt, M., Andersen, N., Garbe-Schönberg, D., 2009. Mid-Pliocene shifts in ocean overturning circulation and the onset of Quaternary-style climates. Clim. Past 5, 269-283.

Scargle, J.D., 1982. Studies in astronomical time series analysis. II. Statistical aspects of spectral analysis of unevenly spaced data. Astrophys. J. 263, 835-853.

Schönfeld, J., Zahn, R., 2000. Late glacial to Holocene history of the Mediterranean outflow. Evidence from benthic foraminiferal assemblages and stable isotopes at the Portuguese margin. Palaeogeogr. Palaeoclimatol. Palaeoecol. 159, 85-111.

Serra, N., Ambar, I., Boutov, D., 2010. Surface expression of Mediterranean water dipoles and their contribution to the shelf/slope-open ocean exchange. Ocean Sci. 6 , 191-209.

Serra, N., Ambar, I., Käse, R.H., 2005. Observations and numerical modelling of the Mediterranean outflow splitting and eddy generation. Deep-Sea Res. II 52, 383-408.

Sierro, F.J., Flores, J.A., Civis, J., González-Delgado, J.A., Francés, G., 1993. Late Miocene globorotaliid event-stratigraphy and biogeography in the NE Atlantic and Mediterranean. Mar. Micropaleontol. 21, 143-168.

Sierro, F.J., Flores, J.A., Zamarreño, I., Vazquez, A., Utruilla, R., Frances, G., Hilgen, F.J., Krigsman, W., 1999. Messinian climatic oscilations, astronomic cyclicity and reef growth in the western Mediterranean. Mar. Geol. 153, 137-146.

Sierro, F.J., Glez Delgado, J.A., Dabrio, C., Flores, J.A., Civis, J., 1991. Paleontologia y Evolució Mem. Iberian Neogene basins especial 2, 209-250.

Sierro, F.J., González-Delgado, J.A., Dabrio, C.J., Flores, J.A., Civis, J., 1996. Late Neogene Depositional Sequences in the Foreland Basin of Guadalquivir (SW Spain). In: Tertiary Basins of Spain (P. Friend y C. Dabrio, eds.). Cambridge University Press, Cambridge, 329-334.

Sierro, F.J., Ledesma, S., Flores, J.A., 2008. Astrobiochronology of late neogene deposits near the strait of Gibraltar (SW Spain). implications for the tectonic control of the messinian salinity crisis. In: Biand, F. (Ed.), CIESM, 2008. The messinian salinity crisis from mega-deposits to microbiology. CIESM workshop monographs, pp. 45-48 Monaco.

Sierro, F.J., Ledesma, S., Flores, J.-A., Torrescusa, S., Martínez del Olmo, W., 2000. Sonic and gamma-ray astrochronology: cycle to cycle calibration of Atlantic climatic to Mediterranean sapropels and astronomical oscillations. Geology 28 (8), 695-698. http://dx. doi.org/10.1130/

Slater, D.R., 2003. The transport of Mediterranean water in the North Atlantic Ocean ( $\mathrm{PhD}$ Thesis), Univ. of Southampton (155 pp.)

Stein, R., Sarnthein, M., Suendermann, J., 1986. Late neogene submarine erosion events along the north-east Atlantic continental margin. In: Summerhayes, C.P., Shackleton, N.J. (Eds.), North Atlantic paleoceanography. Geological Sociey Special Publication 21, pp. 103-118

Stoker, M.A., Praeg, D., Hjelstuen, B.O., Laberg, J.S., Nielsen, T., Shannon, P.M., 2005. Neogene stratigraphy and the sedimentary and oceanographic development of the NW European Atlantic margin. Mar. Pet. Geol. 22, 977-1005.

Stow, D.A.V., Faugères, J.C., Gonthier, E., Cremer, M., Llave, E., Hernández-Molina, F.J., Somoza, L., Díaz del Río, V., 2002b. Faro-Albufeira Drift Complex, Northern Gulf of Cadiz. In: Stow, D.A.V., Pudsey, C.J., Howe, J., Faugères, J.C. (Eds.), Deep-Water
Contourite Systems: Modern Drifts and Ancient Series, Seismic and Sedimentary Characteristics. Geological Society London, Memoirs 22, pp. 137-154 Igcp 432.

Stow, D.A.V. Faugères, J-C. Howe, J.A. Pudsey, CJ., Viana, A.R. 2002a. Bottom currents, contourites and deep-sea sediment drifts: current state-of-the-art. In: Stow, D.A.V Pudsey, C.J., Howe, J.A., Faugères, J.-C., Viana, A.R. (Eds.), Deep-Water Contourite Systems: Modern Drifts and Ancient Series, Seismic and Sedimentary Characteristics. Geological Society, London, Memoirs. 22, pp. 7-20

Stow, D.A.V., Hernández-Molina, F.J., Alvarez Zarikian, C.A., the Expedition 339 Scientists, 2013b. Proceedings IODP, 339. Integrated Ocean Drilling Program Management International, Tokyo http://dx.doi.org/10.2204/iodp.proc.339.2013.

Stow, D.A.V., Hernández-Molina, F.J., Llave, E., Bruno, M., García, M., Díaz del Río, V. Somoza, L., Brackenridge, R.E., 2013a. The Cadiz contourite channel: sandy contourites, bedforms and dynamic current interaction. Mar. Geol. 343, 99-114.

Terrinha, P., Matias, L., Vicente, J., Duarte, J., Luís, J., Pinheiro, L., Lourenço, N., Diez, S. Rosas, F., Magalhães, V., Valadares, V., Zitellini, N., Roque, C., Mendes Víctor, L. Team, M.A.T.E.S.P.R.O., 2009. Morphotectonics and strain partitioning at the IberiaAfrica plate boundary from multibeam and seismic reflection data. Mar. Geol. 267 156-174.

Terrinha, P., Pinheiro, L.M., Henriet, J.-P., Matias, L., Ivanov, M.K., Monteiro, J.H., Akhmetzhanov, A., Volkonskaya, A., Cunha, T., Shaskin, P., Rovere, M., 2003. Tsunamigenic-seismogenic structures, neotectonics, sedimentary processes and slope instability on the southwest Portuguese margin. Mar. Geol. 195, 55-73.

Terrinha, P., Ribeiro, C., Kullberg, J.C., Rocha, R., Ribeiro, A., 2002. Compression episodes during rifting and faunal isolation in the Algarve basins, SW Iberia. J. Geol. 110, 101-113.

TGS, 2005. PD00: non-exclusive 2D Survey, TGS online data zone. (http://www.tgsnopec com/specsheets/PD-00_Spec.pdf).

Thorpe, S.A., 1975. Variability of the Mediterranean in the gulf of Cadiz. Deep-Sea Res. 23, 711-727.

Torelli, L., Sartori, R., Zitellini, N., 1997. The giant chaotic body in the Atlantic ocean off Gibraltar: new results from a deep seismic reflection survey. Mar. Pet. Geol. 14 125-138.

Toucanne, S., Mulder, T., Schönfeld, J., Hanquiez, V., Gonthier, E., Duprat, J., Cremer, M., Zaragosi, S., 2007. Contourites of the gulf of Cadiz: a high-resolution record of the paleocirculation of the Mediterranean outflow water during the last 50,000 years. Palaeogeogr. Palaeoclimatol. Palaeoecol. 246, 354-366.

Vail, P.R., Mitchum Jr., R.M., Thomson III, S., 1977. Global cycles of relative changes of sea level. In: Payton, C.E. (Ed.), seismic stratigraphy-applications to hydrocarbon exploration. American Association of Petroleum Geologists, Memoirs 26, pp. 83-98.

Van der Schee, M., Sierro, F.J., Flecker, R., Gutjahr, M., Jimenez-Espejo, F.J., HernandezMolina, F.J., Grunert, P., Garcia Gallardo, A., Flores, J.A., Hodell, D., Andersen, N., 2015. Discussion on identification of the Mio-Pliocene boundary and onset of the MOW recorded in IODP Site U1387C in the Gulf of Cádiz. RCMNS Interim Colloquium, Mediterranean - Atlantic Gateway (Neogene to present). Rabat (Morocco), 5-8 May, 2015. Abstract volume.

Van Rooij, D., De Mol, B., Huvenne, V., Ivanov, M., Henriet, J.P., 2003. Seismic evidence of current-controlled sedimentation in the belgica mound province, upper porcupin slope, southwest of Ireland. Mar. Geol. 195, 31-53.

Vannucchi, P., Sak, P.B., Morgan, J.P., Ohkushi, K., Ujiie, K. and the IODP Expedition 334 Shipboard Scientists, 2013. Rapid pulses of uplift, subsidence, and subduction erosion offshore central America: implications for building the rock record of convergent margins. Geology, 41, 995-998.

Vergés, J., Fernàndez, M., 2012. Tethys- Atlantic interaction along the Iberia- Africa plate boundary: the betic-Rif orogenic system. Tectonophysics $579,144-172$

Viguier, C., 1974. Le Néogène de l'Andalousie Noroccidentale (Espagne) (Thesis), Univ. Bordeaux (449 pp.).

Villmoare, B., Kimbel, W.H., Seyoum, C., Campisano, C.J., DiMaggio, E. Rowan, J., Braun, D.R., Arrowsmith, J.R., Reed, K.E., 2015. Early Homo at 2.8 Ma from Ledi-Geraru, Afar, Ethiopia. Science http://dx.doi.org/10.1126/science.aaa1343.

Voelker, A.H.L., Lebreiro, S.M., Schönfeld, J., Cacho, I., Erlenkeuser, H., Abrantes, F., 2006. Mediterranean outflow strengthening during northern hemisphere coolings: a salt source for the glacial Atlantic? Earth Planet. Sci. Lett. 245 (1-2), 39-55.

White, R.S., McKenzie, D.P., 1989. Magmatism at rift zones: the generation of volcanic continental margins and flood basalts. J. Geophys. Res. 94, 7685-7729.

Whyte, N., Lovell, B., 1997. Measuring the pulse of a plume with the sedimentary record. Lett. Nat. 387, 888-891.

Wold, C.N., 1994. Cenozoic sediment accumulation on drifts in the northern north Atlantic. Paleoceanography 9, 917-941.

Wright, J.D., Miller, K.G., 1996. Control on north Atlantic deep water circulation by the Greenland-Scotland ridge. Paleoceanography 11, 157-170.

Zachos, J., Pagani, H., Sloan, L., Thomas, E. and Billups, K., 2001, Trends, rhythms, and aberrations in global climate 65 Ma to present: Science, v. 292, p. 686-693.

Zazo, C., Goy, J.L., Dabrio, C., Civis, J., Baena, J., 1985. Paleogeografia de la desembocadura del Guadalquivir al comienzo del cuaternario (provincia de C idiz, espafia). Acta Reun. Cuat. Ibér. 1, 461472.

Zenk, W., 1975. On the Mediterranean outflow west of Gibraltar. "Meteor" Forsch.Ergebnisse 16, 23-34.

Zitellini, N., Gràcia, E., Matias, L., Terrinha, P., Abreu, M.A., DeAlteriis, G., Henriet, J.P. Dañobetia, J.J., Masson, D.G., Mulder, T., Ramella, R., Somoza, L., Diez, S., 2009. The quest for the Africa-Eurasia plate boundary west of the strait of Gibraltar. Earth Planet. Sci. Lett. 280, 13-50. 


\section{Acknowledgements}

Gratitude goes to all people who made this thesis possible, and to three in particular. I would like to thank my always scientifically curious professor Paco Sierro for spending so much time discussing proxy records, cycles, water masses, excursions and for sharing days in the field. Acknowledgments are attributed to Marcus Gutjahr, who has put in a great effort to make me a happy lab-rat, for patiently discussing interpretations of the produced data and for hosting me at GEOMAR, Kiel. I would also like to thank Rachel Flecker for kicking off the fantastic MEDGATE project and for putting in the exceptional effort in helping me writing my first published manuscript.

Co-authors of the manuscripts have helped me to begin, shape, re-shape, finish and to start over (new) scientific articles. All co-authors are acknowledged and special thanks are going to Francis Jiménez-Espejo for sharing his XRF scanning data with me and with who I enjoy brainstorming about the raw data. Likewise, Javier Hernández-Moliña has been very helpful by sharing seismic lines and with his encouragements at the Flamenco section. I have encountered many more highly skilled scientists that helped me interpreting data or doing analyses. Immediate thoughts go out to; Paul Meijer, Wout Krijgsman, Frits Hilgen, Lucas Lourens, Tanja Kouwenhoven, John Gregory, Johanna Lofi, Gert de Lange, Rich Pancost, Rob Ellam, Isabel Cacho and Martin Frank.

Lab technicians Jose-Ignacío and Rocío at Salamanca University are acknowledged for washing samples, picking foraminifera and conversaciones sobre los artes, filosofía y naturaleza, escuchando de Pink Floyed. My Spanish day-to-day life has been much more pleasant drinking Café con leches at Vicentes Cafetería with the extended GGO-crew. Margarita is much appreciated for feeding me in the weekends in her and Chichipato Javis house. The Camino with Misaki (coffee?) was really cool. Ana and Manu, the memories of los juegos will stay with me, just as the invitations to the Sunday lunch table. I have enjoyed real amazing trips to peaks on the Iberian Peninsula with Rubèn and Montse; shorter, Piringuis tours. Javi, thank you for sharing too much information with me. Other office mates that came by and left again will not be forgotten: Thank you Blanca for the joyful time together as well as Raul, Felipe, Angelo, Martha, David, Gloria and Miguel Angel.

For inspiring and motivating conversations, not only about science, I would like to thank all my MADGATE buddies. Bas has been a fantastic neighbour in the office and friend during weekend hiking trips and during our Spanish adventures to bureaucratic offices during (pre-) Puentes, while eating platos típicos. Thank you again for being there for me during the process of mourning of the rejected paper. Diana has been a good roommate in all our trips together and I am very grateful for the time we enjoyed together and the friends you have shared with me. I will never forget enjoying my coffee at the vegetarian place and being the greatest while running and biking around with Walter. Neither do I hope to forget to have played so many games and the laughter during some story telling with JP all around Europe. Maria, you are a perfect BFF and you are much thanked for sharing your wedding and the MEDGATE-baby with us. It can never be foreseen what for confusion will be created while exploring with Dirk, eating apples. I have greatly enjoyed 
working together in the lab and the relaxing conversations with Sevi in Kiel. Eva, you are acknowledged for sharing your laid-back attitude to release some pressure and hosting me in your penthouse in Madrid. And of course, Ali, you are a splendid model to everyone.

Zusätzlich möchte ich mich auch gerne bei meinen Freunden bedanken, mit denen in der tollsten WG in Kiel gewohnt habe: Jojo, Micha, Shelly, Basti, Alex, Hannah, Lena, Knörte, Nico und all euren Freunden. Vielen Dank das ich mit euch zusammen das zu Hause teilen konnte, dort wo wirklich immer was los war!

I could have never survived this extended life experience without the support of my Dutch team from my home. Graag wil ik Laurens bedanken dat ik je echt altijd mocht bellen. Vriendin Lineke, gelukkig hebben we elkaar gevonden en zonder jou was dit avontuur trouwens nooit begonnen. Het vertrouwen van Erik hield me zeker op de been en gedeelde smart is halve smart met Bruno creëerde op zijn minst een harde lach. Brainstormen met Martijn en Ilse over wat er nog meer kan zijn voorbij de horizon heeft met zeker aan het denken gezet. Bedankt!

Natuurlijk wil ik ook graag mijn familie bedanken. Door jullie ben ik wie ik ben en jullie geven me het vertrouwen dat dat goed is. Wilke, die me zeker heeft geinspireerd om verre reizen te maken, en natuurlijk de lieve haissie paissie; sterk en moedig roeiend door het leven, meedenkend als ik wel in Nederland was. Pap en mam, door jullie opvoeding, interesse in natuur en wetenschap is dit avontuur begonnen en nu ook afgerond.

Many more people have helped me fighting paragraphs and extensive homework hours during (short) conversations with strangers, intense moments of unexpected friendships or longer term mutual respect. I received unexpected gifts from some that I try to circulate to others. Powerful encouragements can be provided in small gestures on a normal day. However, it is my opinion that not necessarily all human interactions of my last four years have to be named to confirm its importance. Obviously, my gratitude is much larger than only these few words and eventually shaped my character. 


\section{Scientific publications}

\section{Peer-reviewed journals}

Flecker, R., Krijgsman, W., Capella, W., de Castro Martíns, C., Dmitrieva, E., Mayser, J.P., Marzocchi, A., Modestou, S., Ochoa D.P., Simon, D., Tulbure, M., Van den Berg, B., Van der Schee, M., de Lange, G., Ellam, R., Govers, R., Gutjahr, M., Hilgen, F., Kouwenhoven, T., Lofi, J., Meijer, P., Sierro, F.J., Bachiri, N., Barhoun, N., Alami, A.C., Chacon, B., Flores, J.A., Gregory, J., Howard, J., Lunt, D., Ochoa, D., Pancost, R., Vincent, S., Yousfi, M.Z., 2015. Evolution of the Late Miocene Mediterranean-Atlantic gateways and their impact on regional and global environmental change. Earth-Science Reviews 150, 365-392.

Hernández-Molina, F.J., Sierro, F.J., Llave, E., Roque, C., Stow, D.A.V., Williams, T., Lofi, J., Van der Schee, M., Arnaíz, A., Ledesma, S., Rosales, C., Rodríguez-Tovar, F.J., Pardo-Igúzquiza, E., Brackenridge, R.E., 2015. Evolution of the gulf of Cadiz margin and southwest Portugal contourite depositional system: Tectonic, sedimentary and paleoceanographic implications from IODP Expedition 339. Marine Geology, Van der Schee, M., Sierro, F.J., Jimenez-Espejo, F.J., Flecker, R., Hernández-Molina, F.J., Flores, J.A., Acton, G., Gutjahr, M., Grunert, P., García-Gallardo, A., Andersen, N., submitted.Evidence of bottom water current flow after the Messinian Salinity Crisis in the Gulf of Cadiz. Marine Geology 377, 7-39.

Van der Schee, M., Sierro, F.J., Jimenez-Espejo, F.J., Flecker, R., Hernández-Molina, F.J., Flores, J.A., Acton, G., Gutjahr, M., Grunert, P., García-Gallardo, A., Andersen, N..Evidence of bottom water current flow after the Messinian Salinity Crisis in the Gulf of Cadiz. Marine Geology, in press.

García-Gallardo, Á., Grunert, P., Van der Schee, M., Sierro, F.J., Jiménez-Espejo, F.J., Álvarez Zarikian, C., Piller, W.E., submitted December 2015. Benthic foraminifera-based reconstruction of the first Mediterranean-Atlantic exchange in the early Pliocene Gulf of Cadiz. Marine Micropaleontology, in review.

Van der Schee, M., Sierro, F.J., Jiménez-Espejo, F.J., Flecker, R., Andersen, N. Sedimentary cycles and oceanographic circulation under the influence of MOW over the Miocene-Pliocene boundary in the Gulf of Cadiz. 
